\title{
Hydrologic modelling and prediction of extreme streamflow events in the Jock River Watershed, Ontario, Canada
}

\author{
By \\ Cameron Samson \\ A thesis submitted to the Faculty of Graduate and Postdoctoral Affairs in partial \\ fulfillment of the requirements for the degree of \\ Master of Science \\ in
}

Geography

Carleton University

Ottawa, Ontario

(C) 2018

Cameron Samson 


\begin{abstract}
Historical and predicted extreme streamflows were analysed for the Jock River watershed, using Generalized Extreme Values (GEV) and Streamflow Threshold Level (STL) methods. The historical streamflow shows earlier snow melt peaks ( $\sim 10$ days), decreased snow melt peaks, and decreases in consecutive drought days (CDD), whereas the summer-fall season peaks and mean annual streamflow (MAS) have been increasing. The Jock River Watershed Model (JRWM) was developed using the Raven modelling framework and achieved a Nash-Sutcliffe of 0.76 with reduced capacities to characterize low flows. Predicted streamflow changes from climate change scenarios include snow melt peaks decreased by $50 \%$ and shifted seven weeks earlier by 2099 . GEV analysis showed that extremes are decreasing by $\sim 10 \%$ for the snow melt peaks, while increases in MAS are continuing and the summer-fall peaks are increasing by $\sim 30 \%$. STL analysis for CDD shows the magnitude and number of CDD events are increasing by $\sim 300 \%$.
\end{abstract}




\section{ACKNOWLEDGEMENT}

I am grateful and would like to acknowledge all the people who made this thesis possible. To my two supervisors, Dr. Scott Mitchell and Dr. Murray Richardson, I thank you for your wisdom, guidance, financial support and friendship in both personal and professional, allowing me the freedom to research my project. I would also like to thank the Department of Geography and Environmental Sciences (DGES), whose professors, TAs, and support staff provided me with outstanding teaching and assistance which has seen me through two undergraduate degrees and a master's degree.

I'd like to thank Dan Macdonald, Dr. Ruth Waldick and Agriculture and AgriFood Canada (AAFC), for giving me the opportunity as a Research Affiliate Program (RAP) student to work on the ENVISION project, where I got to listen to local farmers and conservational authorities about their needs and concerns about future climate. Many thanks as well to my colleagues at AAFC that provided me with support, data and input on my thesis, as well the copious cups of coffee! I also thank the GIS staff from the Rideau Valley Conservation Authority (RVCA) with their help in data gathering.

I would like to express my deepest gratitude to my uncle Dr. Rod Taylor, who helped me edit the countless versions of my thesis. A special word of thanks to my friends with whom I have developed everlasting relationships with, and who supported me and listened to me talk about my thesis constantly, even when they didn't understand what I was saying. Finally, I want to thank my brothers and sister for their encouragement through the years. I am especially grateful to my parents, Richard and Debbie, for their unconditional love and dedication, for all their help over the years to support my education, and for teaching me how to become a good man. 


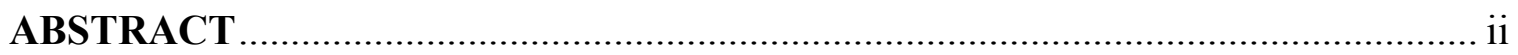

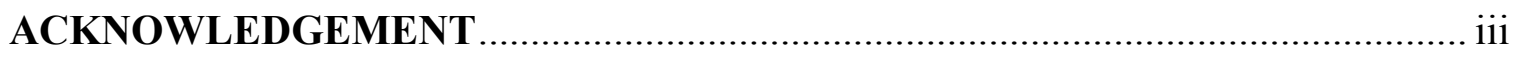

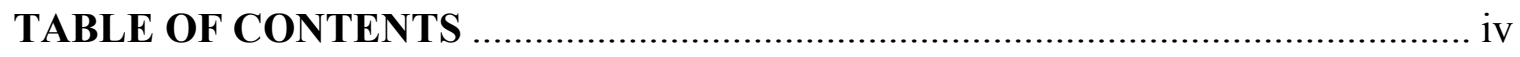

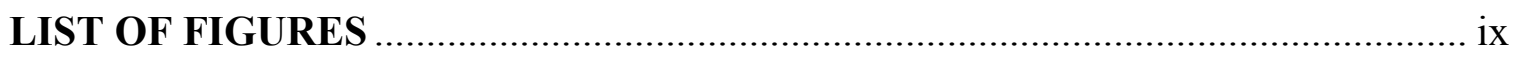

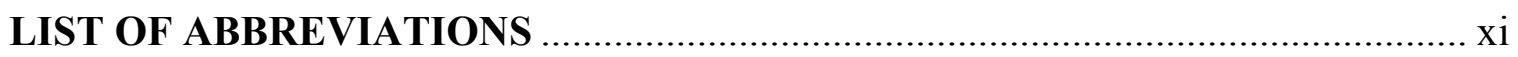

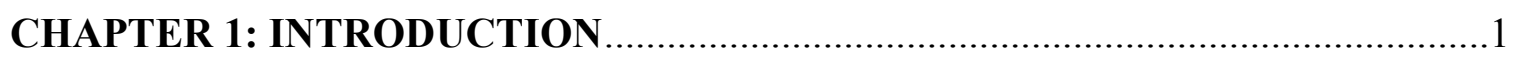

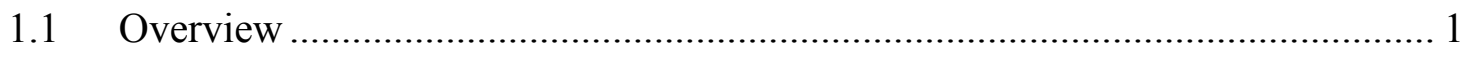

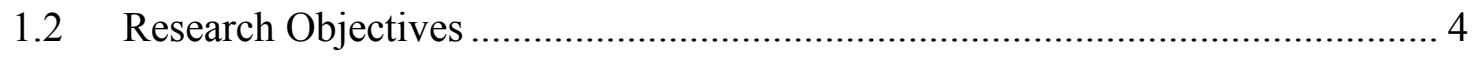

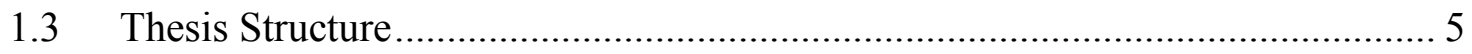

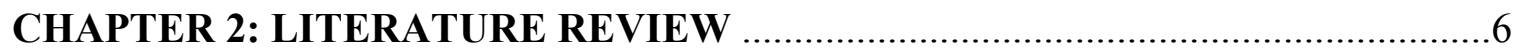

2.1 Climate Change and Water Resources ........................................................... 7

2.1.1. Temperature and Precipitation ................................................................ 8

2.1.2. Streamflow and Runoff...................................................................... 9

2.1.3. Floods and Droughts ............................................................................... 10

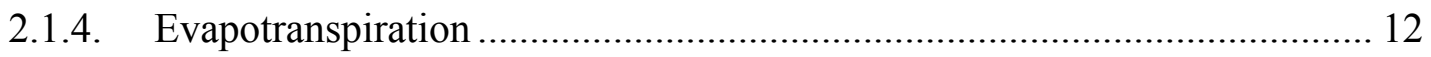

2.1.5. Soil Moisture.................................................................................... 12

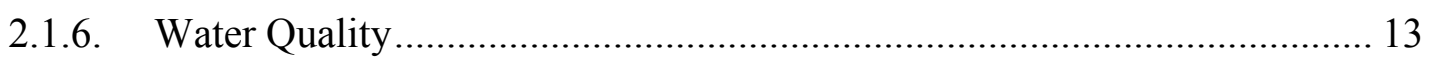

2.1.7. Climate Change in Eastern Ontario .......................................................... 14

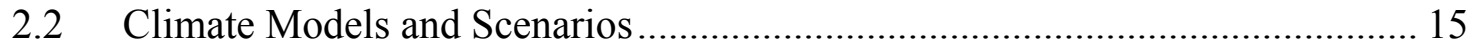

2.3 Climate and Hydrological Extremes ........................................................... 18

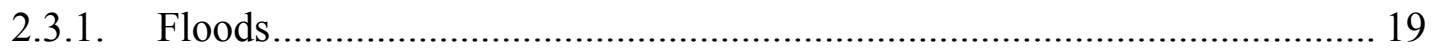

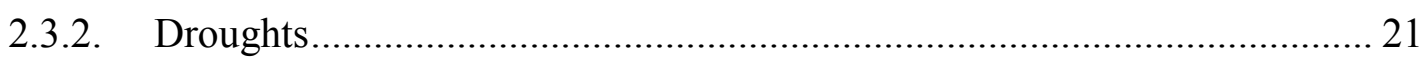

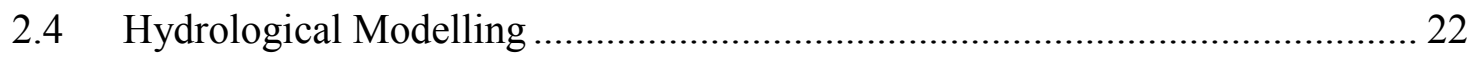

2.4.1 Hydrological Model History ……………………............................... 23

2.4.2 Empirical Models......................................................................... 24

2.4.3 Physically-Based Models....................................................................... 25

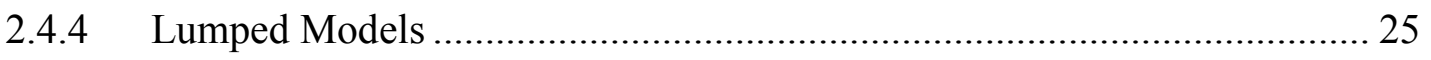

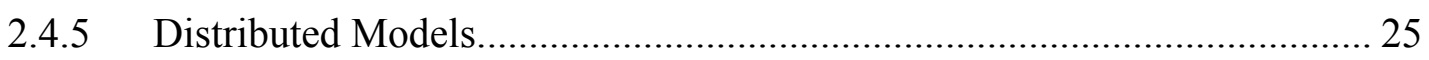

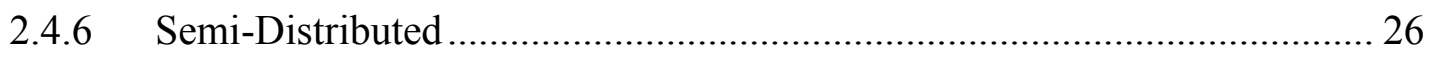




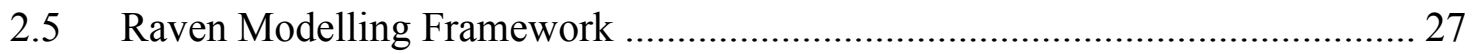

2.6 Model Calibration, Sensitivity and Validation.............................................. 28

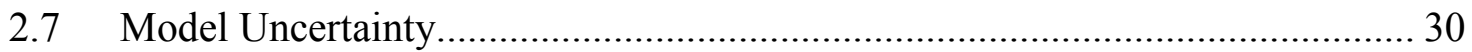

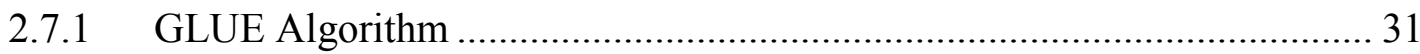

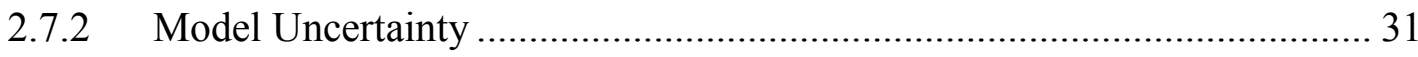

2.8 Hydrological and Climate Change Models .................................................... 32

CHAPTER 3: STUDY AREA AND DATA COLLECTION …………......................33

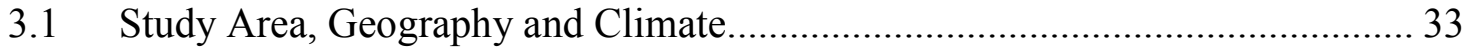

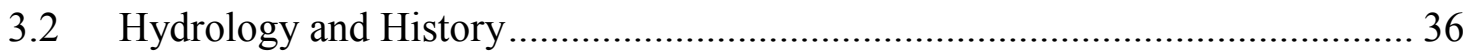

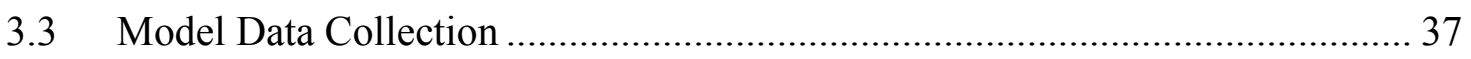

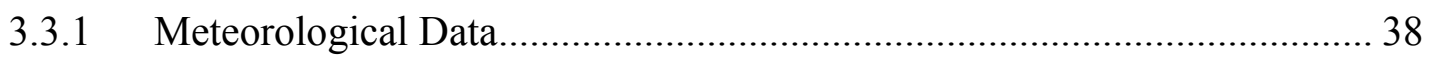

3.3.2 Stream Flow Data .............................................................................. 39

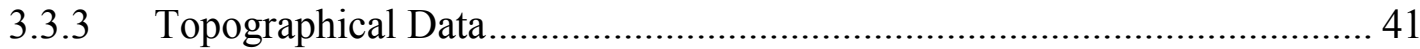

3.3.4 Land Use and Land Cover Classification .................................................. 44

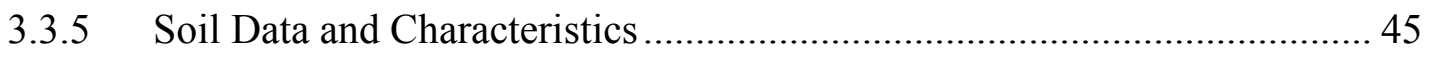

3.3.6 Vegetation LAI, Canopy Coverage and Transpiration Coefficients........... 46

3.4 Climate Change Scenario Data ......................................................................... 48

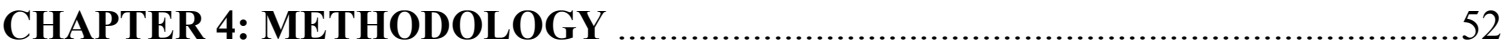

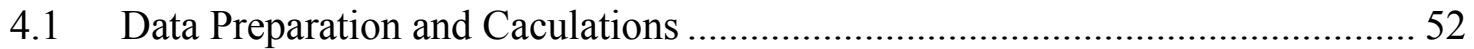

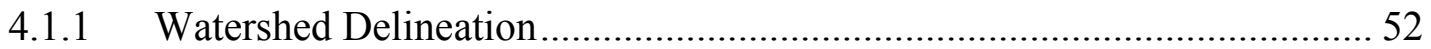

4.1.2 Hydrological Response Unit (HRU) Definition ........................................ 53

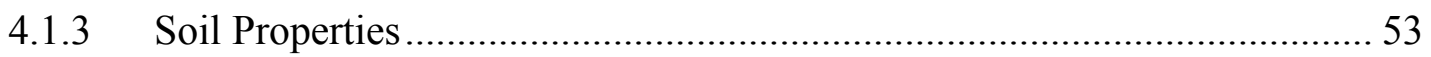

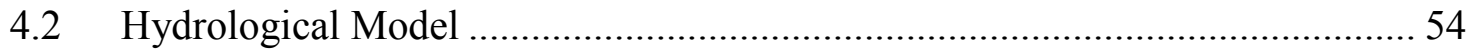

4.2.1 The Raven Modelling Framework .......................................................... 54

4.2.2 Hydrological Processes and Routines ........................................................ 56

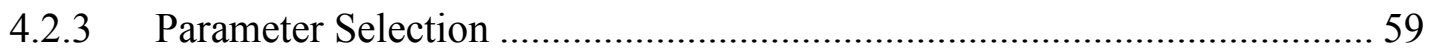

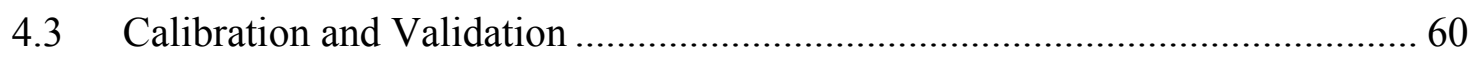

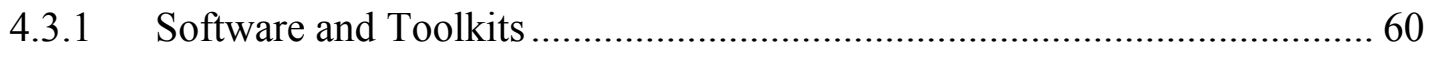

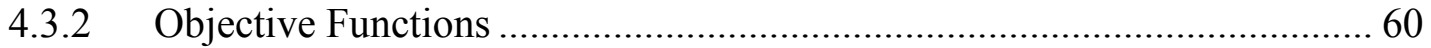

4.3.3 Generalized Likelihood Uncertainty Estimation ......................................... 64

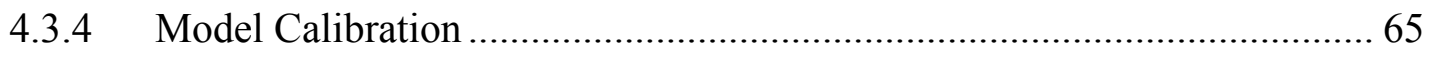

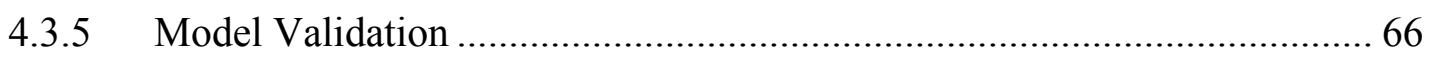




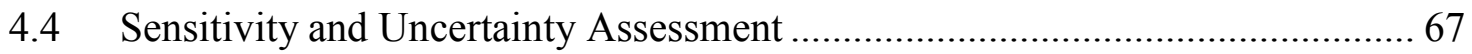

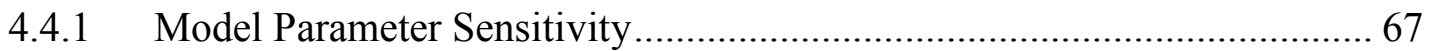

4.4.2 Model Uncertainity Upper and Lower Bounds........................................... 67

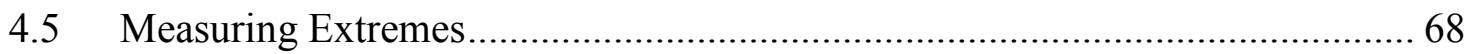

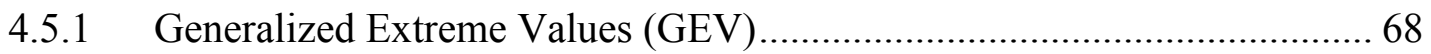

4.5.2 Streamflow Threshold Level (STL) ........................................................... 71

4.6 Hydrological Climate Change Scenario Projections........................................... 72

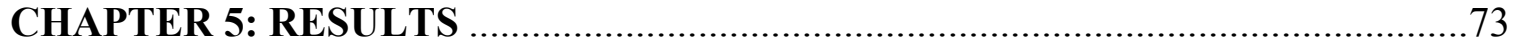

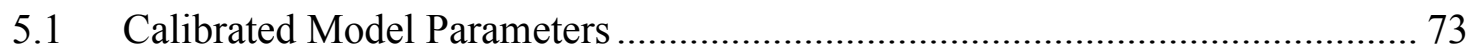

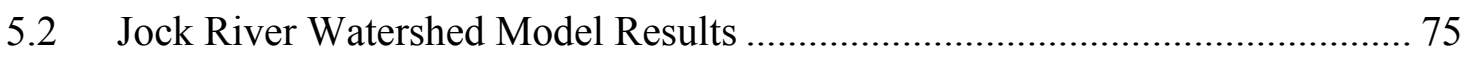

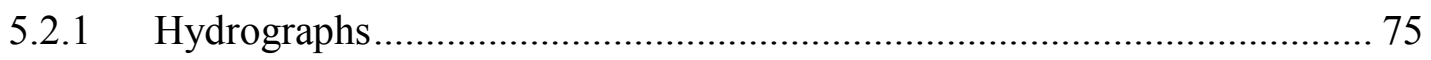

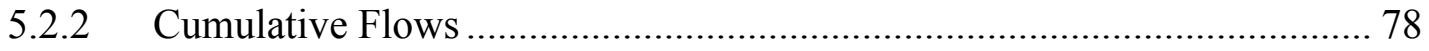

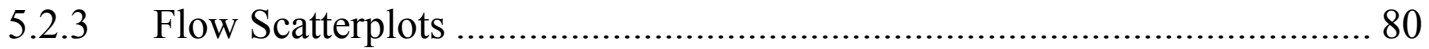

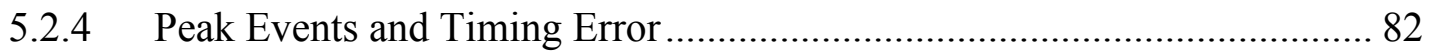

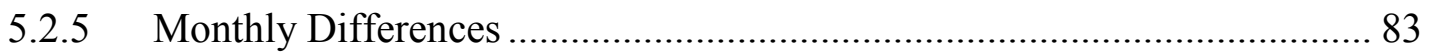

5.3 Validation, Parameter Sensitivity and Uncertainty .......................................... 85

5.3.1 Validation and Objective Functions...................................................... 85

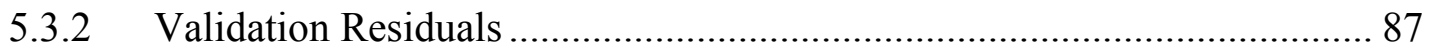

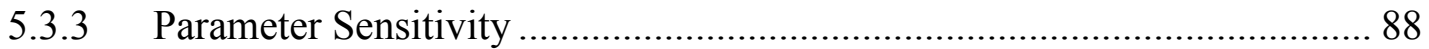

5.3.4 Validation Period for GLUE Uncertainty ……………………................. 90

$5.4 \quad$ Flooding and Drought Extremes .................................................................. 94

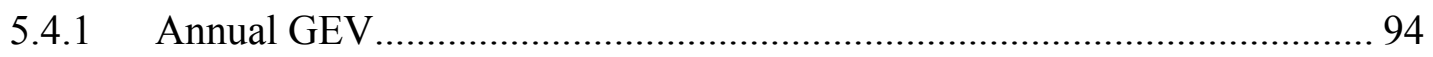

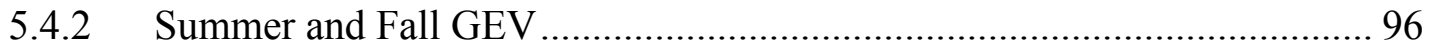

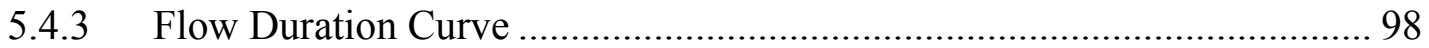

5.4.4 Streamflow Threshold Level................................................................ 100

5.5 Impacts to Streamflow Under Climate Change Scenarios ............................... 102

5.5.1 Annual StreamFlow Changes ………………………........................ 102

5.5.2 Flooding Extremes Using GEV Analysis …………………………....... 109

5.5.3 Drought Extremes Using STL Analysis ……………................................ 112

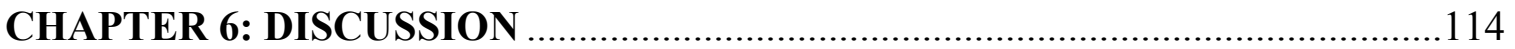

6.1 Performance of Models in the Jock River Watershed........................................ 114

6.1.1 Model Testing and Performance ……………………………….......... 114 
6.1.2 Jock River Watershed Model Parameters ................................................... 115

6.2 Jock River Streamflow Trends and JRWM Performance ................................ 116

6.3 Model Sensitivity and Uncertainty Analysis................................................. 119

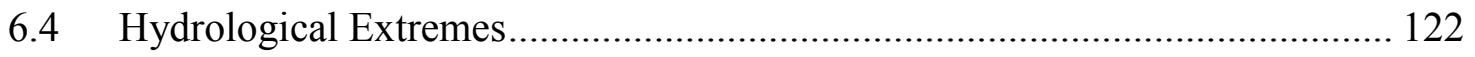

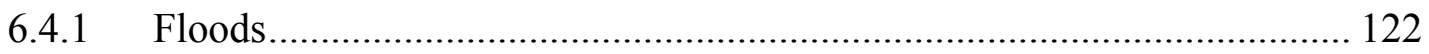

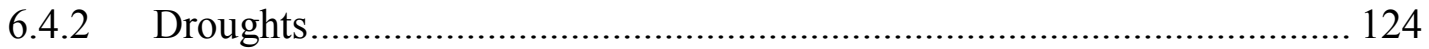

6.5 Projected Streamflow in Climate Change Scenarios........................................ 125

6.5.1 Changes in Snow Melt Streamflow Peaks ............................................... 125

6.5.2 Changes in Summer and Fall Streamflow Peaks ...................................... 127

6.5.3 Changes in Mean Annual Streamflow ................................................... 128

6.5.4 Changes in Drought Days ................................................................... 128

6.6 Recommendations for Future Research ....................................................... 129

CHAPTER 7: CONCLUSIONS ...................................................................130

REFERENCES

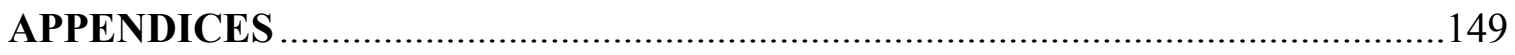

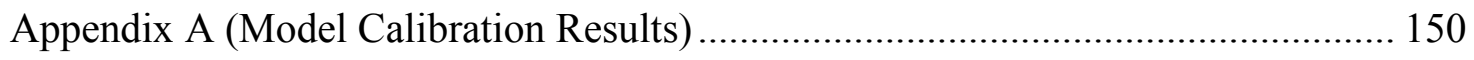

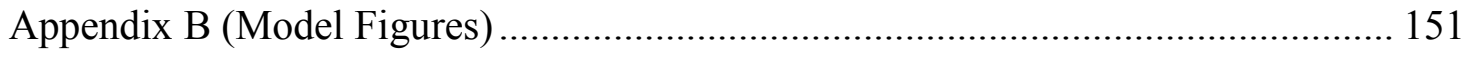

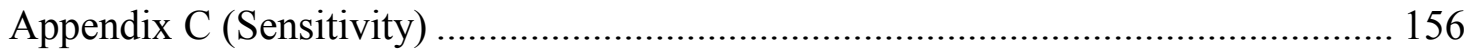

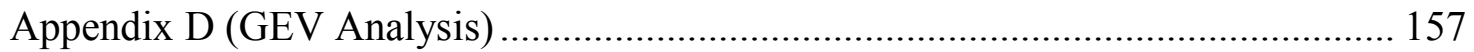

Annual GEV (Probality and Quantile Plots)....................................................... 157

Summer-Fall GEV (Probality and Quantile Plots) …………………………….... 162

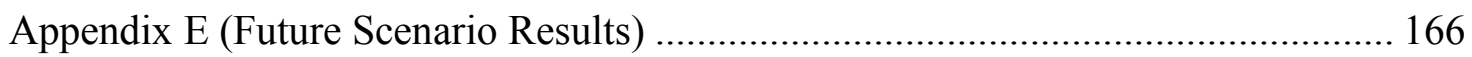

Appendix F (Raven Model Script).................................................................... 173

F.1 JockClimate.rvt ........................................................................................ 173

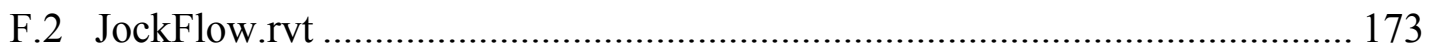

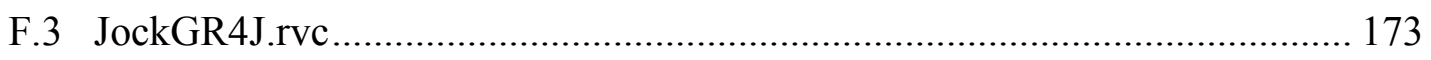

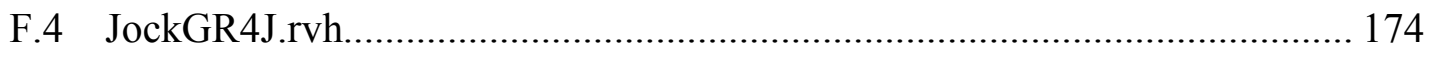

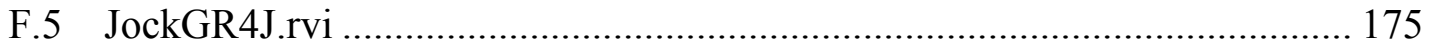

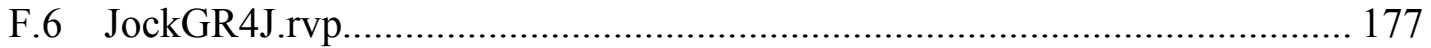

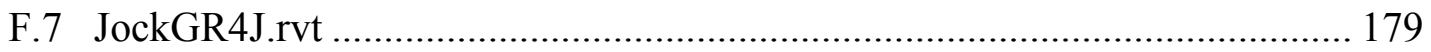




\section{LIST OF TABLES}

Table 3.1. Subwatershed names and properties. Data source: Catchment reports (RVCA, 2016) 33

Table 3.2. The 1981 - 2010 Canadian Climate Normal station data. Data source: Text file (NRCAN, 2018a) 34

Table 3.3. Jock River stream gauge information. Data source: Text file (NRCAN, 2018b)

Table 3.4. Parameter values based on approximate literature values for similar environment of Eastern Ontario. 46

Table 3.5. Values for vegetation coefficients of Max Capacity, the interception fraction and percentage are ranges provided by the Raven manual (Craig et al., 2017).

Table 3.6 The 12 global climate models that maintain variability for Eastern North America, (original table from Flato et al., 2013). Reference information for models is from the IPCC AR5, Table 9.A (IPCC, 2013).

Table 4.1. Hydrological processes used in the JRWM. Full details for each process available in Raven Manual (Craig et al., 2017). ............................................................ 58

Table 4.2 Table of free parameters used in Jock River model and associated ranges...... 59 Table 4.3 Objective functions used for the JRWM. Full Equations details available in the

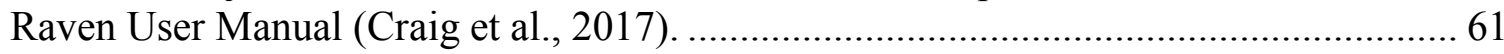

Table 5.1 The top 5 parameter sets and their values for JRWM.................................. 74

Table 5.2 Objective function and diagnostics values for the different model time-periods for JRWM.

Table 5.3 Annual statistics of the return periods for the Jock River model for observed and simulated streamflow. 96

Table 5.4 Summer/Fall statistics of the return periods for the Jock River model for observed and simulated streamflow. 98

Table 5.5 GEV climate change scenario distribution annually for Gumbel distribution.110 Table 5.6 GEV climate change scenario L-moment distribution for summer and fall... 111 


\section{LIST OF FIGURES}

Figure 3.1. The Jock River watershed study area with its tributaries and main subwatersheds that are identified by the Rideau Valley Conservation Authority (RVCA)... 35

Figure 3.2. Mean streamflow (1981-2010) for the Jock River watershed. Blue represents the winter season (December 1st - Mar 31st). Data source: Text file (NRCAN, 2018b). 37

Figure 3.3. Photograph of the Jock River and the Jock River Stream Gauge left bottom corner on April 2012. Data source: Image (Google Maps, 2018a)...

Figure 3.4. Photograph of the Jock River and the Jock River Stream Gauge left bottom corner on June 2012. Data source: Image (Google Maps, 2018b).

Figure. 3.5. Digital elevation model map of the Jock River watershed. Data source:

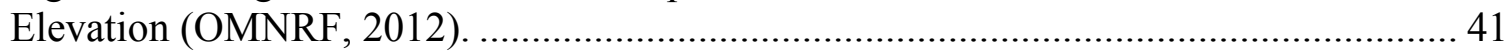

Figure 3.6. Aspect map of the Jock River watershed. Data source: OMNFR (2016). .... 42

Figure 3.7. Slope map of the Jock River watershed. Data source: OMNFR (2016). ....... 43

Figure 3.8. Land use and land cover classification for the 2015 Jock River watershed.

Data source: Soil Survey Complex (RVCA, 2016) ..................................................... 44

Figure 3.9. Surface soils for the Jock River watershed. Data Source: Soil Survey (AAFC, 2017). Abbreviations for figure are C:Clay, S:Sand, L:Loam, F:Fine, SI:Silt, G:Gravel 45

Figure 3.10. Variation in LAI over a year for the Jock River watershed. Derived from NASA NEO, for the year 2007 (similar average climate normal). Data source: (ORNL DAAC, 2017).

Figure 3.11. Map representing the different Giorgi regions for the world. From PCIC (Giorgi and Francisco, 2000) …………................................................................... 49

Figure 4.1. Flowchart of model framework and processes. Based on Craig (2016)........ 55

Figure 4.2. Using a defined threshold level $\left(\mathrm{Q}_{\mathrm{z}}\right)$ : produces a time of occurrence, $\mathrm{t}_{\mathrm{i}}$, and duration in days, $\mathrm{d}_{\mathrm{i}}$, for a deficit volume or severity, $\mathrm{v}_{\mathrm{i}}$, and the minimum flow occurring during the drought event, $Q_{\text {min,i }}$ (Fleig et al., 2006).

Figure 5.1 Hydrograph of observed versus simulated streamflow from (1970 - 1999). Observed data from WSC. Simulated data using the best parameter set for the JRWM. The winter months are represented in blue shading from the December 1st - March 30th. (continued next page).

Figure 5.2. Cumulative flows for the Jock River watershed in millions of $\mathrm{m}^{3}$. Observed data from the WSC. Simulated data from modelled data of the Jock River Watershed... 79

Figure 5.3. Results from the JRWM outputs (1970-2017). Linear regression scatterplots of daily simulated and observed streamflow $\left(\mathrm{m}^{3} / \mathrm{s}\right)$..

Figure 5.4. Percentage error in simulated peaks for each water year. The peaks are calculated as the magnitude of the largest event in each year. 82 
Figure 5.5. Plot of the percent errors in simulated peak events for each water year. The peaks are calculated using flows from the same day as the peak event in the observed series, i.e. the timing of the peak is considered here.

Figure 5.6 Mean monthly simulated and observed streamflow $\left(\mathrm{m}^{3} / \mathrm{s}\right)$ for the $1970-2017$ time-period.

Figure 5.7. A residuals time series plot from 2010-2017 for flow values with a 7-day smoothing filter. The residuals are calculated as simulated versus observed..

Figure 5.8. The top 6 most sensitive parameters that influence the model NSE (NSE is plotted versus the parameter value).

Figure 5.9 (a) Model uncertainty for 2011, showing the $5-95 \%$ prediction intervals. .... 92

Figure 5.9 (b) Model uncertainty for 2012, showing the $5-95 \%$ prediction intervals.... 91

Figure 5.9 (c) Model uncertainty for 2013, showing the $5-95 \%$ prediction intervals. ... 93

Figure 5.9 (d) Model uncertainty for 2014, showing the 5 - 95\% prediction intervals... 93

Figure 5.10. Annual observed (a) and simulated (b) return periods for streamflow. 95

Figure 5.11 Nonstationarity streamflow data, with 2, 20, 100 year return period (a)

observed and (b) simulated.

Figure 5.12. Summer and fall return periods with figure (a) for the observed data and

figure (b) is return period for simulated data.

Figure 5.13. Summer and fall adjusted trend data, with 2, 20, 100 year return period, with figure (a) observed and (b) simulated.

Figure 5.14. Flow duration curve for observed flows, and simulated flows for the 1970-

2017 time-period.

Figure 5.15. STL Consecutive drought days below the 95\% FDC also known as threshold value for the model by year for the 1970-2017, time-period. 101

Figure 5.16. The mean daily streamflow for the different time periods for the mean of the ensemble of the climate change scenario models. 103

Figure 5.17. The mean daily streamflow for 2011-2040 period with the 12 climate change scenario models. 104

Figure 5.18. The mean daily streamflow for 2041-2070 period with the 12 climate change scenario models 105

Figure 5.19. The mean daily streamflow for 2070-2099 period with the 12 climate change scenario models. 106

Figure 5.20 Mean Annual Streamflow for climate change scenarios and historical observed values with their trendlines. 108

Figure 5.21. STL analysis representing the CDDs for historical and simulated and the ensemble mean of the three future scenarios. 


\section{LIST OF ABBREVIATIONS}

Agriculture and Agri-Food Canada (AAFC)

Average absolute error (ABSERR)

Maximum absolute error (ABSMAX)

Consecutive Drought Days (CDD)

The Coupled Model Intercomparison Project phase 5 (CMIP5)

Global Climate Models (GCMs)

Generalized Extreme Value (GEV)

Greenhouse gases (GHGs)

The Generalized Likelihood Uncertainty Estimation (GLUE)

Hydrological response units (HRUs),

Intergovermental Panel on Climate Change (IPCC)

Jock River Watershed Model (JRWM)

Leaf Area Index (LAI)

Land use and land cover (LULC)

Mean annual streamflow (MAS)

Mann-Kendall (MK)

Percent bias (PCT BIAS)

Peak difference (PDIFF)

Nash-Sutcliffe efficiency (NSE)

Regional Climate Model (RCM)

Representative Concentration Pathways (RCPs)

Root-mean-squared Error (RMSE)

Ratio of the root mean square error to the standard deviation of measured (RSR)

Standardize Runoff Drought Index (SRDI)

Streamflow Threshold Level (STL) 


\section{CHAPTER 1: INTRODUCTION}

\subsection{OVERVIEW}

Water allocation and management is an increasing problem around the world, as it is affected by changing climate, population growth and water demands. Water resources and their management play very important roles in eastern Ontario, as water is used by wildlife, industries, agriculture, urban and recreational activities. Eastern Ontario, which is composed of urban, forest and agricultural landscapes, could be facing these types of water resource. The agricultural landscapes make up approximately $9100 \mathrm{~km}^{2}$, which is approximately one third of eastern Ontario (OMAFRA, 2011). Agriculture in eastern Ontario is largely dependent on the weather, especially on rainfall, since there is little to no irrigation performed by farmers. The Intergovernmental Panel on Climate Change (IPCC) specifies that hydrological challenges the agricultural community could face from climate change are extreme precipitation events (flooding and erosion), changes in seasonality of crops, changes in mean precipitation, droughts, as well as new pathogens and diseases (IPCC, 2007a). These impacts can cause crop yield reductions, crop failures, field erosion, nutrient loss, and affect food market demands.

There are numerous studies that show that eastern Ontario over the last 50 years has been changing, with decreased snowfall (Mekis and Vincent, 2001), earlier snow melt seasons (Adamowski et al., 2013), and water quality and quantity problems in groundwater recharge areas (Crabbe and Robin, 2006). Furthermore, the Lemmen et al. (2008) Canadian government report on potential impacts of climate change for Ontario states that there could be increased flooding, droughts, heat waves, hazardous smog conditions, decreased wildlife health and more, with significant economic losses. 
Eastern Ontario contains four major watersheds: Rideau Watershed, OttawaMississippi Watershed, Ottawa-South Nation Watershed, and Upper St. Lawrence Watershed, totalling about $18,000 \mathrm{~km}^{2}$. The Jock River watershed, focus of this thesis, is a sub-watershed of the Rideau Watershed at $556 \mathrm{~km}^{2}$, with rich agricultural lands, wetlands, forests and urban areas. The mean annual precipitation for the Jock River Watershed is approximately $940 \mathrm{~mm}$, and as such, this research will investigate the movement of approximately $5.23 \times 10^{8} \mathrm{~m}^{3}$ of water annually.

A watershed or catchment basin is an area within which several integrated hydrologic processes occur such as precipitation, evapotranspiration, interception, infiltration, percolation, surface runoff, recharge and snowmelt (Beven, 2012). Understanding how these processes interact with each other as a system allows us to analyze the watershed and discover any subtle changes that may occur. Being aware of these interrelated processes is essential to the decision-making process for water resource planning, flood and drought protection, mitigation of contamination, climate change, and other hydrological problems. However, the collection of hydrological data for these processes is a difficult task due to the variety and dynamic nature of the processes, limited measurement techniques, inaccessibility to the field site, sub-surface processes and heterogeneity of the environment (Musa et al., 2011; Beven et al., 2012). Hydrological models can be used to extrapolate from available field data, remote sensing, and knowledge of hydrological processes from the literature to create a predictive modelling framework for a watershed system of interest. Hydrologic models can be particularly useful for predicting changes which may occur in the future, evaluating extremes climate events or can even be applied to ungauged watersheds (where field measurements are not available) 
(Beven, 2012; Cheng et al., 2012). There is no certainty to how much climate change could alter these types of events, but there is a need to understand, forecast, and be prepared.

Global Climate Models (GCMs) are models used to create scenarios of the changing climate, and their downscaled versions can be used for studying regional changes (IPCC, 2007b; Ouranos, 2010). The GCMs are forecasting increases in annual precipitation, seasonality variations and extreme event magnitudes and frequencies (floods and droughts) for eastern Ontario (Ouranos, 2010). Modelling these events in different scenarios will allow for a concentrated effort to identify potential vulnerabilities and form potential mitigation strategies in prevention of further damage to crop land. The hydrological cycle plays a very important role in agriculture and a better understanding as to how this cycle will change in different situations would be beneficial for both the farmer and the consumer.

The fifth assessment report from the IPCC has forecasted an increase in total annual precipitation, shifting seasons and larger variability in extreme precipitation events for mid-latitude wet regions (IPCC, 2013), but it remains difficult to understand and forecast the local-scale hydrologic impacts of these broad-scale trends (Cheiw et al., 2010). Hydrological models coupled with GCMs can produce a model representation of future climate change scenarios and their impacts on our environment. These models can then be used to evaluate and identify any vulnerabilities in currently held water management infrastructure and policies, which will aid in the mitigation and prevention of damaging and harmful effects caused by these changes (IPCC, 2013).

The Raven Hydrological Framework is a hydrological modelling platform for application to hydrological discharge problems in academia and practice (Craig et al., 
2017). The flexible framework, open source code, and large library of processes and forcing functions allow Raven to be used in a variety of applications, from small simple watersheds to large complex watershed systems. Raven is also able to fully replicate hydrological models (such as HBV, GR4J, and UBC), and emulate similar results for other common models (SWAT, VIC, and WATFLOOD) (Craig et al., 2017). Raven can also represent the watershed dynamically with changing vegetation, snowmelt, and landcover changes (Craig et al., 2017). The Raven framework allows for the model to be built according to the project needs and requirements in order to best answer the research objective.

\subsection{RESEARCH OBJECTIVES}

The overarching objective of this study is to evaluate the effectiveness of modelling hydrological climate extreme events in the Jock River watershed of eastern Ontario.

The first sub-objective is to parameterize, calibrate and validate a hydrological model for the Jock River watershed, Ontario, Canada using historic climate and streamflow data.

The second sub-objective is to quantify the model's accuracy, uncertainty and sensitivity, as well as its ability to model extremes.

The third sub-objective is to use the hydrological model and future climate model scenarios to investigate future changes in extreme streamflow in the Jock River watershed along with inherent uncertainties in these scenarios. 


\subsection{THESIS STRUCTURE}

The thesis is composed of seven chapters. Chapter One is this introduction to the thesis. Chapter Two is a literature review, that informs the reader on climate change, water resources, climate extremes, modelling the environment and model uncertainty. Chapter Three describes the study site Jock River watershed and its associated climate, geography, and hydrology. This chapter also describes how the data were collected to be used in the model for the thesis. Chapter Four is the methodology of the thesis, representing the methods for data creation, model framework, calibration, validation and uncertainty as well as determining extremes. Chapter Five describes the results, which are broken up into model outputs, model validation, parameter sensitivity, model uncertainty and extremes. The results for future climate scenarios and their associated extremes using the hydrological model are also included in this chapter. Chapter Six is the discussion, where model outputs, model performance, future scenarios, extremes and the success of the thesis at achieving the research objectives are discussed. Chapter Seven is the conclusion, that summarizes the thesis, highlighted findings and suggestions for future research. 


\section{CHAPTER 2: LITERATURE REVIEW}

Overall, this literature review serves as an introduction to water resources, climate change, hydrological extremes, hydrological and scenario modelling. Water is a finite and precious resource; it is the liquid that sustains living organisms, part of every ecosystem, and covers over $70 \%$ of the earth's surface. The growth of population, agriculture, industry, resource extraction, recreational and residential has increased the demand for water resources all over the world (IPCC, 2013). Canada is often thought of as a country with few issues concerning water resources. However due to some poor management strategies and the uncertainties associated with climate change questions have been raised about the stability, quantity, quality and availability of water resources now and in the future (Bakker and Cook, 2011; IPCC, 2013; Kienzle and Mueller, 2013).

This chapter is broken down into eight different sections: a climate change and water resources section that describes the effects of climate change both globally and regionally in eastern Ontario; a section on climate change modelling and scenarios; a climate and hydrological extremes section that describes what climate extremes are and focuses on two main types of extremes, flood and droughts and their importance in research; a section on hydrological modelling that explains the different types of models; a section on what is the Raven modelling framework and how it is useful; a section on calibration, validation and sensitivity analysis on hydrological models; a section about model uncertainty that describes the uncertainties related to models, climate change and hydrology; and finally, how hydrological models and climate change models are used together for future streamflow scenarios. 


\subsection{CLIMATE CHANGE AND WATER RESOURCES}

Climate change is defined by the Intergovernmental Panel on Climate Change (IPCC) as a change in the state of the climate where its properties can be identified (e.g. using statistical tests) such as changes in the mean and/or the variability, for an extended period (usually $30+$ years) due to natural changes and/or from human activity (IPCC, 2013). Climate change occurs from the energy balance in the atmosphere, ocean or land shifting. This shift is usually represented as a positive or negative change of energy in the atmosphere also known as radiative forcing, which represents a warming of the climate, that in turn causes different patterns, variability and timing of the climate (IPCC, 2013).

Earth has had various climate change events before the industrial age (1750AD), and these changes are hypothesised to have been caused by factors such as the Earth's orbit, sun's intensity, volcanic eruptions, greenhouse gas (GHG) concentrations and ocean currents (Stute et al., 2001; Lemmen et al., 2008). There have been no large changes in these factors except for the concentration of GHGs, such as carbon dioxide $\left(\mathrm{CO}_{2}\right)$, methane $\left(\mathrm{CH}_{4}\right)$, nitrous oxide $\left(\mathrm{N}_{2} \mathrm{O}\right)$, and halocarbons, that have been increasing since the industrial age (IPCC, 2013). The increase in global population growth on Earth has produced more GHGs, known as anthropogenic GHGs, attributed to increases in agriculture, industry, waste products, resource extraction and urbanization.

Since the early 1900s the global Earth surface temperature has increased by approximately $0.74^{\circ} \mathrm{C}$ and this is likely caused by the increase of anthropogenic GHGs, and human activity (IPCC, 2007a). Since 2010, five of the warmest years globally on record since 1880 have been recorded, with 2016 being the highest and 2017 the second highest (NASA, 2017). Examples of climate change impacts around the world include 
increases in temperature, rising sea level, variability in precipitation, retreating glaciers, thawing permafrost, earlier snowmelt, alterations in river discharge, shifting ecosystems, changing landscapes, mass extinctions, droughts, fires, floods, storms, climate-related illness and disease (IPCC, 2007a; 2013).

Impacts of climate change are found all around the world, but they tend to be regionally specific, especially when looking at water resources (Leung and Wigmosta, 1999). Surface freshwater is one of the most important resources for human life and lifestyle, however we can only use approximately $0.01 \%$ of the entire global water, as $97 \%$ is in the form of salt water in oceans, $2 \%$ is frozen in ice caps and glaciers, and $1 \%$ is in groundwater (Gleick, 1996). Due to this very small amount of readily available water, any changes from climate change will have large impacts on fresh water.

The impact of climate change on water resources is a major issue for the world and the issue of assessing the impacts of climate change is a complex one, both in terms of trying to quantify the possible risks and impacts as well attempting to identify the best ways to mitigate these risks. To provide a broader understanding of climate change impacts on water resources, an overview of changes in temperature and precipitation, streamflow and runoff, floods and droughts, evapotranspiration, soil moisture and water quality, will be discussed. This will be followed by a focus on specific changes in eastern Ontario where this thesis is based.

\subsubsection{TEMPERATURE AND PRECIPITATION}

According to the IPCC, an increase in the average global temperature will likely change atmospheric circulations and evaporation rates leading to changes in precipitation and atmospheric moisture around the globe (IPCC, 2007a; 2013). The warmer temperature 
from climate change also means that the atmosphere can hold more moisture (less condensation due to the higher energy of water molecules). Lenderink and Meijaard (2008) found that the increase in holding capacity is approximately $7 \%$ per degree, using the Clausius-Clapeyron relation for moisture holding capacity in western Europe. However, they also found this only to be true for temperatures below $10^{\circ} \mathrm{C}$ and observed up to $14 \%$ increase in holding capacity above $10^{\circ} \mathrm{C}$ (Lenderink and Meijaard, 2008). This implies that

an increase in moisture in the air will change precipitation events in their quantity, intensity, frequency, and type (Lenderink and Meijaard, 2010).

Precipitation is not distributed evenly around the globe, and over the last century mean annual precipitation has increased in regions located between $30^{\circ} \mathrm{N}$ and $85^{\circ} \mathrm{N}$, but decreased between $10^{\circ} \mathrm{N}$ and $30^{\circ} \mathrm{N}$ (IPCC, 2013). Heavy precipitation events have increased over many areas during the past 40 years, with increased amounts of precipitation per event but fewer events (Hsu et al., 2011; Wang et al., 2012).

\subsubsection{STREAMFLOW AND RUNOFF}

Streamflow is the combination of stormflow and baseflow. Stormflow is a flow response from the input of precipitation, while baseflow is the delayed flow that comes from the water moving through soil horizons and groundwater zones that are released into the streams or rivers in a watershed (Freeze, 1979). Climate change is modifying streamflows by reducing them in droughts and changing the timing of peak river flows during storms; these changes impact aspects such as water consumption, agriculture production, economic growth, recreation opportunities, and electricity generation, among other vital services (IPCC, 2007a; Stewart et al., 2004; Stewart et al., 2005; Hidalgo et al., 2009). 
Changes in streamflow have been seen across the globe; Hodgkins et al. (2005) found earlier spring melt streamflow peaks in some New England rivers, mean annual streamflow (MAS) was found to have increased for 96 Canadian watersheds in last 50 years from climate change, while lower soil moisture content from increased human activities have decreased the MAS (Tan and Gan, 2015). Déry et al., (2009) found increased streamflow discharge trends from 1964-2007 at coastal stations in Arctic Canada that they highlight to be caused by an 'intensification' of the hydrological cycle in the region.

The intensification of the hydrological cycle in the arctic has been linked to climate change shifts in permafrost extent, snowpack, evapotranspiration, and soil moisture and could lead to an increase in peak flows in the Northern American high latitudes (Huntington, 2006; Rawlins et al., 2010). Also, rivers in northern and north western Canada have been observed to have decreasing annual streamflow snowmelt peaks (Déry et al., 2003; Cunderlik and Ouarda, 2009). A snowpack is a natural water store that slowly releases water in the spring and summer, especially in mountainous regions. Declines in the snowpack, due to more precipitation falling as rain, late development of snowpack, and earlier thaws in the season, are major concerns for decreases in streamflow in Canada (Kienzle et al., 2012; Tan and Gan 2015).

\subsubsection{FLOODS AND DROUGHTS}

Floods and droughts are natural disasters, and can cause huge economic losses, irreversible ecosystem damage and large death tolls. The annual average precipitation has increased over most of northern Europe, the Arctic, Canada, the northeastern United States, tropical and eastern Africa, the northern Pacific, and Antarctica (IPCC, 2013). Additionally, floods cause damages to water infrastructure, especially intakes and pipe 
distribution networks, and could be increasingly vulnerable to precipitation extreme events. Physical damage to dams' structures and water operations and treatment facilities is a possible consequence of severe floods (Sterk et al., 2016). As climate change causes larger variability and warmer climates, the frequency of flood and drought events will increase (IPCC, 2013).

These frequencies have already been noticed globally and in Canada. Najini and Devineni (2017) conducted a global assessment of flood events from 1985-2015 and showed that the duration of floods and flood frequency has increased by a factor of 4 and 2.5 events per year for the tropics and northern mid-latitudes respectively. While in Canada there has been a mixture of positive and negative trends for floods during the last 30 years, with most of these trends in the timing of the spring snowmelt (Cunderlik and Ouarda, 2009).

Droughts have increased since the 1970s, especially in the tropics and subtropics (Zaidman and Rees, 2000; IPCC, 2013; Masih et al., 2014). A review of droughts on the African continent (Masih et al. 2014) showed that most of the studies based on historical records (instrumental, lake sediment analysis, tree-ring chronologies and written and oral histories) observed drought to have increased in frequency and intensity and are more widespread during the last 50 years. Allen et al. (2010) completed a global overview of drought and heat-induced tree mortality. The extensive studies researched in the overview demonstrate that increased droughts and warmer climates have increased tree mortality rates and shifts in forested ecosystem. Gobena and Gan (2013) simulated summer moisture in western Canada from 1950-2003 and found soil moisture had a decreasing trend in Canadian Prairies and southern British Columbia showed a significant increasing trend. 


\subsubsection{EVAPOTRANSPIRATION}

Evapotranspiration is the process of movement of water from soil, vegetation and waterbodies to the atmosphere. The rate of the process is determined by temperature, wind, vegetation type and cover, soil type, and available water, which are affected by climate change (IPCC, 2013; Friend et al., 1997).

Vegetation cover, type, and properties play a very important role in evaporation (IPCC, 2001; Pollard and Thompson, 1995; Sellers, 1997). Interception of precipitation varies on the different types of vegetation, for example, canopies can re-evaporate up to $50 \%$ of the precipitation through interception (Sellers, 1997; Dijk et al., 2015). A change in catchment vegetation can affect the catchment water balance (Friend et al., 1997). Measuring trends in evapotranspiration rates globally is difficult, since they are influenced by leaf area index (LAI), storm events, El Nino and El Nina cycles, and human activities (Zhang et al., 2015; Brutsaert, 2016). However, it is expected that as climate warms, evaporation will increase, and it anticipated that this could result in more extreme weather (Choi and Fisher, 2003).

\subsubsection{SOIL MOISTURE}

Soil moisture is an important resource for all plants; it affects agriculture, vegetation, and has significant impact on the global climate (Robock, 2000; Bonsal et al., 2011; Seneniratne et al., 2010). Soil moisture affects the fluxes of energy and moisture in both the vertical and horizontal soil profiles, where horizontal moisture relates to streamflow water input (Seneniratne et al., 2010; 2013). Since soil moisture is interconnected with precipitation, streamflow, evaporation, and groundwater, climate change will affect soil moisture and this change will impact human activities. Recent human activities have already decreased soil moisture content, through urbanization, deforestation, tile drainage, 
and land cover change (Bonsal et al., 2011; Yang et al., 2012). Climate change will further decrease soil moisture content, and it is suggested that major changes in agricultural productivity, industry, forestry, ecosystem and human health will occur (Nkemdirim and Purves, 1994; Bonsal et al., 2011; Seneniratne et al., 2010; 2013).

\subsubsection{WATER QUALITY}

Water quality impacts of climate change are likely to be complex and will differ with the physical, geographical and biological characteristics of water resources (Cruise et al., 1999; IJC, 2006; IPCC, 2007). Water quality is an important part of ecosystem health, since many organisms survive in a very narrow range of water quality properties. These properties are a mix of physical (temperature and turbidity), chemical ( $\mathrm{pH}$, salinity, toxicity and dissolved oxygen), and biological (algae and phytoplankton) features and settings (ocean, glaciers, lakes, rivers, groundwater and atmosphere) (Boyd, 2015). Changes in the climate can influence water quality in many ways; for example, higher water temperatures lead to harmful algae blooms (O’Neil et al., 2012) and lower dissolved oxygen (Cruise et al., 1999); changes in the timing, intensity, and duration of precipitation can flush more contaminants and sediments into lakes and rivers causing shifts in $\mathrm{pH}$, nitrogen and dissolved oxygen levels (Cruise et al., 1999; Chang et al., 2001; Bouraoui et al., 2002).

Higher flows from extreme precipitation can dilute pollutants, thereby improving water quality, however this will also increase the risk of water contamination from increased sediment and pollutants loading from runoff from agricultural land, and urban sources as well as possible sewage overflows (Sterk et al., 2016; IPCC, 2013). With decreased flows, there will be less available water to dilute pollutants, resulting in increased concentrations of pollutants and salinity (IPCC, 2013). 


\subsubsection{CLIMATE CHANGE IN EASTERN ONTARIO}

Many assessments for the region have projected that lower mean water levels in lakes and other bodies of water are likely towards the end of the century due to decreased supply (Lindroth, 2003; IJC, 2006). This reduction in water level could lead to large economic losses for the region, particularly by means of reduced hydropower generating capacity in the range of \$437-660 million/yr (Ouranos 2004). Snowfall was reported to be increasing in Canada's North, but decreasing in the rest of the country (Mekis and Vincent, 2011).

Eastern Ontario is experiencing climate change impacts; Adamowski et al. (2013) found the Rideau River annual streamflow for the watershed has shifted $\sim 10$ days earlier for melt/winter streamflow peak and has generally lower annual streamflow peaks. Further, they report that the Ottawa River has shifted $\sim 50$ days earlier, but also note that this could be from waterway regulation (e.g. dams). Crabbe and Robin (2006) studied the South Nation watershed, and found that no water scarcity is expected for the region even under unusually dry weather scenarios.

Lemmen et al. (2008) studied potential impacts of climate change across the province of Ontario and raised serious concerns that with increased peak flood events that there are greater risks of ice jams and flooding. A warmer climate can adversely impact health through means such as prolonged heat waves, smog conditions, and outbreaks of water-borne diseases due to increased events of extreme precipitation (Cheng et al., 2012). Beyond the impacts to structures on the river that could result due to increased peak flow events, impacts on water treatment plants, delivery systems, and transportation systems such as canals and locks can also be anticipated (Lemmen et al., 2008). Wetlands and other 
sensitive ecosystems can be dramatically impacted by shifts in temperature and precipitation. Not only can the sustainability of these areas be impacted but their effectiveness in terms of pollutant removal can also be reduced. Changes in fish species, variance in aquatic life, and the health of arctic animals residing around the Hudson Bay area such as polar bears and seals are also anticipated to be impacted (Lindroth et al., 2003; IJC, 2006; Lemmen et al., 2008).

\subsection{CLIMATE MODELS AND SCENARIOS}

Global climate models (GCMs) are research tools used to create scenarios of future climate, under different possible environmental conditions, at global extents and thus using a relatively coarse resolution (Giorgi and Mearns, 1991; Taylor et al., 2012; IPCC, 2013). IPCC (2013) reports GCM predictions that the global surface temperatures will increase by $0.2^{\circ} \mathrm{C}$ per decade throughout the 21 st century. The most updated climate models are

presented in the Coupled Model Intercomparison Project Phase 5 (CMIP5), that provides scenarios, simulations, and projections of future climate change from present until 2100 and beyond, with horizontal resolutions between $1^{\circ}$ to $2.5^{\circ}(\sim 100-250 \mathrm{~km})$ (IPCC, 2013; Taylor et al., 2012).

A climate model is a computerized model that represents Earth's processes and systems (atmosphere, hydrosphere, land surface, cryosphere, geosphere, and biosphere), and their interactions. GCMs combine such models with scenarios that represent the possible future $\mathrm{GHG}$ emission of $\mathrm{CO}_{2}$ projections produced by demographic, economic, social, environmental and technological developments (Arnell, 2004; IPCC, 2007a; 2013). These emission scenarios are grouped into scenarios called representative concentration 
pathways (RCPs). There are four RCPs, named RCP2.6, RCP4.5, RCP6, and RCP8.5, reflecting the scenario's total radiative forcing values of $+2.6,+4.5,+6.0$, and $+8.5 \mathrm{~W} / \mathrm{m}^{2}$, respectively, in the year 2100 relative to the values of the pre-industrial age (1750 AD) (IPCC, 2013).

The coarse resolution of these models makes it hard to do regional and hydrological studies and analysis, as the model units are a few hundred kilometres in extent and simulate temperature trends better than precipitation (Pierce et al., 2009; Toreti et al., 2013). As a solution to provide higher spatial resolutions to GCMs and better representation of the climate, downscaling techniques are used (Sachindra, 2014; Giorgi et al., 1994; Snyder et al., 2002; Chiew et al., 2010; Tebaldi et al., 2005).

There are two common methods to downscaling GCMs for climate change impacts on hydrology, dynamic and statistical, and each has advantages and disadvantages. The dynamic method uses the outputs from GCMs as input into regional climate model (RCMs) as a boundary condition, and is based on atmospheric processes, but also has large computational cost (Yang et al., 2012; Sachindra et al., 2014). The statistical method uses an empirical relationship between large-scale predictors (GCM outputs) and regional-scale predictors (historical climate data) to develop the relationship and produce region-specific forecasts, with low computational cost (Hay and Clark, 2003; Sachindra et al., 2014; Pierce et al., 2013). However, the statistical method also misses physical processes such as snow albedo feedback (Walton et al., 2016), has reduced accuracy in warmer climates (Gutiérrez et al., 2013), lacks temporal stability, and often has poor relationships for precipitation (Chen, et al., 2014). 
There are many GCMs available. They have different algorithms and processes used to represent the future climate, which is why using an ensemble of models is the best way to represent the various models that are available. Box (1979) wrote "all models are wrong, but some are useful", as it very difficult to represent all real-world systems in one specific model, but a close approximation is possible (KanJi, 1986). They can be especially useful when an ensemble of models is used, that allows for a better picture of the range of possible scenarios, and a focus on whether they converge on specific topics, patterns or reoccurring themes that are presented in the future scenarios, which indicates or highlights areas for further study (Giorgi et al., 2003).

Climate change models have been used to assess the impacts of climate change in hydrological regimes across the globe, e.g.: Milly (2008) found that low regional streamflow effects lead to less freshwater in many regions; Arnell and Gosling (2013) projected increases in runoff in Canada, eastern Europe and Siberia and decreases in runoff in central Europe, central America and Brazil; Viola et al. (2015) assessed the Upper Grande River Basin and showed an increase in the MAS; Forbes et al. (2011), revealed that higher temperatures and precipitation resulted in an increase in winter and spring streamflow and a reduction of summer and fall streamflow under future climate scenarios (A1, B2, and A1T) for southern Alberta, Canada.

Cheng et al. (2012) studied climate change impacts for extreme weather events, such as freezing rain, heavy rainfall, high-/low-streamflow events, in four watersheds and four cities, including the Rideau River watershed (of which the Jock River watershed is a sub-watershed) and the city of Ottawa. Their results showed that the frequency and intensity of future extreme weather events and their impacts are generally projected to 
significantly increase late this century. Rainfall events impacting the Rideau River were predicted to have a 30\% increase in three-day accumulated rainfall extremes for 20012050, and greater than $40 \%$ after 2050. Across Canada, increases in precipitation of over $20 \%$ for summer and winter have been projected in climate models (IPCC, 2007a).

\subsection{CLIMATE AND HYDROLOGICAL EXTREMES}

Increased frequency and intensity of extreme climate such as droughts, heat waves, floods, and heavy precipitation events has the potential to damage ecosystems, infrastructure and impact agricultural crop production and water supply (IPCC, 2013; Cheng et al., 2012). An extreme weather event is defined by the IPCC (2013) as an event that is rare as or rarer than the $10^{\text {th }}$ or $90^{\text {th }}$ percentile of a probability density function estimated from observations at a particular place and time of year, that persists for some time, such as a season, especially if it yields an average or total that is itself extreme (e.g., drought or heavy rainfall over a season). This definition is important since it supports that an extreme event is rare, is season dependent, but also that a statistical understanding of their distribution is also required to classify a rare event.

Extreme climatic events are relative to time and space, where an extreme precipitation event in one region can cause a flood, but the same event at a different time or location may not create a flood (Lavell et al., 2012). Zhang and Zwiers (2013) demonstrate that to study the changes on a regional scale the probability distribution known as an extreme events analysis must be considered on a regional basis and across temporal scales to determine the baseline distributions for that area to assess impacts correctly.

To understand how a watershed behaves under climate change conditions, the type of climate and hydrological extremes that exist in a watershed are required. The temperature 
and precipitation of a watershed are considered the most important parameters that influence hydrologic response of a watershed (Cayan et al., 1993). The extremes for these parameters have large impacts on the environment and natural disasters. A temperature extreme can affect vegetation of a watershed, such as temperature stress where the plant exceeds its critical temperature and causes the plant damage and/or death (Luo, 2011; Zaytseva, 2016). Vegetation stress and damage are especially high during early reproductive stages, such as flowering, pollination, and grain and fruit formation (Zaytseva, 2016). Additionally, the general warming trend will also very likely lead to an earlier snow melt and increase in evaporation, leading to earlier spring peak flow events and lower summer streamflows in some regions (IPCC, 2013).

The largest increase in precipitation has been projected for the large intense short duration storms (Räisänen and Joelsson, 2001; Lavell et al., 2012). These intense storms are projected to have large changes in streamflow, ranging from double in wet and temperate areas to more than five times in arid areas (Chiew et al., 1995). These types of extremes have direct impacts on the environment and watershed, however they can also be two tier, where they can cause additional changes for extremes, especially in the hydrological response, such as droughts and floods discussed in the following subsections.

\subsubsection{FLOODS}

Increased frequency and intensity of precipitation events, warming, and shifts in seasonal precipitation regimes, result in projections of increased flooding and more intense low flows for many watersheds across the world (Arnell et al., 2003; Hsu et al., 2011; Lehner et al., 2006; Orlowsky and Seneviratne, 2012). Najini and Devineni (2017) found that extreme flood durations at the global scale, tropics, subtropics, and mid-latitudes last 
10 days longer post-2000 (around 30 days), as opposed to the 1980s and 1990s (around 20 days).

Examining and forecasting flood frequencies is a complex problem. There are several considerations that have to be made: which parameter to use (precipitation, water level, discharge), what is the flood threshold value, which GCMs, downscaling methods, watershed models, time interval of flow data (hourly, daily), period of simulation $(2,5,10$, $20,30,50,100$ years), future climate/emission scenarios considered, catchment characteristics (area, topography etc.), and flood mechanism (snow melt, evaporation, ENSO, etc) (Zaidman and Rees, 2000; Xu, 2002; Beven, 2012).

The development of extreme analysis methods has been motivated by the need to design systems (e.g. dams, flood protection systems, water supply system) to be able to safely handle the peak flow events while being economically viable (Condon et al., 2015). The increasing knowledge on physical processes and watershed interactions has improved hydrological models for determining flows, however statistical analysis of extremes is used to determine the frequency and magnitude that an extreme event could occur.

There are several ways to measure flood frequency but the most common is measuring the return period for the events. A return period is the probability of an event occurring, usually expressed in \% or years until it will occur again (Dingman, 2015). For example, a return period of a 100 years would have a $1 \%$ probability of that event occurring in any that one year. There are two main methods to calculate this, the first is using a trend analysis such as the generalized extreme value theory (GEV), the other is through a flow duration curve (FDC). The GEV approach is a statistical method with three different probability distributions (Gumbel, Fréchet and Weibull), which are used to determine the 
likelihood of an extreme event to occur (Coles, 2001). FDC is a plot that is used to measure the percentage of time that flow exceeds a specified streamflow value and used to measure the temporal variability of flow (Dingman, 2015).

\subsubsection{DROUGHTS}

Summers are expected to dry further in the future for Canada, while an increase in intensity and decrease in return period for both shorter and longer duration extreme precipitation events is expected in most areas based on the results from climate models (Lemmen et al., 2008; IPCC, 2013). As previously mentioned there will be more low flows in streamflow, and increased evaporation.

Generally, droughts can be classified into four categories: meteorological drought, hydrological drought, agricultural drought and socioeconomic drought (Wilhite and Glantz, 1985) which are closely related and interact with each other (Dingman, 1994). Among the mentioned types of drought, hydrological drought plays a vital role in the planning and management of water resource systems due to the increasing water demand of the growing populations (Lememen et al., 2008; IPCC, 2013). Typically, hydrological drought is defined as a significant decrease in the amount of available water, such as decrease in streams and rivers flows, and decline in water level in lakes, reservoirs and groundwater (Wilhite and Glantz, 1985).

There are several different ways to measure hydrological droughts; Streamflow Threshold Level (STL), Standardized Runoff Drought Index (SRDI), and GEV are commonly used. The STL was used by Yevjevich in 1967 to define droughts that do not meet a water demand and then later in 1983 simplified it to a constant demand of water, also known as a threshold level, where periods below the threshold are considered droughts 
(Fleig et al., 2006). The STL is a measurement of the drought duration above a threshold, and how many days that proceed to have this threshold or lower, also known as consecutive drought days (CDD) (Wu et al., 2015). Threshold levels are used to represent a water demand, such as agriculture needs, power plants, or water supply (Fleig et al., 2006). Many studies have been successful in applying this method to measure droughts (Fleig et al., 2006; Wu et al., 2015; Zaidman and Rees, 2000; Zaidman et al., 2001).

\subsection{HYDROLOGICAL MODELLING}

Water resources and watersheds can be represented, conceptualized and investigated using hydrological models (Xu, 2002; Beven, 2012). The purpose of a model is to represent a complex system in a simplified way. There is a wide variety of model types and approaches to represent the complex hydrological system. They can be used to determine and examine ground-water, streamflow, water quality, snow melt, evapotranspiration, and other aspects of the hydrological system (Xu, 2002; Beven, 2012). They currently have a wide range of uses such as water resource assessment, management decisions, research, and ecosystem health (Xu, 2002). Furthermore, coupled with climate change scenarios, hydrological models can be used to determine potential future climate and hydrological characteristics of the watershed, which is further explored in Section 2.9.

Determining which hydrological model to use for an application can be difficult since there are over a hundred variations of models available and each has their own unique pros, cons, data requirements, programming language, software, and availability (Xu, 2002; Bourdin et al., 2009; Beven, 2012). This complexity is highlighted in Bourdin et al. (2009), which explains the importance of model function, availability, and familiarity when 
choosing a model. The succeeding sections will review the history of hydrological models, and the different classification of hydrological models and their functionality.

\subsubsection{HYDROLOGICAL MODEL HISTORY}

Modelling hydrology first began in the 1850s by Mulvaney (1850), who developed the first concept for linking peak discharge to time of concentration of rainfall measurements $(\mathrm{Xu}, 2002)$. However, there was no method to model discharge until Kuichiling (1889) formulated the rational method (Equation 1.1), for urban sewer design:

$$
Q_{\mathrm{p}}-C i A
$$

(Equation 1.1)

where $Q_{\mathrm{p}}$ is peak flow, $C$ is the coefficient of runoff, $i$ is the intensity of rainfall in time and $A$ is the area of catchment.

The unit hydrograph was introduced by Sherman (1932). It represents a model that treats the watershed as a linear system, using a measurement of unit volume of rainfall that fell at a constant intensity and is uniformly distributed over the watershed (e.g. $1 \mathrm{~mm}$ of rain over the watershed) (Xu, 2002; Todini, 2007). The unit hydrograph is still being used as a technique in current hydrological models (Schulz et al., 2017).

Hydrological models really began to make large improvements in the 1960s with the help of computing power, and when Nash (1957) modelled the catchment as linear reservoirs with a storage unit (Xu, 2002). A response function for hydrological models was first introduced by Minshall (1960), which represented a lag time for a rainfall intensity, and later Diskin (1964) found that storm sizes (size of rainfall intensity), had different lag times. Soon after, Chow (1964) and Laurenson (1964) recognized that non-linear relationships (physical processes) in hydrological models could be used to represent the catchment in a more realistic behaviour (Xu, 2002). Then in the 1970s, models were being 
used as a warning tool for flood prone areas in real time and for hydraulic infrastructure (Xu, 2002). By the late 1970s, TOPMODEL was developed by Beven and Kirkby (1979), as the first model of its kind to incorporate topography as a dominant influence on hydrology (Xu, 2002). Afterwards the evolution of hydrological models continued, with addition of features such as computer computation, spatial distribution, elevation models, land-use changes, three-dimensions, satellite imagery, etc. (Xu, 2002).

Today, hydrological models are based on well-known small-scale theories built into coupled balance equations for mass and momentum and are divided into physical/deterministic and or stochastic/empirical models (Beven, 2012). With the continued increase in computing power and understanding of models and how they function, hydrological models are further classified into scale of lumped, distributed and semi distributed models (Beven, 2012).

\subsubsection{EMPIRICAL MODELS}

Empirical models, also known as conceptual models, use statistical relationships such as linear regressions to simulate water flow processes and storages (Beven, 2012; Dingman, 2015). They are usually described by a set of equations linking the input and output variables using equations, coefficients and probability distributions without considering the governing physical laws of the processes involved (Xu, 2002; Beven, 2012; Dingman, 2015). Empirical models tend to have low data requirements (but not always), and usually represent the watershed closely, but may also be less accurate when applying other conditions to the model that were not determined in the building of relationships (Beven, 2012). They have been used for determining peak flow and the time-to-peak of a unit hydrograph (Beven, 2012; Schulz et al., 2012). 


\subsubsection{PHYSICALLY-BASED MODELS}

Physical models are based on the understanding of physical processes that control basin responses and are typically derived from equations using basic physics such as the conservation of mass, energy, or momentum (Beven, 2012; Xu, 2002; Dingman, 2015). Generally, they have higher accuracy for predicting the effects of changes in land use, snow melt, vegetation, topography, and climate (Bourdin et al., 2009; Beven, 2012). However, some models are considered inadequate due to their higher data requirements (Beven, 2012), heavy over-parameterization, time consumption, setup, and difficult calibration (Bourdin et al., 2009).

\subsubsection{LUMPED MODELS}

A lumped model is a simplification of reality where structure, inputs, parameters and output are spatially averaged throughout the watershed (Beven, 2012). They assume that the watershed is a homogenous system without considering the spatial distribution of processes $(\mathrm{Xu}, 2002)$. The assumption means that there are very little data required for the model, as only one value for any parameter is required. This however also means that there are large discrepancies in values, especially in large watersheds (Beven, 2012). A simple example of a lumped model is the unit hydrograph that has an equal amount of precipitation that falls at the same intensity on the whole watershed.

\subsubsection{DISTRIBUTED MODELS}

Distributed hydrological models are a better representation of reality, as their structure, inputs, hydrological characteristics, parameters and responses are represented in a spatially distributed manner, usually in a square, or isometric grid system (Xu, 2002; Beven, 2012). 
This allows for the heterogeneity of the watershed system to be represented; for example, areas are divided as a grid net where water flows from one grid point to another when water drains through the basin (Xu, 2002; Beven, 2012). They also provide a detailed and potentially more correct description of hydrological processes in the catchment than other model types (Xu, 2002; Beven, 2012), and couple hydrological processes with a variety of physically based models of biological and chemical processes (Xu, 2002; Beven, 2012).

However, the improved hydrological processes and heterogeneity also require large amounts of geospatial data (e.g., topography, geology, soil, land cover, vegetation, etc.) and time series data (precipitation, temperature, streamflow, etc.), as well as setup and run time (Beven, 2012). For a small watershed, the data requirements may be low, but for a larger watershed, structuring and providing data for every model element can become a difficult and limited to the data available (Xu, 2002; Beven, 2012). Nonetheless, they provide a connection between scientific disciplines, and their ability to assess the impacts of climate change has been recognized (Miller et al., 1999; Liu et al., 2007; Yao et al., 2009; Maurer et al., 2010; Kienzle et al., 2012; Viola et al., 2015).

\subsubsection{SEMI-DISTRIBUTED}

Semi-distributed hydrologic models are similar to distributed, however they calculate flow contribution from subwatersheds or hydrological response units (HRUs), where the subwatersheds and HRUs are considered homogenous (Xu, 2002). HRUs are user defined objects that represent the specific hydrological features unique to that area, but its subwatershed controls where the flow outputs are routed downstream or groundwater flows laterally between soil layers (Craig, 2016). This allows for lower data requirements, but still maintains the physical processes and some of the heterogeneity of the system. 


\subsection{RAVEN MODELLING FRAMEWORK}

Raven is a modelling framework developed by James Craig, and the Raven research team from the University of Waterloo (Craig et al., 2017). Raven is robust, flexible, and designed for application to challenging hydrological problems in academia and practice (Craig et al., 2017). This framework allows for building anything from simple single watershed lumped models with only a handful of state variables, to a semi-distributed system model with HRUs, physically-based processes and routing (Craig et al., 2017). The framework is built on an open source object-oriented code that allows flexibility and creativity for spatial discretization, interpolation, process representation, and forcing function generation (Craig et al., 2017).

Due to its flexibility and open source, it can be easily used with time series databases and GIS applications, and emulate similar results from many hydrological models, as well as full replication for some models, including the UBC Watershed model, HBV-EC, and GR4J (Craig et al., 2017). The framework has the capabilities of turning a lumped model into a semi-distributed model, as it separates the watershed into the subwatersheds and a routing routine can be defined, allowing previously-lumped models to function in a semidistributed fashion. Raven also contains a large library of different methods to calculate hydrological processes, these processes include: canopy interception, infiltration, baseflow, percolation, interflow, soil evaporation, capillary rise, canopy evaporation,

canopy drip, snow melt and snow balance, glacial melt, crop heat balances and more listed in the Raven manual (Craig et al., 2017). 


\subsection{MODEL CALIBRATION, SENSITIVITY AND VALIDATION}

Empirical or physically based models often requires a process of calibration, sensitivity and validation to ensure that they represent the watershed as best as possible and ensure suitability for use. These predictions are being used for water resources management and research such as streamflow runoff, timing and magnitude of runoff events, flood estimation, drought durations, reservoir operation, agriculture, fisheries management and various human water needs throughout each year (Beven, 2012; Xu, 2002). Calibration, sensitivity analysis, and validation are tools that allow one to modify the models' parameters to find the best simulation for a watershed, and to evaluate how well the model represents that watershed.

Calibration is accomplished by finding the best fit for a specific set of data, where the parameters are adjusted to find the least error between the simulated model and the observed historical data (Beven, 2012). Objective functions, also known as model evaluation statistics, are different measurements used to minimize the error between simulated and observed data, and they are commonly used in calibration (Beven, 2012). Common examples of these include linear regression coefficients, or in hydrology the Nash-Sutcliffe coefficient of efficiency (NS) (Nash and Sutcliffe, 1970). A model will also have more flexibility or usefulness if the calibration step is flexible, so it can be calibrated for a variety of watersheds. This step is highly dependent on the field observations that were obtained for the area, which is the main reason that conceptual and physically based models are not very successful in ungauged streams (Bourdin et al., 2009; Beven, 2012). Calibration is also highly dependent on the precipitation data, as they are the main input into the model and a change in rainfall is generally amplified as a larger percent change in 
runoff (Chiew et al., 2010; Beven, 2012). There are several techniques in a calibration process, and once the model is built and a range of parameters are available for the model, an optimization tool can be applied to optimize for the best parameter set for the model to be used.

Sensitivity of a model is usually evaluated as a measurement of how sensitive a model is to changes in parameter values, which can be used to show which parameters have the greatest influence on the outputs of a model. This step is especially important if the model is being used for hydrological studies, where land use land cover, vegetation, or topography changes could have very large changes in the outputs of the model (Gerbaux et al., 2009; Beven et al., 2012).

Model validation is the process of determining how accurate the model is. This step is essential to ensure that the model is not over-calibrated for a particular time period or other context, to the point that it is no longer effective at modelling other contexts. It is also important as it measures how reliable the model is for annual, seasonal, daily and extreme values. The validation process usually involves simulating prosses using data not used in the calibration step, and uses objective functions to provide an evaluation of certain aspects of model simulation, including how well simulated data match measured data in terms of timing and magnitude of peak flows and shape of the recession curve. The model performance is very important, however due to the nature of models and the possibility of over-parameterization there are always uncertainties in the model, which are described in the following section. 


\subsection{MODEL UNCERTAINTY}

Model uncertainty has been described by the slogan "more knowledge, less certainty", (Trenberth, 2010), and addressing uncertainty is a common theme in modelling research. There is a problem of overfitting hydrological model parameters, and the equifinality of the infinite number of possibilities that exists for a model with many parameters (Beven, 2006; Bourdin et al., 2009; Beven, 2012). Modelling every single aspect, process and state of a watershed is nearly impossible, which is why we have assumptions, simplifications, and estimates for the processes and data of the models. These assumptions, simplifications, and estimates give rise to uncertainties in the model, which affect quality, costs, decisions, and risks with use of the model (Konikow and Bredehoeft 1992; Beven, 2011). It is also important to note that there is uncertainty associated with model structure, selected processes, and observational values.

Climate models are similar to hydrological models except they are used to represent the physical processes in the atmosphere, land, ocean, and cryosphere, usually with spatial resolutions of a few degrees. This means that they have similar uncertainties for their assumptions, simplifications, and estimates, except on broader extents. There are also uncertainties in the climate sensitivity, emission scenarios, and downscaling methods, which causes a large range of uncertainty that has been pointed out by numerous studies (Tebaldi et al., 2005; Taylor et al., 2012; Gramelsberger and Feichter, 2013). This means there are many different types of uncertainties that can exist within modelling which is why it is important to measure these or at least acknowledge them.

Trying to evaluate all the uncertainties that propagate through a model or with the use of climate models will not only take a large amount of computational power but will also 
likely result in uncertainty bounds that are not useful (Shiogam et al., 2016). Evaluating the model structure and parameter uncertainty is the most common method of measuring uncertainty for hydrological models. This type of uncertainty is commonly measured by using statistical methods to determine probabilities, and upper and lower prediction intervals, however GLUE uses a non-statistical approach to uncertainty, explained in the following section.

\subsubsection{GLUE ALGORITHM}

The Generalized Likelihood Uncertainty Estimation (GLUE) method can both be used as a calibration tool and as a non-statistical method to determine upper and lower prediction intervals of a model. GLUE uses the premise that no single correct model parameter set exists, but that a degree of freedom can be associated with the model parameter sets (Beven and Binley, 1992). It is based on the concept of equifinality, where there are different model structures and parameter sets that provide acceptable fits to calibration data (Beven and Binley, 1992; Beven, 2012). These acceptable parameter sets are used to provide different predictions, and the predictions then can be used to estimate the resulting uncertainty by measuring the highest and lowest values at each time interval for a degree of belief (Beven, 2012). GLUE has been used in many different calibration processes of hydrological models (Beven, 2012; Musa et al., 2015).

\subsubsection{MODEL UNCERTAINTY}

The uncertainty of these models is not likely to improve soon, since that would require improvements to the knowledge of the models' processes, and finer resolution (Kundzewicz et al., 2018). Furthermore, uncertainty of climate models has been gaining focus only in the last decade, and often instead of being seen as useful, popular media and 
skeptics have characterized the uncertainty as being low or high, instead of understanding what can be learned from the actual analyses (Gramelsberger and Feichter, 2013).

\subsection{HYDROLOGICAL AND CLIMATE CHANGE MODELS}

Once a hydrological model has been created and calibrated it can be used to explore the topic of future climate change. This is not the same as measuring return periods or trend analysis but rather using a future climate series as the climate data input with the model's optimized parameter values, to model future runoff and compare it to historical runoff to estimate impacts of climate change for the watershed (Forbes, 2011).

Depending on the type of hydrological model and its purpose, the model can simulate a variety of hydrological variables for future climate scenarios based on GCMs. The GCMs provide the hydrological model with climate data for variables such as temperature and precipitation, and the model can simulate different aspects of the hydrology such as ground-water, streamflow, water quality, evapotranspiration, snow melt, and other aspects of the hydrological system. There are large uncertainties with this process, however they are useful for climate change, policy making, resource management, and mitigation and adaptation strategies (Lemmen et al., 2008; Dessai and Hulme, 2007). Furthermore, return periods and trend analysis using GEV methods can be applied to the results to provide more details on extreme distributions. For example, Hao et al. (2014) found decreasing spring streamflow melts using a nonstationary GEV model in China, and Condon et al. (2015) found opposite results with an increase in streamflow melt peaks in western U.S. 


\section{CHAPTER 3: STUDY AREA AND DATA COLLECTION}

\subsection{STUDY AREA, GEOGRAPHY AND CLIMATE}

The Jock River watershed is a subwatershed of the Rideau River parent, located southwest of the Ottawa city center. The Jock River is approximately $75 \mathrm{~km}$ in length, and its catchment encompasses an area of roughly $557 \mathrm{~km}^{2}$. The watershed is further divided into 12 sub-watersheds, and their properties can be found in Table 3.1. The Jock River hydrometric gauge is located on Moodie Drive near the town of Richmond (Figure 3.1). The Barrhaven sub-watershed is downstream from the Jock River gauge (Figure 1 and section 3.3.3), which is the driving streamflow data used for this thesis. Therefore, 11 of the subwatersheds are modelled and the Barrhaven subwatershed was not modelled, and information was not collected for this area.

Table 3.1. Subwatershed names and properties. Data source: Catchment reports (RVCA, 2016)

\begin{tabular}{|l|l|l|l|l|l|l|}
\hline Name & $\begin{array}{l}\text { Area } \\
\left(\mathrm{km}^{2}\right)\end{array}$ & $\begin{array}{l}\text { Elevation } \\
(\mathrm{m})\end{array}$ & $\begin{array}{l}\text { Latitude } \\
(\mathrm{deg})\end{array}$ & $\begin{array}{l}\text { Longitude } \\
(\mathrm{deg})\end{array}$ & Dam & Gauge \\
\hline $\begin{array}{l}\text { Ashton-Dwyer } \\
\text { Hill }\end{array}$ & 45.9 & 128 & 45.154 & -76.010 & YES & NO \\
\hline Flowing Creek & 53.8 & 111 & 45.217 & -75.904 & NO & NO \\
\hline Franktown & 80.4 & 138 & 45.066 & -76.070 & NO & NO \\
\hline Hobbs Drain & 32.6 & 117 & 45.182 & -75.927 & NO & NO \\
\hline $\begin{array}{l}\text { Jenkinson } \\
\text { Drain }\end{array}$ & 24.2 & 131 & 45.191 & -75.991 & NO & NO \\
\hline Kings Creek & 93.0 & 126 & 45.075 & -75.978 & YES & NO \\
\hline Lemay Creek & 20.4 & 95 & 45.227 & -75.796 & NO & YES \\
\hline $\begin{array}{l}\text { Monahan } \\
\text { Drain }\end{array}$ & 41.0 & 101 & 45.258 & -75.856 & NO & NO \\
\hline Nichols Creek & 79.4 & 119 & 45.075 & -75.909 & NO & NO \\
\hline Richmond Fen & 24.6 & 102 & 45.143 & -75.878 & YES & NO \\
\hline JR Richmond & 28.6 & 96 & 45.184 & -75.827 & NO & NO \\
\hline
\end{tabular}


The Jock River watershed is mostly composed of agriculture broadleaf deciduous woodlands, agriculture and wetlands, with some urban area. It is located in a temperate humid continental climate zone, and has large seasonal differences, dominated by mostly cold winters and humid summers. The growing season is approximately 160 days and starts towards the end of April and ends near the beginning of October. The wettest month of the year is July and the driest is February. The climate normal data from 1981-2010 can be found in Table 3.2.

Table 3.2. The 1981 - 2010 Canadian Climate Normal station data. Data source: Text file (NRCAN, 2018a)

\begin{tabular}{|l|r|r|r|r|}
\hline & $\begin{array}{l}\text { Temperature } \\
\left({ }^{\circ} \mathrm{C}\right)\end{array}$ & $\begin{array}{l}\text { Rainfall } \\
(\mathrm{mm})\end{array}$ & $\begin{array}{l}\text { Snowfall } \\
(\mathrm{cm})\end{array}$ & $\begin{array}{l}\text { Precipitation } \\
(\mathrm{mm})\end{array}$ \\
\hline Jan & -10.3 & 25 & 53.9 & 65.4 \\
\hline Feb & -8.1 & 18.7 & 43.3 & 54.3 \\
\hline Mar & -2.3 & 31.1 & 38.3 & 64.4 \\
\hline Apr & 6.3 & 63 & 11.3 & 74.5 \\
\hline May & 13.3 & 80.1 & 0.2 & 80.3 \\
\hline Jun & 18.5 & 92.8 & 0 & 92.8 \\
\hline Jul & 21 & 91.9 & 0 & 91.9 \\
\hline Aug & 19.8 & 85.5 & 0 & 85.5 \\
\hline Sep & 15 & 90.1 & 0 & 90.1 \\
\hline Oct & 8 & 82.2 & 3.7 & 86.1 \\
\hline Nov & 1.5 & 64.5 & 20.2 & 81.9 \\
\hline Dec & -6.2 & 33.5 & 52.5 & 76.4 \\
\hline Year & 6.4 & 758.2 & 223.5 & 943.4 \\
\hline
\end{tabular}

*Note that the rainfall and snowfall do not match to total precipitation as snow is measured in $\mathrm{cm}$ and $1 \mathrm{~cm}$ does not always equal $1 \mathrm{~mm}$ of rain depending on the type of snowfall. 


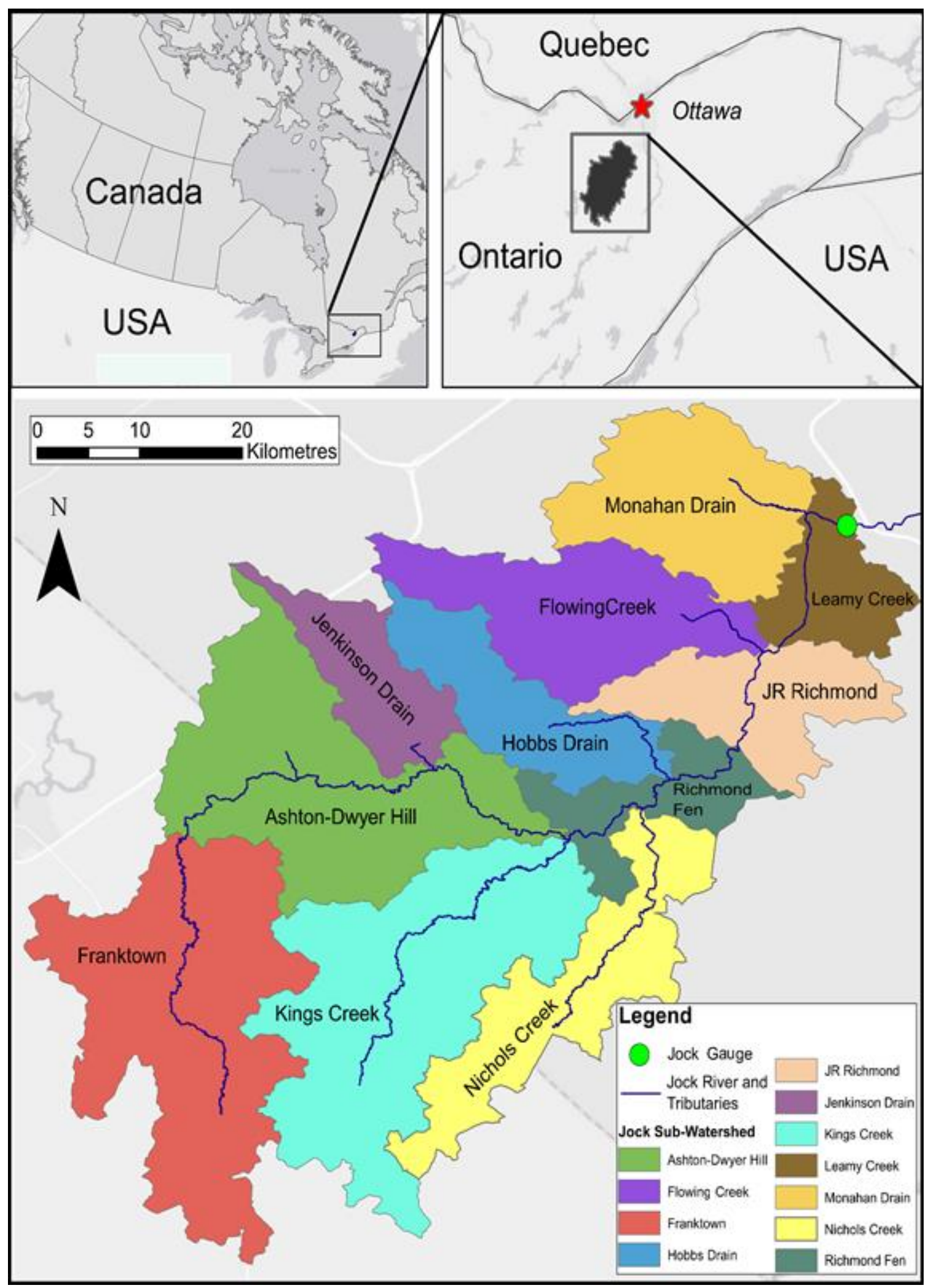

Figure 3.1. The Jock River watershed study area with its tributaries and main subwatersheds that are identified by the Rideau Valley Conservation Authority (RVCA). 


\subsection{HYDROLOGY AND HISTORY}

The Jock River watershed (Figure 3.1) is in the Saint Lawrence River watershed and connects to the left tributary of the Rideau River. The Jock River flows from headwaters composed of mostly woodlands and wetlands, then through mixed woodland, wetland and agricultural lands in its middle reaches, and finally, through increasing agricultural and urban land in the lower reaches near Ottawa's South Urban area (RVCA, 2016).

The Jock River Watershed is a large heterogeneous watershed, which requires a variety of data such as spatial, topography, meteorological, soils, land cover, and stream discharge. The upper half of the watershed is dominated by wetlands and woodlands, due to the flat topography, soil, geology, climate, and high-water tables in the area (RVCA, 2016). These wetlands are mixed with the woodlands and have varying sizes (RVCA, 2016). The RVCA watershed report (RVCA, 2016) reported variable surface water quality ranging from good to poor from its headwaters to its lower reaches.

The Jock River is governed by a variety of hydrological processes which include but are not limited to: infiltration, evaporation, evapotranspiration, interception, rainfall, freezing, thawing, melting, and flow. There is a large dam located in the Barrhaven watershed, and the stream gauge is therefore located upstream from the dam. There are also smaller barriers and dams located in watershed that were built in the 1960s and are managed by the RVCA to help wildlife and ecosystem protection (RVCA, 2018). There also several groups (e.g. municipal water supply, sewage, golf courses, industrial uses, quarry/pit and construction dewatering) that that have active take water permits for the watershed (RVCA, 2016). This means that the Jock River and its tributaries are not natural rivers due to the upstream dams, barriers and diversions. These dams cause the flow 
volumes observed to not be perfect representations of the natural flow of the river and can be difficult to analyze and generalize. The flow normal from 1981-2010 for the Jock River gauge can be seen in Figure 3.2, illustrating the large variability of flow for the seasons with a large streamflow during the winter melt, and low flows in the late summer and fall season.

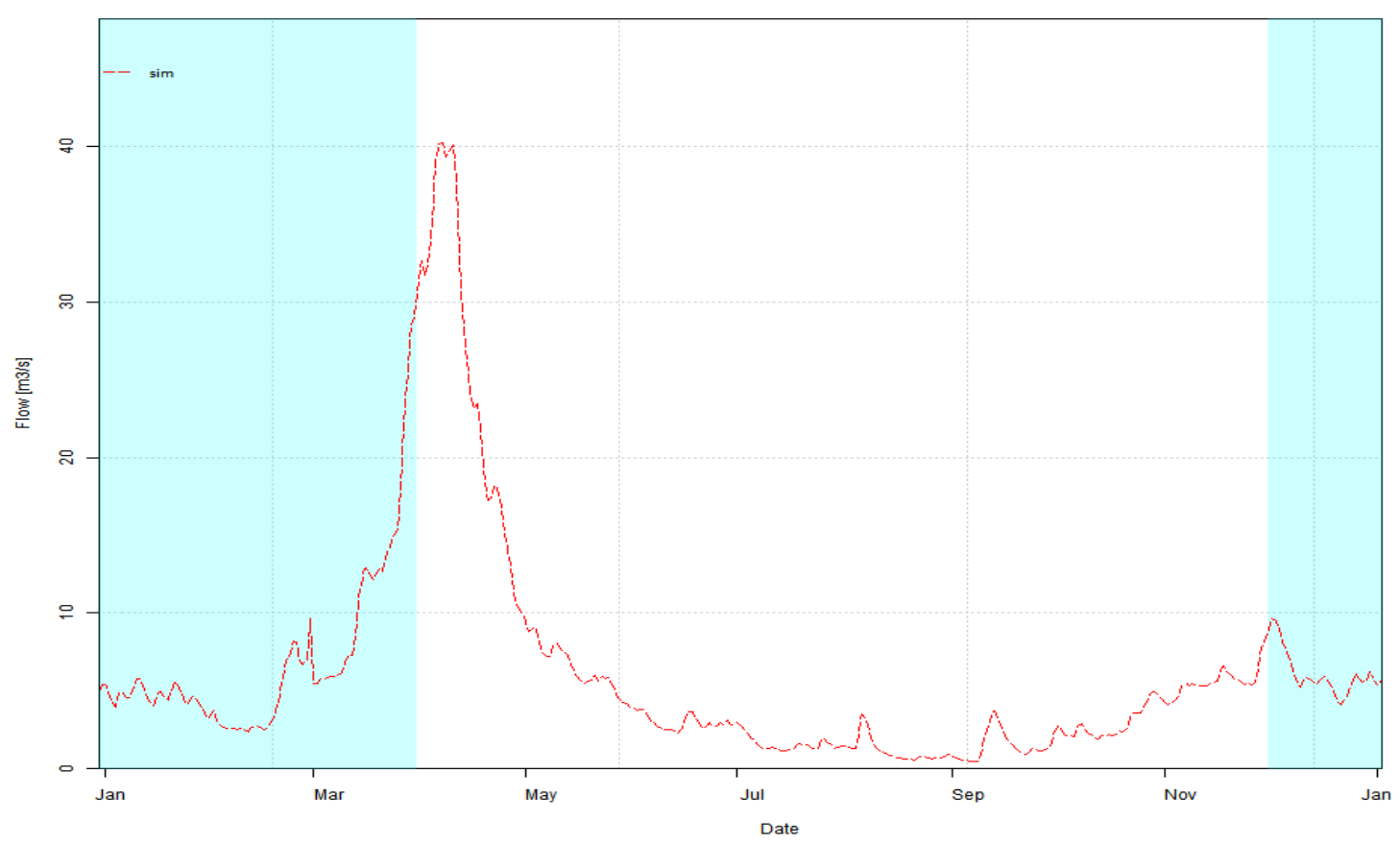

Figure 3.2. Mean streamflow (1981-2010) for the Jock River watershed. Blue represents the winter season (December 1st - Mar 31st). Data source: Text file (NRCAN, 2018b).

\subsection{MODEL DATA COLLECTION}

Data collection is a very important step and requirement for the use of hydrological models, and it can also be the limiting factor in the decision process of which model and at what level of complexity one can simulate the hydrological processes in a watershed. The following section describes what, where, and how the data were collected.

The model options explored in this thesis required the following data: meteorological data (historical precipitation and minimum and maximum air temperature, and average 
monthly evaporation data); streamflow data $\left(\mathrm{m}^{3} / \mathrm{s}\right)$ and channel profile (single or multiple gauges); topographical and geographic information (location, area, elevation, aspect, and slope for subwatersheds); Land Use and Land Cover (LULC) classification; soil data (soil type, soil porosity, field capacity, and wilting point); average monthly leaf area index (LAI); and model coefficients (plant interception and transpiration, and snow melt and refreeze coefficients).

\subsubsection{METEOROLOGICAL DATA}

A complete historical meteorological dataset, that doesn't contain data gaps, and has been verified as an accurate representation of the site, is vital to model calibration and validation. This can be difficult, especially if the climate station is not located in or near the study area. Two meteorological datasets were used in this study; the first is a $10 \mathrm{~km}$ gridded dataset, and the second is a nearby climate station.

The $10 \mathrm{~km}$ gridded dataset is a meteorological dataset for the Canadian landmass south of $60^{\circ} \mathrm{N}$ between 1961-2015. It consists of daily minimum and maximum temperatures ( $T_{\min }$ and $T_{\max }$ ) and precipitation from 1961-2003 (Hutchinson et al., 2009). This dataset is interpolated from daily Environment Canada climate station observations from 1961-2003, using a thin plate smoothing spline surface fitting method (see Hutchinson et al. (2009) for further details). Natural Resources Canada provides updates to the dataset as new data become available and resources allow, and as of this writing the years 1950-2015 are available (NRCAN, 2018a). The size of the watershed and the distance away from the station were considered in selecting the gridded dataset as the best option for calibration and validation in this large watershed, as the weather station would have been greater then $50 \mathrm{~km}$ away from the furthest point in the watershed. 
The second dataset, from 2016-2017, was obtained from the nearest climate station to the center of the Jock River watershed which is the OTTAWA MACDONALDCARTIER INT'L A ONTARIO Weather Station (ID 4337), 30km away (NRCAN, 2018a). This dataset was needed as the $10 \mathrm{~km}$ gridded meteorological dataset is only available until 2015.

\subsubsection{STREAM FLOW DATA}

A historical streamflow dataset for the Jock River watershed was obtained from the Jock River stream gauge maintained by Water Survey of Canada (WSC) and Environment Canada. The stream gauge measures daily discharge $\left(\mathrm{m}^{3} \mathrm{~s}^{-1}\right)$ and water height $(\mathrm{m})$. Observations of historical streamflow are available in near real-time or in an archived format and can be downloaded from the Environment and Climate Change Canada website for the period 1969 - 2018 (present). Additional information for the gauge can be found in

Table 3.3. Photographs showing the gauge are shown in Figure 3.3 and Figure 3.4.

Table 3.3. Jock River stream gauge information. Data source: Text file (NRCAN, 2018b)

\begin{tabular}{|l|l|l|l|l|l|l|l|}
\hline $\begin{array}{l}\text { Station } \\
\text { Name }\end{array}$ & $\begin{array}{l}\text { Station } \\
\text { ID }\end{array}$ & $\begin{array}{l}\text { Latitude } \\
(\mathrm{deg})\end{array}$ & $\begin{array}{l}\text { Longitude } \\
(\mathrm{deg})\end{array}$ & $\begin{array}{l}\text { Elevati } \\
\text { on }(\mathrm{m})\end{array}$ & $\begin{array}{l}\text { Observed } \\
\text { Time } \\
\text { Period }\end{array}$ & $\begin{array}{l}\text { Drainage } \\
\text { Area } \\
\left(\mathrm{km}^{2}\right)\end{array}$ & $\begin{array}{l}\text { Operational } \\
\text { Schedule }\end{array}$ \\
\hline $\begin{array}{l}\text { Jock } \\
\begin{array}{l}\text { River } \\
\text { Station }\end{array}\end{array}$ & $\begin{array}{l}02 \mathrm{LA}- \\
007\end{array}$ & $\begin{array}{l}45^{\circ} 14^{\prime} \\
57^{\prime \prime} \mathrm{N}\end{array}$ & $\begin{array}{l}75^{\circ} 47^{\prime} \\
26^{\prime \prime} \mathrm{W}\end{array}$ & 115 & $\begin{array}{l}1969- \\
2017\end{array}$ & 526 & Continuous \\
\hline
\end{tabular}




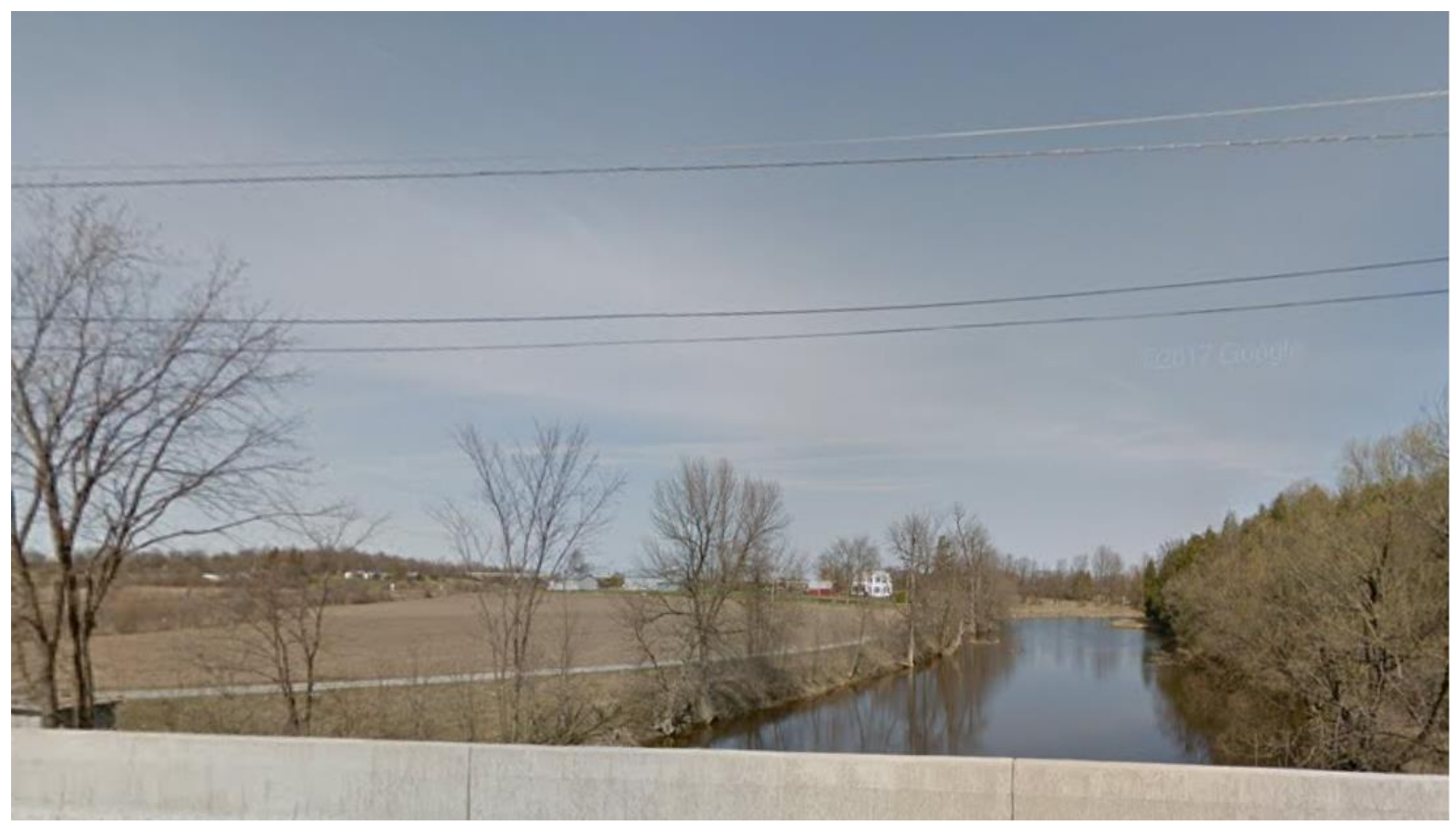

Figure 3.3. Photograph of the Jock River and the Jock River Stream Gauge left bottom corner on April 2012. Data source: Image (Google Maps, 2018a)

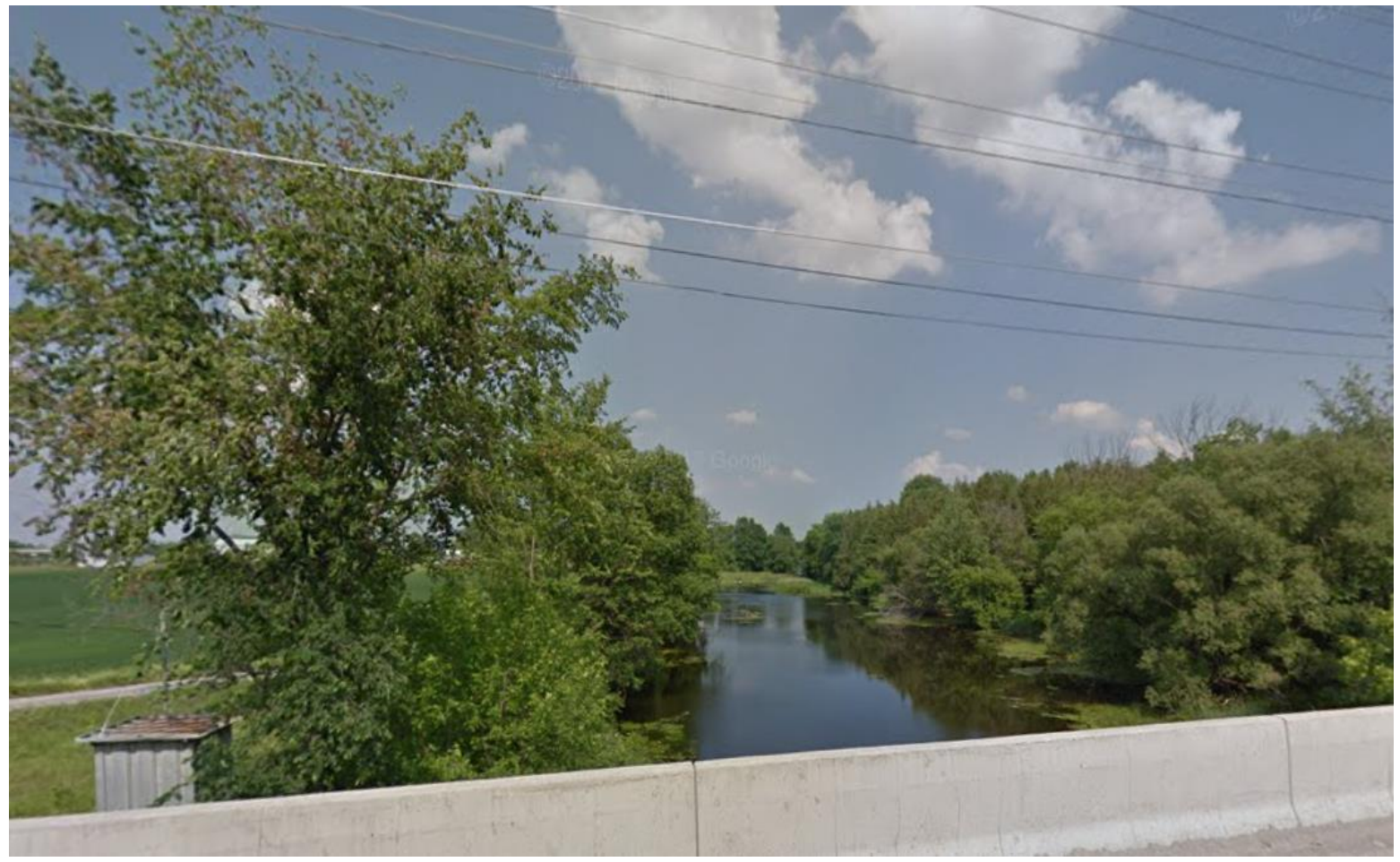

Figure 3.4. Photograph of the Jock River and the Jock River Stream Gauge left bottom corner on June 2012. Data source: Image (Google Maps, 2018b) 


\subsubsection{TOPOGRAPHICAL DATA}

The topographical information used in the thesis came from a 30 metre hydrologically-corrected DEM for the study area (Figure 3.5) acquired from the Ontario Ministry of Natural Resources and Forestry (OMNRF) (OMNRF, 2013). Additionally, an aspect map (Figure 3.6) and a slope map (Figure 3.7) are derived from the DEM.

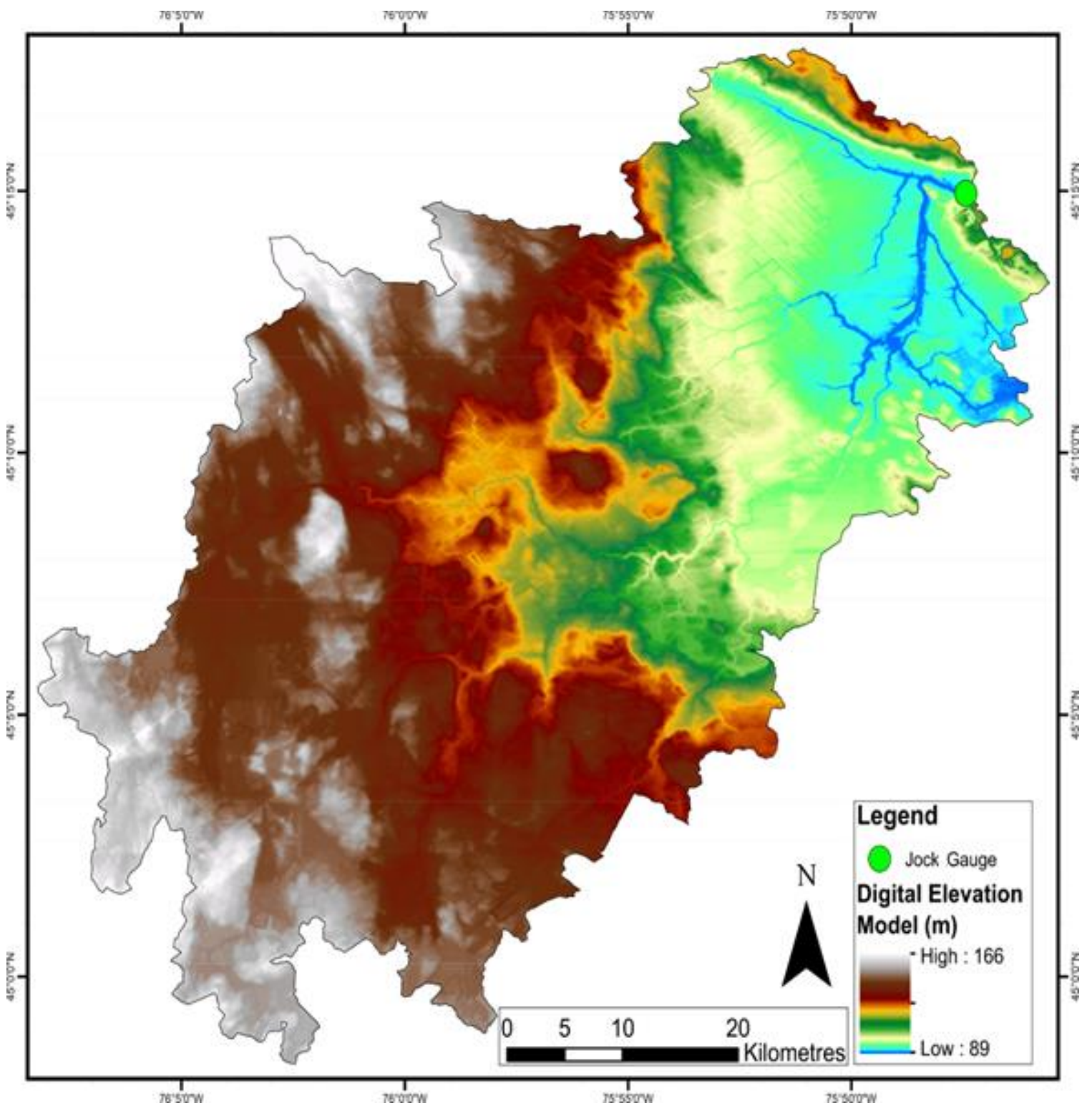

Figure. 3.5. Digital elevation model map of the Jock River watershed. Data source: Elevation (OMNRF, 2012). 


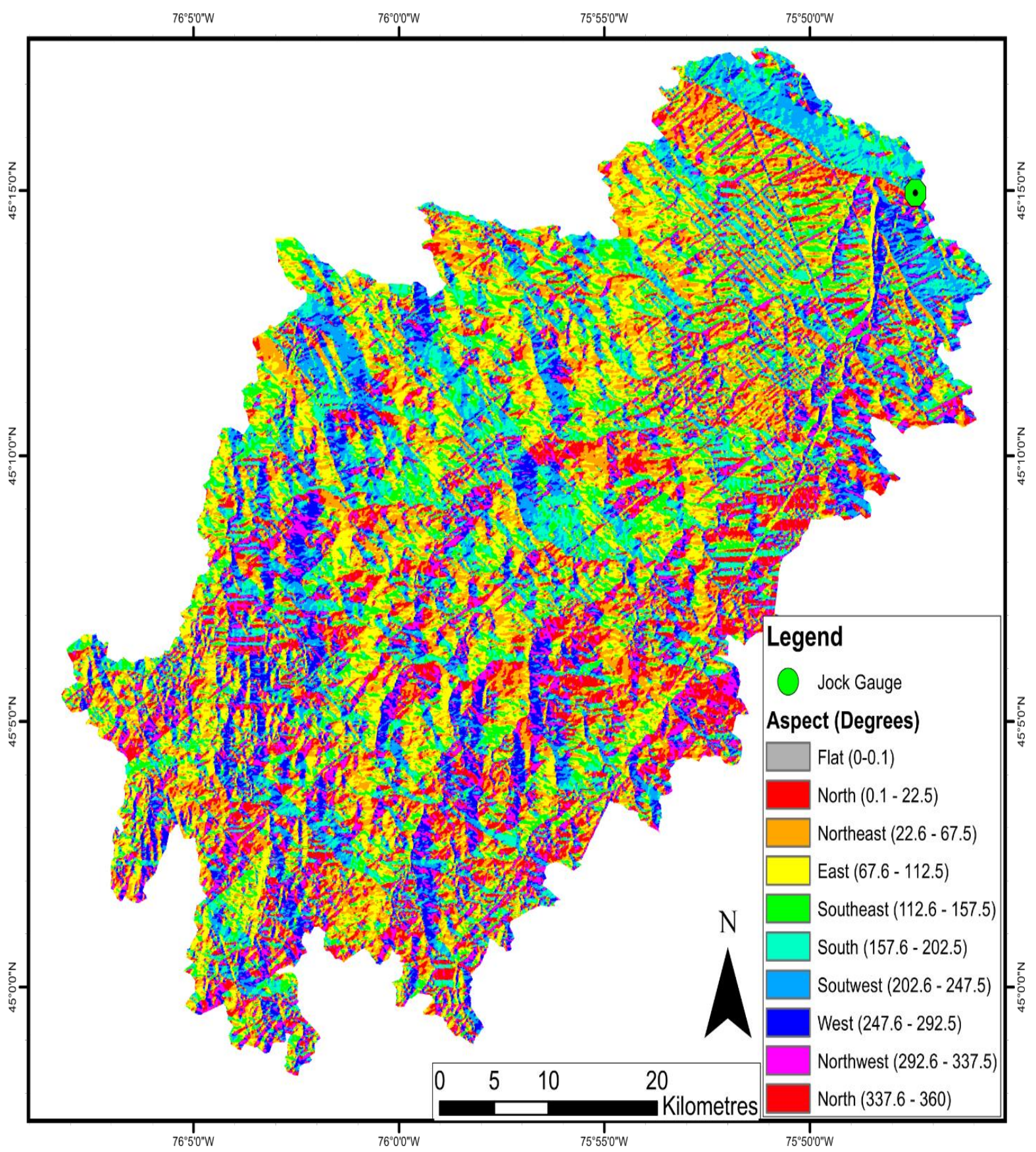

Figure 3.6. Aspect map of the Jock River watershed. Data source: OMNFR (2016). 


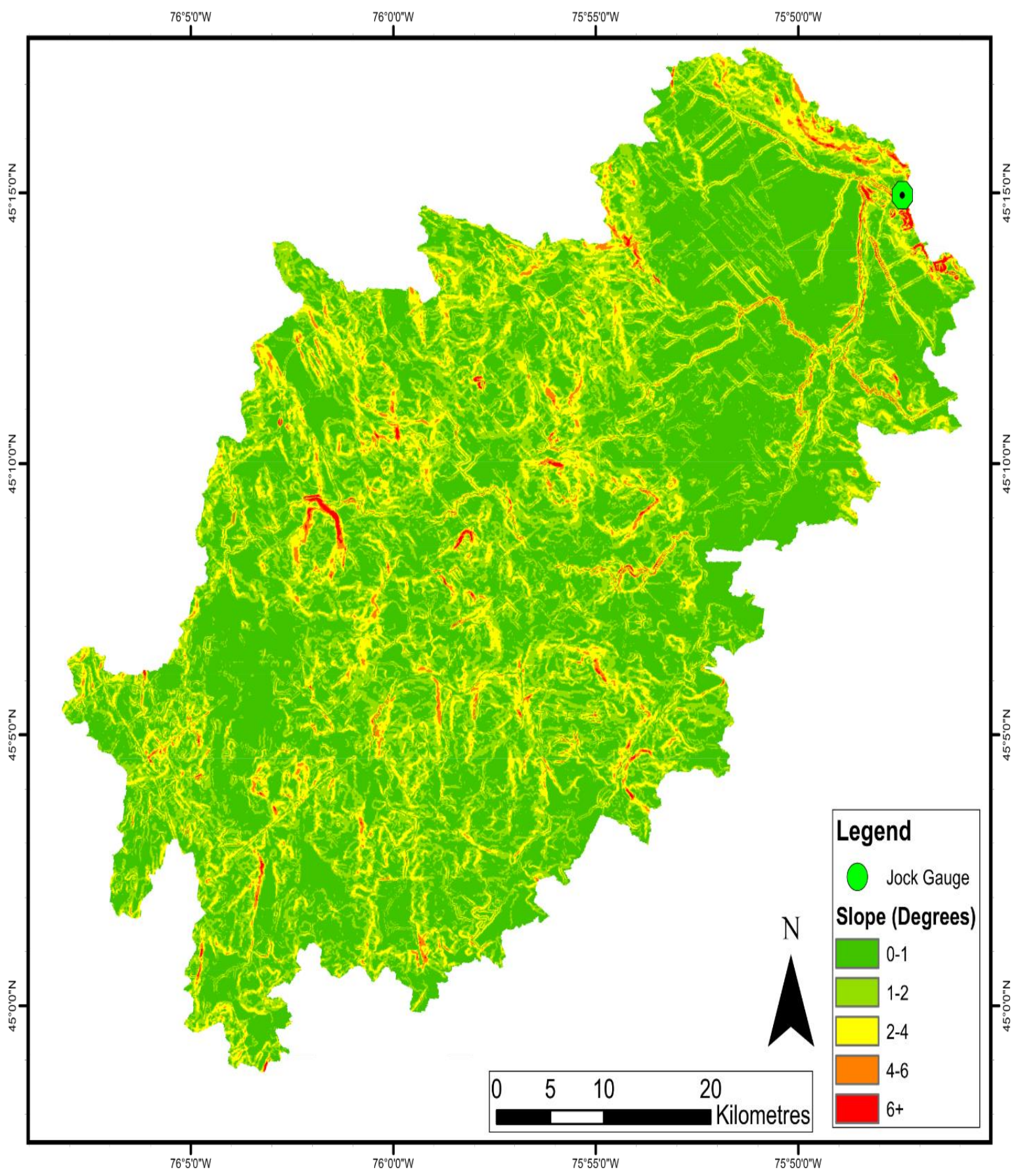

Figure 3.7. Slope map of the Jock River watershed. Data source: OMNFR (2016). 


\subsubsection{LAND USE AND LAND COVER CLASSIFICATION}

A LULC dataset for the Jock River Watershed was obtained from the RVCA from a 2015 survey of the region. The dataset contains features for aggregate sites, agriculture and pasture, wetlands, meadows, urban, forest and water (Figure 3.8).

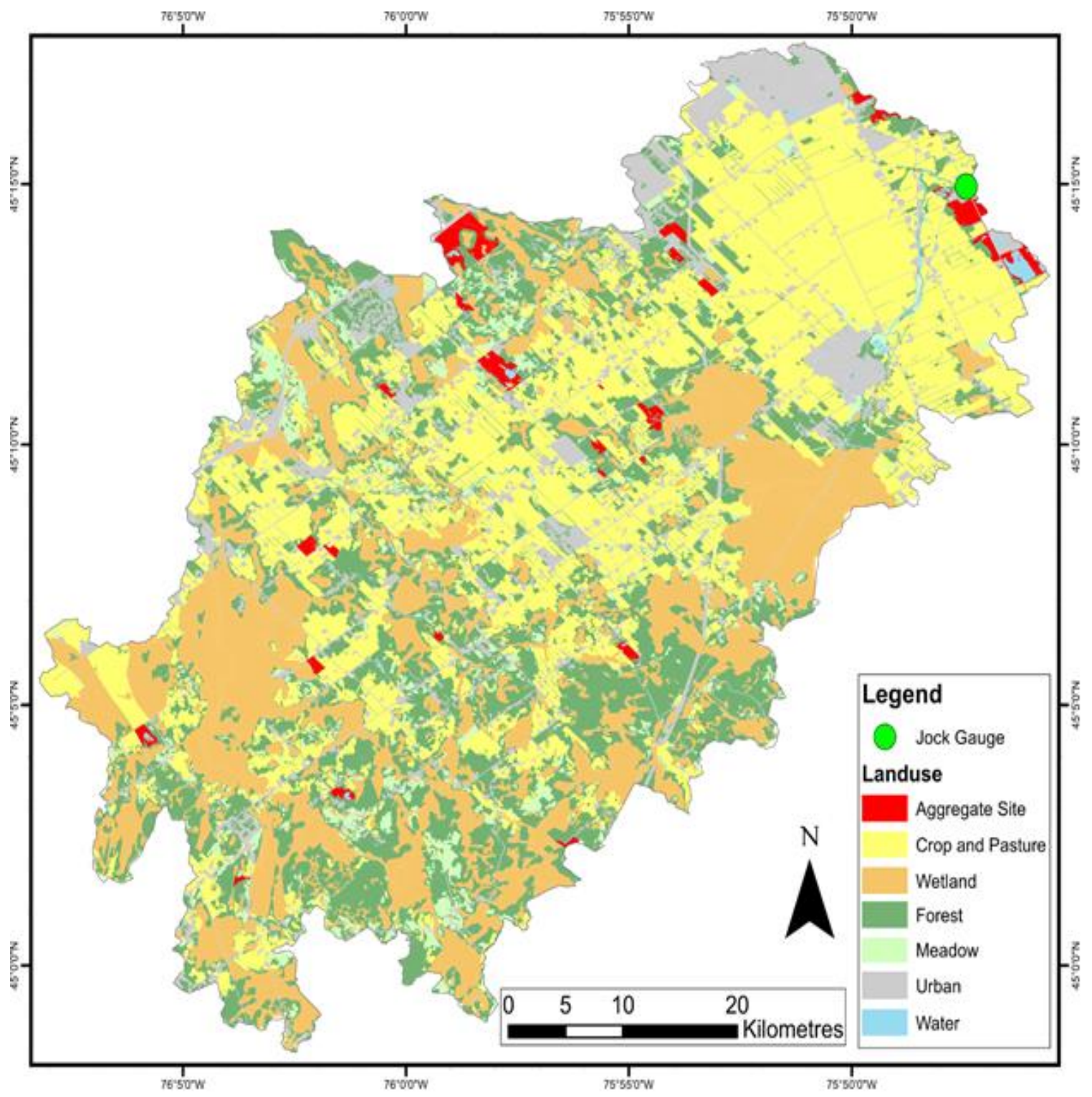

Figure 3.8. Land use and land cover classification for the 2015 Jock River watershed. Data source: Soil Survey Complex (RVCA, 2016). 


\subsubsection{SOIL DATA AND CHARACTERISTICS}

Soil data for the Jock River watershed on surface soil type and soil characteristics (Figure 3.9) were obtained from AAFC. This dataset was a collaboration between City of Ottawa, and County of Lanark, and the final product contained two merged datasets.

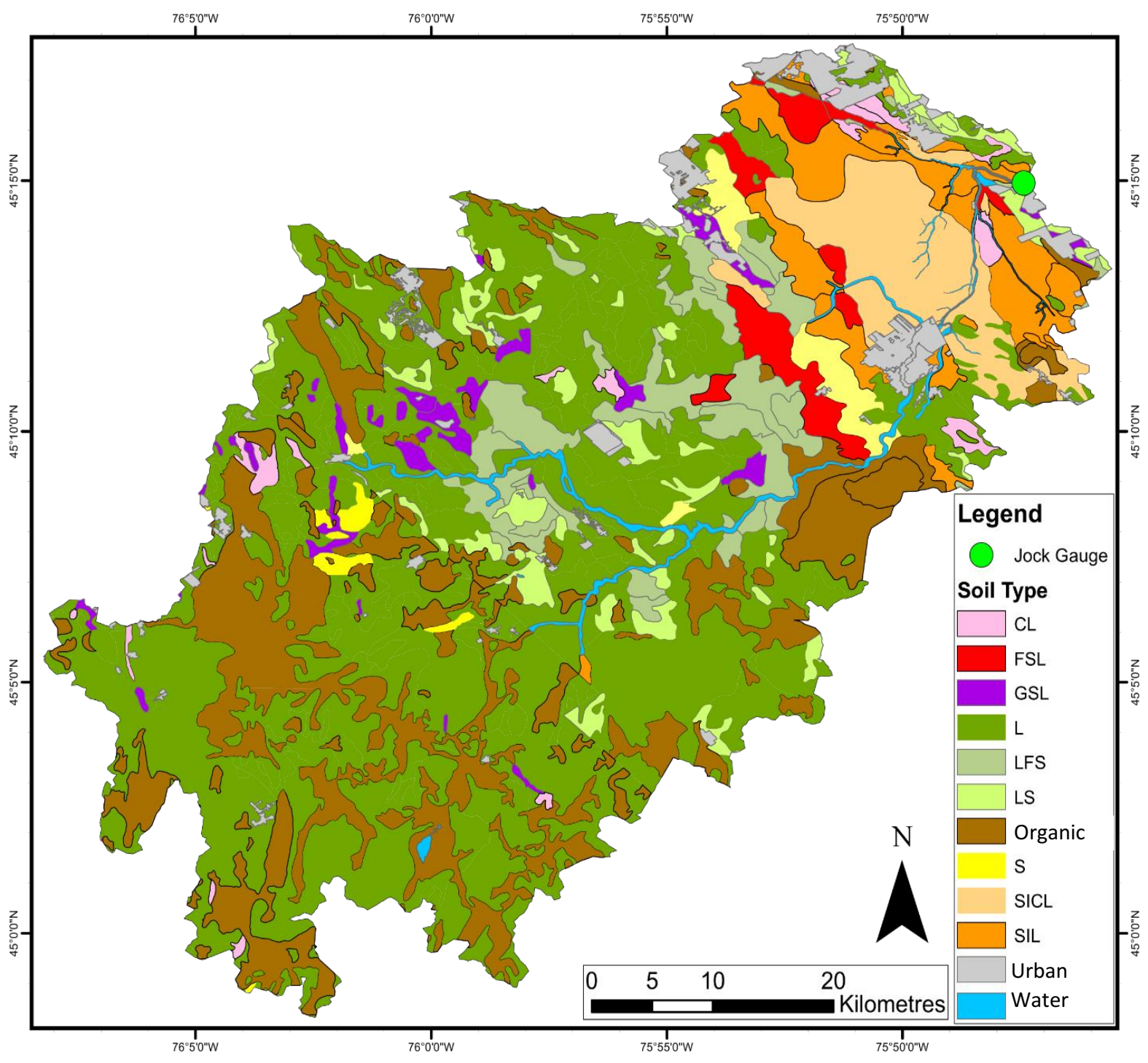

Figure 3.9. Surface soils for the Jock River watershed. Data Source: Soil Survey (AAFC, 2017). Abbreviations for figure are C:Clay, S:Sand, L:Loam, F:Fine, SI:Silt, G:Gravel. 


\subsubsection{VEGETATION LAI, CANOPY COVERAGE AND TRANSPIRATION COEFFICIENTS}

Vegetation plays a dynamic role in hydrology with its root water intake, transpiration, and canopy interception (Qualls and Gultekin, 1997). In the Jock River, the forested areas are made up of several dominant conifer and broadleaf species and their maximum height and leaf conductance values were obtained from the literature (Table 3.4). The leaf area index (LAI) which is the planimetric area of a plant (e.g; forest canopy, agricultural crop density) relative to the soil surface area, was obtained from a NASA dataset of global LAI values derived from MODIS (Moderate Resolution Imaging Spectroradiometer) satellite images (ORNL DAAC, 2017).

The year 2007 was chosen as a suitable year for LAI data because the 2007 mean annual temperature was identical to the mean annual temperature of the baseline period $1981-2010$ of $6.4^{\circ} \mathrm{C}$, and the summer and fall season only differ by $0.1^{\circ} \mathrm{C}$. Ideally LAI for each different type of vegetation land class should be used, however that type of data is not available, and a generalized LAI from the MODIS images was used.

Table 3.4. Parameter values based on approximate literature values for similar environment of Eastern Ontario.

\begin{tabular}{|l|l|l|l|}
\hline & $\begin{array}{l}\text { Max Canopy Height } \\
(\mathrm{m})\end{array}$ & $\begin{array}{l}\text { Max LAI } \\
\left(\mathrm{m}^{2} / \mathrm{m}^{2}\right)\end{array}$ & $\begin{array}{l}\text { Max Leaf Conductance } \\
(\mathrm{mm} / \mathrm{s})\end{array}$ \\
\hline $\begin{array}{l}\text { Crop and } \\
\text { pasture }\end{array}$ & $3($ Liao et al., 2017) & $6(\mathrm{Chen}, 2002)$ & $7($ Fuentes and King, 1989) \\
\hline Forest & $50($ Benzie, 2013) & $7($ Chen, 2002) & $\begin{array}{l}8(\text { McCaughey and Icobelli, } \\
1994)\end{array}$ \\
\hline Wetland & $\begin{array}{l}2(\text { Anderson and } \\
\text { Idso, 1987) }\end{array}$ & $\begin{array}{l}5.5(\text { Luo et al., } \\
2015)\end{array}$ & $\begin{array}{l}10(\text { Anderson and Idso, } \\
1987 ; \text { Lafleur, 1987) }\end{array}$ \\
\hline
\end{tabular}




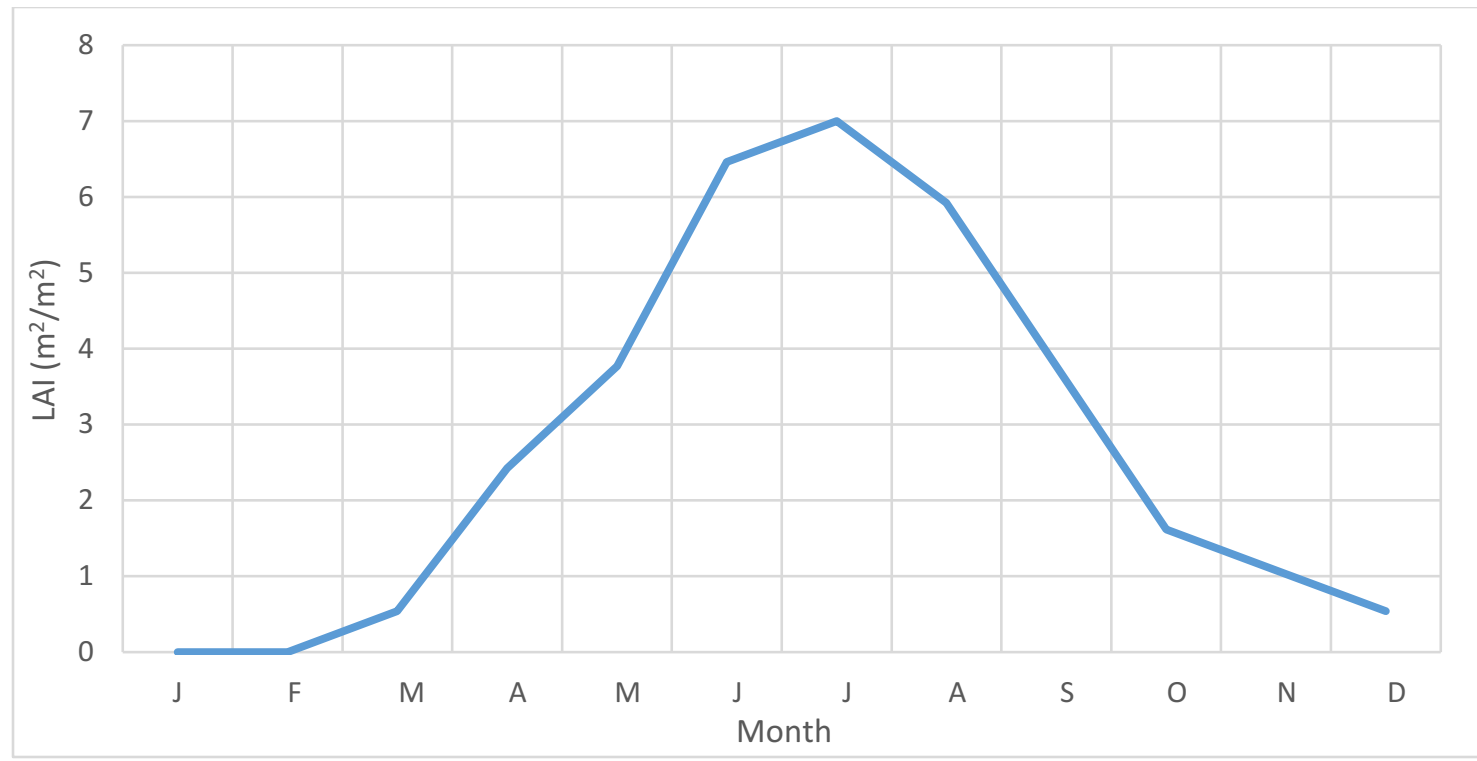

Figure 3.10. Variation in LAI over a year for the Jock River watershed. Derived from NASA NEO, for the year 2007 (similar average climate normal). Data source: (ORNL DAAC, 2017).

Values for vegetation and snow parameters were obtained from literature values for a similar vegetation type and landscape (Table 3.5). Manual calibration of the interception fraction is required by the user by trial and error and the ranges are posted in Table 3.5. Although the model allows for separate parameterization for crop and wetland parameters, they were defaulted to the same value of forest, due to the lack of information in the study area.

Table 3.5. Values for vegetation coefficients of Max Capacity, the interception fraction and percentage are ranges provided by the Raven manual (Craig et al., 2017).

\begin{tabular}{|l|l|l|l|l|}
\hline & $\begin{array}{l}\text { Max Capacity } \\
(\mathrm{mm})\end{array}$ & $\begin{array}{l}\text { Max Snow } \\
\text { Capacity }(\mathrm{mm})\end{array}$ & $\begin{array}{l}\text { Rain Interception } \\
\text { fraction }\end{array}$ & $\begin{array}{l}\text { Snow Interception } \\
\text { fraction }\end{array}$ \\
\hline Forest & $\begin{array}{l}40(\text { Stork, } \\
2002)\end{array}$ & $\begin{array}{l}35(\text { Stork, } \\
2002)\end{array}$ & $0.02-0.1$ & $0.02-0.2$ \\
\hline
\end{tabular}




\subsection{CLIMATE CHANGE SCENARIO DATA}

Twelve climate change scenarios were used to represent the future climates from 2011 to 2099. The scenarios come from The Pacific Climate Impacts Consortium (PCIC) which is a regional climate service centre at the University of Victoria. The data are derived from the statistically downscaled daily Canada-wide climate scenarios, to the same $10 \mathrm{~km}$ grid used in this study for the historical meteorological data (NRCAN, 2018a), for the simulated period of 1950-2100 at different RCPs. The variables include minimum temperature, maximum temperature, and precipitation, and were provided by The Climate Change $\begin{array}{lllll}\text { Extremes } & \& & \text { Ontario } & \text { Agriculture } & \text { Research }\end{array}$ (https://carleton.ca/envisionontarioag/about/).

The 12 scenarios were chosen from previous work by Cannon (2015), using the Katsavounidis-Kuo-Zhang (KKZ) cluster analysis algorithm (Katsavounidis et al. 1994). This method allows for the reduction of the hundreds of available climate models while maintaining the variability of the possible extremes under the RCP 8.5 scenario, for both temperature and precipitation. The 12 models that maintain variability and that are being evaluated for the watershed are listed in Table 3.5, with their associated year, institution, features, and model reference. The 12 models are further divided into different regions (Giorgi regions; see Figure 3.11), from highest variability to lowest, and are selected to provide the widest spread in projected future climate for smaller subsets of the full ensemble. 


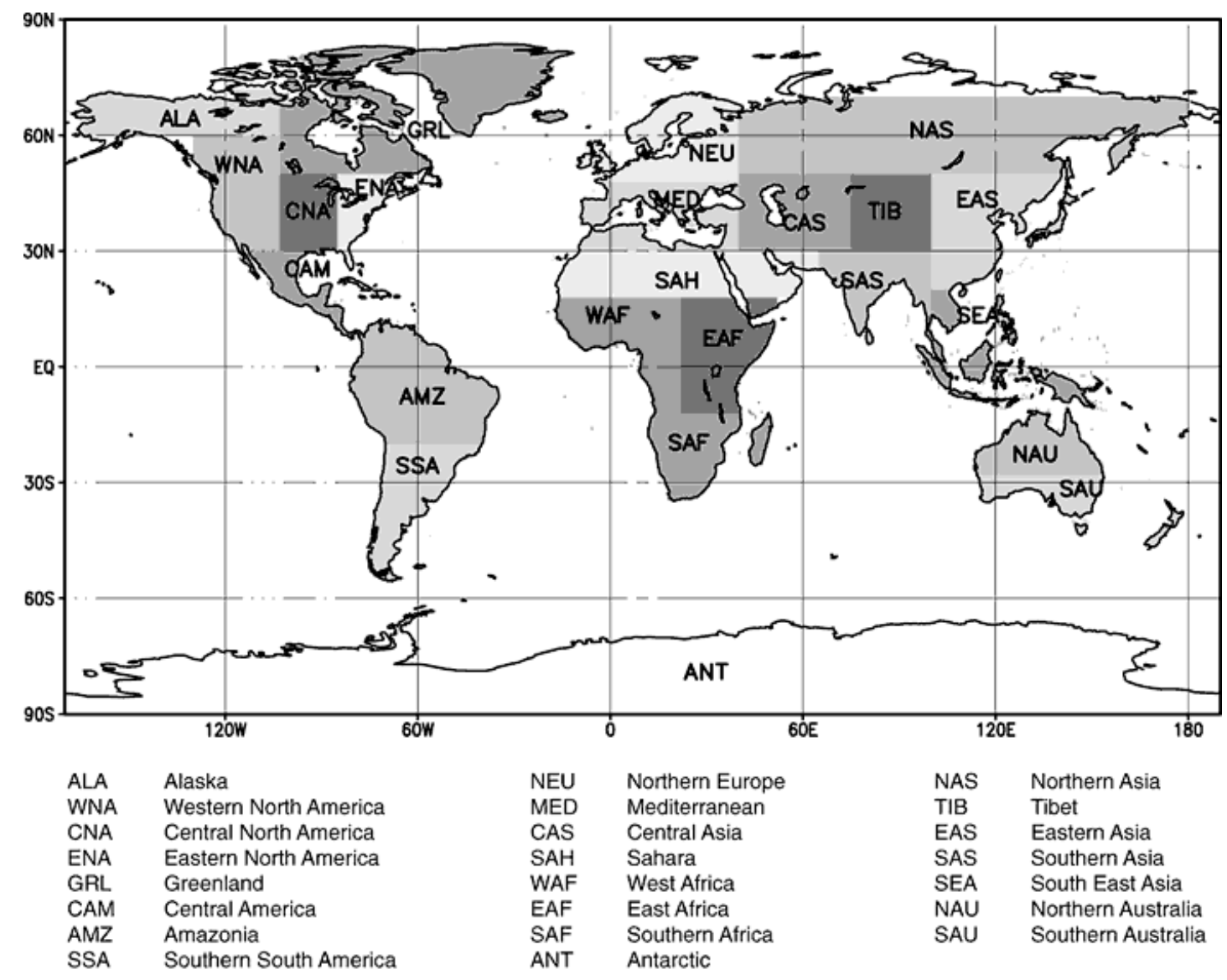

Figure 3.11. Map representing the different Giorgi regions for the world. From PCIC (Giorgi and Francisco, 2000) 
Table 3.6 The 12 global climate models that maintain variability for Eastern North America, (original table from Flato et al., 2013). Reference information for models is from the IPCC AR5, Table 9.A (IPCC, 2013).

\begin{tabular}{|c|c|c|c|c|c|c|}
\hline $\begin{array}{l}\text { Model } \\
\text { Name } \\
\text { (2) Year }\end{array}$ & Institution & Atmosphere & $\begin{array}{l}\text { Land } \\
\text { Surface }\end{array}$ & Ocean & Sea Ice & $\begin{array}{l}\text { Main } \\
\text { Reference }\end{array}$ \\
\hline $\begin{array}{l}\text { MPI-ESM- } \\
\text { LR } \\
\text { (2) } 2009\end{array}$ & $\begin{array}{l}\text { Max Planck Institute for } \\
\text { Meteorology }\end{array}$ & ECHAM6 & JSBACH & MPIOM & Included & $\begin{array}{l}\text { Giorgetta } \\
\text { et al., } 2013\end{array}$ \\
\hline $\begin{array}{l}\text { INM-CM4 } \\
\text { (2) } 2009\end{array}$ & $\begin{array}{l}\text { Russian Institute for } \\
\text { Numerical Mathematics }\end{array}$ & Included & Included & Included & Included & $\begin{array}{l}\text { Volodin et } \\
\text { al., } 2010\end{array}$ \\
\hline $\begin{array}{l}\text { CNRM- } \\
\text { CM51 } \\
\text { (2) } 2010\end{array}$ & $\begin{array}{l}\text { Centre National de } \\
\text { Recherches } \\
\text { Meteorologiques and Centre } \\
\text { Europeen de Recherche et } \\
\text { Formation Avancees en } \\
\text { Calcul Scientifique. }\end{array}$ & $\begin{array}{l}\text { ARPEGE- } \\
\text { Climat }\end{array}$ & SURFEX & NEMO & Gelato5 & $\begin{array}{l}\text { Voldoire et } \\
\text { al., } 2013\end{array}$ \\
\hline $\begin{array}{l}\text { CSIRO- } \\
\text { Mk3.6.0 } \\
\text { (2) } 2009\end{array}$ & $\begin{array}{l}\text { Queensland Climate Change } \\
\text { Centre of Excellence and } \\
\text { Commonwealth Scientific } \\
\text { and Industrial Research } \\
\text { Organisation }\end{array}$ & Included & Included & $\begin{array}{l}\text { Modified } \\
\text { MOM2.2 }\end{array}$ & Included & $\begin{array}{l}\text { Rotstayn et } \\
\text { al., } 2012\end{array}$ \\
\hline $\begin{array}{l}\text { HadGEM2- } \\
\text { ES } \\
\text { (2) } 2009\end{array}$ & $\begin{array}{l}\text { UK Met Office Hadley } \\
\text { Centre }\end{array}$ & HadGAM2 & Included & Included & Included & $\begin{array}{l}\text { Collins et } \\
\text { al., 2011; } \\
\text { Martin et } \\
\text { al., } 2011\end{array}$ \\
\hline $\begin{array}{l}\text { CanESM2 } \\
\text { (2) } 2010\end{array}$ & $\begin{array}{l}\text { Canadian Center for Climate } \\
\text { Modelling and Analysis }\end{array}$ & Included & $\begin{array}{l}\text { CLASS 2.7; } \\
\text { CTEM }\end{array}$ & Included & Included & $\begin{array}{l}\text { Arora et } \\
\text { al., 2011; } \\
\text { von Salzen } \\
\text { et al., } 2013\end{array}$ \\
\hline $\begin{array}{l}\text { MRI- } \\
\text { CGCM3 } \\
\text { (2) } 2011\end{array}$ & $\begin{array}{l}\text { Meteorological } \\
\text { Research Institute }\end{array}$ & $\begin{array}{l}\text { MRI- } \\
\text { AGCM3.3 }\end{array}$ & $\overline{\mathrm{HAL}}$ & MRI.COM3 & $\begin{array}{l}\text { Included } \\
\text { (MRI. } \\
\text { COM3) }\end{array}$ & $\begin{array}{l}\text { Yukimoto } \\
\text { et al., } \\
2011 \text {; }\end{array}$ \\
\hline
\end{tabular}




\begin{tabular}{|l|l|l|l|l|l|l|}
\hline $\begin{array}{l}\text { CCSM4 } \\
\text { (2) } 2010\end{array}$ & $\begin{array}{l}\text { US National Centre for } \\
\text { Atmospheric Research }\end{array}$ & CAM4 & $\begin{array}{l}\text { Community } \\
\text { Land } \\
\text { Model 4 } \\
\text { (CLM4) }\end{array}$ & $\begin{array}{l}\text { POP2 with } \\
\text { modifications }\end{array}$ & $\begin{array}{l}\text { CICE4 with } \\
\text { modifications }\end{array}$ & $\begin{array}{l}\text { Gent et al., } \\
2011\end{array}$ \\
\hline $\begin{array}{l}\text { MIROC5 } \\
\text { (2) } 2010\end{array}$ & $\begin{array}{l}\text { University of Tokyo, } \\
\text { National Institute for } \\
\text { Environmental Studies, and } \\
\text { Japan Agency for Marine- } \\
\text { Earth Science and } \\
\text { Technology }\end{array}$ & $\begin{array}{l}\text { CCSR/NIES/ } \\
\text { FRCGC } \\
\text { AGCM6 }\end{array}$ & MATSIRO & COCO4.5 & Included & $\begin{array}{l}\text { Watanabe } \\
\text { et al., 2010 }\end{array}$ \\
\hline $\begin{array}{l}\text { ACCESS1.0 } \\
\text { (2) } 2011\end{array}$ & $\begin{array}{l}\text { Commonwealth Scientific } \\
\text { and Industrial Research } \\
\text { Organization } \\
\text { CSIRO) and Bureau of } \\
\text { Meteorology (BOM), } \\
\text { Australia }\end{array}$ & $\begin{array}{l}\text { Included (as in } \\
\text { HadGEM2 } \\
\text { (r1.1)) }\end{array}$ & MOSES2.2 & $\begin{array}{l}\text { ACCESS-OM } \\
\text { (MOM4p1) }\end{array}$ & CICE4.1 & $\begin{array}{l}\text { Bi et al., } \\
2013 b ; \\
\text { Dix et al., } \\
2013\end{array}$ \\
\hline $\begin{array}{l}\text { HadGEM2- } \\
\text { ES } \\
\text { (2) 2009 }\end{array}$ & $\begin{array}{l}\text { UK Met Office Hadley } \\
\text { Centre }\end{array}$ & HadGAM2 & Included & Included & Included & $\begin{array}{l}\text { Collins et } \\
\text { al., 2011; } \\
\text { Martin et } \\
\text { al., 2011 }\end{array}$ \\
\hline $\begin{array}{l}\text { GFDL- } \\
\text { ESM2G } \\
\text { (2) 2012 }\end{array}$ & $\begin{array}{l}\text { NOAA Geophysical } \\
\text { Fluid Dynamics Laboratory }\end{array}$ & Included & Included & GOLD & SIS & $\begin{array}{l}\text { Dunne et } \\
\text { al., 2012; } \\
\text { Dunne et } \\
\text { al., 2013 }\end{array}$ \\
\hline
\end{tabular}

Notes: Abbreviations for models available in model references and from Flato et al., (2013). 


\section{CHAPTER 4: METHODOLOGY}

The following chapter describes the multiple procedures, steps and methods used to use and evaluate a hydrological model for extremes and climate change scenarios. The first section contains data preparation and calculations, describing the processes for watershed delineation, hydrological response unit (HRUS), and soil data, that are needed prior to modelling efforts in Raven. The second section contains the model-building process using the Raven modelling framework, hydrological processes, routines, and parameter selection. The third section contains the calibration and optimization process for the model. The fourth section is the validation, sensitivity and uncertainty analysis. The fifth is the methods used to measure flood and drought extremes. Finally, the sixth section describes the methods used to model future scenarios using the CGMs.

\subsection{DATA PREPARATION AND CACULATIONS}

\subsubsection{WATERSHED DELINEATION}

The subwatersheds in the Jock River were delineated using the Environmental Systems Research Institute (ESRI) ArcHydro methods (ESRI, 2015). A preprocessed DEM from the OMNRF for the area was used, as it provided sinks, barriers and depression areas, to ensure a continuous flow for the delineation (OMNRF, 2013). A flow direction was used to find the flow accumulation to build a stream network using the flow accumulation and a catchment area threshold. Finally, multiple defined pour points (outlets) locations were used to calculate subwatershed and channel geometry to finalize the watershed polygons. The pour point locations were selected at the Jock River streamflow gauging station, and stream junctions highlighted by the RVCA (2016), to produce the 11 subwatersheds seen in Figure 3.1 and Table 3.2. 


\subsubsection{HYDROLOGICAL RESPONSE UNIT (HRU) DEFINITION}

HRUs were developed using ArcSWAT, which is an Texas A\&M University ArcGIS extension (http://swat.tamu.edu/software/arcswat/). The delineation of HRUs to be used in Raven are based on a subwatershed level and the combination of four categorical variables: slope class, aspect, soil type, and LULC. The first step was to overlay the five variables containing the subwatershed, slope classes, aspect, soil types, and LULC into one feature map using the ArcSWAT tool. Given the numerous combinations of LULC, soil, aspect, and soil types in the basin, the number of unique HRUs for a given subwatershed can number in the thousands. Many of these HRUs are very small, possibly on the scale of one grid cell. ArcSWAT allows the user to define an entire subwatershed as an HRU or have multiple HRUs in a subwatershed. The model configuration for Raven requires HRUs per subwatershed, therefore for this thesis a single HRU for an entire subwatershed was used. This causes the loss of spatial information, but computation time for simulations greatly decreases from hours per simulation to seconds. The subwatershed HRU was determined by defining unique HRUs for each subwatershed and then determining the dominant class variable for LULC, soil, aspect, and soil type in that subwatershed. Also, it is important to note that the subwatersheds determined in the Jock River are predefined by the RVCA and could be much smaller producing better spatial information even at the HRU subwatershed scale. HRU at the subwatershed level could also be done by basic statistics of largest area for each class variable in each subwatershed.

\subsubsection{SOIL PROPERTIES}

The soil properties were estimated based on a method developed and described by Kienzle et al. (2012), which relies on the association between clay, silt, sand, and organic 
content to build associated water holding parameters (PO, WP, and FC). This association was based on available literature involving land classification and soils in the Rocky Mountains (Pettapiece, 1971; Craig et al., 2017). There is considerable uncertainty and error associated with generalizing soil, especially when they are scaled up to the subwatershed scale, and often there is large variability that is present in the soil dataset (Figure 3.9), where only one soil type is represented for each subwatershed.

\subsection{HYDROLOGICAL MODEL}

Many hydrological models and modelling platforms exist and determining which one to implement for a particular application can be difficult (Bourdin et al., 2009; Beven, 2012). The Raven modelling framework was selected because it incorporates several hydrology models and algorithms in a modular fashion. The following section will describe the Raven modelling framework and the processes, algorithms, methods that were used to build a hydrological model for the Jock River watershed.

\subsubsection{THE RAVEN MODELLING FRAMEWORK}

Raven was used to build a hydrological model called the Jock River Watershed Model (JRWM) to understand and forecast future extreme hydrology events for the Jock River watershed. Figure 4.2 shows the flowchart for the JRWM, representing the model setup for parameters, hydrological processes, routines and layout. The JRWM was built from the large selection of hydrological processes, algorithms, routines and parameters available in the Raven modelling framework and is describe in detail in the next section (4.2.2). Once the JRWM was built, it was put through a calibration, validation, sensitivity and uncertainty analysis to determine how accurate the model is and whether it is reliable (described in Section 4.4). 


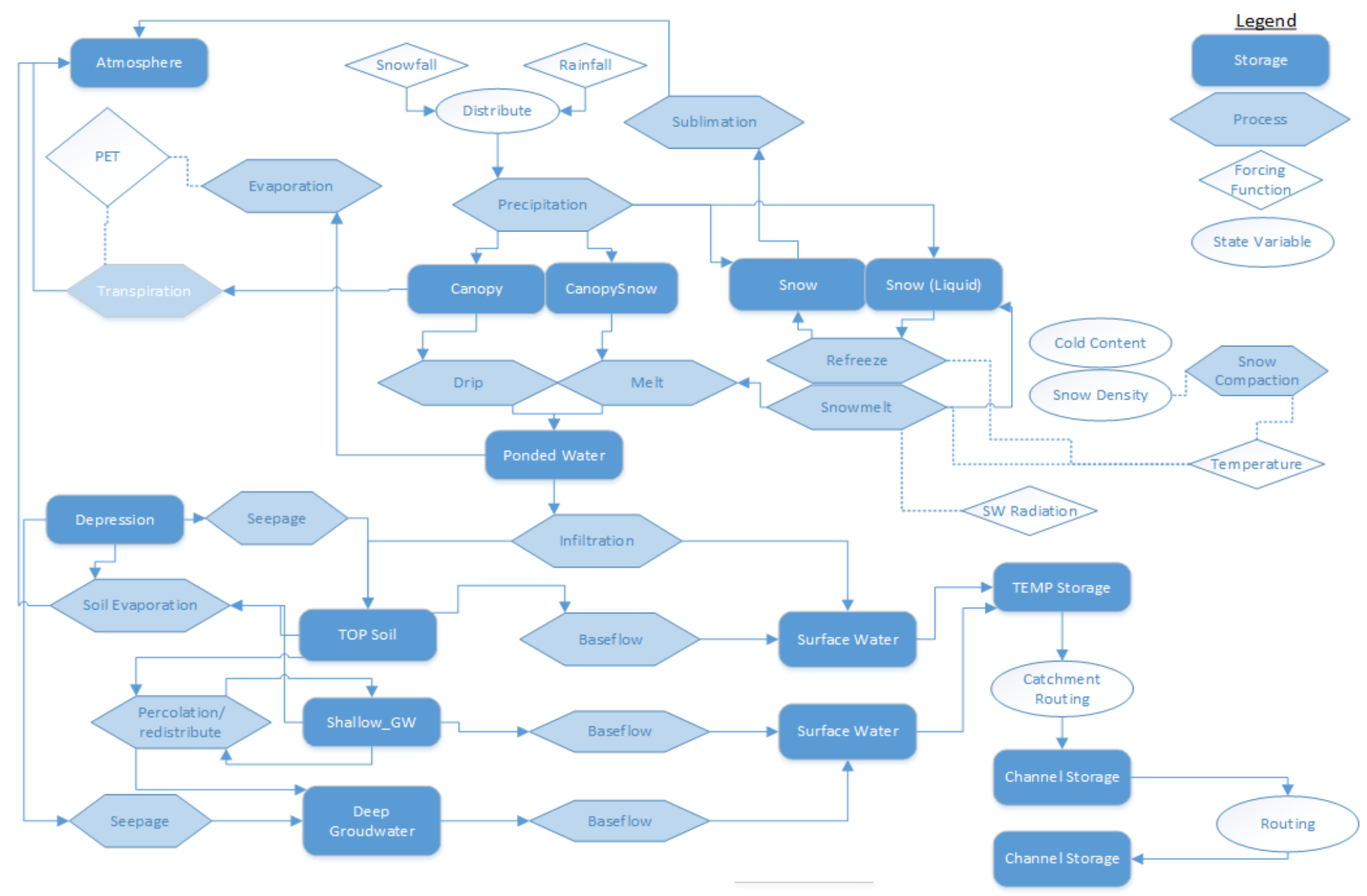

Figure 4.1. Flowchart of model framework and processes. Based on Craig (2016) 


\subsubsection{HYDROLOGICAL PROCESSES AND ROUTINES}

Due to the modular format of the Raven modelling framework, there can be hundreds of available combinations and possibilities when building a model. The Raven manual has pre-built model code for GR4J, HBV and UBC. The GR4J model code was modified for the Jock River watershed to build the JRWM and the hydrological processes chosen to build the JRWM were determined by trial and error focusing on the best performance for extremes.

The choices made for the JRWM include: A multi layer soil profile (SOIL MULTILAYER3) method that has three soil layers (top, shallow, and deep), where each layer could have a different hydrological process applied to it, allowing for the movement of water between the soil layers. The catchment routing (ROUTE TRI CONVOLUTION) method that better represented larger peak streamflows compared to the other options were selected: this method using a triangular distribution algorithm to calculate the unit hydrograph inside a HRU which is then passed to the routing method. The routing (ROUTE HYDROLOGIC) method is used to move water between HRUs and is an iterative application of Newton's route-finding algorithm and is the fastest algorithm available in Raven to calculate routing (Craig et al., 2017). The evapotranspiration method (PET HARGREAVES 1985) was used for both evaporation and open water evaporation in the model. The 1985 Hargreaves evapotranspiration equation only requires temperature and incoming solar radiation (Hargreaves and Allen, 2003; Craig et al., 2017) making it useful for daily calculations in Raven. The canopy evaporation (CANEVP ALL) method was used as it allowed for the greatest evaporation in the watershed to reduce some of the summer streamflow to better represent low flows. The rain snow fraction (RAINSNOW 
DINGMAN) algorithm (Dingman, 2015) partitions precipitation into either snow or rain and that threshold was left at the default value of $0^{\circ} \mathrm{C}$. An orographic (elevation) correction (OROCORR SIMPLELAPSE) method for both temperature and precipitation was set to be minimal as the HRUs in the Jock River watershed do not have significant elevation changes. A precipitation interception fraction (PRECIP ICEPT USER) method is used to allow independent values of interception for precipitation to be applied a vegetation type. The precipitation (PRECIP RAVEN) method allows a precipitation text file to be used in the model.

The Génie Rural à 4 paramètres Journalier (GR4J) model by Perrin et al. (2003), was chosen due to its simple structure and its available model structure code in Raven. The model has four parameters; the first (GR4J_X1), is a maximum capacity of the production store (mm); the second (GR4J_X2), is a percolation coefficient (mm) which is used to calculate percolation rates. The third (GR4J_X3), is water storage $(\mathrm{mm})$ in the soil, and the fourth (GR4J_X4), is a land use parameter (Craig et al., 2017). The GR4J_X3 and GR4J_X4 are used to calculate the infiltration (INF GR4J), and baseflow (BASE GR4J) methods. While trough trial and error, replacing the hydrological processes for GR4J_X1 and GR4J_X2 with a potential melt (POTMELT DEGREE DAY) and constant percolation (CONSTANT) process, respectively, improve model results. The Snow Balance (SNOBAL CEMA NIEGE) method which is used to simulate mass and energy balance equations controlling melting and refreezing of snow pack and is used to correct the POTMELT DEGREE DAY by specifying the average annual snow amount. A Snow Temperature Evolve (SNOTEMP NEWTONS) method which is air/snow heat transfer coefficient in units of [1/d], as used in the snow temperature evolution routine was also set to default. 
Table 4.1 summarizes the methods described above used for the JRWM with a brief description of the method and their corresponding Raven code. The Raven Manual provides a larger in-depth explanation of each method, process and algorithm (Craig et al., 2017). See Appendix F for full model structure and code.

Table 4.1. Hydrological processes used in the JRWM. Full details for each process available in Raven Manual (Craig et al., 2017).

\begin{tabular}{|c|c|c|}
\hline Method & Use & Raven Name \\
\hline Soil Model & $\begin{array}{l}\text { Sets the number of soil profiles to } \\
\text { apply other hydrological processes }\end{array}$ & SOIL_MULTILAYER3 \\
\hline Routing & $\begin{array}{l}\text { Movement of water between HRUs } \\
\text { downstream }\end{array}$ & ROUTE_HYDROLOGIC \\
\hline Catchment Route & $\begin{array}{l}\text { Creates a unit hydrograph on an } \\
\text { individual HRU basis }\end{array}$ & ROUTE_TRI_CONVOLUTION \\
\hline Evaporation & Process of soil evaporation & PET_HARGREAVES_1985 \\
\hline Rain Snow Fraction & Determines the ratio of rain/snow & RAINSNOW_DINGMAN \\
\hline $\begin{array}{l}\text { Oro Temperature } \\
\text { Correct }\end{array}$ & $\begin{array}{l}\text { Corrects temperatures according to } \\
\text { elevation }\end{array}$ & OROCORR_SIMPLELAPSE \\
\hline $\begin{array}{l}\text { Oro Precipitation } \\
\text { Correct }\end{array}$ & $\begin{array}{l}\text { Corrects precipitation according to } \\
\text { elevation }\end{array}$ & OROCORR_SIMPLELAPSE \\
\hline $\begin{array}{l}\text { Open Water } \\
\text { Evaporation }\end{array}$ & $\begin{array}{l}\text { Process of evaporation for open } \\
\text { water bodies }\end{array}$ & PET_HARGREAVES_1985 \\
\hline $\begin{array}{l}\text { Precipitation } \\
\text { Interception Fraction }\end{array}$ & $\begin{array}{l}\text { Allows user to input interception } \\
\text { fraction for vegetation }\end{array}$ & PRECIP_ICEPT_USER \\
\hline Precipitation & Used for text file input & PRECIP_RAVEN \\
\hline $\begin{array}{l}\text { Potential Melt } \\
\text { Method }\end{array}$ & $\begin{array}{l}\text { Calculate how the snow in the } \\
\text { watershed is melted }\end{array}$ & POTMELT_DEGREE_DAY \\
\hline Snow Balance & $\begin{array}{l}\text { Corrects the potential melt with a } \\
\text { average annual snow parameter }\end{array}$ & SNOBAL_CEMA_NIEGE \\
\hline $\begin{array}{l}\text { Snow Temperature } \\
\text { Evolve }\end{array}$ & $\begin{array}{l}\text { A air/snow heat transfer coefficient } \\
\text { for the snow balance }\end{array}$ & SNOTEMP_NEWTONS \\
\hline Canopy Evaporation & $\begin{array}{l}\text { Used to measure evaporation on the } \\
\text { canopy }\end{array}$ & CANEVP_ALL \\
\hline Infiltration & $\begin{array}{l}\text { Part of the GR } 4 \mathrm{~J} \text { model for } \\
\text { infiltration of water into the soil }\end{array}$ & INF_GR4J \\
\hline Percolation & $\begin{array}{l}\text { Applies a constant percolation to } \\
\text { the soil from a water storage unit }\end{array}$ & PERC_CONSTANT \\
\hline Baseflow & $\begin{array}{l}\text { Part of the GR4J model for } \\
\text { baseflow of water in the soil }\end{array}$ & BASE_GR4J \\
\hline
\end{tabular}




\subsubsection{PARAMETER SELECTION}

Depending on the model structure and the number of HRUs, the model can contain hundreds of parameters. Most of the parameters used in the JRWM are based on data input (e.g. soil, vegetation, topography, and LULC). However, there are four "free parameters," that are not based on data, but rather are calibrated across a range of possible values (Table 4.2). These parameters are used for snow melt (MELT_FACTOR), baseflow (GR4J_X3), routing (GR4J_X4) and percolation (Percolation Constant). See Appendix F for the model parameter file which was used "JockGR4J.rvp" with full parameter structure and set up. To improve results parameters were changed from a single "default" value for all HRUs to a "independent" value, meaning that instead of only four parameters, it was four multiplied by the number of HRUs, soils and land use types. This increases the number of parameters, but with a large watershed it also accounts for some of the variability that occurs in the watershed's characteristics.

Table 4.2 Table of free parameters used in Jock River model and associated ranges.

\begin{tabular}{|l|l|l|l|l|}
\hline Process & Parameter & Unit & Low & High \\
\hline $\begin{array}{l}\text { Energy (Degree Day } \\
\text { Method) }\end{array}$ & MELT_FACTOR & $\mathrm{mm} / \mathrm{d} / \mathrm{K}$ & 0.01 & 10 \\
\hline Storage & GR4J_X3 & $\mathrm{mm}$ & 1 & 10000 \\
\hline $\begin{array}{l}\text { Time routine (land use } \\
\text { parameter) }\end{array}$ & GR4J_X4 & $\mathrm{d}$ & 0.01 & 100 \\
\hline Percolation & $\begin{array}{l}\text { Percolation } \\
\text { Constant }\end{array}$ & $\mathrm{mm} / \mathrm{d}$ & 0.001 & 10000 \\
\hline
\end{tabular}




\subsection{CALIBRATION AND VALIDATION}

Calibration requires an adequate historical dataset that covers the large variations in climate and streamflow that are present in the environment, to ensure the calibration period of the model represents the real environment under different conditions. The calibration process also requires a one year 'spin-up' period, to gather the initial values for the state of the system which is common for most hydrological models (Beven, 2012).

\subsubsection{SOFTWARE AND TOOLKITS}

Optimization Software Toolkit for Research Involving Computational Heuristics $(\mathrm{OSTRICH})$ is an open source model-independent optimization and calibration tool (Matott, 2005). It includes a diverse set of algorithms that can be used for calibration, and optimization of the model parameters, according to a user-defined objective function (OSTRICH, 2017). OSTRICH can be used with a modelling program that uses text-based input and output file formats and can also compute prediction intervals, parameter correlation, tests of normality and non-linearity, and observation influence and parameter sensitivity measures for calibration processes (OSTRICH, 2017).

\subsubsection{OBJECTIVE FUNCTIONS}

The objective functions listed in Table 4.3 were calculated for different time periods to evaluate the model's performance between calibration, validation and other time periods of interest. Nash-Sutcliffe Efficiency (NSE) was used in the calibration and optimization process. Table 4.3 contains the objective function names with their associated equations, uses and references. 
Table 4.3 Objective functions used for the JRWM. Full Equations details available in the Raven User Manual (Craig et al., 2017).

\begin{tabular}{|c|c|c|c|}
\hline Objective Function & Equation & Use & Reference \\
\hline $\begin{array}{l}\text { Nash-Sutcliffe } \\
\text { Efficiency (NSE) }\end{array}$ & $\mathrm{NS}=1-\frac{\sum_{i=1}^{N} w_{i}\left(\hat{\phi}_{i}-\phi_{i}\right)^{2}}{\sum_{i=1}^{N} w_{i}\left(\bar{\phi}-\phi_{i}\right)^{2}}$ & $\begin{array}{l}(\mathrm{NSE}=1) \text { corresponds to a } \\
\text { perfect match of modelled } \\
\text { discharge to the observed } \\
\text { data }\end{array}$ & $\begin{array}{l}\text { Nash, J. E. and } \\
\text { Sutcliffe, J. V. } \\
\text { (1970) }\end{array}$ \\
\hline $\begin{array}{l}\text { Log Transformed } \\
\text { Nash-Sutcliffe } \\
\text { Efficiency (LOG } \\
\text { NASH) }\end{array}$ & $\mathrm{NS}=1-\frac{\sum_{i=1}^{N} w_{i}\left(\ln \left(\hat{\phi}_{i}\right)-\ln \left(\phi_{i}\right)\right)^{2}}{\sum_{i=1}^{N} w_{i}\left(\ln (\phi)-\ln \left(\phi_{i}\right)\right)^{2}}$ & $\begin{array}{l}\text { Similar to NSE, however } \\
\text { has more emphasis on low } \\
\text { flows }\end{array}$ & $\begin{array}{l}\text { (Krause et al., } \\
2005)\end{array}$ \\
\hline $\begin{array}{l}\text { Root-mean-squared } \\
\text { Error (RMSE) }\end{array}$ & $\mathrm{RMSE}=\sqrt{\sum_{i=1}^{N} w_{i}\left(\hat{\phi}_{i}-\phi_{i}\right)^{2}}$ & $\begin{array}{l}\text { Difference between } \\
\text { simulated values and } \\
\text { observed values }\end{array}$ & $\begin{array}{l}\text { (Craig et al., } \\
\text { 2017) }\end{array}$ \\
\hline $\begin{array}{l}\text { Ratio of Standard } \\
\text { Deviation of } \\
\text { Observations to } \\
\text { RMS (RSR) }\end{array}$ & $\mathrm{RSR}=\frac{\sqrt{\sum_{i=1}^{N}\left(S_{i} O_{i}\right)^{2}}}{\sqrt{\sum_{i=1}^{N}\left(O_{i} \quad O_{\text {mean }}\right)^{2}}}$ & $\begin{array}{l}\text { Standardizes RMS using } \\
\text { standard deviation of the } \\
\text { observations }\end{array}$ & $\begin{array}{l}\text { (Moriasi et al. } \\
\text { 2007) }\end{array}$ \\
\hline $\begin{array}{l}\text { Percentage Bias } \\
\text { (PCT BIAS) }\end{array}$ & PCT_BIAS $=\frac{\sum_{i=1}^{N}\left(\hat{\phi}_{i}-\phi_{i}\right)}{\sum_{i=1}^{N}\left(\phi_{i}\right)}$ & $\begin{array}{l}\text { Measures the average } \\
\text { tendency of the simulated } \\
\text { values to be larger or } \\
\text { smaller than their observed } \\
\text { ones }\end{array}$ & $\begin{array}{l}\text { (Craig et al., } \\
2017 \text { ) }\end{array}$ \\
\hline
\end{tabular}




\begin{tabular}{|c|c|c|c|}
\hline $\begin{array}{l}\text { Average Absolute } \\
\text { Error (ABSERR) }\end{array}$ & $\operatorname{ABSERR}=\frac{1}{N} \sum_{i=1}^{N} w_{i}\left|\hat{\phi}_{i}-\phi_{i}\right|$ & $\begin{array}{l}\text { Measures the average } \\
\text { difference between the } \\
\text { simulated and observed } \\
\text { values }\end{array}$ & $\begin{array}{l}\text { (Craig et al., } \\
\text { 2017) }\end{array}$ \\
\hline $\begin{array}{l}\text { Maximum Absolute } \\
\text { Error (ABSMAX) }\end{array}$ & $\operatorname{ABSMAX}=\max \left\{\left|\hat{\phi}_{i}-\phi_{i}\right|\right\}$ & & $\begin{array}{l}\text { (Craig et al., } \\
\text { 2017) }\end{array}$ \\
\hline $\begin{array}{l}\text { Peak difference } \\
\text { (PDIFF) }\end{array}$ & $\mathrm{PDIFF}=\max \left\{\hat{\phi}_{i}\right\}-\max \left\{\phi_{i}\right\}$ & $\begin{array}{l}\text { Measures the maximum } \\
\text { difference between the } \\
\text { simulated and observed } \\
\text { values }\end{array}$ & $\begin{array}{l}\text { (Craig et al., } \\
2017 \text { ) }\end{array}$ \\
\hline $\begin{array}{l}\text { Monthly Mean } \\
\text { Squared Error } \\
\text { (TMVOL) }\end{array}$ & TMVOL $=\sum_{j=1}^{M}\left[\frac{1}{N} \sum_{i=1}^{N_{j}} w_{i}\left(\hat{\phi}_{i}-\phi_{i}\right)^{2}\right]$ & $\begin{array}{l}\text { Measured on a monthly } \\
\text { basis }\end{array}$ & $\begin{array}{l}\text { (Craig et al., } \\
\text { 2017) }\end{array}$ \\
\hline $\begin{array}{l}\text { Correlation of Error } \\
\text { (RCOEF) }\end{array}$ & $\mathrm{RCOEF}=\frac{1}{\sigma_{\phi} \sigma_{\hat{\phi}}} \frac{1}{N^{*}-1} \sum_{i=1}^{N-1}\left(\hat{\phi}_{i}-\phi_{i}\right)\left(\hat{\phi}_{i+1}-\phi_{i+1}\right)$ & $\begin{array}{l}\text { Measures the error between } \\
\text { time steps }\end{array}$ & $\begin{array}{l}\text { (Craig et al., } \\
\text { 2017) }\end{array}$ \\
\hline $\begin{array}{l}\text { Number of Sign } \\
\text { Changes (NSC) }\end{array}$ & Number is above or below the observed values. & $\begin{array}{l}\text { Measures if simulated } \\
\text { values are overestimating } \\
\text { or underestimating }\end{array}$ & $\begin{array}{l}\text { (Craig et al., } \\
\text { 2017) }\end{array}$ \\
\hline
\end{tabular}

*Note the following symbols:

- $\bar{\phi}$ is the weighted mean of observations

- $\mathrm{M}$ is the number of months in the simulation

- $\mathrm{N}_{\mathrm{j}}$ is the number of data points in month $\mathrm{j}$

- $\sigma_{\phi}$ is the standard deviation of the observed data

- $\sigma_{\hat{\phi}}$ is the standard deviation of the modelled data

- $\mathrm{N}^{*}$ is the number of adjacent non-blank data entries 


\subsubsection{GENERALIZED LIKELIHOOD UNCERTAINTY ESTIMATION}

The Generalized Likelihood Uncertainty Estimation (GLUE) is a different approach to model calibration. Instead of finding an optimum parameter set, GLUE finds a set of possible parameters in the parameter space that provide similar results (Beven and Binley, 1992). GLUE is based on the equifinality principle, which states that there could exists many acceptable parameter sets that cannot be easily rejected as they produce similar results (Beven, 2006). These multiple parameter sets are used to assess and estimate the uncertainty of the model by evaluating the upper and lower prediction intervals for the model simulations.

The GLUE algorithm requires a number of decisions by the user for implementing the optimization procedure including: (1) a random sampling technique for parameter sets or a Monte Carlo simulation, depending on prior knowledge and time consumption of the algorithm (Shen et al., 2012); the parameter distributions that represent the a priori state of knowledge about their ranges and likelihoods (Table 4.2); (2), an objective function (Table 4.3) for mathematics optimization that must increase monotonically with increasing goodness-of-fit (Beven, 2012); and (3), a threshold value that separates simulations into behavioural and non-behavioural (Shen et al., 2012). A non-behavioural simulation is one that does not reproduce observations sufficiently well (Beven, 2006; 2012). The threshold value is determined by what the user defines as an acceptable limit of error in the model (Beven, 2006; 2012).

The GLUE algorithm was implemented within the OSTRICH software, following the method of Nott et al. (2012), and parameters were updated into Raven in parallel to calculate the objective functions. The specific procedure was as follows: 
(1) Generate a large number of parameter sets $\left(n_{i}\right)$ by random sampling based on prior parameter $(\mathrm{p}(\theta))$ distributions (Tang, 1993);

(2) Each parameter set is then updated into the JRW, and an objective function $\mathrm{G}(n i ; y), \mathrm{i}=1 \ldots \ldots, \mathrm{n}$ is calculated;

(3) Using the threshold $c$, parameters sets $\left(n_{i}\right)$ are discarded when $\mathrm{G}\left(n_{i} ; y\right)<c$ and the remaining sets, result in a "behavioural'" set of solutions, which are denote as $\theta_{1}, \ldots, \theta_{\mathrm{m}}$.

\subsubsection{MODEL CALIBRATION}

A random subspace search using the GLUE method was applied for calibration, while an optimization algorithm could have found a better parameter set for the model, the GLUE method provided an adequate NSE and the uncertainty and parameter sensitivity were determined to be a larger focus for model performance in extremes. The model was calibrated using a 30-year historical dataset at the daily time step from 1980-2010, with the year 1979 as a spin-up year, based on observed streamflow data. A shorter calibration period could have increased model performance, but it could also miss climate conditions only seen over a longer period, and be unrepresentative for those conditions (Beven, 2012). A NSE objective function was used in the calibration process to determine the optimum parameter set and with a Latin hypercube sampling (Tang, 1993) due to the lack of information on prior parameters, and to avoid uneven parameter sets (Shen et al., 2012). The Ostrich software was used to apply the GLUE calibration and Latin hypercube sampling method. A threshold value of 0.7 for the NSE was used for the behavioural parameter sets. This step required some manual calibration and trial and error, as the threshold value is determined depending on purpose and use. The threshold value represented a good model performance where not all simulations produce behavioural sets. 
The 30-year calibration dataset contains a variety of streamflow conditions, ranging from a high of $142.0 \mathrm{~m}^{3} / \mathrm{s}$, to a low of $0.01 \mathrm{~m}^{3} / \mathrm{s}$. A larger calibration period was used due to the variability in climate events such as monsoons, El-Nina and El Nino, where if a small calibration period is used than only one of these events are calibrated and does not represent all the climate conditions of the watershed (Sorooshian et al., 1983; Beven, 2012). GLUE was set to find 50,000 behavioural sets with an NSE of 0.7 or greater. Approximately 350,000 parameter sets were performed with 300,000 of them being non-behavioural and the procedure only required 150 parameter sets before an NSE of 0.7 was achieved.

\subsubsection{MODEL VALIDATION}

Three independent datasets for climate and precipitation (1970 to 1979, 2011 to 2015, and 2016 to 2017) were used for validation of the Jock River model. These datasets contain high and low streamflow conditions to provide unbiased results for the extremes. The validation process uses the same objective functions presented in Table 4.3 to calculate the model efficiency on representing the simulated data versus observed data. A 7-day smoothing filter was applied to the residuals of the model using a moving average method. This smoothing method was applied to the validation period to compare event trends from observed and simulated values.

Moriasi et al. (2007) reviewed literature on calibration, validation, and application of watershed models, and determined that a model is satisfactory if the criteria of a NSE > $0.50, \mathrm{RSR}<0.70$, and PCT BIAS $+/-25 \%$ is met. Additionally, the model is represented by graphical techniques (visual representation of the model simulations and results), quality and quantity of measured data, model calibration procedure, validation, and a parameter sensitivity and uncertainty assessment (Moriasi et al., 2007). 


\subsection{SENSITIVITY AND UNCERTAINTY ASSESSMENT}

\subsubsection{MODEL PARAMETER SENSITIVITY}

The parameters used in the JRWM have a large range of possible values (Table 4.2); this means that depending on model structure and the parameter, the model results can vary greatly. Parameter sensitivities were determined using the random samples generated by Latin hypercube sampling. A qualitative assessment of parameter sensitivities was evaluated using dotty plots, with coefficient of correlations and regression analysis. These allow for a visual determination of the model sensitivity and the degree of correlation by trends illustrating higher sensitivity, or a haphazard relationship showing low sensitivity (Hamby, 1994).

\subsubsection{MODEL UNCERTAINITY UPPER AND LOWER BOUNDS}

Using the 50,000 acceptable parameter sets created in the GLUE method (section 4.3.3), the upper and lower bounds of uncertainty were then calculated by calculating equal weighted values for the behavioural parameter sets. This was done by calculating cumulative equal likelihood weighted distributions to find the quantiles for the lower $5 \%$ and upper $95 \%$ at every daily time step, accomplished by taking the weighted values for the behavioural sets (that add up to 1 ) at $t_{i}$ and ordering them from highest to lowest. This produced a distribution of values for $t_{i}$, that was used to find the lower $(5 \%)$ and upper (95\%) prediction interval at $t_{i}$. The process was repeated for each $t_{i+1}$ with uncertainty ranges calculated separately for each time step; parameter sets used to determine the range could be unique at each time step. The quantile bounds of 5 and $95 \%$ are commonly used to plot the range of possible outcomes in GLUE (e.g. Beven and Binley, 1992; Jin et al., 2010). Note that due to the computational time for the large number of parameter sets, 
prediction intervals estimates using GLUE were only calculated for the years 2011-2014. This time span was chosen as it was independent from the calibration dataset and contains a large variability in streamflow with both high and low streamflow extremes.

\subsection{MEASURING EXTREMES}

The evaluation of model performance related to the prediction of extreme hydrologic events requires a clear definition of "extreme". In this thesis, extreme events refer to streamflow events commonly described as floods (a high streamflow) and droughts (a low streamflow that persists over time). Different methods exist to define peak streamflows (floods), and low streamflows (droughts), depending on the application. The methods used to analyze extremes for this thesis were generalized extreme values (GEV) (Adlouni et al., 2007) and a streamflow threshold level (STL) for droughts (Fleigh et al., 2006).

\subsubsection{GENERALIZED EXTREME VALUES (GEV)}

GEV theory states that the extreme limits in a sufficiently long-time series of block maxima will approach the asymptote at large sample sizes (Coles, 2001). Block maxima in this thesis will refer to the streamflow peaks. The development of frequency analysis of extreme events has been motivated by the need to design systems (e.g. dams and flood protection systems) to be able to safely handle the peak flow events while being economically viable. Due to the lack of knowledge about generating mechanisms, extreme events are usually not well reproduced in physical models and are thus usually addressed using statistical methods. The GEV has two assumptions that (1) the data are independent 
and identically distributed; and (2) the series is stationary, meaning that its statistical properties are independent of time (Coles, 2001; Liu et al., 2014). The GEV has three different probability distributions (Gumbel, Fréchet and Weibull), where the Gumbel distribution has been used in many applications for flood analysis (Bergström et al., 2001; Clark, 2002; Matti et al., 2016; Tan et al., 2015)

The Gumbel distribution represented by Equation 4.3 (Coles, 2001);

$$
F_{x}(z)=\exp \left\{-\exp \left[\frac{(z-b}{a}\right]\right\} \quad-\infty<x<\infty
$$

(Equation 4.3)

where $\mathrm{F}_{x}$ is the distribution, $\mathrm{z}$ is random variable of $x, b$ is the location parameter, and $a$ is a scale parameter. (Coles, 2001). The scale parameter $(a)$ is calculated by using the variance $\left(\sigma_{\mathrm{x}}^{2}\right)$ of the data with Equation 4.4.

$$
a=\sqrt{\left(\frac{6 \sigma^{2}}{\pi^{2}}\right)}
$$

The location parameter $(b)$ is calculated by using the mean $\left(\mu_{\mathrm{x}}\right)$ and Equation 4.4.

$$
b=\mu_{\mathrm{x}}-0.57772 a
$$

(Equation 4.5)

The Gumbel distribution was used for yearly streamflow maximums and L-moments were used for summer and fall time streamflow maximums, as the Gumbel distribution did not represent summer/fall streamflow maximums well for the (1980-2017) time period. The parameters for the distributions were calculated using the maximum likelihood method (Coles, 2001). The maximum likelihood estimation is a method to calculate the parameters of a statistical method by applying a maximum likelihood function which finds the highest probability to obtain the parameter of interest using the observed data. These produced return periods for flood frequency, which can be used to measure the return frequency of an extreme event to occur, and the 50 year return period are classified as an extreme event for this dissertation. 
Milly et al., (2008) states that "Stationarity is Dead" - it has been shown that in watersheds streamflow is nonstationary over time (Adlouni et al., 2007; Liu et al., 2014). Nonstationarity in the Jock River watershed was tested using the nonparametric MannKendall (MK) test, which indicated if there are any significant trends in the data, as it does not make assumptions about the data distribution, except that the data are independently distributed in time (Mann 1945; Kendall, 1975). It is used to evaluate if the data has a monotonic upward or downward trend for the variable of interest over time and is often used in extreme analysis for streamflow (Matti et al., 2016; Wang et al., 2012). When a trend did exist a nonstationary GEV model was used, to remove trends in the streamflow data associated with other top-down influences such as longer-term temperature increases, seasonal cycles, human activities and management or any other trends (following Hayhoe et al., 2006; Marshall and Randhir, 2008; Meals et al., 2011). Time was introduced as a covariate and the location and scale parameters were changed as a function of the time and the maximum likelihood method was used to find the parameters (following Clark, 2002; Adlouni et al., 2007). The eXtremes package in R (Gilleland and Katz, 2016) was used to conduct GEV, maximum likelihood and nonstationarity measurements.

Flow duration curves (FDCs) are plots that represent the likelihood that flow is expected to equal or exceed some frequency or magnitude of interest at the daily, weekly, or monthly flows for a given period of time. The FDCs are used to examine the historical flood and drought extremes of a river and to determine the frequency of a flow which is greater than a certain flow. In order to examine these changes a "yearly-ensemble" approach was taken, creating a FDC for the Jock River for both the historical and simulated dataset to evaluate the streamflow extremes at the $95 \%$ low flows. The flow duration 
package hydroTSM (Zambrano-Bigiarini, 2017) for the R programing language was used to perform flow duration.

\subsubsection{STREAMFLOW THRESHOLD LEVEL (STL)}

Droughts were evaluated using a Streamflow Threshold Level (STL) method. This method defines a water threshold level, $\mathrm{Q}_{\mathrm{z}}$, with drought defined as periods where there are any consecutive days in which the discharge is below the threshold level (Fleigh et al., 2006). Figure 4.2 illustrates this threshold and its application to a time series. This study defined the threshold level as the 95-percentile flow (Q95) from the FDC, which has been indicated by Fleigh et al. (2006) to be a common value used for perennial streams.

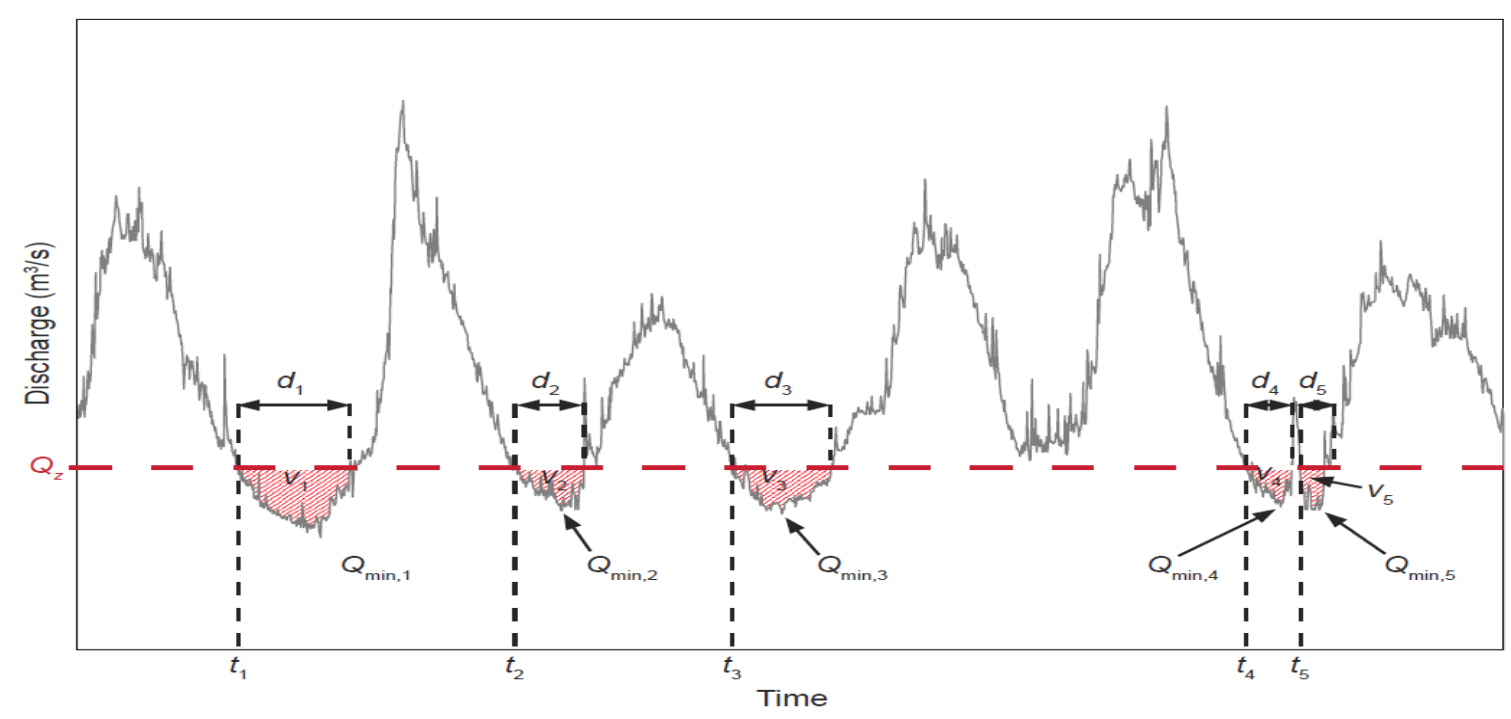

Figure 4.2. Using a defined threshold level $\left(\mathrm{Q}_{\mathrm{z}}\right)$ : produces a time of occurrence, $\mathrm{t}_{\mathrm{i}}$, and duration in days, $\mathrm{d}_{\mathrm{i}}$, for a deficit volume or severity, $\mathrm{v}_{\mathrm{i}}$, and the minimum flow occurring during the drought event, Qmin,i (Fleig et al., 2006). 


\subsection{HYDROLOGICAL CLIMATE CHANGE SCENARIO PROJECTIONS}

The outputs from the 12 climate models selected in Section 3.4 were used as climate

data input into the JRWM, over a simulation period from 2011-2099, using the calibrated parameter set, producing 12 streamflow scenarios. The results were then split into threetime periods (2011-2040, 2041-2070 and 2071-2099) and evaluated using quantitative plots, GEV analysis FDCs, and SRDI to evaluate climate changes in streamflow for the Jock River watershed. Because of the levels of uncertainty in GCMs discussed above, multiple models of climate change scenarios were used to reduce some of those uncertainties (Kundzewicz et al., 2018). The full ensemble of model predictions was analysed to give context to the ensemble means. 


\section{CHAPTER 5: RESULTS}

The results chapter consists of five sections. The first section describes the model calibration and parameters. The second section presents streamflow simulation results using the historical climate data and comparison to the historical streamflow record. The third part is the parameter sensitivity, validation and uncertainty of the model. The fourth section shows results of flooding and drought extremes in the observed and simulated streamflow. Finally, Section 5.5 describes the climate change scenario simulation results.

\subsection{CALIBRATED MODEL PARAMETERS}

The GLUE method produced several different parameters sets that have high objective function values. Table 5.1 reports the top five parameter sets to illustrate the difference that exists between parameter sets. See Appendix A for additional calibration diagnostics.

Although the model only uses four parameters for calibration, the parameters are also further divided into the seven soil classes for two parameters and four land use properties for the other two parameters in the HRUs, meaning that there are 22 parameters. The parameters are identified as par_\#, where parameter 1 is noted at par_1. The snow/land use parameters are the GR4J_X4 (days) for parameters (par_1-par_5) and MELT_FACTOR $(\mathrm{mm} / \mathrm{d} / \mathrm{K})$ for (par_6-par_10). The soil properties are the GR4J_X3 (mm) for parameters (par_11-par_17), and constant (mm/d) for parameters (par_18-par_24).

The objective functions for the top five parameters have a NSE value over 0.75 . A parameter in a parameter set can vary from a few thousandths to 10 times the original value compared to the same parameter in a different parameter set. Between these top five parameter sets, the parameter that changes the least relative to the NSE is the land use 
parameter par_8 (MELT_FACTOR and related to the forest LULC) at $122 \%$, and the parameter that changes the most is par_1 (GR4J_X4 and related to agriculture LULC) with $231 \%$ change difference.

Parameters par_11-par_22 are composed of soil properties and are divided up into different soil types in HRUs. There are 7 different types of soil, and "JockGR4J.rvh" file presented in Appendix F lists their clay, silt, and sand composition. The parameter with the least variation is par_12 at $115 \%$, and the one with the largest is par_16 at $1066 \%$.

Table 5.1 The top 5 parameter sets and their values for JRWM

\begin{tabular}{|c|c|c|c|c|c|c|c|}
\hline & \multicolumn{2}{|c|}{$\begin{array}{l}\text { Objective Function } \\
\text { NSE }\end{array}$} & $\begin{array}{l}\text { Par 1 } \\
\text { GR4J X4 }\end{array}$ & $\begin{array}{l}\text { Par } 2 \\
\text { GR4J X4 }\end{array}$ & $\begin{array}{l}\text { Par } 3 \\
\text { GR4J X4 }\end{array}$ & $\begin{array}{l}\text { Par } 4 \\
\text { GR4J X4 }\end{array}$ & $\begin{array}{l}\text { Par } 5 \\
\text { GR4J X4 }\end{array}$ \\
\hline 1 & \multicolumn{2}{|c|}{0.76} & 2.40 & 4.40 & 2.72 & 2.19 & 2.42 \\
\hline 2 & \multicolumn{2}{|l|}{0.76} & 2.62 & 4.01 & 4.51 & 2.75 & 3.11 \\
\hline 3 & \multicolumn{2}{|l|}{0.76} & 3.45 & 2.63 & 3.07 & 2.48 & 4.38 \\
\hline 4 & \multicolumn{2}{|l|}{0.76} & 4.74 & 4.02 & 3.26 & 4.79 & 4.95 \\
\hline \multirow[t]{2}{*}{5} & \multicolumn{2}{|l|}{0.76} & 2.05 & 2.77 & 4.72 & 4.18 & 2.25 \\
\hline & $\begin{array}{l}\text { Par } 6 \\
\text { M-F }\end{array}$ & $\begin{array}{l}\text { Par } 7 \\
\text { M-F }\end{array}$ & $\begin{array}{l}\text { Par } 8 \\
\text { M-F }\end{array}$ & $\begin{array}{l}\text { Par } 9 \\
\text { M-F }\end{array}$ & $\begin{array}{l}\text { Par } 10 \\
\text { M-F }\end{array}$ & $\begin{array}{l}\text { Par } 11 \\
\text { M-F }\end{array}$ & $\begin{array}{l}\text { Par } 12 \\
\text { M-F }\end{array}$ \\
\hline 1 & 10.74 & 5.25 & 10.91 & 8.36 & 10.84 & 33.70 & 39.09 \\
\hline 2 & 9.32 & 5.92 & 11.90 & 9.30 & 6.94 & 57.49 & 37.52 \\
\hline 3 & 7.45 & 7.71 & 13.37 & 6.19 & 10.55 & 31.94 & 35.04 \\
\hline 4 & 7.54 & 7.22 & 11.32 & 14.29 & 9.88 & 36.88 & 33.98 \\
\hline \multirow[t]{2}{*}{5} & 8.47 & 6.37 & 12.89 & 7.00 & 12.82 & 24.03 & 35.08 \\
\hline & $\begin{array}{l}\text { Par } 13 \\
\text { GR4J X3 }\end{array}$ & $\begin{array}{l}\text { Par } 14 \\
\text { GR4J X3 }\end{array}$ & $\begin{array}{l}\text { Par } 15 \\
\text { GR4J X3 }\end{array}$ & $\begin{array}{l}\text { Par } 16 \\
\text { GR4J X3 }\end{array}$ & $\begin{array}{l}\text { Par } 17 \\
\text { GR4J X3 }\end{array}$ & $\begin{array}{l}\text { Par } 18 \\
\text { Constant }\end{array}$ & $\begin{array}{l}\text { Par } 19 \\
\text { Constant }\end{array}$ \\
\hline 1 & 59.64 & 66.56 & 49.96 & 7.17 & 45.45 & 7.91 & 3.97 \\
\hline 2 & 64.30 & 57.71 & 58.42 & 38.83 & 29.33 & 5.95 & 3.34 \\
\hline 3 & 38.93 & 51.50 & 65.11 & 18.88 & 41.36 & 6.74 & 3.42 \\
\hline 4 & 20.74 & 26.09 & 47.51 & 47.61 & 43.80 & 7.39 & 3.38 \\
\hline 5 & 37.34 & 76.45 & 39.82 & 76.42 & 51.58 & 6.48 & 3.58 \\
\hline & $\begin{array}{l}\text { Par } 20 \\
\text { Constant }\end{array}$ & $\begin{array}{l}\text { Par } 21 \\
\text { Constant }\end{array}$ & $\begin{array}{l}\text { Par } 22 \\
\text { Constant }\end{array}$ & $\begin{array}{l}\text { Par } 23 \\
\text { Constant }\end{array}$ & $\begin{array}{l}\text { Par } 24 \\
\text { Constant }\end{array}$ & \multirow{6}{*}{\multicolumn{2}{|c|}{$\begin{array}{l}\text { Par \# = parameter number } \\
\mathrm{M}-\mathrm{F}=\text { Melt_Factor }\end{array}$}} \\
\hline 1 & 4.09 & 4.47 & 9.67 & 10.53 & 1.89 & & \\
\hline 2 & 2.76 & 2.18 & 9.22 & 9.56 & 1.28 & & \\
\hline 3 & 12.11 & 5.88 & 9.87 & 2.76 & 1.24 & & \\
\hline 4 & 2.54 & 4.35 & 7.78 & 6.91 & 1.75 & & \\
\hline 5 & 3.75 & 4.77 & 9.58 & 10.05 & 1.68 & & \\
\hline
\end{tabular}




\subsection{JOCK RIVER WATERSHED MODEL RESULTS}

The following sections present the modelled streamflow in comparison with both the 1970-1979 and the 2011-2017 validation time series (see Section 5.3). The figures are separated into 5 decadal time-periods starting with 1970-1979, as well as a combined 19702017 period.

\subsubsection{HYDROGRAPHS}

Daily hydrographs for 1970-2017 (Figure 5.1) shows that the overall performance for the JRWM simulates streamflows well. Most of the streamflow variation (high and low) in the watershed are captured in the 30-year calibration period (1980-2010), meaning that the model is not sensitive to small weather events. The NSE has a higher performance $\sim 0.76$ for the 1980-2010 period compared to the individual decade time periods of 1980-1990, 1990-2000, 2000-2010, that have a lower NSE of $0.75,0.74$, and 0.72 respectively (Table 5.2). This higher NSE occurs due to the mean of the results shifting with the addition of multiple years and is also beneficial as the mean is a better representation of the mean of the actual streamflow for the river.

Additionally, the snow melt peak at the end of winter (approximately April $1^{\text {st }}$ ) and summer low flows are represented well, except where there is a large precipitation event that occurs in the summer-fall season, where the model usually simulates higher flows than observed. The hydrographs for streamflow usually follow a seasonal streamflow pattern with high melt peaks in the early spring from snow melt, low summer flow and a mixed fall season, except in 2017, where there are five distinctive peak flows in summer-fall that are higher than some of the snow melt peaks years. 

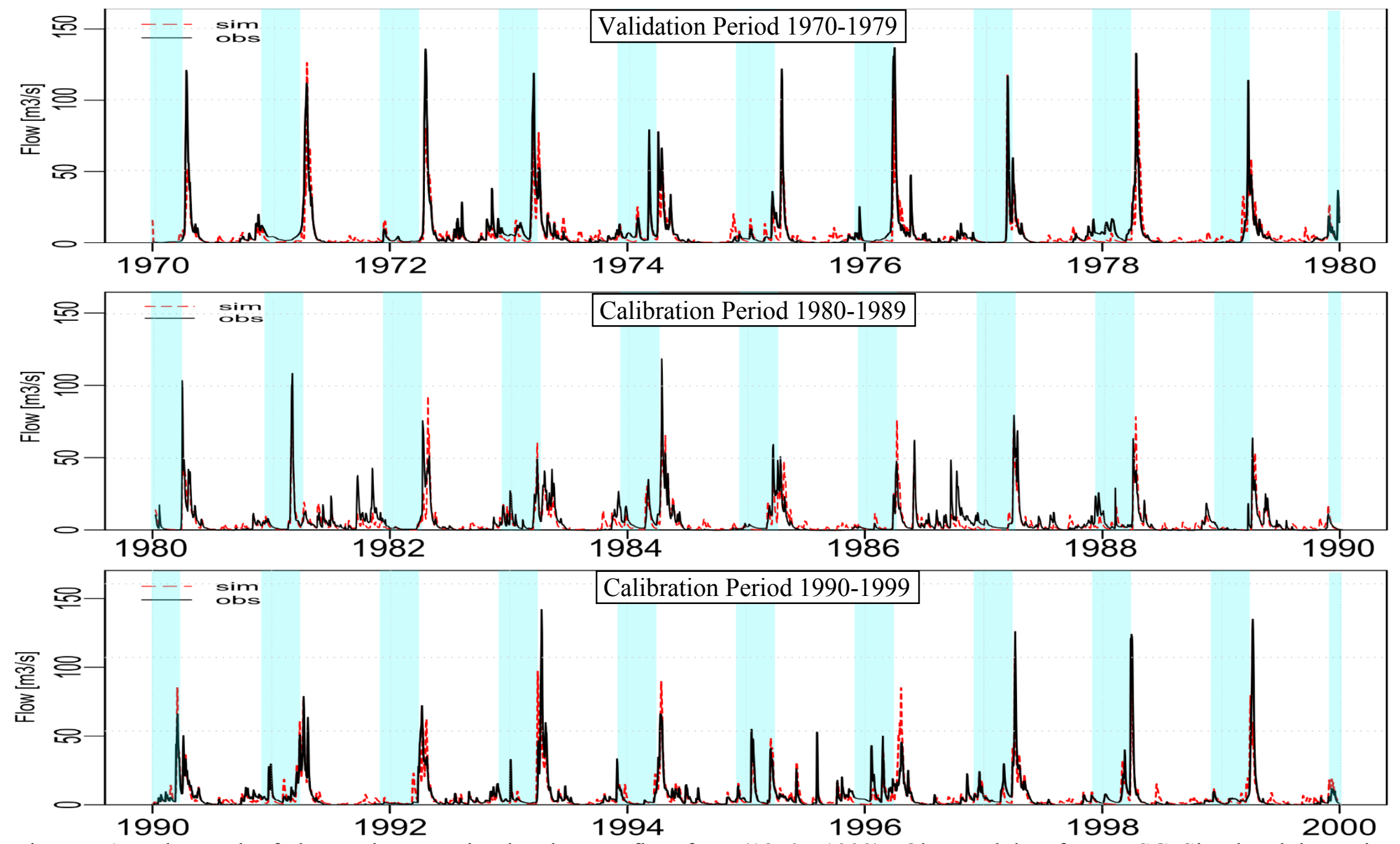

Figure 5.1 Hydrograph of observed versus simulated streamflow from $(1970$ - 1999). Observed data from WSC. Simulated data using the best parameter set for the JRWM. The winter months are represented in blue shading from the December 1st - March 30th. (continued next page) 

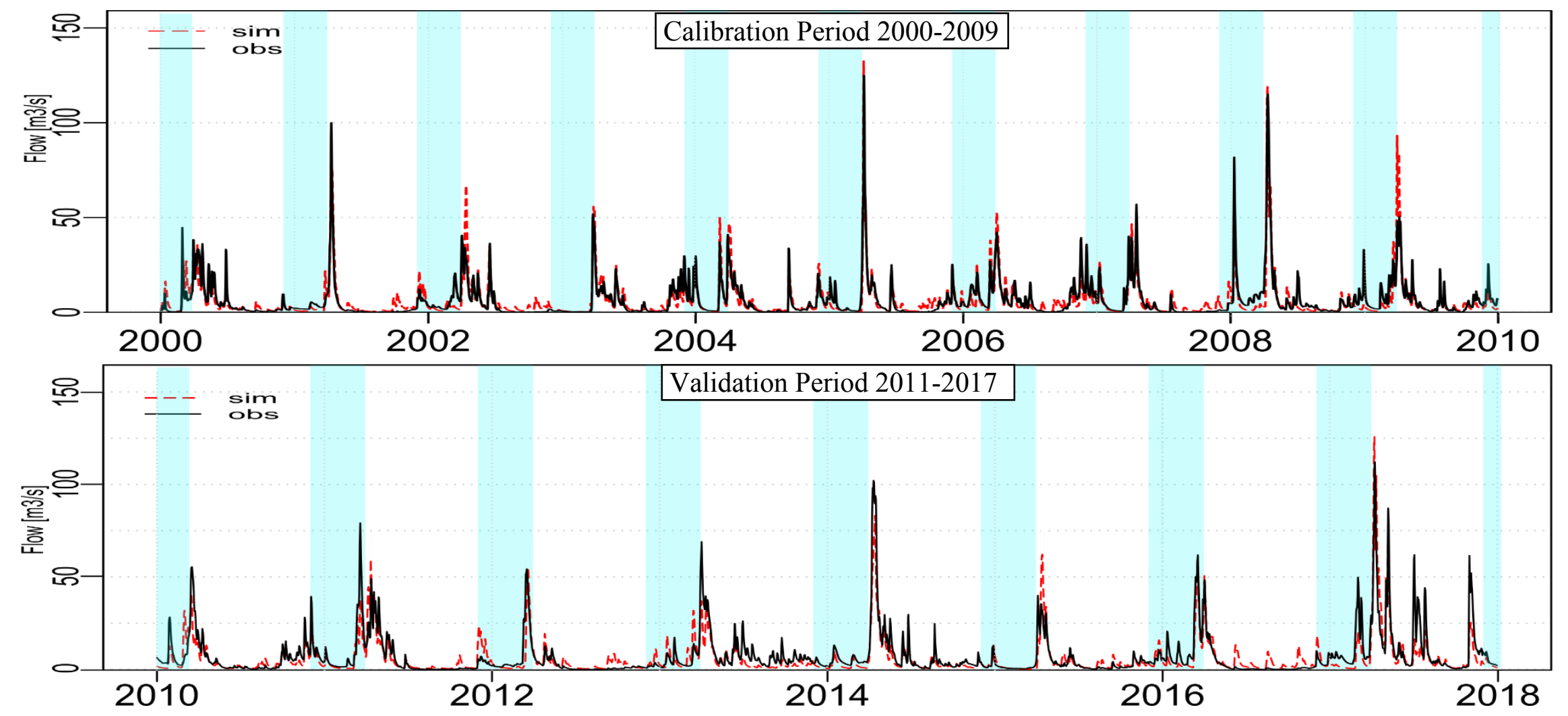

(continued) Figure 5.1. Hydrograph of observed versus simulated streamflow from (2000- 2017). Observed data from WSC.

Simulated data was obtained using the best parameter set for the JRWM. The winter months are represented in blue shading from the December 1st - March 30th. 


\subsubsection{CUMULATIVE FLOWS}

Cumulative flow (summed flow for a water year, October 1st - September 30th), plotted in Figure 5.2, shows that the simulated flows are represented very well for low flow years, with almost an identical flow throughout the year for these periods. The years with a medium cumulative flow have a mixed range of results, with some years being underestimated and some being overestimated. Years with higher cumulative flow are often underestimated by the model, with the largest error occurring in the beginning of the winter season by high flows, followed by a few years that have high summer streamflows.

The snow melt period is modelled very well across most years, as the large rise in streamflow matches closely the observed values, even during the years where the model has underestimated flow during the winter, the melt season is still represented well. The plot starts at the end of the September 30th time-period, where the first few months are the end of the fall season, followed by the lower flows of the winter season. The years that have higher flows during these months are often the years with a higher cumulative flow overall. The summer period for the plot can usually be seen where the rise in cumulative flows levelled off to a lower flow period and do not rise very much unless they are from a wet summer year. The lowest cumulative flow was in the year 2000 at just under 150 million $\mathrm{m}^{3}$, with more than double that in the highest flow in 2017 at 377 million $\mathrm{m}^{3}$. A total annual mean and mean monthly comparison can be seen in Appendix B, Figure B.1. 

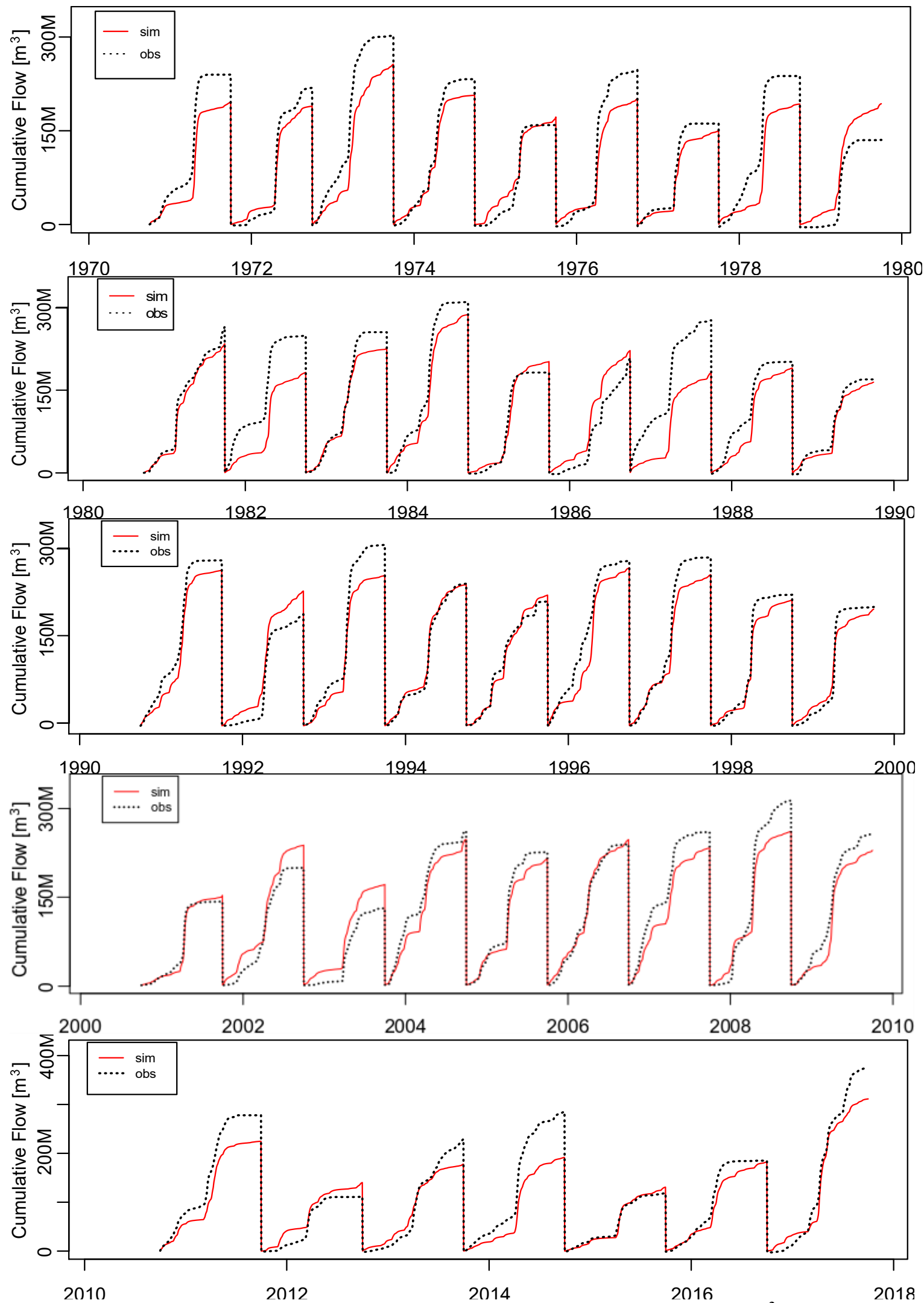

Figure 5.2. Cumulative flows for the Jock River watershed in millions of $\mathrm{m}^{3}$. Observed data from the WSC. Simulated data from modelled data of the Jock River Watershed. 


\subsubsection{FLOW SCATTERPLOTS}

Linear regression scatterplots of daily simulated and observed streamflow $\left(\mathrm{m}^{3} / \mathrm{s}\right)$ for the entire historical period (Figure 5.3(a)) show that low to mid flows dominate, and the majority of these low to mid flows are simulated well. However, as the flow increases there is more variation in the density of the points, where most of the higher flows can be seen to be underestimated for the time-period. In the first decade (Figure 5.3(b)), the high observed flows are represented well in the model, with a few underestimated high flows and an overall $\mathrm{R}^{2}$ value of 0.78 . In the $1980 \mathrm{~s}$, the low to mid range flows were underestimated, with an $\mathrm{R}^{2}$ value of 0.73 (Figure 5.3(c)). The 1990s (Figure 5.3(d)) were similar, but also had a few very high simulated flows when there were lower flows in the observed data, and the $\mathrm{R}^{2}$ value was 0.75 . The 2000 - 2009 time-period (Figure 5.3(e)) has the best matched flows, where the high and low flows are being represented very well with the least scattering between the observed and simulated and has the highest $\mathrm{R}^{2}$ value at 0.79. The 2010-2017 time-period has the worst results, but also this scatter plot only represents 8 years of data compared to the 10 years of data in the other simulations. There are no larger outliers between the observed and simulated, however the results are not as centered around the 1:1 line as the other time periods. The time-period also has the lowest $\mathrm{R}^{2}$ value at 0.72 . 

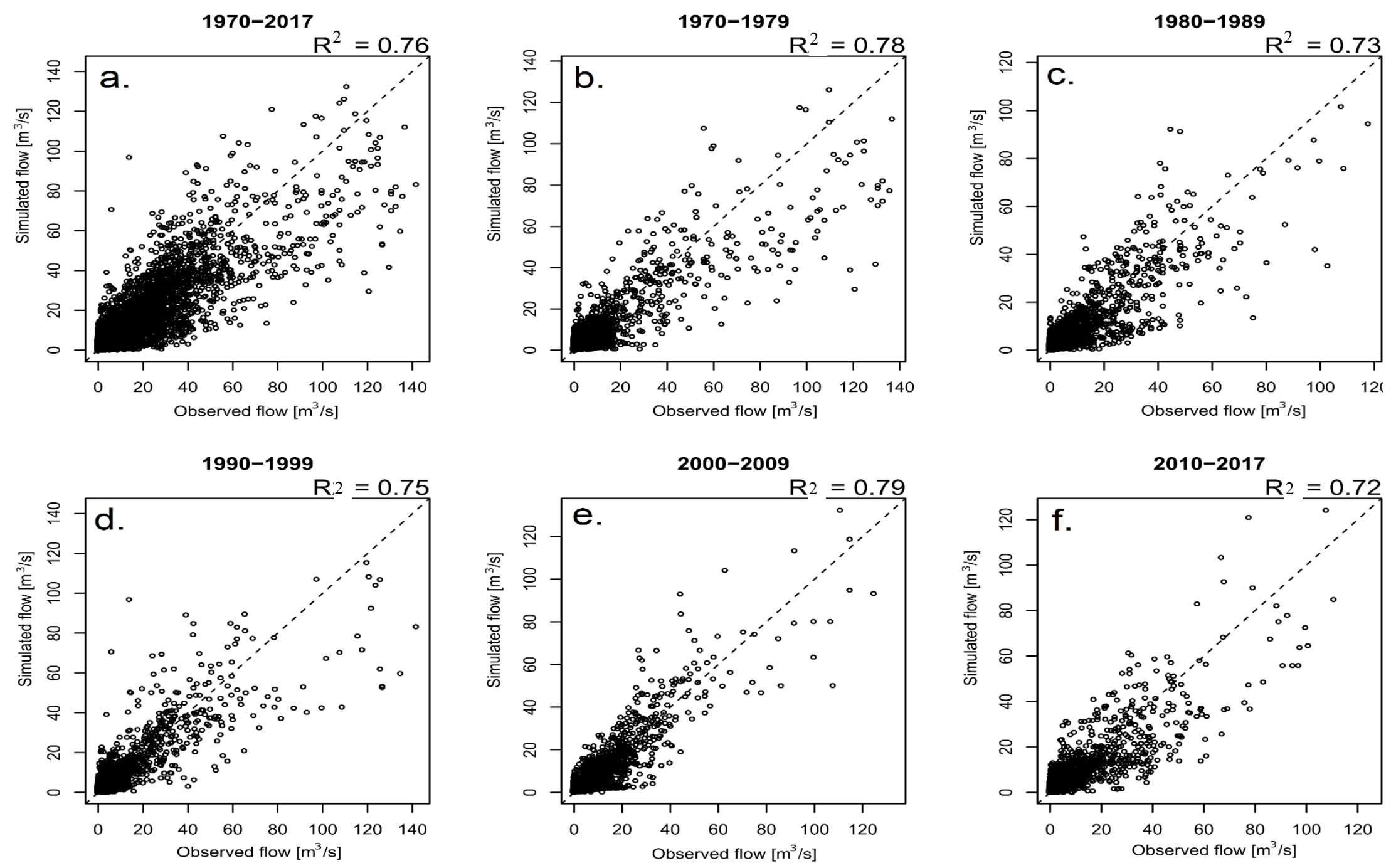

Figure 5.3. Results from the JRWM outputs (1970-2017). Linear regression scatterplots of daily simulated and observed streamflow $\left(\mathrm{m}^{3} / \mathrm{s}\right)$. 


\subsubsection{PEAK EVENTS AND TIMING ERROR}

The percentage error difference in peak events is shown in Figure 5.4 and Figure 5.5. Figure 5.4 illustrates the difference in peak error even if the timing of the peak for that the year is off in the model. The simulated values are underestimated compared to the observed values, with most of the values at $20 \%$ or less for the peak error. There are four years that exceed $40 \%$ underestimation, with the largest by $60 \%$ in 1980 , however there are also four years that exceed $40 \%$ overestimation, with the largest by $70 \%$ in 2009 . Figure 5.5 shows the peaks from the same day as the peak event in the observed series, i.e. the timing of the peak is considered here. The graph is very similar to the results of Figure 5.4, however the graph shows that most of the peaks are underestimated when the timing is included. Additional model comparisons for timing error, total volume, percent error, and day difference are available in Appendix B (B.3-B.6).

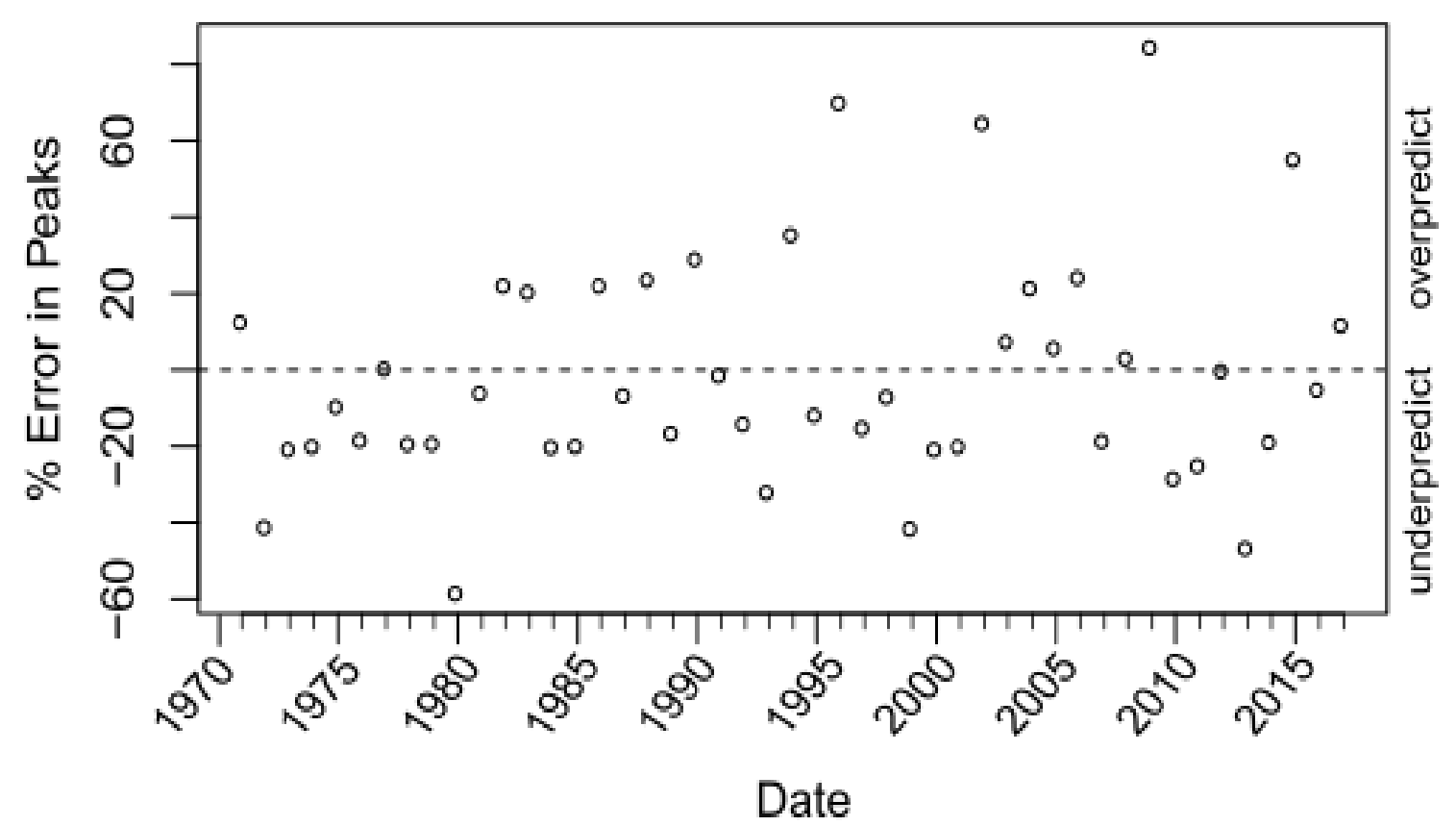

Figure 5.4. Percentage error in simulated peaks for each water year. The peaks are calculated as the magnitude of the largest event in each year. 


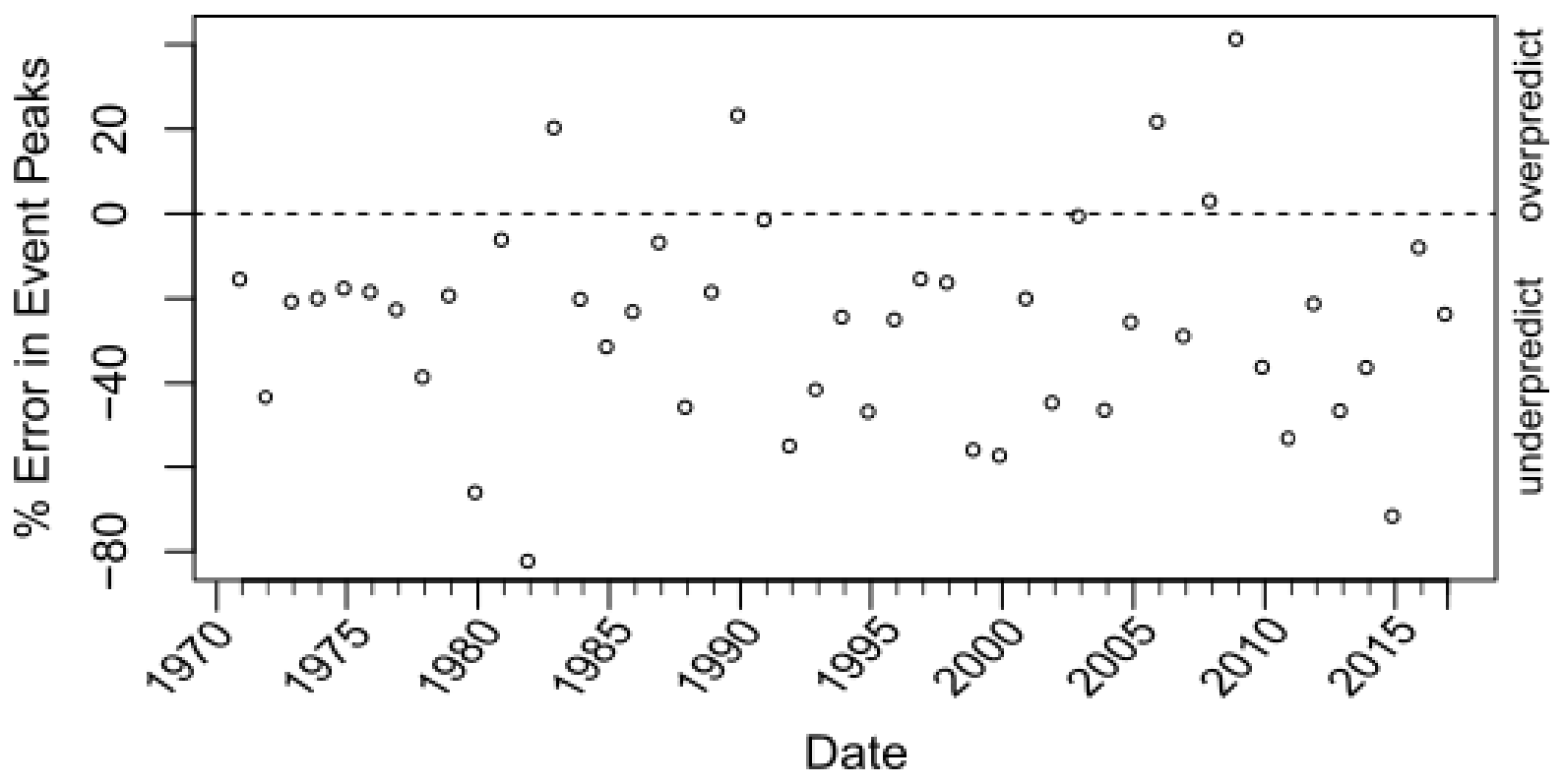

Figure 5.5. Plot of the percent errors in simulated peak events for each water year. The peaks are calculated using flows from the same day as the peak event in the observed series, i.e. the timing of the peak is considered here.

\subsubsection{MONTHLY DIFFERENCES}

The mean monthly streamflow for the historical time-period (1970-2017) is shown in Figure 5.6, where the overall average monthly streamflow is modelled very closely to the observed values. The winter flows for the simulated period are underestimated by about $2 \mathrm{~m}^{3} / \mathrm{s}$ compared to the observed data. The late winter and spring (including melt season) are modelled very well with nearly exact streamflow, where the rising limb and falling limb of the mean streamflow in March, April, and May match closely. At the beginning of August streamflow is overestimated by $\sim 1-2 \mathrm{~m}^{3} / \mathrm{s}$ until the end of the fall season. Towards the end of the fall season the model begins to underestimate again by about $2 \mathrm{~m}^{3} / \mathrm{s}$. The total volume for monthly differences both normalized and non-normalized can be seen in Appendix B (Figures B.7 and B.8). 


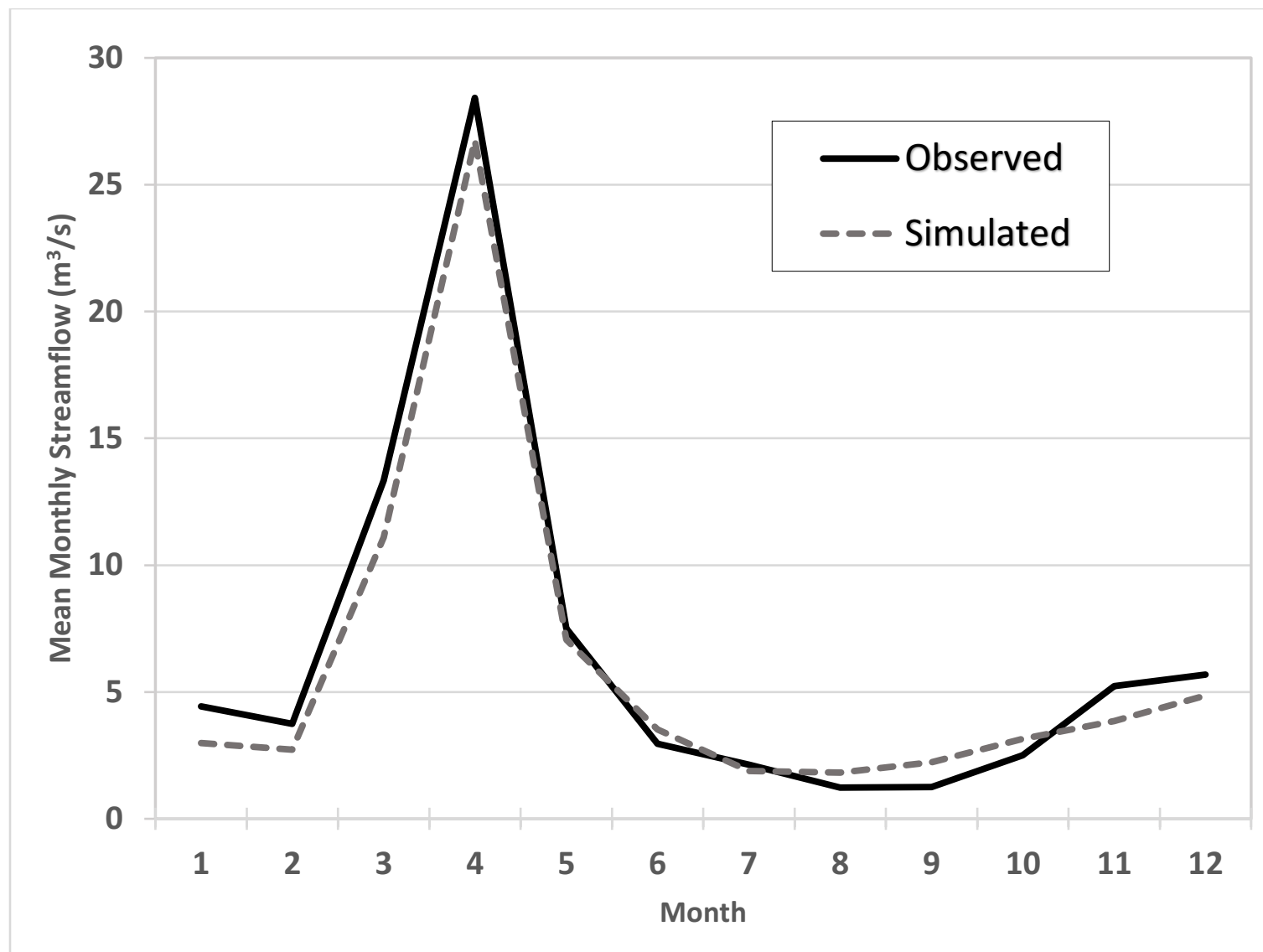

Figure 5.6 Mean monthly simulated and observed streamflow ( $\left.\mathrm{m}^{3} / \mathrm{s}\right)$ for the 1970-2017 time-period. 


\subsection{VALIDATION, PARAMETER SENSITIVITY AND UNCERTAINTY}

\subsubsection{VALIDATION AND OBJECTIVE FUNCTIONS}

The model performance measurements (objective functions) for each decade are reported in Table 5.2. The calibration period (1980-2010) shows a strong correlation between observed and simulated streamflow with a NSE of 0.75 and an $\mathrm{R}^{2}$ of 0.75 . The calibration period also shows that the model tends to underestimate values with a percent bias (PCT BIAS) of -5.2 and also underestimates peaks with a peak difference (PDIFF) of about $9.4 \mathrm{~m}^{3} / \mathrm{s}$. The RMSE and RSR are 5.84 and 0.50 , respectively. The average absolute error (ABSERR) is 2.9 and maximum absolute error (ABSMAX) is 82.9.

There are three validation periods: 1970-1979, 2011-2015 and 2016-2017. The 2016-2017 period is considered separately from the 2011-2015 dataset due to the different type of climate data used. The 2011-2015 period has a NSE of 0.72 and an $R^{2}$ of 0.74 . The model also underestimates values with a PCT BIAS of -16.6 and PDIFF of $-18.7 \mathrm{~m}^{3} / \mathrm{s}$. The RMSE and RSR are 5.82 and 0.53 , respectively. The ABSERR is 3.0 and ABSMAX is 47.9. The 2016-2017 period has a NSE of 0.68 and an $\mathrm{R}^{2}$ of 0.71 . The model also underestimates values with a PCT BIAS of -22.7 and PDIFF of $13.4 \mathrm{~m}^{3} / \mathrm{s}$. The RMSE and RSR are 8.57 and 0.56, respectively. The ABSERR is 5.1 and ABSMAX is 45.1. 
Table 5.2 Objective function and diagnostics values for the different model time-periods for JRWM.

\begin{tabular}{|c|c|c|c|c|c|c|c|c|c|c|}
\hline Years & NS_SUTCLIFFE & PCT_BIAS & PDIFF & R2 & RMSE & RSR & ABSERR & TMVOL & ABSMAX & $\mathrm{NSC}$ \\
\hline $\begin{array}{l}1970- \\
1980\end{array}$ & 0.78 & -10.8 & -10.6 & 0.79 & 7.58 & 0.47 & 3.3 & 1920.4 & 91.2 & 155 \\
\hline $\begin{array}{l}1980- \\
1990\end{array}$ & 0.72 & -11.6 & -16.3 & 0.72 & 5.98 & 0.53 & 3.1 & 1472.8 & 75.8 & 162 \\
\hline $\begin{array}{l}1990- \\
2000\end{array}$ & 0.74 & -3.3 & -26.3 & 0.74 & 5.84 & 0.50 & 2.9 & 1341.4 & 82.9 & 201 \\
\hline $\begin{array}{l}2000- \\
2010\end{array}$ & 0.79 & -4.3 & 7.59 & 0.80 & 4.81 & 0.46 & 2.6 & 811.5 & 57.6 & 226 \\
\hline $\begin{array}{l}2011- \\
2017\end{array}$ & 0.70 & -18.2 & 13.4 & 0.71 & 6.69 & 0.55 & 3.5 & 1875.4 & 45.1 & 133 \\
\hline $\begin{array}{l}1970- \\
2017\end{array}$ & 0.76 & -8.2 & -9.4 & 0.76 & 6.32 & 0.49 & 3.1 & 7140.6 & 91.2 & 879 \\
\hline $\begin{array}{l}1970- \\
1979\end{array}$ & 0.78 & -11.0 & -10.6 & 0.79 & 7.59 & 0.47 & 3.3 & 1917.3 & 91.2 & 155 \\
\hline $\begin{array}{l}1980- \\
2010\end{array}$ & 0.75 & -5.2 & -9.4 & 0.75 & 5.84 & 0.50 & 2.9 & 3586.1 & 82.9 & 589 \\
\hline $\begin{array}{l}2011- \\
2015\end{array}$ & 0.72 & -16.6 & -18.7 & 0.74 & 5.82 & 0.53 & 3.0 & 826.9 & 47.9 & 85 \\
\hline $\begin{array}{l}2016- \\
2017 \\
\end{array}$ & 0.68 & -22.8 & 13.4 & 0.71 & 8.57 & 0.56 & 5.1 & 971.2 & 45.1 & 25 \\
\hline
\end{tabular}




\subsubsection{VALIDATION RESIDUALS}

The residuals of the validation years (2011-2017) for the model are plotted in Figure 5.7. The residuals have a 7-day smoothing filter applied to them. There is a common theme in the residuals for all years, with large differences in the winter melt season, and quick fluctuations between positive and negative residuals with magnitudes of about 20 . This fluctuation reinforces the timing issues that are present in the melt season. The residuals also reveal that when the model simulates mid to large streamflow residuals for the summer/fall season, they are predominantly negative or positive residuals for the entire season. This implies that the model is not capturing the dry and wet seasonal variation that exists within the watershed well, by overestimating streamflow during the dry and underestimating streamflow during the wet season. Other residuals for the remaining years (1970-2010) can be found in Appendix B, Figure B.9.

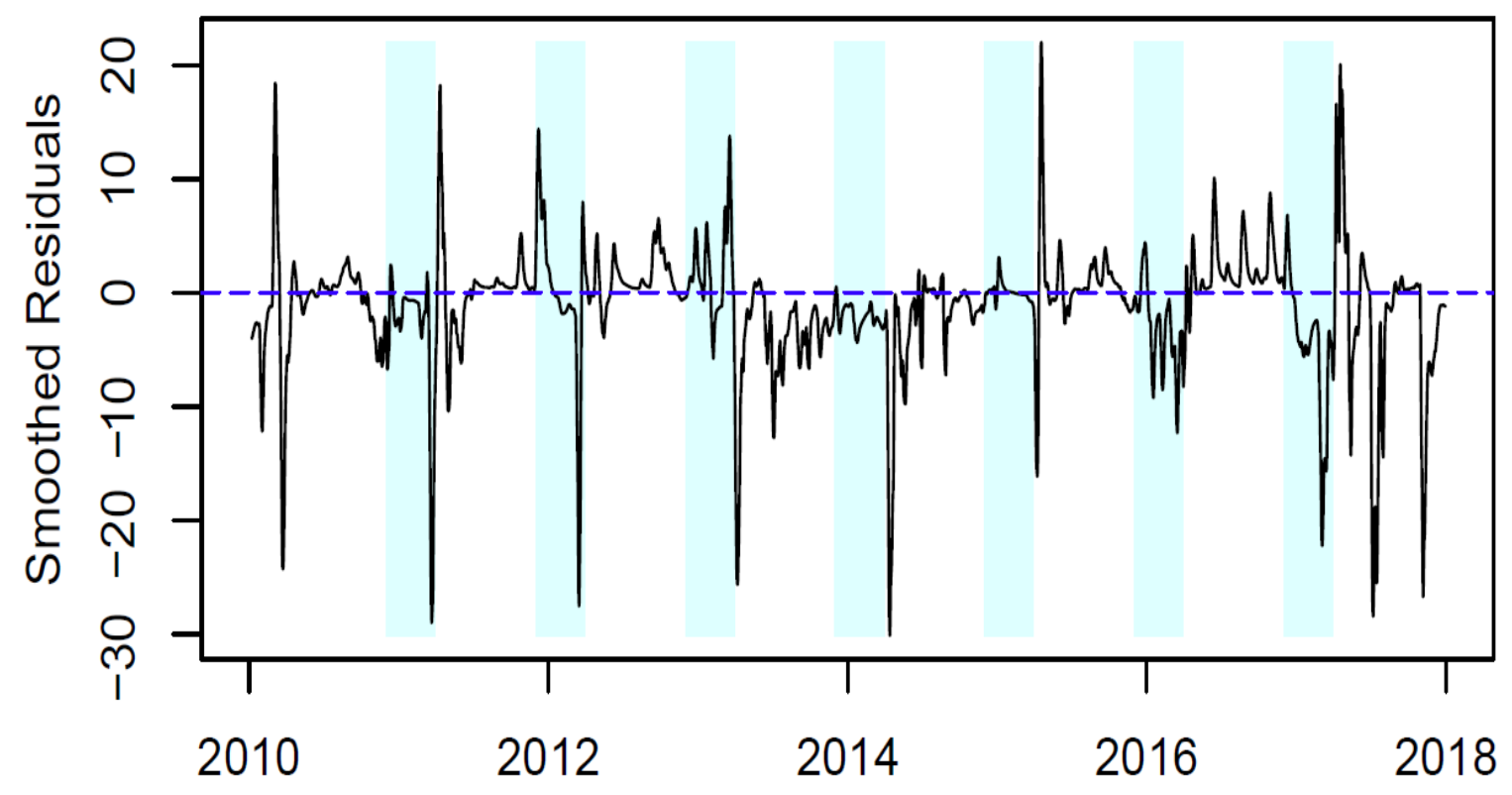

Figure 5.7. A residuals time series plot from 2010-2017 for flow values with a 7-day smoothing filter. The residuals are calculated as simulated versus observed. 


\subsubsection{PARAMETER SENSITIVITY}

The most sensitive six parameters using quantitative techniques are shown in Figure 5.8 for the GLUE analysis as sensitivity dotty plots. The entire set of 24 parameter sensitivity plots can be seen in Appendix C (Figure C.1). Additionally, some of these parameters can be assigned to multiple HRUs, if the soil type or land use type are the same in that specific HRU. These top six results show the sensitivity of the parameters to the result. The parameters are par_5 (GR4J_X4 and wetland), par_7 (MELT FACTOR and agriculture/mixed forest), par_12 (GR4J_X3 and SOIL 2), par_15 (GR4J_X3 and SOIL 5), par_19 (Percolation constant and SOIL 2), and par_22 (Percolation Constant and SOIL 5). Parameters 5 and 7 both belong to the two smallest HRUs in the watershed, each making up only about $\sim 5 \%$ of the watershed area. Whereas the soil parameters par_12 and par_19 are part of the most dominant soil in the watershed at $50 \%$ of the area, while par_15 and par_22 are at about $33 \%$ of the area.

Parameter 5 and 7 both follow a similar spreading pattern with higher NSE values being concentrated towards the left of the graph and gradually becoming a larger range of lower NSE values as the parameter is increased, with a decrease in higher NSE as the parameter approaches the larger extreme of the range on the right. Parameters 12, 15, 19, and 22 follow a similar spreading pattern with higher NSE values concentrated towards the right of the graph and gradually decrease the NSE value as the parameter is decreased, with a decrease in higher NSE as the parameter approaches the larger extreme of the range on the left. 

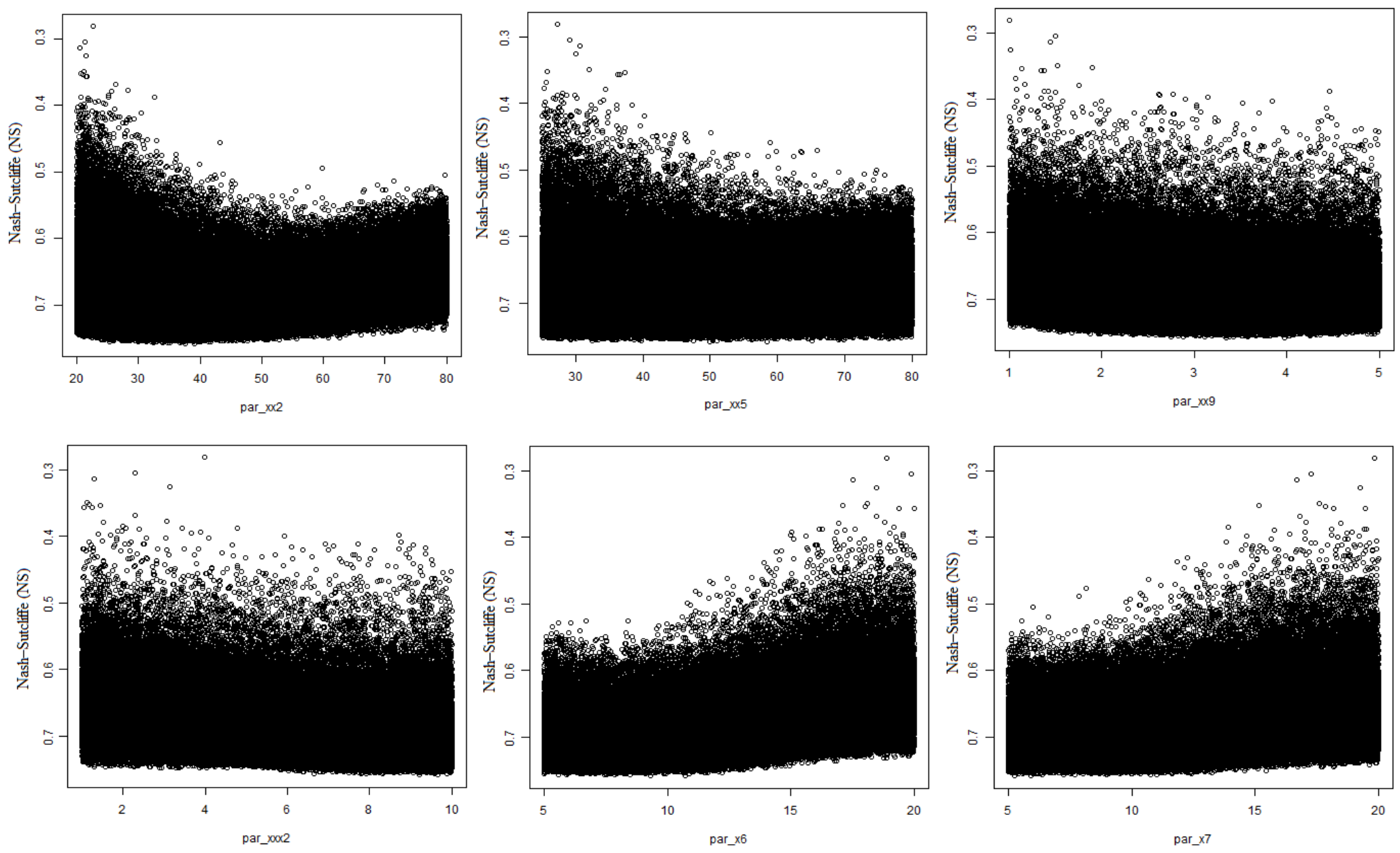

Figure 5.8. The top 6 most sensitive parameters that influence the model NSE (NSE is plotted versus the parameter value). 


\subsubsection{VALIDATION PERIOD FOR GLUE UNCERTAINTY}

The GLUE analysis produced 50, 000 parameter sets that contain an NSE above 0.7. The results for the upper and lower prediction intervals at the $95 \%$ and $5 \%$ bounds are found in Figures 5.9(a)-5.9(e) for the 2011-2014 period. These figures show the observed, simulated and range for the value for the model results from GLUE. The figures show that the overall performance of the model is good with a narrow upper and lower prediction interval for most of the years, with the highest in the melt season, and the lowest in the summer season. The model does not perform very well when there is a large rainfall in the summer season, producing an overestimation of streamflow, and it fails to capture large streamflows in the late fall to early winter season.

The simulation for 2011 (Figure 5(a)) fails to capture the snow melt peak in mid March for the simulated values, and although the uncertainty improves, the peak is still underestimated. The following spring and early summer peaks are captured well within the uncertainty bounds. The late summer and fall are overall modelled well with only one peak that is overestimated. The late fall and beginning winter season are overestimated for peaks. Also, interestingly the simulated data for the peak on April $12^{\text {th }}$ falls out of the prediction interval, meaning that streamflow is much higher than any of the simulations.

Although a few days late, in the simulation of 2012 (Figure 5(b)), the rising limb and falling limb of the snow melt season were modelled very well for the simulated snow melt peak in mid March. The following spring and early summer peaks are modelled closely to the observed values with a small change in the overall difference. However, the summer, fall and beginning winter season all overestimate streamflow with a variety of peaks that are not observed in historical dataset. 
The worst simulation is for the 2013 year (Figure 5(c)), with varying peaks in the winter season that are overestimated and underestimated, the winter snow melt season is also estimated three weeks early compared to the observed results. Spring peaks and early summer peaks are modelled well, however the late summer and all of fall is underestimated, with some of the peaks being completely missed in the simulated data compared to the observed.

The best modelled year is 2014 (Figure 5(d)), when even though the model shows a smaller snow melt peak, the timing of the event is the same, and the observed peak is within the uncertainty bounds for the peak. Additionally, the falling limb of the model is also approximately the same for the change in magnitude and timing for the end of the snow melt peak. The subsequent peaks in late spring and early summer are underestimated but captured by the uncertainty interval. The lows in the summer, fall and winter are represented very well in this modelled year. 


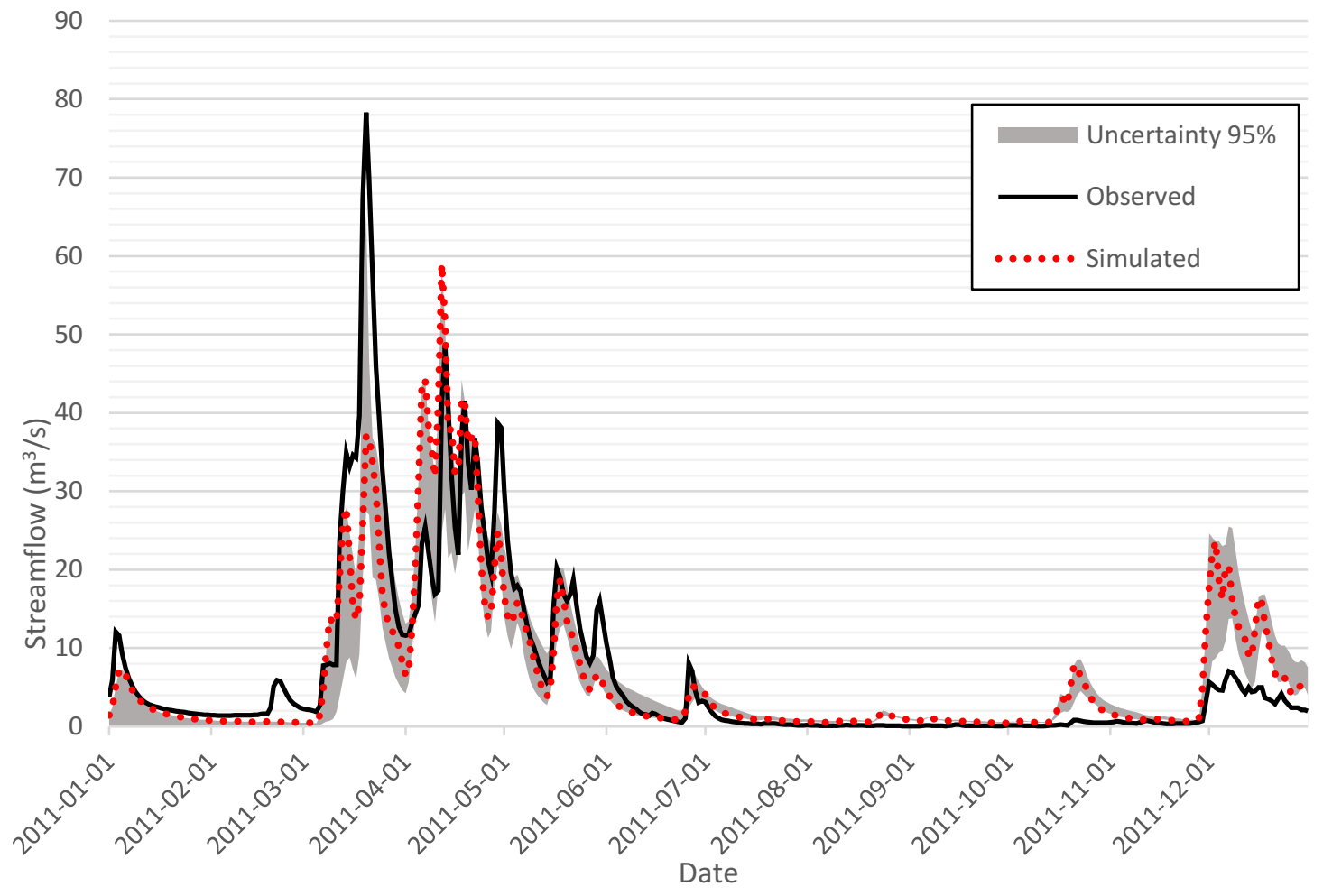

Figure 5.9 (a) Model uncertainty for 2011, showing the $5-95 \%$ prediction intervals.

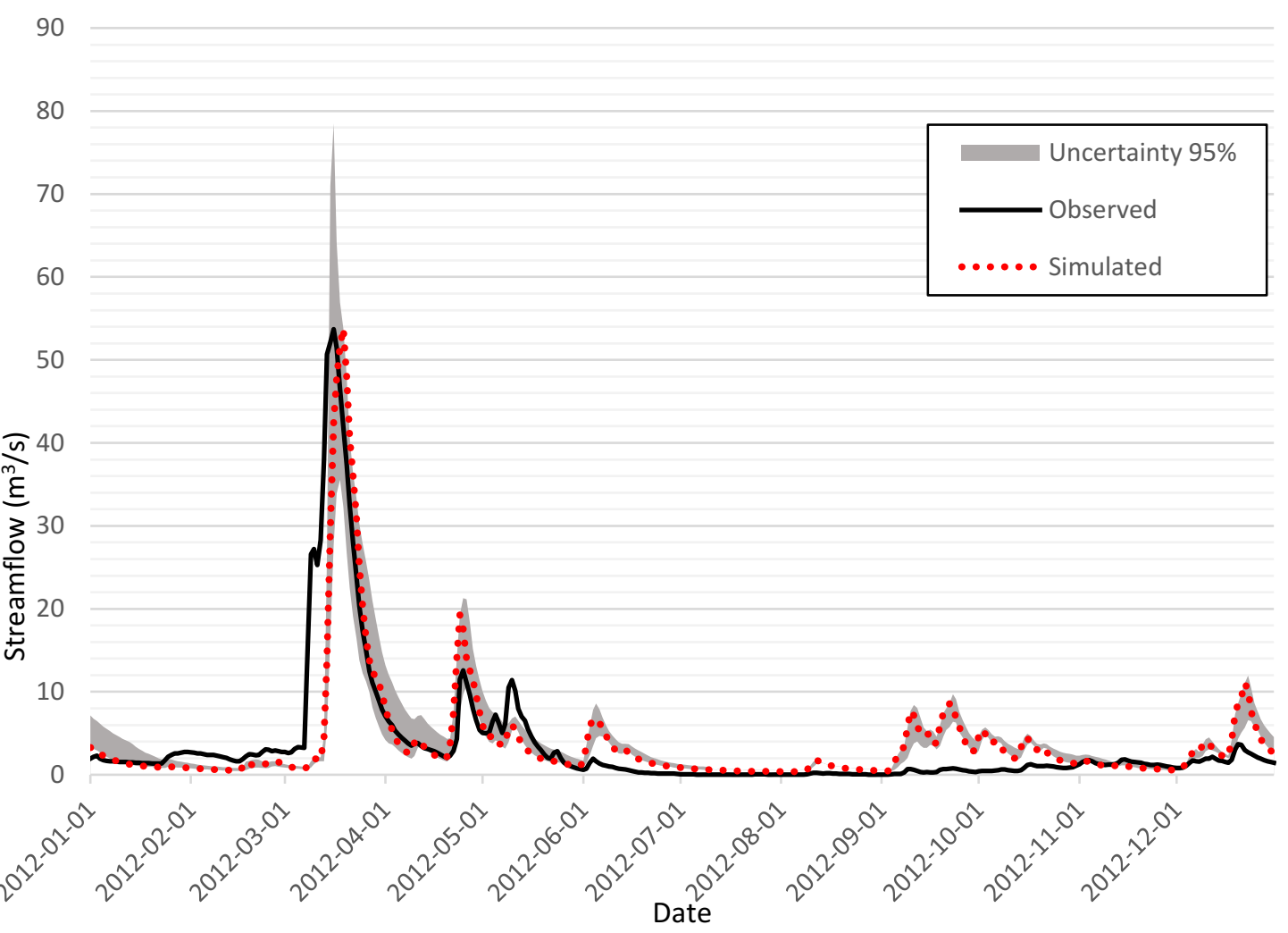

Figure 5.9 (b) Model uncertainty for 2012, showing the $5-95 \%$ prediction intervals. 


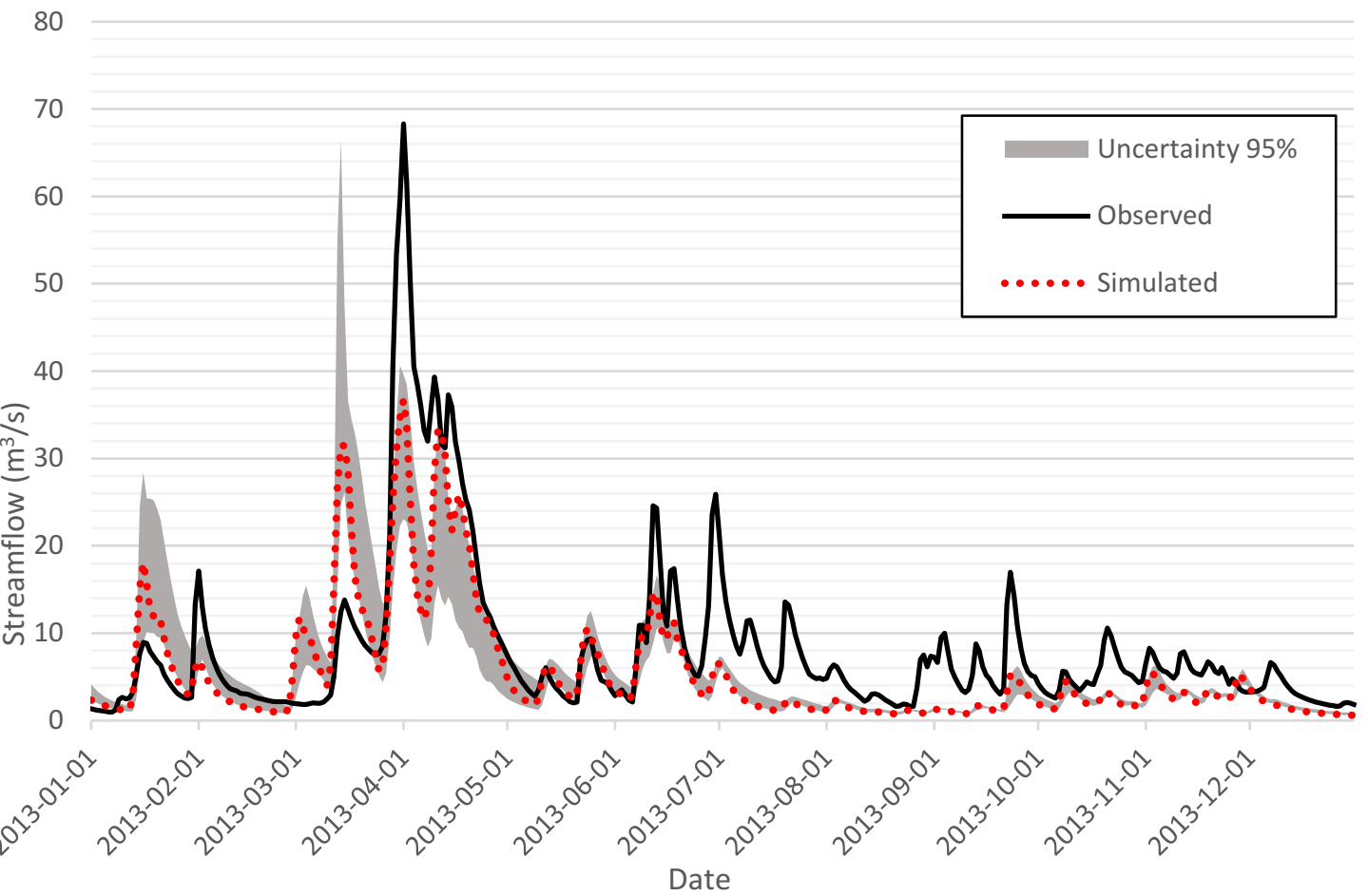

Figure 5.9 (c) Model uncertainty for 2013, showing the $5-95 \%$ prediction intervals.

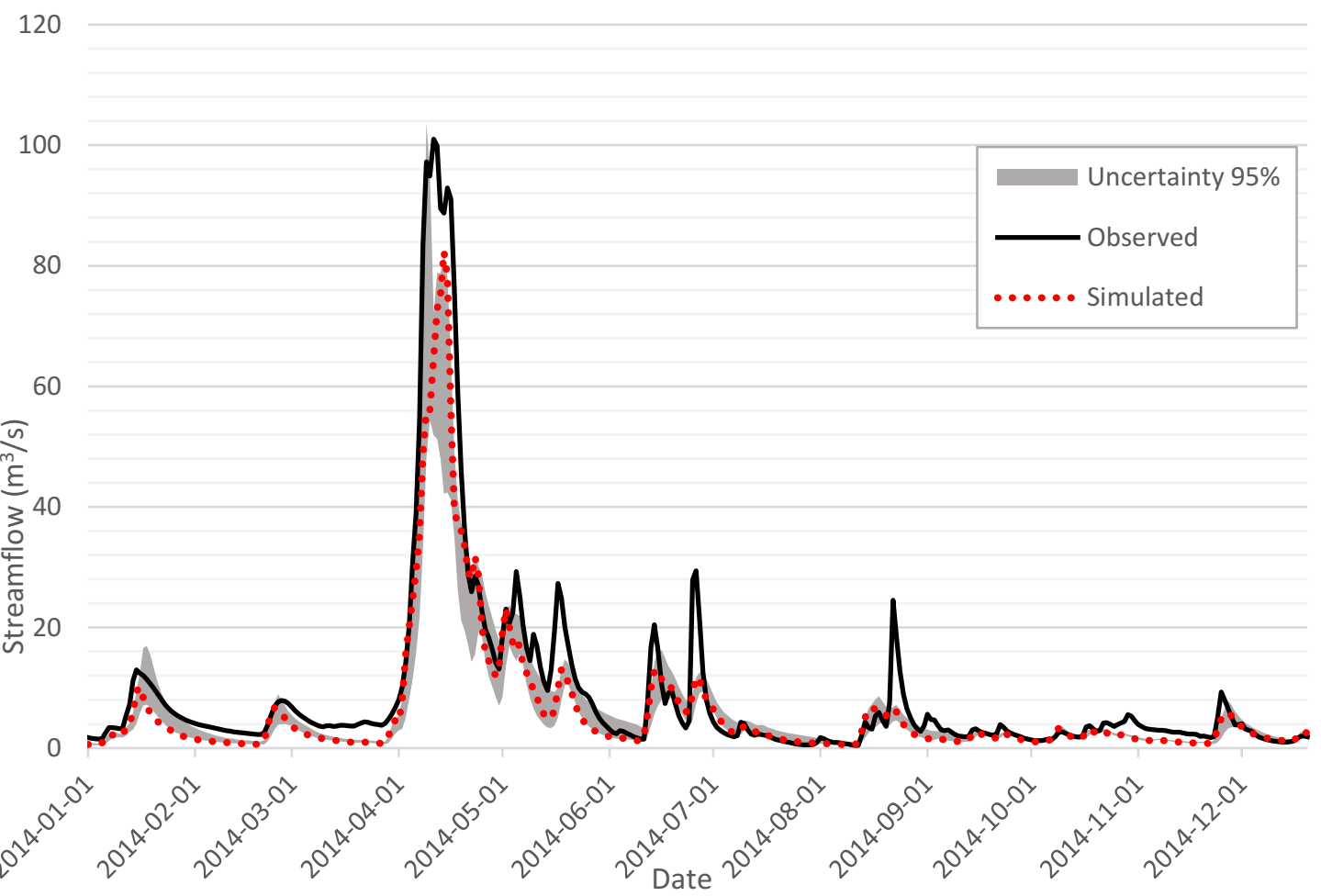

Figure 5.9 (d) Model uncertainty for 2014, showing the $5-95 \%$ prediction intervals. 


\subsection{FLOODING AND DROUGHT EXTREMES}

\subsubsection{ANNUAL GEV}

The overall model results replicate the observed data well, with high agreement for objective functions with only a few discrepancies. The Generalized Extreme Value (GEV) analysis was performed on the annual dataset for observed and simulated data to compare the two in an indirect evaluation of the model's ability to model extremes overall in the watershed. The return periods for a Gumbel distribution are plotted for both observed (Figure $5.10(\mathrm{a})$ ) and simulated (Figure $5.10(\mathrm{~b})$ ), and their return periods for 2, 5, 10, 20, 50, 100, 200, and 500 years are reported in Table 5.3. Mann Kendall analysis indicated significant negative trends for both observed $(\tau=-0.32$, p2-tail $=0.001)$ and simulated $(\tau$ $=-0.195, \mathrm{p} 2$-tail $=0.052)$. The data were plotted again with a nonstationary model and the results are plotted in Figure 5.11 (a) and Figure 5.11 (b) for extreme flows for both observed and simulate values. Additional information on GEV for different distributions and their associated probabilities, quantiles and density trends for both observed and simulated data can be seen in Appendix D (Figure D.1-D.3 and Table D.1). 

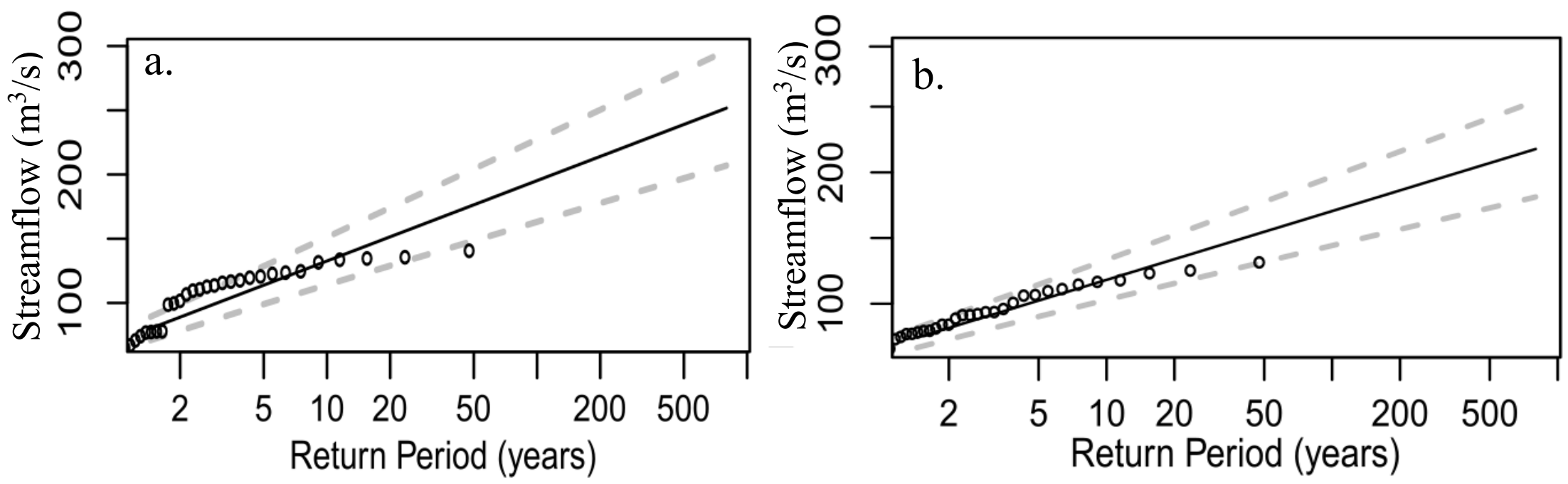

Figure 5.10. Annual observed (a) and simulated (b) return periods for streamflow.
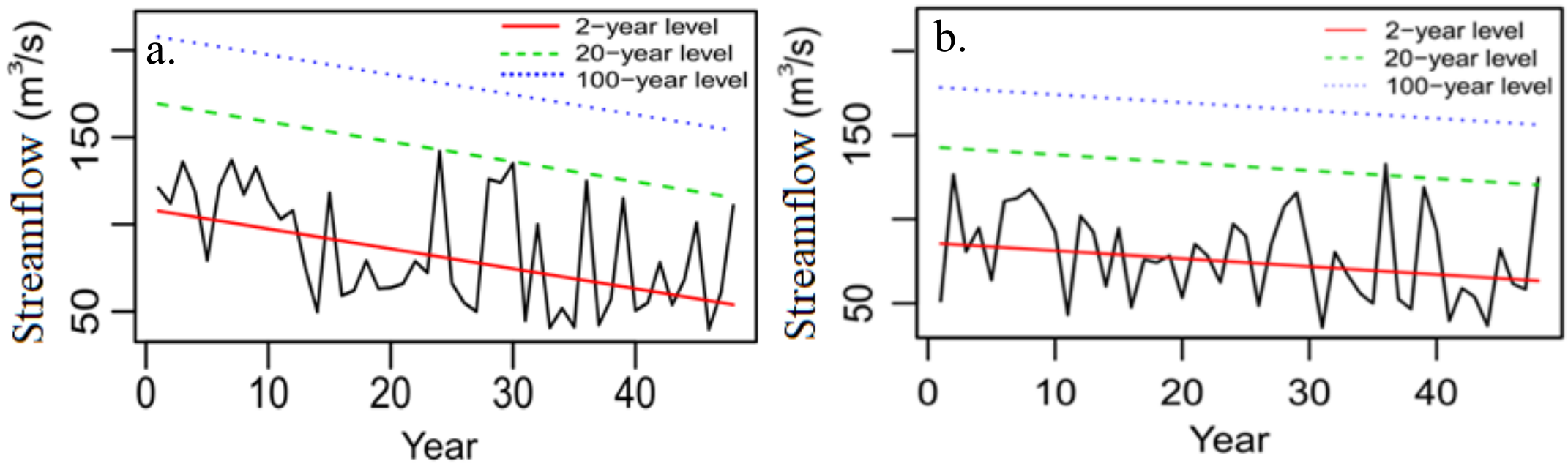

Figure 5.11 Nonstationarity streamflow data, with 2, 20, 100 year return period (a) observed and (b) simulated. 
Table 5.3 Annual statistics of the return periods for the Jock River model for observed and simulated streamflow.

\begin{tabular}{|l|l|l|l|}
\hline Annual & $\begin{array}{l}\text { Observed } \\
\text { Streamflow }\left(\mathrm{m}^{3} / \mathrm{s}\right)\end{array}$ & $\begin{array}{l}\text { Simulated } \\
\text { Streamflow }\left(\mathrm{m}^{3} / \mathrm{s}\right)\end{array}$ & $\begin{array}{l}\text { Difference } \\
\left(\mathrm{m}^{3} / \mathrm{s}\right)\end{array}$ \\
\hline 2-year & 80.1 & 74.2 & 5.9 \\
\hline 5-year & 110.9 & 100 & 10.9 \\
\hline 10-year & 131.3 & 117 & 14.3 \\
\hline 20-year & 150.8 & 133.4 & 17.4 \\
\hline 50-year & 176.1 & 154.5 & 21.6 \\
\hline 100-year & 195.1 & 170.4 & 24.7 \\
\hline 200-year & 214 & 186.2 & 27.8 \\
\hline 500-year & 238.9 & 207.1 & 31.8 \\
\hline
\end{tabular}

\subsubsection{SUMMER AND FALL GEV}

The model simulations for the summer and fall season replicate the observed data well, with some discrepancies, such as overestimated low flows and mixed results for high flows. GEV analysis was performed on the annual dataset for observed and simulated data to compare the two in an indirect evaluation of the model's ability to model extremes in the summer and fall overall in the watershed. The return periods for a L-moment distribution are plotted (Figure 5.12), and return periods for 2, 5, 10, 20, 50, 100, 200, and 500 years are reported in Table 5.4. Mann Kendall analysis indicated positive trends for both observed $(\tau=0.208, \mathrm{p} 2$-tail $=0.038)$ and simulated $(\tau=0.259, \mathrm{p} 2$-tail $=0.001)$. The data were plotted again with a nonstationary model and the results are seen in Figure 5.13 (a) for observed and 5.13 (b) for simulated extreme flows. Additional information on GEV for different distributions and their associated probabilities, quantiles and density trends for both observed and simulated data can be seen in Appendix D (Figure D.4-D.7 and Table D.2). 

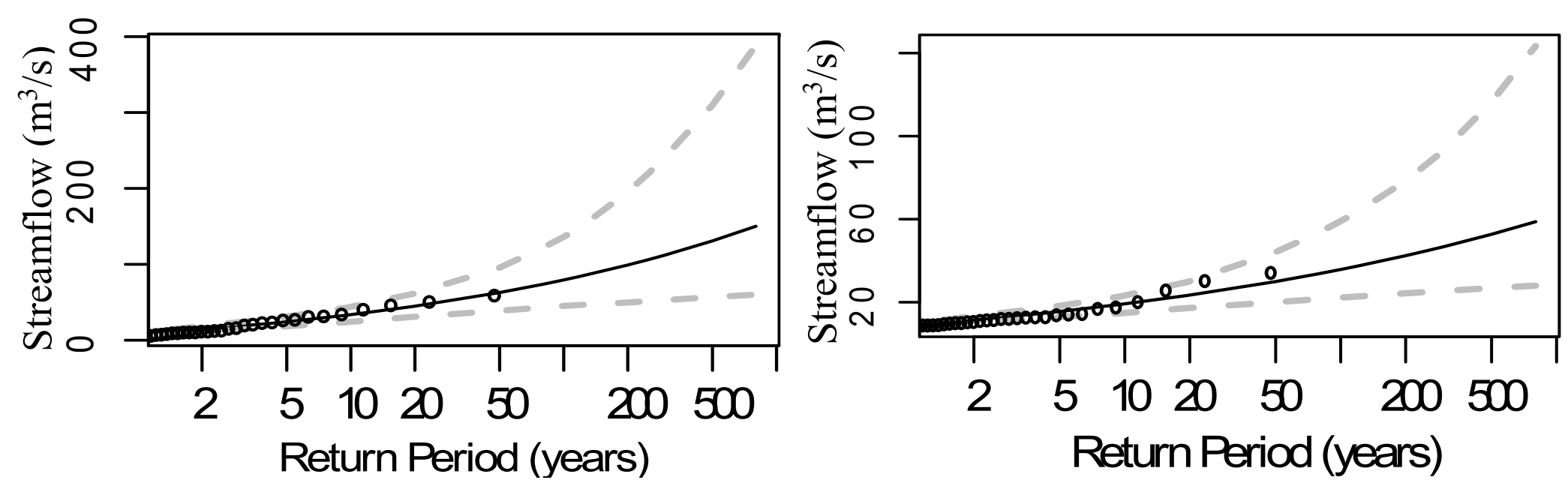

Figure 5.12. Summer and fall return periods with figure (a) for the observed data and figure (b) is return period for simulated data.
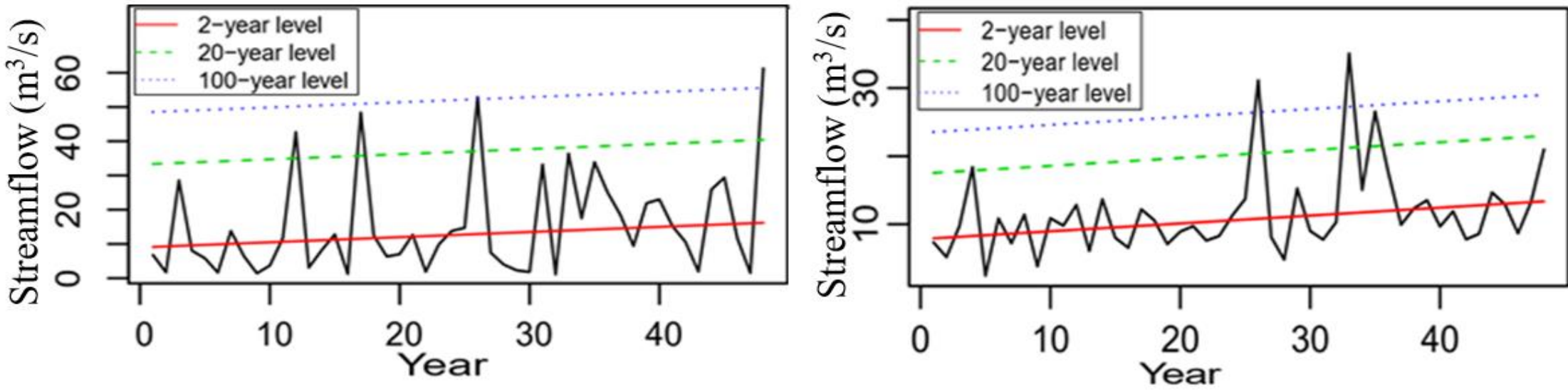

Figure 5.13. Summer and fall adjusted trend data, with 2, 20, 100 year return period, with figure (a) observed and (b) simulated. 
Table 5.4 Summer/Fall statistics of the return periods for the Jock River model for observed and simulated streamflow.

\begin{tabular}{|l|l|l|l|}
\hline Summer/Fall & \multicolumn{1}{|c|}{$\begin{array}{c}\text { Observed } \\
\text { Streamflow }\left(\mathrm{m}^{3} / \mathrm{s}\right)\end{array}$} & $\begin{array}{c}\text { Simulated } \\
\text { Streamflow }\left(\mathrm{m}^{3} / \mathrm{s}\right)\end{array}$ & $\begin{array}{l}\text { Difference } \\
\left(\mathrm{m}^{3} / \mathrm{s}\right)\end{array}$ \\
\hline 2-year & 10.9 & 10.1 & 0.8 \\
\hline 5-year & 22.9 & 15 & 7.9 \\
\hline 10-year & 32.9 & 18.9 & 14 \\
\hline 20-year & 44.4 & 23.3 & 21.1 \\
\hline 50-year & 61.1 & 29.9 & 31.2 \\
\hline 100-year & 79.3 & 35.7 & 43.6 \\
\hline 200-year & 99 & 42.4 & 56.6 \\
\hline 500-year & 130.8 & 52.7 & 78.1 \\
\hline
\end{tabular}

\subsubsection{FLOW DURATION CURVE}

The flow accumulation plot for the 1970-2017 period for observed and simulated streamflow (Figure 5.14) shows that the mid to high flows are modelled very similarly from the $0 \%$ to $55 \%$ exceedance. The low flows at the $55 \%$ exceedance and higher (less than $2 \mathrm{~m}^{3} / \mathrm{s}$ ) are not modelled very well compared to observed flows, as the simulated flows do not capture the very low flows between 0.01 and $2 \mathrm{~m}^{3} / \mathrm{s}$. The flows show that the observed values have a more rapid decrease in streamflow compared to the simulate that is much more gradual. The flow at the $95 \%$ exceedance for observed values is $0.08 \mathrm{~m}^{3} / \mathrm{s}$ while the simulated $95 \%$ exceedance is $0.53 \mathrm{~m}^{3} / \mathrm{s}$. 


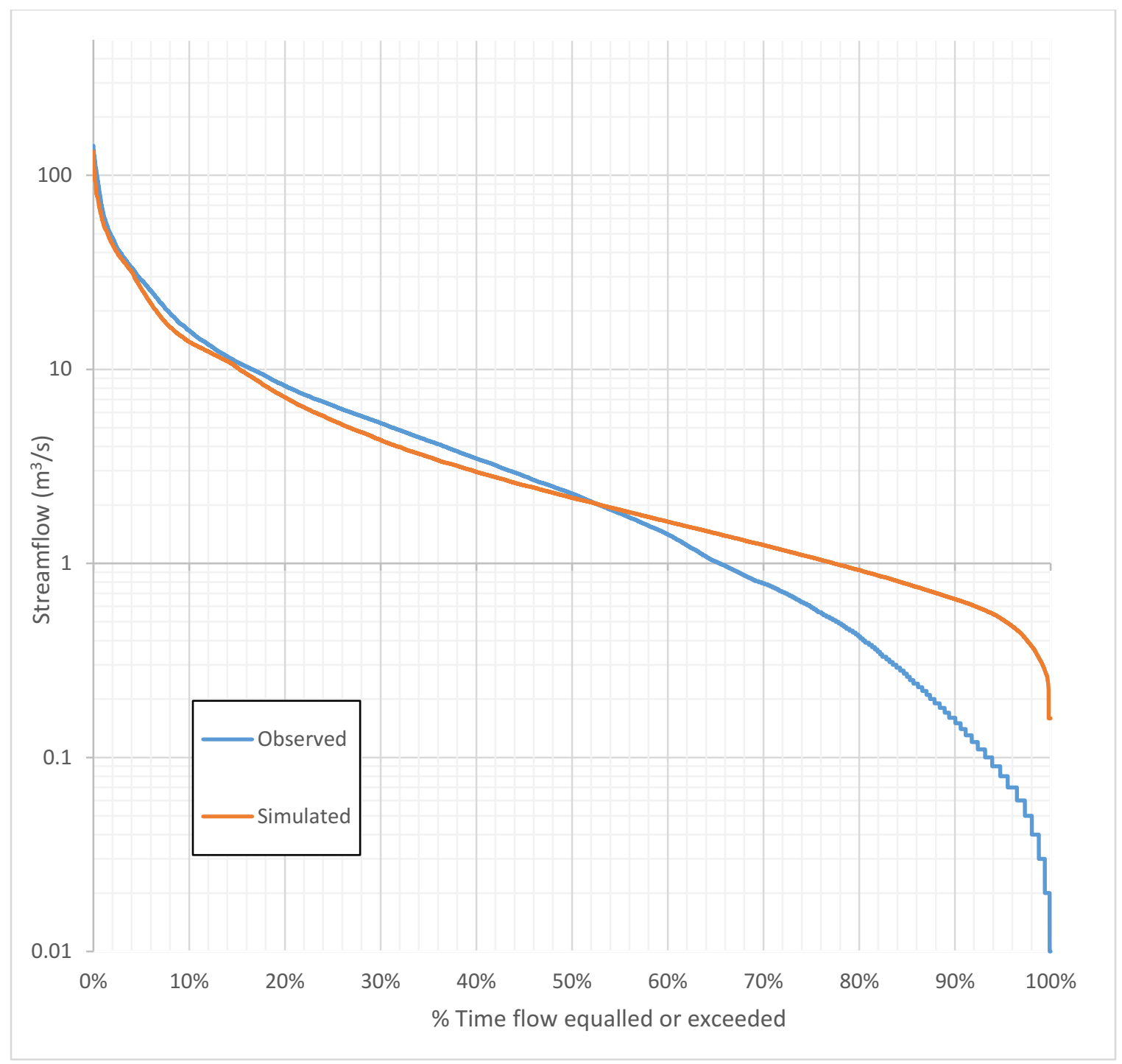

Figure 5.14. Flow duration curve for observed flows, and simulated flows for the 19702017 time-period. 


\subsubsection{STREAMFLOW THRESHOLD LEVEL}

Threshold values for the STL were used from the 95\% FDC, where the values for the observed are $0.08 \mathrm{~m}^{3} / \mathrm{s}$ and $0.53 \mathrm{~m}^{3} / \mathrm{s}$ for the simulated periods. The maximum number of consecutive days for each year during the June $1^{\text {st }}$ to November $30^{\text {th }}$ period, where the streamflow was below the 95\% FDC is plotted in Figure 5.15. The observed streamflow with the largest consecutive drought days (CDD) was in 1985 with 90 days that were below the 95\% FDC (Figure 5.15). The model underestimates CDD in 12 years (i.e. it models higher streamflow than observed values), with some years some having large magnitudes of differences in the amount of days predicted. Additionally, the model simulates a drought on the same year as the observed streamflow for only $65 \%$ of the years, where 9 years have observed CDDs and the model fails to simulate any. However, the model also simulates four years that have very small consecutive drought days that are not present in the historical observations. The data shows that there is a larger amount of consecutive drought years in the first half of the dataset for both simulated and observed values. There are seven

years where CDDs for observed streamflow is above 50 days, only a single year where simulated streamflow is above 50 days, and 17 years where neither an observed or simulated CDD is present. 


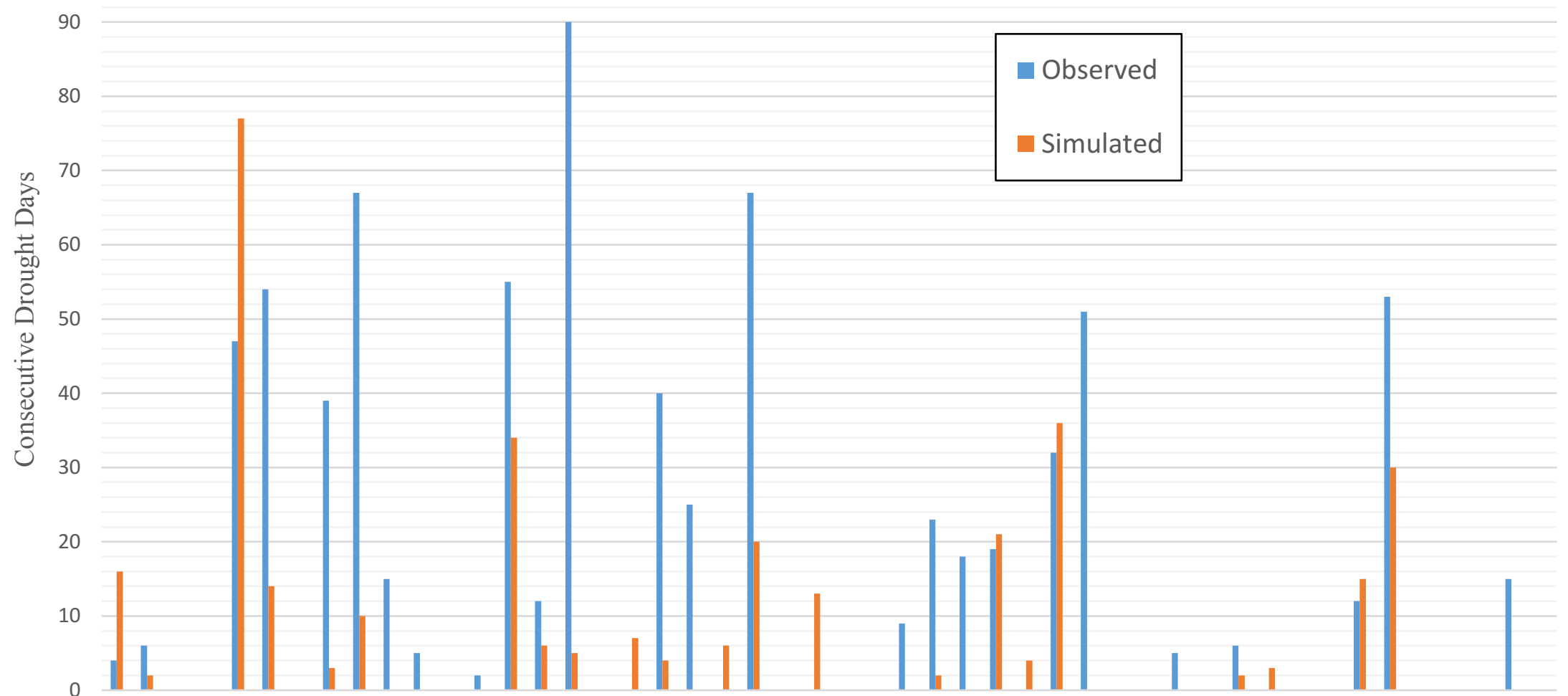

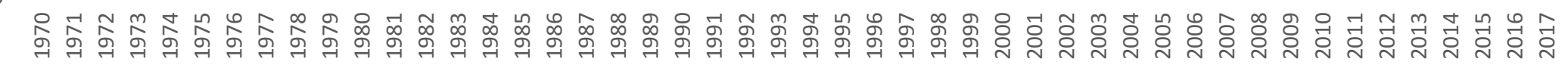
Date

Figure 5.15. STL Consecutive drought days below the 95\% FDC also known as threshold value for the model by year for the 1970 2017, time-period. 


\subsection{IMPACTS TO STREAMFLOW UNDER CLIMATE CHANGE SCENARIOS}

The climate change scenarios are separated into three time-periods, an early (20112040), mid (2041-2070), and late (2071-2099) period. The results are also grouped together in the same fashion with either a mean ensemble plot for the years or each time-period plotted separately against the simulated and the observed values.

\subsubsection{ANNUAL STREAMFLOW CHANGES}

The climate change scenario for streamflow changes for the three periods can be seen in Figure 5.16, representing the ensemble mean of the 12 climate change scenarios for all time periods. The average daily simulated and observed values for the figure show very similar results with observed values having a $\sim 5 \mathrm{~m}^{3} / \mathrm{s}$ higher peak than the simulated for the snow melt peak around April $1^{\text {st }}$. The summer-fall season difference between the simulated and observed have a similar decreasing pattern, however the observed values are smaller, with small peaks, while the simulated is more gradual.

The three-climate change scenario periods differ greatly. The 2011-2040 period has a large decrease in snow melt peak which has shifted 2 weeks earlier. The 2041-2070 period has decreased again in snow melt peak and has shifted another 2 weeks earlier. The 20712099 period has a very gradual snow melt peak and what looks like another 2 weeks earlier for the melt but is difficult to determine as there is no sharp peak increase in streamflow and the streamflow increase starts in November.

The observed streamflow shows that there are some streamflow peaks that do appear at the end of fall and beginning of winter season. These peaks are also present in the simulated data but are largely underestimated. The climate change scenario data shows that there is an increase in streamflow that can be seen in the late fall to early winter season 
where streamflow gradually increases by $2-3 \mathrm{~m}^{3} / \mathrm{s}$ for every time-period with the 2070 2099 period having a high flow of about $10 \mathrm{~m}^{3} / \mathrm{s}$ at the end of the year. However, the presence of peaks for this streamflow are less defined and gradually decrease as the climate change scenarios move from early to late periods.

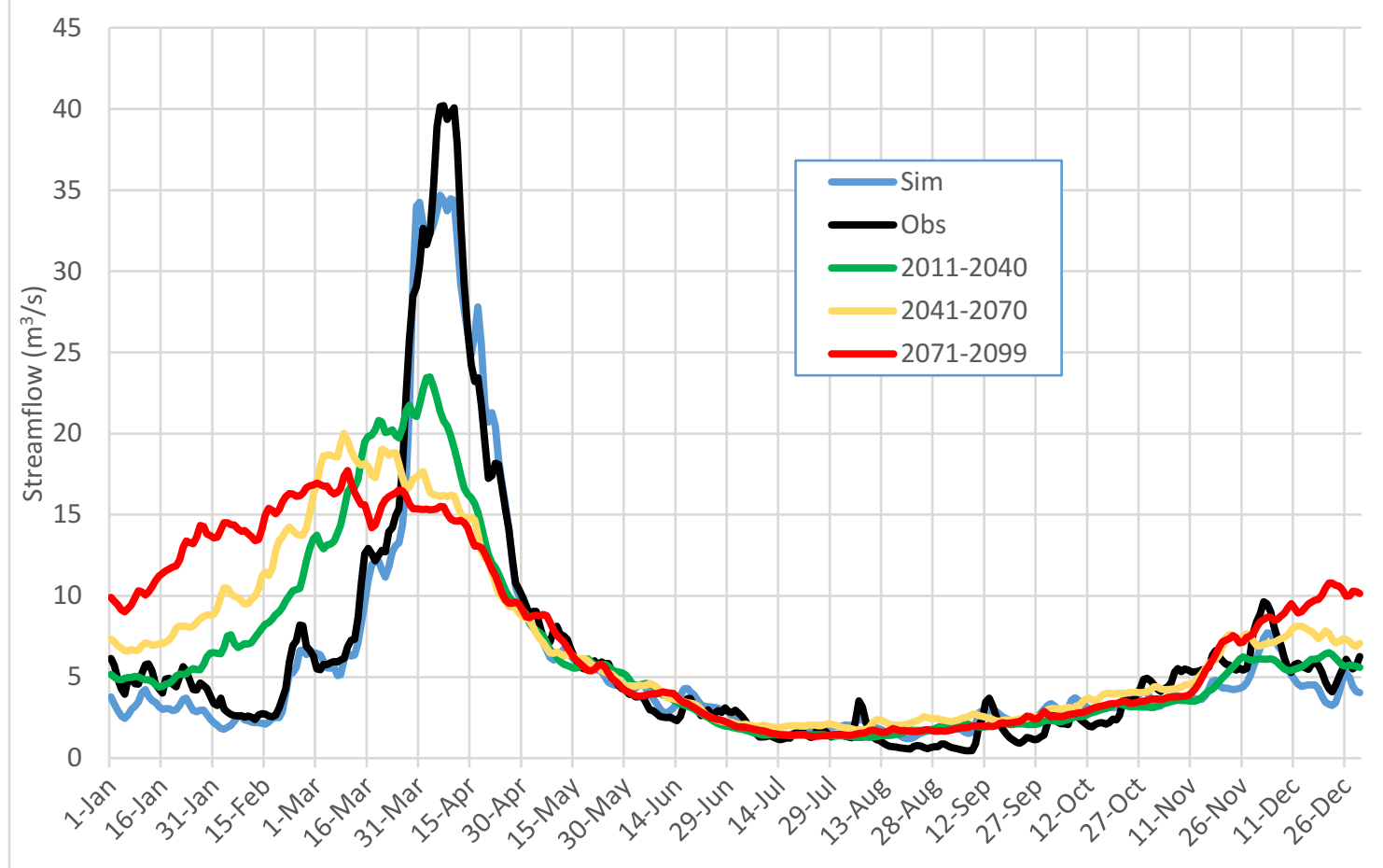

Figure 5.16. The mean daily streamflow for the different time periods for the mean of the ensemble of the climate change scenario models.

The Figures 5.17 to 5.19 are similar to Figure 5.16 (mean daily streamflow), but they show the ensemble of 12 climate change scenario models individually, allowing individual analysis of the models' representations of extremes, where the models converge or diverge, and circumstances where models are large outliers.

The time period of 2011-2040 in Figure 5.17 shows that most of the models lead to simulated snowmelt periods that are about 2 weeks earlier than the observed values, and 
have similar peak discharge as the simulated daily mean streamflow values of approximately $35 \mathrm{~m}^{3} / \mathrm{s}$, accept for the ACCESS and CNRM models that have a similar timing for melt snow peak as the observed values. The two HADGEM2 (CS and ES) climate models do not predict a snowmelt peak and are much more distributed evenly throughout the winter season. Streamflows from all GCM models converge towards the beginning of June and have similar shape and flow as the observed low summer-fall streamflow season, until the end of fall and beginning of winter where the models being to spread apart and have a large variation in flow with the two HADGEM2 models having the largest difference in streamflow overall.

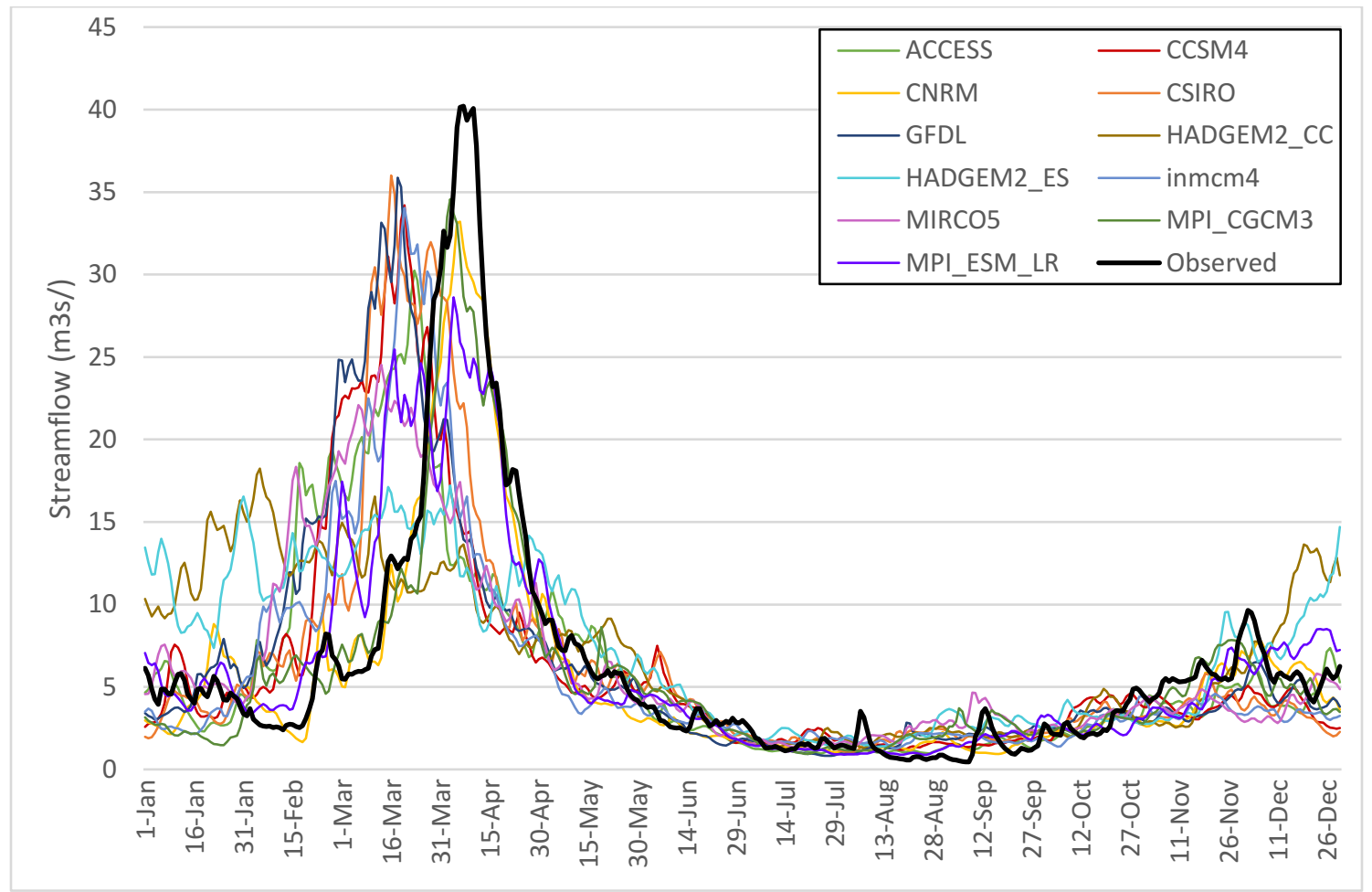

Figure 5.17. The mean daily streamflow for 2011-2040 period with the 12 climate change scenario models.

The time period of 2041-2070 in Figure 5.18 shows that most of the models have snow melt season 4-6 weeks earlier (Feb $15^{\text {th }}$-March $1^{\text {st }}$ ) than the observed values. The discharge values for most have decreased to about $25 \mathrm{~m}^{3} / \mathrm{s}$, with the CSIRO and GFDL model being 
the highest still at $35 \mathrm{~m}^{3} / \mathrm{s}$. The two HADGEM2 (CS and ES) climate models both do not have clear defined snow peak melt seasons and the summer low streamflow is much more varied with many smaller peaks and much higher flow than other models and observed values. The other 10 models still converge in the summer streamflow, but not until the end of June and then begin spreading much earlier at the beginning of August. There is a much larger presence of streamflow peaks in the fall season, some that more closely resemble the observed streamflow compared to the 2011-2040 period.

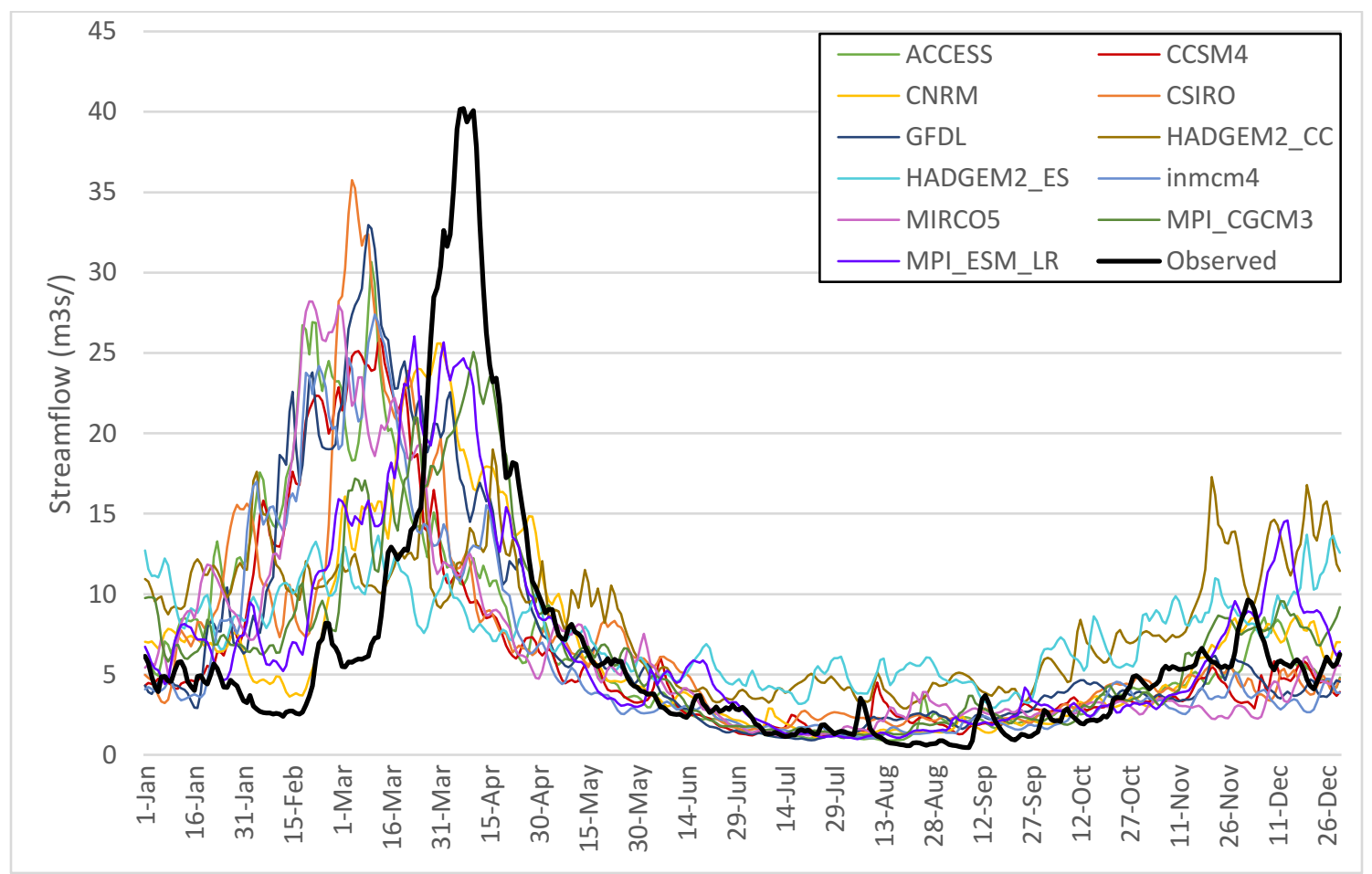

Figure 5.18. The mean daily streamflow for 2041-2070 period with the 12 climate change scenario models.

The time-period of 2071-2079 in Figure 5.19 has no evident snow melt peak season, with model varying from Jan $31^{\text {st }}$ - April $1^{\text {st }}$ or 0-8 weeks earlier (Feb $15^{\text {th }}$ - March $1^{\text {st }}$ ) than the observed values. Furthermore, the snowmelt streamflow peaks are less than the previous observed for climate change periods and have an increase in smaller individual peaks than 
one large peak during the melt season. Multiple models are showing a larger streamflow in the late spring and early summer period compared to the observed values. The streamflows once again converge in the summer around the beginning of July, and agree fairly well with each other until the beginning of November, where they being to spread again with a variety of different streamflow peaks. Most of the models also result in larger streamflows in the winter season compared to the observed values.

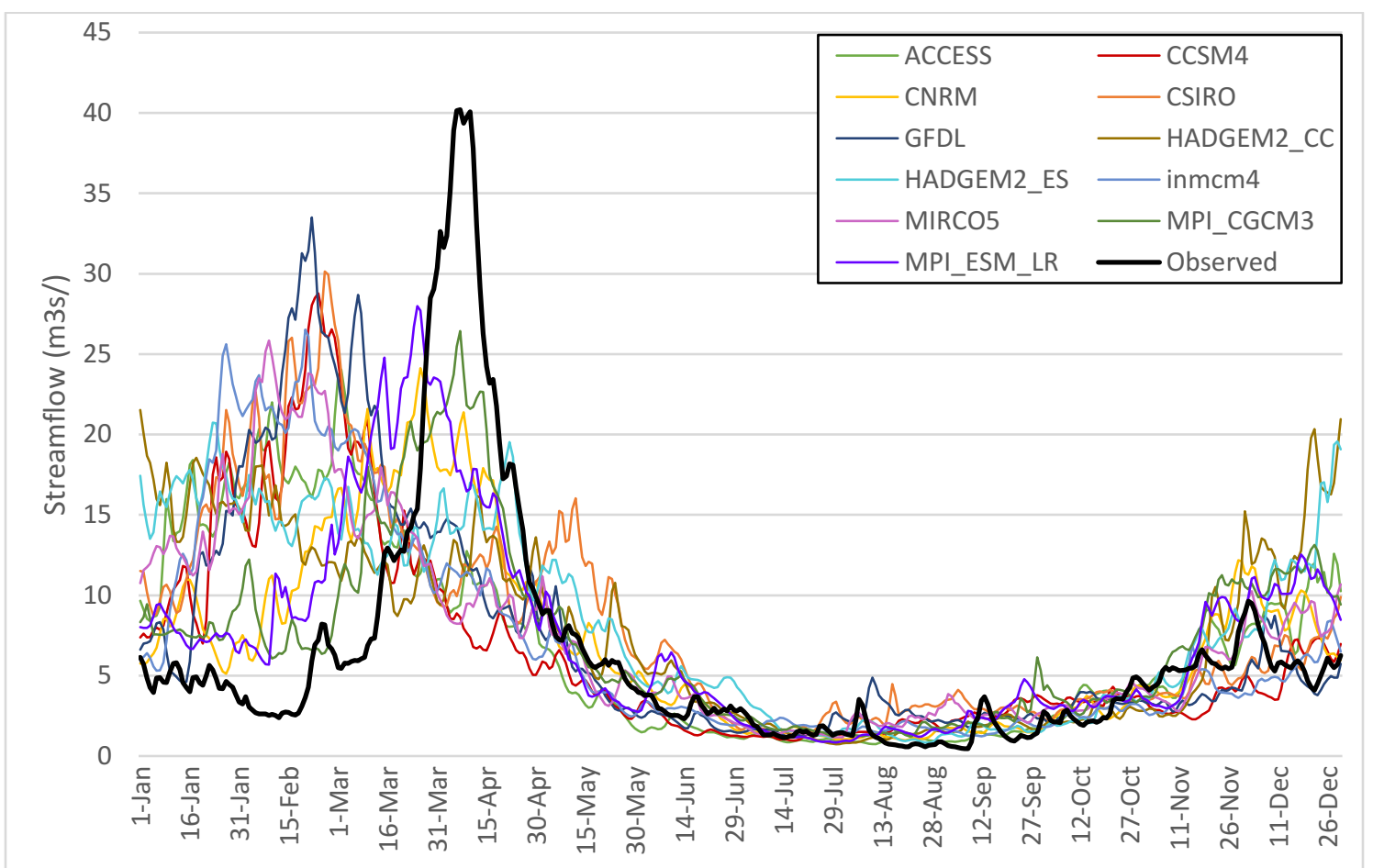

Figure 5.19. The mean daily streamflow for 2070-2099 period with the 12 climate change scenario models.

In all three figures for Figure 5.17 to 5.19, the ACCESS and CSIRO models have the highest mean daily streamflow snow melt peaks, and have low summer and fall streamflow with a few peaks. These two models resemble the simulated data most closely for streamflow distribution. The two HADGEM2 models vary the most from all other models and do not resemble the distribution for the simulated values. 
The historical dataset and climate change scenario mean streamflow are plotted in Figure 5.20, along with their trend lines. The historical data has a large variance in mean streamflow with 2012 at $3.5\left(\mathrm{~m}^{3} / \mathrm{s}\right)$ and the highest at $13.9\left(\mathrm{~m}^{3} / \mathrm{s}\right)$ in 2017 , both of which are the extremes in the entire dataset even against the climate change scenario data. It has a trendline of increasing at approximately $0.008 \mathrm{~m}^{3} / \mathrm{s}$ every year.

The ensemble of models for the climate change scenarios show that the average mean annual streamflow falls within the same range for the current increase in streamflow, however they are increasing at a rate of $0.018 \mathrm{~m}^{3} / \mathrm{s}$ per year (more than double the historical rate). The range of streamflow for the ensemble of models is approximately $4 \mathrm{~m}^{3} / \mathrm{s}$ for the early climate change period and then gradually increases to a value of $6 \mathrm{~m}^{3} / \mathrm{s}$ towards the end of the century.

The two highest mean streamflow years come from the ACCESS model, in 2053 and 2085, where its mean streamflow is larger than $13 \mathrm{~m}^{3} / \mathrm{s}$, and are much higher than the other models in the ensemble. There are a several models that have low mean streamflows, but the CCSM4 and CNRM have the most reoccurring small mean streamflows with the smallest being $3.6 \mathrm{~m}^{3} / \mathrm{s}$, and $3.7 \mathrm{~m}^{3} / \mathrm{s}$, respectively. There is additional FDC for all three time-periods in Appendix E (Figures E.1- E.3). 


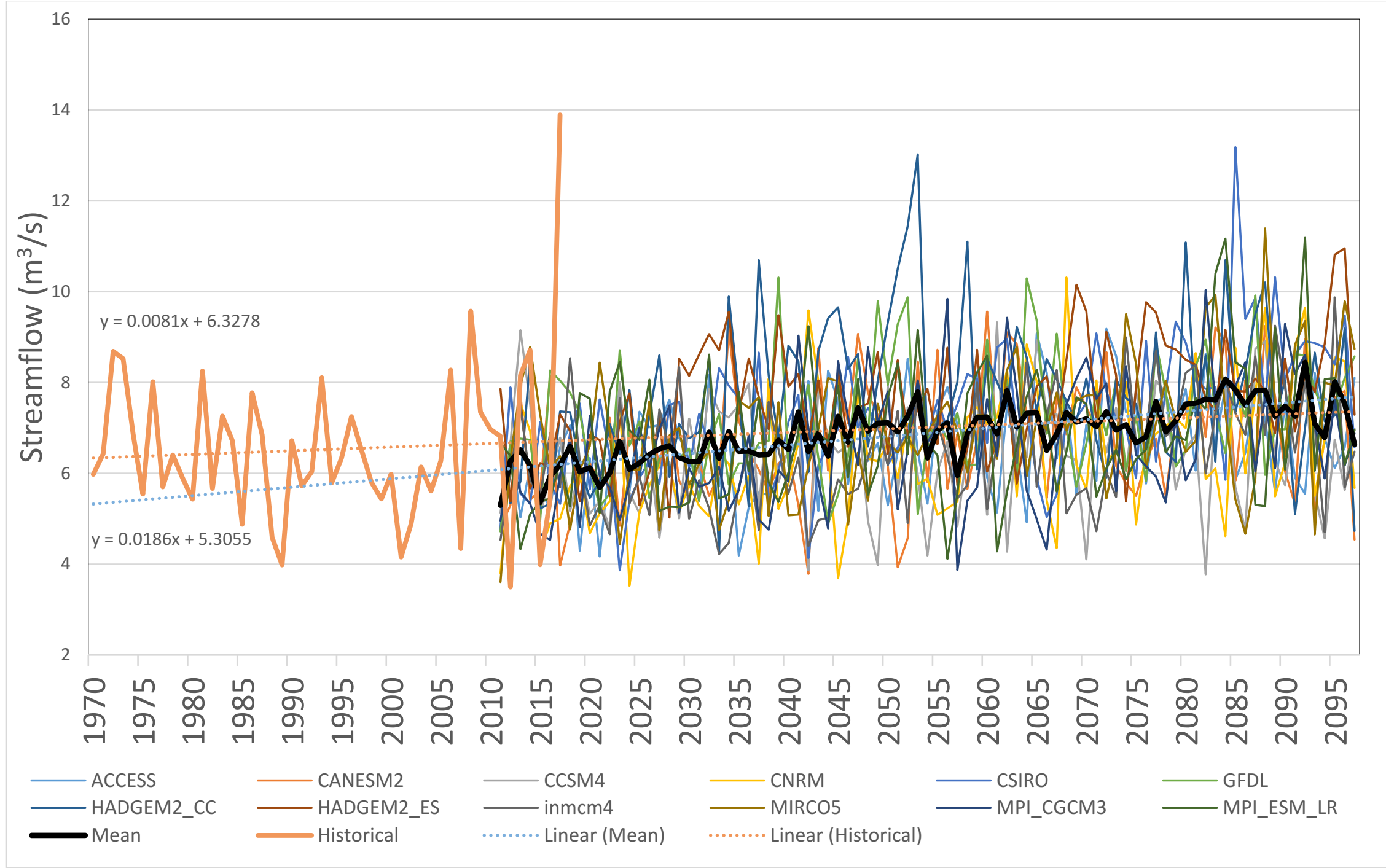

Figure 5.20 Mean Annual Streamflow for climate change scenarios and historical observed values with their trendlines. 


\subsubsection{FLOODING EXTREMES USING GEV ANALYSIS}

GEV analysis was performed on each climate change model for each time-period, on an annual basis, and the ensemble mean results are presented in Table 5.5. The GEV for the annual basis used the same method described in Section 5.4.1 on the observed and simulated values with a Gumbel distribution and most likely simulate the snow melt peak. Table 5.5 is split into four parts, the first is the historical and simulated GEV values with their return periods, the other three are the three future time periods (2011-2040), (20412070), and (2071-2099) with the 12 climate models and as well as the ensemble mean of models.

The GEV analysis shows that the annual snow melt peak discharge is slowly decreasing at the 100 year return period for the mean ensemble. Where the historical simulated streamflow at $170.5 \mathrm{~m}^{3} / \mathrm{s}$ is decreasing in the early (2011-2040) period to 154.0 $\mathrm{m}^{3} / \mathrm{s}$, then increases slightly in (2041-2070) to $159.2 \mathrm{~m}^{3} / \mathrm{s}$ and then finally to a low of 148.2 $\mathrm{m}^{3} / \mathrm{s}$ or a decrease by $22.3 \mathrm{~m}^{3} / \mathrm{s}$ compared to the historical simulated.

The individual models in the period of 2011-2040 mostly agree on an overall decrease in streamflow compared to the simulated period with smallest being the CANESM2 at $127.8 \mathrm{~m}^{3} / \mathrm{s}\left(-42.6 \mathrm{~m}^{3} / \mathrm{s}\right.$ over simulated), except for the GFDL model that has the largest increase at $182.7 \mathrm{~m}^{3} / \mathrm{s}\left(+14.6 \mathrm{~m}^{3} / \mathrm{s}\right.$ over simulated) for the 100 -year return period.

The individual models in the period of 2041-2070 vary greatly with 8 models that have decreased streamflow and 4 that have increased. The model with the largest decrease is the HADGEM2_ES at $125.5 \mathrm{~m}^{3} / \mathrm{s}\left(-44.9 \mathrm{~m}^{3} / \mathrm{s}\right.$ over simulated), and the model with the 
largest increase is the CANESM2 model that has an increase to $201 \mathrm{~m}^{3} / \mathrm{s}\left(+30.6 \mathrm{~m}^{3} / \mathrm{s}\right.$ over simulated) for the 100-year return period.

The individual models in the period of 2071-2099 mostly agree on a decrease in streamflow compared to the simulated period with smallest being the inmcm4 model at $123.1 \mathrm{~m}^{3} / \mathrm{s}\left(-47.3 \mathrm{~m}^{3} / \mathrm{s}\right.$ over simulated), except for the CSIRO model that has an increase to $197.3 \mathrm{~m}^{3} / \mathrm{s}$, or $+10.7 \mathrm{~m}^{3} / \mathrm{s}$ over simulated for the 100 -year return period.

Table 5.5 GEV climate change scenario distribution annually for Gumbel distribution. For Individual model results please see Appendix E, Table E.1.

\begin{tabular}{|l|l|l|l|l|l|l|l|l|l|}
\hline Time period & Model & \multicolumn{9}{|c|}{ Return Periods } \\
\hline & & 2 & 5 & 10 & 20 & 50 & 100 & 200 & 500 \\
\hline $\mathbf{1 9 7 0 - 2 0 1 7}$ & $\begin{array}{l}\text { Observed - } \\
\text { Gumbel }\end{array}$ & 80.1 & 110.9 & 131.3 & 150.8 & 176.1 & 195.1 & 214.0 & 238.9 \\
& $\begin{array}{l}\text { Simulated - } \\
\text { Gumbel }\end{array}$ & 74.2 & 100.0 & 117.0 & 133.4 & 154.5 & 170.4 & 186.2 & 207.1 \\
\hline $\mathbf{2 0 1 1 - 2 0 4 0}$ & Ensemble Mean & 66.2 & 89.7 & 105.2 & 120.2 & 139.5 & 154.0 & 168.4 & 187.5 \\
\hline $\mathbf{2 0 4 1 - 2 0 7 0}$ & Ensemble Mean & 66.5 & 91.3 & 107.7 & 123.5 & 143.9 & 159.2 & 174.5 & 194.6 \\
\hline $\mathbf{2 0 7 1 - 2 0 9 7}$ & Ensemble Mean & 63.5 & 86.2 & 101.2 & 115.6 & 134.3 & 148.2 & 162.2 & 180.5 \\
\hline
\end{tabular}

A GEV analysis was also performed on the summer-fall season of the climate change scenario data and the ensemble mean results are presented in Table 5.6, in the same format as Table 5.5. The GEV for the summer-fall season used the same method that was done for Section 5.4.2 on the observed and simulated values with a L-moment distribution to avoid the snow melt peak.

The GEV analysis for the summer-fall season have very large differences compared to the simulated. The summer-fall peaks show an increase in the 100 year return period for the mean ensemble, where the simulated is $35.7 \mathrm{~m}^{3} / \mathrm{s}$ and is increasing in the early (2011-2040) period to $45.5 \mathrm{~m}^{3} / \mathrm{s}$, then increases in (2041-2070) to a high of $65.8 \mathrm{~m}^{3} / \mathrm{s}$ and then finally to $47.9 \mathrm{~m}^{3} / \mathrm{s}$. 
The individual models in the period of 2011-2040 have a large variance, with a mix of models that increase, decrease or have a mixture of increased and decreased streamflow depending on the model. The largest decrease is the CNRM model at $18.9 \mathrm{~m}^{3} / \mathrm{s}\left(-16.8 \mathrm{~m}^{3} / \mathrm{s}\right.$ over simulated), and the CCSM4 model increases by more than double the original flow at $78.5 \mathrm{~m}^{3} / \mathrm{s}\left(+42.8 \mathrm{~m}^{3} / \mathrm{s}\right.$ over simulated) for the 100 -year return period.

The 2041-2070 period also has varying streamflow in the individual models, with a mixture of increases and decreases in the return periods. However most of the models that do increase have predictions far above the rest, with the highest being the HADGEM_ES model at $128.4 \mathrm{~m}^{3} / \mathrm{s}\left(+92.7 \mathrm{~m}^{3} / \mathrm{s}\right.$ over simulated), while the largest decrease is the ACCESS model at $29.5 \mathrm{~m}^{3} / \mathrm{s}\left(-6.2 \mathrm{~m}^{3} / \mathrm{s}\right.$ over simulated), for the 100 -year return period.

The individual models in the period of 2071-2099 mostly agree on an increase in streamflow compared to the simulated period with smallest being the inmom 4 model at $21.3 \mathrm{~m}^{3} / \mathrm{s}\left(-19.2 \mathrm{~m}^{3} / \mathrm{s}\right.$ over simulated), the largest increase is the MPI_CGCM3 model at $85.9 \mathrm{~m}^{3} / \mathrm{s}\left(+50.2 \mathrm{~m}^{3} / \mathrm{s}\right.$ over simulated), and the CSIRO model also has a similar increase at $85.7 \mathrm{~m}^{3} / \mathrm{s}\left(+50.0 \mathrm{~m}^{3} / \mathrm{s}\right.$ over simulated) for the 100 year return period.

Table 5.6 GEV climate change scenario L-moment distribution for summer and fall. For individual model results please see Appendix E, Table E.2.

\begin{tabular}{|l|l|l|l|l|l|l|l|l|l|}
\hline Time period & Model & \multicolumn{9}{|c|}{ Return Periods } \\
\hline & & 2 & 5 & 10 & 20 & 50 & 100 & 200 & 500 \\
\hline $\mathbf{1 9 7 0 - 2 0 1 7}$ & $\begin{array}{l}\text { Observed - } \\
\text { L-moment }\end{array}$ & 10.9 & 22.9 & 32.9 & 44.4 & 61.1 & 79.3 & 99.0 & 130.8 \\
\cline { 2 - 11 } & $\begin{array}{l}\text { Simulated - } \\
\text { L-moment }\end{array}$ & 10.1 & 15.0 & 18.9 & 23.3 & 29.9 & 35.7 & 42.4 & 52.7 \\
\hline $\mathbf{2 0 1 1 - 2 0 4 0}$ & Ensemble Mean & 10.5 & 16.9 & 22.1 & 27.9 & 37.1 & 45.5 & 55.6 & 72.1 \\
\hline $\mathbf{2 0 4 1 - 2 0 7 0}$ & Ensemble Mean & 13.3 & 21.8 & 29.0 & 37.6 & 51.9 & 65.8 & 83.5 & 114.9 \\
\hline $\mathbf{2 0 7 1 - 2 0 9 7}$ & Ensemble Mean & 11.1 & 17.6 & 22.8 & 28.9 & 38.7 & 47.9 & 59.5 & 79.4 \\
\hline
\end{tabular}




\subsubsection{DROUGHT EXTREMES USING STL ANALYSIS}

The STL drought index was performed for all 12 climate change scenario models. The drought analysis is grouped into the three time-periods and the ensemble mean is plotted in Figures 5.21. Individual model results are available in Appendix E (Figures E.4E.6). The early time-period of 2011-2040 exhibits mild droughts for most models, with a short mean drought value for 14.6 days for all models across all years. The ACCESS model produces the two longest drought values with one at 101 days and the second at 86 days; this value is more than twice the maximum drought values that were simulated with historical data. ACCESS is also the model with the largest average drought days at 23.4 days per year, with the lowest being MPI_CGCM3 at 9.2 days.

The time-period 2041-2070 had even fewer droughts for most models, with a low mean drought value of 13.7 days for all models across all years. The climate model CANESM2 had CDDs of 99 days and also had the largest average drought days at 19.8 days per year, with the lowest being the HADGEM_CC at 7.7 days.

The late period 2071-2097 had the most drought according to most models, with a high mean drought value of 20.5 days for all models across all years, almost a $300 \%$ change compared to the historical simulated data of 6.9 days. The climate model HADGEM2_CC has the largest drought, at 84 days, however the CANESM2 model has larger average drought days at 36.7 days, compared to 35.8 days for HADGEM2_CC model. The lowest drought prediction was from MPI_CGCM3, at an average of 9 drought days. The years 2098 and 2099 are missing from the analysis due to technical errors in missing climate model data for some time periods. 


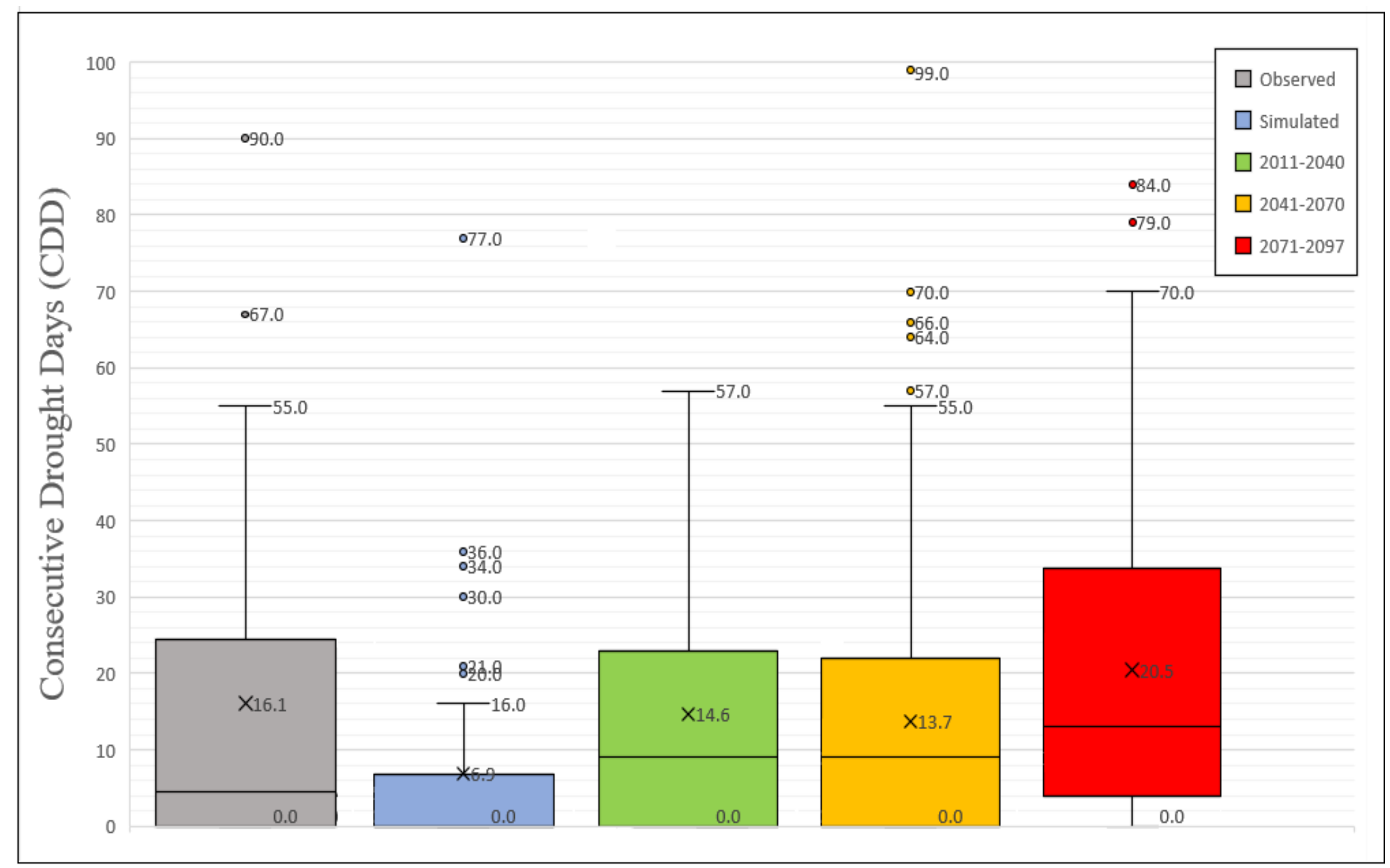

Figure 5.21. STL analysis representing the CDDs for historical and simulated and the ensemble mean of the three future scenarios. 


\section{CHAPTER 6: DISCUSSION}

Hydrological extremes can have detrimental effects on agriculture, ecosystems and infrastructure. The Jock River watershed is characterized by such extremes with high streamflows in the spring and very low streamflows in the summer, which makes it an ideal research site to model extremes under climate change scenarios. The discussion is divided into five sections. The first section addresses the creation of the Jock River Watershed Model (JRWM) and its parameters. The second section discusses the Jock River watershed's trends and performance of the JRWM. The third section discusses the model's parameter sensitivity and uncertainty. The fourth section describes the hydrological extremes of the Jock River watershed. The fifth section describes the future climate change scenarios and the changes in the streamflow for the Jock River watershed. Finally, the last section has some recommendations for future work.

\subsection{PERFORMANCE OF MODELS IN THE JOCK RIVER WATERSHED}

\subsubsection{MODEL TESTING AND PERFORMANCE}

The JRWM was chosen as the best model to study extremes after unsatisfactory results from both a lumped HBV-light model as implemented by Seibert (2005) and a Raven semi-distributed HBV model were tested. These results are not included in the thesis, but a similar study found that the HBV model produced low NSE values for their study area (Rusli and Liu, 2015), and while the semi-distributed HBV model did improve the NSE, extreme streamflows for the snow melt and summer periods were not represented well. Improvement in model performance from changing a lumped model to a semidistributed model has been demonstrated by Pechlivandis et al. (2010), however as Rusli 
and Liu, (2015) have shown even in a semi-distributed fashion, the HBV model can have low performance depending on the watersheds.

After developing familiarity with Raven, several models were tested and the GR4J model performance was the highest for the Jock River watershed compared to the other models. The GR4J model has also been found to be a favourable model by Perrin et al. (2003) and by Tian et al. (2003), where the GR4J model performed better than the HBV model for their watershed. The GR4J also meets the data requirements for the available data in the watershed and has been successful in applications with climate change studies (Tian et al., 2013; Guo et al., 2017). However, using the modular capabilities of the Raven modelling framework, the GR4J model was modified by changing two of its parameters with different methods to form the JRWM.

\subsubsection{JOCK RIVER WATERSHED MODEL PARAMETERS}

Using the Raven modelling framework, the JRWM was created by altering the GR4J model's treatment of snow melt and percolation methods to improve simulations of hydrological extremes. These methods are normally covered by simple parameterization in GR4J (described in section 4.2.3), however to improve model results for the higher snowmelt peaks, and the low summer streamflows, the methods were replaced with a degree day (snow melt) and constant percolation (percolation). A similar modification by Sha et al. (2014) was used on a different model to improve low flows by changing their groundwater algorithms. This is one of Raven's greatest strengths, as it can replace any hydrological processes or algorithm in the model with a method that may be more suitable to the watershed's characteristics. 
The improved model performance from changing the model to a degree day method for snow melt is from constraining the snow melt process with a land use parameter. The snow accumulation/melt has been found to be sensitive to the type of land use in Ontario (Oni et al., 2014). The improved low streamflow results from using a constant percolation method is difficult to interpret, however the assumption is that soil moves water from the top soil surface to the shallow groundwater at a constant rate, and that is represented in the model structure (see flowchart Figure 4.1 for visualization). A constant percolation rate has been successfully applied in other models (Abebe et al., 2010; Samuel et al., 2011). The JRWM could be improved further by applying a better suited hydrological model (inside the Raven framework or a different application), however, it does produce satisfactory results for the analysis of extremes.

\subsection{JOCK RIVER STREAMFLOW TRENDS AND JRWM PERFORMANCE}

The Jock River is experiencing changes in streamflow extremes, snow melt timing and watershed characteristics. The JRWM does simulate the historical streamflow well and even simulates similar trends that are seen in the observed data. These trends vary from decreasing snow melt streamflow peaks and drought events, to increased summer-fall season peaks increased and mean annual streamflow (MAS). Some of these trends are possibly related to agricultural and urbanization activities as there are more streamflow peaks in the first 25 years of the data from 1970-1995 compared to the 1996-2017 timeperiod. This type of pattern has been specified in other studies to be caused by the increase in agricultural area and urbanization, as well as climate change (Schilling and Helmers, 2008; Tan and Gan, 2015; Cunderlik and Ouarda, 2009). However most of these increased peaks are during the spring and summer, which Schilling and Helmers (2008) directly 
relates to increase in tile drainage in agricultural areas and more precipitation events in this season for Canada. The watershed is experiencing a decrease in the magnitude of the streamflow peaks, which can be seen in the first 25 years with mostly large spring melt peak streamflows, whereas the last 25 years have seen a reduction in streamflow peaks, especially since 2009. The decrease in snow melt peaks are most likely a result of less available snow for melt, which Mekis and Vincent (2011) have indicated is occurring for mid and southern Canada. Decreasing melt streamflow peaks have also been observed by Adamowski et al. (2013). They studied the Rideau River from 1969 to 1992 and found both decreasing streamflow magnitudes and a shift in snow melt by $\sim 10$ days earlier. Cunderlik and Ouarda (2009) found earlier snow melt peaks across southern Canada. There is also a decrease in magnitude and number of consecutive drought days (Figure 5.15) in the last 25 years for the summer-fall season, which is most likely due to the increase in precipitation during these seasons. The trend of fewer consecutive drought days leads to an increase in soil moisture, which is occurring in southern British Columbia (Gobena and Gan, 2013).

The comparison of the historical data to the JRWM simulation shows that the snow melt seasons are represented well, especially at the beginning of the snow melt, when there is a sharp increase in the rising limb of the hydrograph, and the model captures the rapid increase in streamflow. This type of performance is common for watershed studies that have snow melt processes, as using objective functions such as NSE during calibration can emphasis the large snow melt peaks which NSE is known to be sensitive to these high streamflow values (Moiasi et al., 2007). However, the peaks are slightly underestimated in the cases of very large peaks, and this is most likely because the model underestimates the 
amount of available snow on the landscape for melt, which is consistent with the SWAT model that also struggles with high streamflow peaks from snowmelt (Yu et al., 2013).

Low flows are overestimated in the JRWM, where the FDC clearly shows that the extremely low flows are not represented. Oyerinde and Diekkrüger (2017) had similar results using the GR4J model. A large amount of evidence that suggests evapotranspiration has a large influence on streamflows, especially on low streamflows in the summer-fall season (Krishnaswamy et al., 2013; Dvořáková et al., 2014), and it is likely that underestimated evapotranspiration is causing overestimated streamflows. The model also creates minor streamflow peaks during the summer-fall season when a mid precipitation event occurs and this is most likely due to antecedent soil moisture and surface storage not being represented well, which Shook et al. (2013) has demonstrated to have large influence on streamflow response.

Streamflow timing issues are common in hydrological studies and have been observed by Winstral and Marks (2016) to be different between wet and dry seasons, caused by processes of percolation through the snowpack, and flow at the base of the snowpack to streams. Timing issues are evident in the model, where most peaks are underestimated by $40 \%$, with the largest being the 1982 peak where the model does capture the streamflow melt peak, however a week late, causing an $80 \%$ error in streamflow. The winter season has the largest underestimated streamflow for the year, which could be caused by the model having little to no defined hydrological processes for the winter season; processes such as sublimation, winter melt and percolation at the snowpack

The objective functions for the validation periods for the JRWM (Table 5.3) meet the criteria of a NSE $>0.50, \mathrm{RSR}<0.70$, and PCT BIAS $+/-25 \%$ for streamflow, presented 
by Moriasi et al., (2007) as guidelines to consider a watershed model as satisfactory. The highest NSE value is for the 1970-1979 time-period, which is higher than the calibration period or decades within the calibration (Table 5.3). This high NSE value can be attributed to the very low streamflows and few peaks in the summer/fall periods, which accounts for less error during the summer period. Although this period has a high NSE and a high $\mathrm{R}^{2}$ value, it also contains the highest ABSMAX error at $91.86 \mathrm{~m}^{3} / \mathrm{s}$, where the observation is being underestimated in the model on the snow melt peak for the 1970-04-15 date. This could be caused by the model not having adequate time to spin-up to achieve initial conditions for the watershed, which has been demonstrated by Goodrich et al. (1994) and Seck et al. (2015) to be critical in rainfall-runoff models. Moriasi et al. (2007) also indicate that a model's sensitivity and uncertainty should also be assessed to determined its performance.

\subsection{MODEL SENSITIVITY AND UNCERTAINTY ANALYSIS}

The structure of the JRWM and input of physical data (meteorological, LULC, soil and vegetation) have the largest influence on the model's sensitivity and uncertainty. The low parameter sensitivity has been attributed to model structure (Oyerinde and Diekkrüger, 2017) and to large input of geographical and spatial data (Petrucci and Bonhomme, 2014). Most of the free parameters that required calibration have a low sensitivity as there is a large range of values in these parameters that produce a reasonable NSE and only 6 parameters are considered to be somewhat sensitive.

These six sensitive parameters are directly related to soil and LULC properties, which have also been found by Wei et al. (2018) and Petrucci and Bonhomme (2014) to be the most sensitive parameters in their models. Of the six parameters, four are soil 
parameters par_12/par_15 related to GR4J_X3, and par_19/par_22 related to percolation constant. The parameters par_12 an par_19 have the most unique sensitivity as they are only found in a single HRU (the flowing creek subwatershed) in the model, while par_15/par_22 are in multiple HRUs. This illustrates that a HRU can have a large influence on the timing of streamflow. Wei et al. (2018) has shown similar findings where the soil properties of their subwatersheds had a larger influence on streamflow timing than subwatershed size or distance to the stream gauge. The remaining two sensitive parameters are the LULC parameters par_6/par_7 related to GR4J_X4 that show the importance of the LULC on timing of streamflow, that Petrucci and Bonhomme, (2014) indicate that land use has a large influence on streamflow. As sensitive as these parameters are, they do have a large range of acceptable values for a NSE and cause difficulties in the GLUE uncertainty analysis.

When trying to establish a GLUE threshold for the uncertainty analysis, as Beven (2006) has demonstrated, there was no clear-cut boundary for defining a threshold value for the GLUE behavioural and non-behavioural sets in the large range of parameters. A NSE of 0.6 could have been used as an acceptable threshold value, as the top six sensitive parameters fall within this range. However, parameter sets of this value were evaluated and they produce unsatisfactory results for extremes, therefore a NSE value of 0.7 was used as the threshold. The large range of parameter sets also demonstrates that the JRWM suffers from equifinality, which is described by Beven (2006) when different parameter sets produce similar acceptable values of an objective function. To better understand the extent of equifinality in the JRWM, prediction intervals for the 2011-2014 time period model were calculated. Only 4 years were calculated as the calculations were computationally 
intensive as the 50,000 GLUE parameter sets with a threshold of 0.7 or greater had to be evaluated on a daily time step. Calculating prediction intervals from GLUE has been known to have long computational times with large parameter sets (Jin et al., 2010).

Most of the equifinality is related to the snow melt peak seasons as they have the largest prediction bands and the largest streamflow peaks, which NSE has been described as being sensitive to. This is not uncommon for hydrological models as they often have large prediction bands certainties around the melt season (Beven and Binely, 1992; Jin et al., 2010), and this is most likely due to the additional parameters for snow melt in models, as well as the sensitivity of snow melt to temperature and precipitation inputs.

Other than the snow melt peak, most of the observed data are within a narrow prediction band, with the exceptions of the specific over- and under-estimations discussed above. These areas require improvement and can be caused by the model not being calibrated to those types of conditions, or to error sources identified by Wang et al, (2006) as being due to model structure, or errors in input data used for the model. It is possible that the hydrological process is being modelled properly, but with a timing error. For example, the 2013 melt season peak in Figure 5.5 is underestimated, however the same magnitude of peak is captured within the prediction interval two weeks earlier, which indicates that the model is simulating an earlier melt season for this peak.

Due to the nature of the modelling of hydrological systems it is important to acknowledge that there are other uncertainties that arise with the model and that they are not only limited to model simulations and GCMs uncertainties. These uncertainties can be grouped into uncertainties due to data inputs, model framework and implementation, and other unknown errors. Data uncertainties include topographical information, soil type, 
vegetation, temperature, LULC, precipitation, streamflow, radiation, evapotranspiration, and LAI (Beven, 2012). The model framework includes watershed delineation, model structure, parameters, coefficients, algorithms, and hydrological processes. The uncertainties mentioned above can propagate into the model and therefore the uncertainty of the model can be much larger than what is shown in the model uncertainty estimation (Beven, 2012).

There is room for improvement in the JRWM either in model structure, data input or using an optimization tool instead of the best GLUE parameter set during calibration, which is possible due to the Raven flexibility and modular capabilities (Craig et al., 2017). However, following Moiasi et al. (2007) guidelines the JRWM is suitable to be used in hydrological extremes analysis as well as to be used for climate change studies.

\subsection{HYDROLOGICAL EXTREMES}

\subsubsection{FLOODS}

GEV analysis of the Jock River watershed shows that the watershed is experiencing nonstationarity changes in streamflow with decreased peaks in the snow melt season and increased flow in the summer-fall season. Adamowski et al. (2013) found similar nonstationary changes in the streamflow during the snow peak season in the Rideau River watershed, to which the Jock River watershed is a tributary. Some of these decreases could be attributed to the very small barriers and dams that the RVCA placed around the watershed in the 1960s. However, these are very small and do not have large effects on the extremes. The methods of GEV that were used to estimate the extreme changes do have some discrepancies between the observed and simulated extremes. 
The GEV analysis shows that the extremes for the snow melt are overestimated and are caused by the logarithmic distribution of the observed data, while the GEV Gumbel distribution produces a linear distribution for return periods. This type of difference is not uncommon as Liu et al., (2015) had similar results, where their observed values also followed a logarithmic pattern. However, the simulated results (Figure 5.10b) do follow the Gumbel distribution well, very much like Liu et al. (2015), where model simulations also had a more linear shape matching the Gumbel distribution. The nonstationarity GEV method shows that the JRWM can simulate streamflow under nonstationary conditions, which has been demonstrated by Condon et al. (2015) to be useful for climate change studies.

The L-moment distributions for the summer-fall season GEV analysis were used as the Gumbel distribution provided unsatisfactory results. This is most likely due to the Lmoment being less sensitive to the extreme streamflow outliers (in this case the year 2017 is a large outlier), which has been shown to be an advantage of the L-moment distribution (Yilmax and Perera, 2014). Using the L-moment distribution results, the 2017 summer streamflow of $61.3 \mathrm{~m}^{3} / \mathrm{s}$ would classify as a 50 -year extreme. There is a large difference between the observed and simulated return periods, caused by the model underestimating some of the larger peaks, which causes a lower streamflow for return periods. However, the L-moment distributions for observed and simulated streamflows have similar shapes for values and error, meaning that the simulated streamflow is represented well for the summer-fall season, but at an underestimated value.

The nonstationary model for the summer-fall season has similar problems of underestimated streamflow as the stationary model. Although underestimated, it does 
represent the trends that exist within the data, as the pattern and slope for the trend are very similar between the observed and simulated. This similar pattern and distributions means that the model is a good representation of the streamflow in the summer season, even if it produces underestimated peaks for high stream flows and some artificial peaks.

\subsubsection{DROUGHTS}

The JRWM does not simulate droughts very well, in that the model often overestimates the low flows, and the STL shows that the magnitude of CDD events are underestimated. Improvements were applied in the analysis by using a threshold level at the $95^{\text {th }}$ percentile for simulated flow $\left(0.53 \mathrm{~m}^{3} / \mathrm{s}\right)$ instead of the $0.08 \mathrm{~m}^{3} / \mathrm{s}$ threshold level that was used in the observed analysis. Using $0.08 \mathrm{~m}^{3} / \mathrm{s}$ values for the simulated threshold would have been a good comparison for model accuracy, however, it is evident that there would not have been a single drought day in the simulated results, as the simulated data never reaches below 0.1 $\mathrm{m}^{3} / \mathrm{s}$. Even when using this threshold value, the STL results (Figure 5.15) show that the magnitude of CDD events are largely underestimated compared to the observed. These results could be improved with a GEV analysis on the magnitude of CDD events to provide information on the return periods of these events and a nonstationary GEV could be used for the trends of decrease, as it has been shown that the streamflow in the watershed is nonstationary. However, since the model does simulate a drought (although usually underestimated) when there is a large drought event, the occurrence of the larger events is being captured and can still be useful for the analysis of climate change scenario projections. 


\subsection{PROJECTED STREAMFLOW IN CLIMATE CHANGE SCENARIOS}

The projected streamflows for the Jock River watershed under future climate change scenarios are demonstrating similar changes in streamflow that have been discussed in the historical dataset (1970 to 2017) and presented by Adamoski et al. (2013) for the Rideau River and region. The following discussion describes the continuing changes as well as some new changes that the watershed will experience, under the influence of climate change. It should be noted that due to the simulated and climate change scenario results being modelled by the JRWM, they are used as a comparison in the discussion to provide a more appropriate assessment of changes in the future findings.

\subsubsection{CHANGES IN SNOW MELT STREAMFLOW PEAKS}

The mean ensemble annual hydrograph (Figure 5.16), for the three future scenarios (2011-2040, 2041-2070, 2071-2099) are indicating a decrease in streamflow magnitudes and shifting to earlier melt seasons. This pattern has already been recognized in the historical dataset and by Adamowski et al. (2013), with the Rideau River having decreased streamflow magnitudes and a shift in snow melt by $\sim 10$ days earlier. This is a common theme in climate change studies for streamflow, where the timing and magnitudes of snow melt peaks are shifting (Arora and Boer, 2001; Leung and Wigmosta, 1999; Crossman et al., 2013). The precipitation and temperature are the key climate factors driving these changes. Comparing the historical dataset to the mean ensemble of the late climate change scenario (2071-2099), the watershed will have shifted by about 7 weeks earlier and have approximately $50 \%$ of the streamflow magnitude. The shift in the streamflow magnitude can also be linked to the increase in 
multiple rain on snow events throughout the season which leads to less snowpack at the end of the winter season.

The warmer temperatures causing the earlier snow melt season will be beneficial to agricultural practices which coincides with Pearson et al., (2008) findings that the growing season for eastern Canada is expected to increase by 5-7 weeks by the end of 2099. Additionally, the earlier spring melt means that ground frost will be reduced, increasing groundwater recharge by allowing more water to infiltrate into the ground (Eckhardt and Ulbrich, 2003).

The individual model results (Figures 5.17 - 5.19) show that climate model results for the annual hydrographs are similar in the early future (2011-2040) and begin to diverge in the later scenarios, with most of the changes occurring in the timing of the snow melt peaks. Similar divergence has been indicated by Eisner et al., (2017), and identified as being caused by the climate model structure, processes and input data deriving from different forcing functions. However, the GEV analysis (Table 5.5) demonstrates that the results do not diverge very much between climate change scenarios, but rather between models, however all models do exhibit a decreasing trend in streamflow peaks in the future climate scenarios.

These decreases strengthen the concerns raised about streamflow changes in Canada from declining snowpacks and earlier thaws in the season (Kienzle et al., 2012; Tan and Gan 2015). However, decreasing streamflow peaks will lessen the impacts raised by Lemmen et al. (2008) on structures such as water treatment plants, delivery systems, canals, and locks due to risks of ice jams and flooding in the spring. 


\subsubsection{CHANGES IN SUMMER AND FALL STREAMFLOW PEAKS}

The continuing increase in large summer-fall season streamflow peaks that is projected in the future climate change scenarios will pose large concerns to the agricultural community. The changes in mean ensemble annual streamflow hydrograph (Figure 5.16) for the summer-fall season are less predominant than the melt season since the values of streamflow are much lower but are increasing overall with most of the changes occurring in the late fall season.

The climate change projections from Cheng et al. (2012) for the Rideau River watershed show that short duration rainfall events are increasing by $30 \%$ from $2001-2050$ and 40\% from 2050-2099. Deng et al. (2016) found similar increases, with increases in very heavy precipitation days for the area. These results match closely to the summer-fall season flow results, where the GEV analysis of streamflows during these seasons reveal that the distribution of extremes is increasing by about $40 \%$. The increase in streamflow extremes could also be larger than indicated, as the model underestimates peaks for these seasons, meaning that the increase in streamflow could be even larger.

These increases in streamflow are directly linked to the increased number of short duration rainfall events, which will have detrimental effects to agriculture. The increase in intensity of these short duration rainfall events, means an increase in the erosive power of the rainfall, which causes soil erosion and washouts in agricultural fields (Nearing, 2001). The increase in precipitation also means larger flooding events during the summer and fall, which can be seen in the 2017 streamflow data (Figure 5.1), where AAFC reported record highs for flooding during the growing season, affecting about 10 to 15 percent of fields that were flooded during seeding for eastern Ontario (AAFC, 2018). 


\subsubsection{CHANGES IN MEAN ANNUAL STREAMFLOW}

The mean annual streamflow is increasing in the watershed, which matches Tan and Gan (2015) findings from the Rideau River and neighboring watersheds that have shown an increased in MAS in the last 50 years, which they claim is due to climate change and human activities. The streamflow increase for the historic dataset is similar to the mean ensemble of the future climate scenarios, only differing by about $\sim 0.01 \mathrm{~m}^{3} / \mathrm{s}$ per year. However, as indicated in the discussion, the year 2017 is an outlier for streamflow and is the wettest year on record for the Jock River watershed. Furthermore, its mean streamflow is much larger $\left(\sim 1 \mathrm{~m}^{3} / \mathrm{s}\right)$ than any climate change scenario model projection. Climate change models are often criticized in the media for being exaggerated (Freudenburg and Muselli, 2010), however, the current historical trend in streamflow is a close match to the climate change scenario trend. Furthermore, the year 2017 proves that the GCMs still need to be improved, especially in the amount of predicted precipitation as they are often projected to have larger but fewer precipitation events.

\subsubsection{CHANGES IN DROUGHT DAYS}

The JRWM has demonstrated poor performance for low flows and drought events, with significantly overestimated low flows and a resulting underestimation of CDDs. Therefore, we can consider that all the results for the drought analysis to have large uncertainties but that overall, they are being underestimated. The climate change scenarios project that droughts in the Jock River watershed are going to almost triple compared to the mean CDDs for simulated. This means that the past decrease in droughts that has been observed will be changing to much larger and more frequent droughts. 
Examining the individual models raises more concerns for droughts as some of the models simulated much higher magnitudes of CDD values than observed values, indicating that there will be unprecedented low streamflows, especially since the model underestimates CDDs. These predicted lower streamflow levels will pose large challenges to both the ecosystems that rely on the water and to the various groups in the Jock River watershed community that that have permits to take water from the watershed. These results match numerous studies that have indicated an increase in summer low streamflows under climate change scenarios (Neff et al., 2000; Kiensle et al., 2012; Chien et al., 2013; Crossman et al., 2013), as well as Crabbe and Robin (2006) findings for the neighbouring South Nation watershed, where the watershed was vulnerable to monthly droughts for some climate change scenarios.

\subsection{RECOMMENDATIONS FOR FUTURE RESEARCH}

There are several recommendations to improve the JRWM results. They include: using a better suited hydrological model (inside the Raven framework or a different application), using smaller HRUs instead of a sub-watershed size HRU or a fully distributed model, better detailed input data (for example: soil properties, vegetation, DEMs, and multiple stream gauges), and using an optimization tool instead of the best GLUE parameter set. Also, the climate change scenarios used have a radiative forcing of RCP 8.5 , mostly to provide emphasis on the extremes under climate change, and therefore other RCP models should also be used to examine the changes under these models and how they differ from the RCP 8.5 models.

Methods of extreme analysis such as GEV and STL have been shown to be beneficial with the use of hydrological models. Further extreme analysis for the Jock River 
watershed would be beneficial, such as a flood threshold level used to evaluate the duration of flooding events both historically and in future scenarios, as well as a GEV on analysis on CDDs to determine the distribution of CDD events and how their return periods are expected to change in the future. Additional nonstationary GEV models could be applied to examine which parameters in the GEV distribution are most affected by nonstationarity and how they can be optimized.

Lastly, the methods presented in this thesis could be used to help develop other watershed models for the surrounding areas at the conservation and municipality scales. This could be accomplished if similar data for the watershed of interest are available for input, as parameters wouldn't require much calibration to produce satisfactory results. This also means that streams that are ungauged could also be modelled if the data is available. If the modelling approach is not possible, then a GEV analysis on the streamflow data for the watershed would indicate its return periods. The nonstationarity GEV approach which has been demonstrated to follow the current climate change trends could be used as an indicator for future changes without having to apply scenarios or a hydrological model. These options would allow watersheds to be evaluated for extremes and possible changes that could occur in the future, to better assess the impacts of climate change and help design options for mitigation and prevention of extreme risks to the agriculture, environment, infrastructure and public. Additionally, a comparison of the future climate change streamflow should be compared to nearby and southern watersheds, to see if the streamflow patterns are similar or if they are changing towards a more southern streamflow pattern.

\section{CHAPTER 7: CONCLUSIONS}


The Jock River Watershed Model (JRWM) was created using the Raven hydrological modelling framework and applied to the Jock River watershed to evaluate extremes. JRWM achieved a Nash-Sutcliffe efficiency value of 0.76 , and the Generalized Likelihood Uncertainty Estimation (GLUE) determined that the model uncertainty is greatest during the snow melt season. Results indicate that the model underestimates very high streamflows and overestimates low streamflows which is not favourable for extreme events especially for the droughts. However, using the Generalized Extreme Value (GEV) method demonstrates that the model can produce satisfactory results for the application of extreme high streamflows, as well as extremes in climate change scenarios. Using Streamflow Threshold Level (STL) shows that the model doesn't represent droughts for streamflow very well even when using an extreme analysis method.

The historical dataset shows that the Jock River watershed is experiencing multiple changes, such as: a decrease in snow melt streamflow magnitudes; earlier snow melt peak since 1970 ( $~ 10$ days); increase in streamflow peaks in the summer-fall season; an increase in the mean annual streamflow; and a decrease in both the magnitude and number of Consecutive Drought Day (CDD) events.

Twelve climate change scenario models were used with JRWM to evaluate potential streamflow changes in the future. Predictions based on these scenarios show by 2099 the streamflow is predicted to decrease by $50 \%$ in magnitude and shift 7 weeks earlier. The mean annual streamflow continues to increase in future scenarios, however the recorded 2017 mean streamflow is still larger than any scenario prediction. GEV analysis showed that extremes are decreasing by $\sim 10 \%$ for the snow melt peaks, while the summer-fall peaks are increasing by $\sim 30 \%$. Increases in mean annual streamflow (MAS) are continuing, 
but the MAS for 2017 is larger than any future scenario. Though the model does underestimate the magnitude and duration of droughts, the STL analysis for CDD shows that the magnitude and number of CDD events are increasing by $\sim 300 \%$ compared to simulated.

These results demonstrate that climate change in eastern Ontario is already occurring and that under future climate change scenarios the changes to the hydrology will continue to increase, as well as new challenges that will arise with the increase in droughts. The agricultural community in the Jock River watershed could increase crop productivity from the longer growing seasons and increased groundwater recharge from the projected future climate caused by earlier snow melt seasons. However, these benefits do not outweigh the risks and economic cost of the projected larger short duration precipitation events and increased frequency and intensity of floods and droughts in the summer-fall season.

\section{REFERENCES}


AAFC (2017). "Extracted from the Agriculture and Agri-Food Canada Soil Survey web site: (http://sis.agr.gc.ca/cansis/publications/surveys/on/on58/index.html) on [June 2017]" AAFC (2018). "2017 Annual Report Of Agroclimate Conditions Across Canada" http://www.agr.gc.ca/eng/programs-and-services/drought-watch/2017-annual-report-ofagroclimate-conditions-across-canada/? id=1519400741748\#a3

Abebe, N. A., Ogden, F. L., Pradhan, N. R. (2010). Sensitivity and uncertainty analysis of the conceptual HBV rainfall-runoff model: Implications for parameter estimation. Journal of Hydrology, 389(3), 301-310.

Adamowski, J., Adamowski, K., Prokoph, A. (2013). Quantifying the spatial temporal variability of annual streamflow and meteorological changes in Eastern Ontario and southwestern Quebec using wavelet analysis and GIS. Journal of Hydrology, 499, 27-40.

Adlouni, S. E., T. B. M. J. Ouarda, Zhang, X., Roy, R., Bobée, B. (2007). Generalized maximum likelihood estimators for the nonstationary generalized extreme value model. Water Resources Research, 43(3), W03410.

Aizen, V.B., Aizen, E.M., Melack, J.M., Dozier, J. (1997). Climatic and hydrologic changes in the Tien Shan, Central Asia. Journal of Climate, 10:1393:1404.

Allen, R.G., Pereira, L.S., Raes, D., Smith, M. (1998). Crop evapotranspirationGuidelines for computing crop water requirements-FAO Irrigation and drainage paper 56. FAO, Rome, 300, 6541.

Allen, C. D., Macalady, A. K., Chenchouni, H., Bachelet, D., McDowell, N., Vennetier, M., Cobb, N. (2010). A global overview of drought and heat-induced tree mortality reveals emerging climate change risks for forests. Forest Ecology and Management, 259(4), 660-684.

Anderson, M. G and Idso, S. B. (1987). Surface geometry and stomatal conductance effects on evaporation from aquatic macrophytes. Water Resources Research, 23(6), 1037.

Arnell, N.A. (1999). Climate change and global water resources. Global Environmental Change, 9:31-49.

Arnell, N.W., Gosling, S.N., (2013). The impacts of climate change on river flow regimes at the global scale. Journal of Hydrology, 486: 351-364.

Arora, V.K. and Boer, G. J. (2001). Effects of simulated climate change on the hydrology of major river basins. Journal of Geophysical Research 106(D4): 3335-3348.

Bakker, K and Christina, C. (2011). Water Governance in Canada: Innovation and Fragmentation. International journal of water resources development. (27)2. p.275 - 289.

Barnett, T.P., Pierce, D.W., Hidalgo, H.G., Bonfils, C., Santer, B.D., Das, T., Dettinger, D. (2008). Human-induced changes in the hydrology of the Western United States. Science, 319:1080-1083. 
Barontini, S., Grossi, G., Kouwen, N., Maran, S., Scaroni, P., Ranz, R. (2009). Impacts of climate change scenarios on runoff regimes in the Southern Alps. Hydrology and Earth System Sciences Discussion, HESSD, 6:3089-3141.

Bergstrom, S., Carlsson, B., Gardelin, M., Lindstrom, G., Pettersson, A., Rummukainen, M. (2001). Climate change impacts on runoff in Sweden assessments by global climate models, dynamical downscaling and hydrological modeling. Climate Research,16:101112.

Beven, K., and Binley, A. (1992). The future of distributed models: Model calibration and uncertainty prediction. Hydrological Processes, 6(3), 279-298.

Beven K.J. (2006). A manifesto for the equifinality thesis. Journal of Hydrology, 320(1), $18-36$.

Beven, K.J. (2012). Rainfall-runoff Modelling: The Primer. Chichester, UK: J. Wiley. Print.

Beven, K. J., and Alcock, R. E. (2012). Modelling everything everywhere: A new approach to decision-making for water management under uncertainty. Freshwater Biology, 57, 124-132.

Bonfils, C., B.D. Santer, D.W. Pierce, H.G. Hidalgo, G. Bala, T. Das, T.P. Barnett, D.R. Cayan, C. Doutriaux, A.W. Wood, A. Mirin, T. Nozawa (2008). Detection and attribution of temperature changes in the western U.S. Journal of Climate, 21:6404-6424.

Bonsal, B. R., Wheaton, E. E., Chipanshi, A. C., Lin, C., Sauchyn, D. J., Wen, L. (2011). Drought research in Canada: A review. Atmosphere-Ocean, 49(4), 303-319.

Bouraoui, F., Galbiati, L. \& Bidoglio, G. (2002) Climate change impacts on nutrient loads in the Yorkshire Ouse catchment (UK). Hydrol. Earth Sys. Sci. 6, 197-209.

Bourdin, D. R., Fleming, S. W., Stull, R. B. (2012). Streamflow modelling: A primer on applications, approaches and challenges. Atmosphere-Ocean, 50(4), 507-536.

Box, G. E. P. (1979). Robustness in Statistics pp. 201-236 (London, Academic Press).

Boyd, C. E. P. (2015). Water quality: An introduction (Second ed.). Cham: Springer.

Brander, K. M. (2007). The role of growth changes in the decline and recovery of North Atlantic cod stocks since 1970. Atlantic, 64(2), 211-217.

Brutsaert, W. (2016). Global land surface evaporation trend during the past half century: Corroboration by Clausius-Clapeyron scaling. Advances in Water Resources, 106, 3-5

Cannon, A. J. (2015). Selecting GCM scenarios that span the range of changes in a multimodel ensemble: Application to CMIP5 climate extremes indices. Journal of Climate, 28(3), 1260-1267.

Cayan, D. R., Riddle, L. G., Aguado, E. (1993). The influence of precipitation and temperature on seasonal streamflow in California. Water Resources Research, 29(4), $1127-1140$. 
Chang, N., H.W. Chen and S.K. King, (2001). Identification of river water quality using the fuzzy synthetic evaluation approach. J. Environ. Manage., 63: 293-305.

Chang, H (2003). Basin hydrologic response to changes in climate and land use: the Conestoga River Basin, Pennsylvania, Physical Geography 24, 222-247

Chen, J. M., Pavlic, G., Brown, L., Cihlar, J., Leblanc, S. G., White, H. P., . . Pellikka, P. K. E. (2002). Derivation and validation of Canada-wide coarse-resolution leaf area index maps using high-resolution satellite imagery and ground measurements. Remote Sensing of Environment, 80(1), 165-184.

Chen, J., Brissette, F. P., Leconte, R. (2014). Assessing regression-based statistical approaches for downscaling precipitation over north America: Hydrological Processes, 28(9), 3482-3504.

Cheng, C. S., Li, G., Li, Q., Auld, H. (2010). A synoptic weather typing approach to simulate daily rainfall and extremes in Ontario, Canada: Potential for climate change projections. Journal of Applied Meteorology and Climatology, 49(5), 845-866.

Cheng, C. S., Auld, H., Li, Q., Li, G. (2012). Possible impacts of climate change on extreme weather events at local scale in south-central Canada. Climatic Change, 112(3), 963-979.

Cherkauer, K.A., and T. Sinha. (2010). Hydrologic impacts of projected future climate change in the Lake Michigan region. Journal of Great Lakes Research, 36, 33-50.

Chiew, F., D. Kirono, D. Kent, A. Frost, S. Charles, B. Timbal, K. Nguyen, and G. Fu. (2010). Comparison of runoff modelled using rainfall from different downscaling methods for historical and future climates. Journal of Hydrology 387(1):10-23.

Choi, O. and A. Fisher, (2003): The impacts of socioeconomic development and climate change on severe weather catastrophe losses: Mid-Atlantic Region MAR and the U.S. Climatic Change, 58(1-2), 149-170.

Chung ES, Park K, Lee KS, (2011). The relative impacts of climate change and urbanization on the hydrological response of a Korean urban watershed. Hydrol Process 2011;25 (4):544-60. Resources Association 35: 1539-1550.

Clarke, R. T. (2002). Estimating tre nds in data from the Weibull and ageneralized extreme value distribution, Water Resour. Res., 38(6), 1089.

Coles, Stuart (2001). An Introduction to Statistical Modeling of Extreme Values. Springer Series in Statistics. London: Springer. Print

Condon, L. E., Gangopadhyay, S., Pruitt, T. (2015). Climate change and non-stationary flood risk for the upper truckee river basin. Hydrology and Earth System Sciences, 19(1), $159-175$.

Crabbé P, Robin M (2006). Institutional adaptation of water resource infrastructures to climate change in Eastern Ontario. Climatic Change 78(1):103-133. 
Craig, J. R., Ph.D. (2016). Raven Short Course I: Modular Hydrologic Modelling \& the Raven Framework. Lecture presented at Workshop in Carleton University, Ottawa.

Craig, J.R., and the Raven Development Team (2017). Raven user's and developer's manual (Version 2.7), URL: http://www.civil.uwaterloo.ca/jrcraig/Raven/Main.html (Accessed June, 2017).

Crossman, J., Futter, M. N., Oni, S. K., Whitehead, P. G., Jin, L., Butterfield, D., . . . Dillon, P. J. (2013). Impacts of climate change on hydrology and water quality: Future proofing management strategies in the lake Simcoe watershed, Canada. Journal of Great Lakes Research, 39(1), 19-32

Cruise, J. F., A. S. Limaye and N. A. Abed (1999). Assessment of impacts of climate change on water quality in the southeastern United States. Journal of the American Water

Cunderlik, J.M., Ouarda, T.B., (2009). Trends in the timing and magnitude of floods in Canada. Journal of Hydrology, 375 (3): 471-480.

Deng, Z., Qiu, X., Liu, J., Madras, N., Wang, X., Zhu, H. (2016). Trend in frequency of extreme precipitation events over Ontario from ensembles of multiple GCMs. Climate Dynamics, 46(9), 2909-2921.

Déry, S.J., Wood, E., (2005). Decreasing river discharge in northern Canada. Geophys. Res. Lett., 32: L10401.

Déry, S.J., Hernández-Henríquez, M.A., Burford, J.E., Wood, E.F., (2009). Observational evidence of an intensifying hydrological cycle in northern Canada. Geophys. Res. Lett., 36(13): L13402.

Dessai, S., and Hulme, M. (2007). Assessing the robustness of adaptation decisions to climate change uncertainties: A case study on water resources management in the East of England. Global Environmental Change, 17(1), 59-72.

Dijk, A. I. J. M., Gash, J. H., van Gorsel, E., Blanken, P. D., Cescatti, A., Emmel, C., Wohlfahrt, G. (2015). Rainfall interception and the coupled surface water and energy balance. Agricultural and Forest Meteorology, 214-215(Complete), 402-415.

Dingman, S. L. (2015). Physical hydrology. Long Grove, IL: Waveland Press, Inc.

Douglas, E.M., R.M. Vogel, C.N. Kroll, (2000). Trends in floods and low flows in the United States: impact of spatial correlation. J. Hydrol., 240(1-2), 90-105.

Dvořáková, Š., Kováŕ, P., Zeman, J. (2014). Impact of evapotranspiration on discharge in small catchments. Journal of Hydrology and Hydromechanics, 62(4), 285-292.

Eckhardt, K., Ulbrich, U. (2003). Potential impacts of climate change on groundwater recharge and streamflow in a central european low mountain range. Journal of Hydrology, 284(1), 244-252.

Ehsanzadeh, E., Kamp, G., Spence, C. (2012). The impact of climatic variability and change in the hydroclimatology of lake Winnipeg watershed. Hydrological Processes, 26(18), 2802-2813. 
Eisner, S., Flörke, M., Chamorro, A., Daggupati, P., Donnelly, C., Huang, J., Krysanova, V. (2017). An ensemble analysis of climate change impacts on streamflow seasonality across 11 large river basins. Climatic Change, 141(3), 401-417.

Flato, G., Marotzke, J., Abiodun, B., Braconnot, P., Chou, S. C., Collins, W. J., Forest, C. (2013). Evaluation of climate models. In: climate change 2013: the physical science basis. Contribution of working group I to the fifth assessment report of the intergovernmental panel on climate change. Climate Change 2013, 5, 741-866.

Forbes, K.A., Kienzle, S.W., Coburn, C.A., Byrne, J.M., and Rasmussen, J. (2011). Simulating the hydrological response to predicted climate change on a watershed in southern Alberta, Canada. Climatic Change, 105(3-4), 555-576.

Friend, A.D., A.K. Stevens, R.G. Knox, and M.G.R. Cannell, (1997). Aprocessbased, terrestrial biosphere model of ecosystem dynamics (HYBRID v3.0). Ecological Modelling, 95, 249-287.

Freeze, R. A., and Cherry, J. A. (1979). groundwater. Englewood Cliffs, N.J: PrenticeHall.

Fuentes, J. D., and King, K. M. (1989). Leaf photosynthesis and leaf conductance of maize grown hydroponically and in soil under field conditions. Agricultural and Forest Meteorology, 45(3), 155-166.

Gerbaux, M., Hall, N., Dessay, N., Zin, I. (2009). The sensitivity of sahelian runoff to climate change. Hydrological Sciences Journal, 54(1), 5-16.

Gibson, C.A., Meyer, J.L., Poff, N.L., Hay, L.E., Georgakakos, A., (2005). Flow regime alterations under changing climate in two river basins: Implications for freshwater ecosystems. River Research and Applications, 21(8): 849-864.

Gilleland, E., Katz, R.W., (2016). extRemes 2.0: An Extreme Value Analysis Package in R. Journal of Statistical Software, 72(8), 1-39.

Giorgetta, M. A., Jungclaus, J., Reick, C. H., Legutke, S., Bader, J., Böttinger, M., Stevens, B. (2013). Climate and carbon cycle changes from 1850 to 2100 in MPI-ESM simulations for the coupled model intercomparison project phase 5. Journal of Advances in Modeling Earth Systems, 5(3), 572-597.

Giorgi, F. and L. O. Mearns (2003). Probability of regional climate change based on the Reliability Ensemble Averaging (REA) method. Geophysical Research Letters, 30(12):1629.

Giorgi, F., Shields Brodeur, C., Bates, G. T. (1994). Regional climate change scenarios over the United States produced with a nested regional climate model. Journal of Climate, 7(3), 375-399.

Gleick, P. H., (1996). Water resources. In Encyclopedia of Climate and Weather, ed. by S. H. Schneider, Oxford University Press, New York, vol. 2, pp.817-823. print 
Gleick, P.H. (1999). Introduction: Studies from the water sector of the National Assessment. JAWRA. Journal of the American Water Resources Association, 35(6), 1297-1300.

Gleick, P. H., Chalecki, E. L. (1999). the impacts of climatic changes for water resources of the Colorado and Sacramento-San Joaquin river basins. JAWRA Journal of the American Water Resources Association, 35(6), 1429-1441.

Gobena, A. K., and Gan, T. Y. (2013). Assessment of trends and possible climate change impacts on summer moisture availability in western Canada based on metrics of the palmer drought severity index. Journal of Climate, 26(13), 4583-4595.

Goetz, S. J., A. G. Bunn, G. J. Fiske., R. A. Houghton, (2005). Satellite-observed photosynthetic trends across boreal North America associated with climate and fire disturbance. Proceedings of the National Academy of Sciences, 102: 13521-13525.

Goodrich, D. C., Schmugge, T. J., Jackson, T. J., Unkrich, C. L., Keefer, T. O., Parry, R., Amer, S. A. (1994). Runoff simulation sensitivity to remotely sensed initial soil water content. Water Resources Research, 30(5), 1393-1405.

Google Maps, (2018a). Retrieved https://www.google.ca/maps/@45.2491315,75.7907593,3a,75y,60.5h,86.17t/data=!3m6!1e1!3m4!1 sgit0bPdUdgpNaqOde6wAYA!2 e0!7i13312! $8 \mathrm{i} 6656$

Google Maps, (2018b). Retrieved from http://www.google.ca/maps/@45.249290175.7908298,3a,75y,85.25h,86.87t/data=!3m6!1e1!3m4!1sHQpGE7jgMLvxRAmDhDeyg!2e0!7i13312!8i6656

Gramelsberger, G., Feichter, J., (2011). Climate change and policy: The calculability of climate change and the challenge of uncertainty (1st ed.). Heidelberg;New York;Berlin;: Springer.

Groisman, P.Y., R.W. Knight and T.R. Karl (2001). Heavy precipitation and high streamflow in the contiguous United States: trends in the twentieth century, Bulletin of the American Meteorological Society 82, 219-246.

Gutiérrez, J. M., San-Martín, D., Brands, S., Manzanas, R., ., Herrera, S. (2013). Reassessing statistical downscaling techniques for their robust application under climate change conditions. Journal of Climate, 26(1), 171-188. 10.1175/JCLI-D-11-00687.1

Hamlet A. F., Lettermaier D. P., (1999). Effects of Climate change on Hydrology water resources in the Columbia River Basin. Journal of the American water resources association Vol. 35., No.6 p1597-1623.

Hamby, D. M. (1994). A review of techniques for parameter sensitivity analysis of environmental models. Environmental Monitoring and Assessment, 32(2), 135-154.

Hargreaves, G. H., and Allen, R. G. (2003). History and evaluation of hargreaves evapotranspiration equation. Journal of Irrigation and Drainage Engineering, 129(1), 5363. 
Hay, L. E., and Clark, M. P. (2003). Use of statistically and dynamically downscaled atmospheric model output for hydrologic simulations in three mountainous basins in the western United States. Journal of Hydrology, 282(1), 56-75.

Hayhoe, K., C.P. Wake, T.G. Huntington, L. Luo, M.D. Schwartz, J. Sheffield, E. Wood, D. Wolfe. (2006). Past and future changes in climate and hydrological indicators in the U.S. Northeast. Climate Dynamics, 28:381-407.

Hidalgo, H.G. Das, T; Dettinger, M. D; Cayan, D. R; Pierce, D. W; Barnett, T. P; Bala, G; Mirin, A; Wood, A. W; Bonfils, C; Santer, B. D; Nozawa, T (2009). Detection and attribution of streamflow timing changes to climate change in the western United States. J. of Climate, 22:3838-3855.

Hodgkins, R., Cooper, R., Wadham, J., Tranter, M. (2005). Interannual variability in the spatial distribution of winter accumulation at a high-Arctic glacier (Finsterwalderbreen, Svalbard), and its relationship with topography. (J. Dowdeswell \& I. C. Willis, Eds.) Annals Of Glaciology, 42(1), 243-248.

Hodgkins, R., Cooper, R., Wadham, J., Tranter, M. (2005). Interannual variability in the spatial distribution of winter accumulation at a high-arctic glacier (finsterwalderbreen, svalbard), and its relationship with topography. Annals of Glaciology, 42(1), 243-248.

Hsu, P.-C., T. Li, and B. Wang (2011). Trends in global monsoon area andprecipitation over the past 30 years, Geophys. Res. Lett., 38, L08701.

Huntington, T.G., (2006). Evidence for intensification of the global water cycle: Review and synthesis. Journal of Hydrology, 319: 83-95.

Huntington, T. G., Hodgkins, G. A., Keim, B. D., Dudley, R. W. (2004). Changes in the Proportion of Precipitation Occurring as Snow in New England (1949-2000). Journal of Climate, 17(13), 2626-2636. journals.ametsoc.org.

Houghton, J.T., G.J. Jenkins and J.J. Ephraums (1990). Climate Change: The IPCC Scientific Assessment. Cambridge University Press, 364 pp.

IJC. (International Joint Commission). (2006). Advice to governments on their review of the great lakes water quality agreement: A special report to the governments of Canada and the united states. Washington, D.C.; Ottawa, Ont: International Joint Commission.

IPCC (Intergovernmental Panel on Climate Change), (2001). Climate Change 2001: Mitigation. Contribution of Working Group III to the Third Assessment Report of the Intergovernmental Panel on Climate Change, B. Metz, O. Davidson, R. Swart and J. Pan, Eds., Cambridge University Press, Cambridge.

IPCC, (2007a). Climate Change 2007: The Physical Science Basis. Contribution of Working Group I to the Fourth Assessment Report of the Intergovernmental Panel on Climate Change [Solomon, S., D. Qin, M. Manning, Z. Chen, M. Marquis, K.B. Averyt, M. Tignor and H.L. Miller (eds.)]. Cambridge University Press, Cambridge, United Kingdom and New York, NY, USA, 996 pp. 
IPCC. (2007b). Climate Change 2007: Synthesis Report. Contribution of Working Groups I, II and III to the Fourth Assessment Report of the Intergovernmental Panel on Climate Change (pp.104). Geneva, Switzerland: IPCC.

IPCC, (2013). Summary for Policymakers. In: Climate Change 2013: The Physical Science Basis. Contribution of Working Group I to the Fifth Assessment Report of the Intergovernmental Panel on Climate Change [Stocker, T.F., D. Qin, G.-K. Plattner, M. Tignor, S.K. Allen, J. Boschung, A. Nauels, Y. Xia, V. Bex and P.M. Midgley (eds.)]. Cambridge University Press, Cambridge, United Kingdom and New York, NY, USA.

Jian, W. and L. Shuo (2006). Effect of climate change on snowmelt runoffs in mountainous regions of inland rivers in Northwestern China. Science in China, 49(8):881-888.

Kanji, G. K. (1986). Editorial: "all models are wrong but some are useful". Journal of the Royal Statistical Society. Series D (the Statistician), 35(2), 95-96.

Katsavounidis, I., Kuo, C. C. J., Zhang, Z. (1994). A new initialization technique for generalized Lloyd iteration. IEEE Signal processing letters, 1(10), 144-146.

Kauffman, G. J. and Vonck, K. J. (2011). Frequency and intensity of extreme drought in the Delaware Basin, 1600-2002. Water Resources Research, 47(5).

Kay, A.L., R.G. Jones and N.S. Reynard (2006). RCM rainfall for UK flood frequency estimation. II. Climate change results. Journal of Hydrology, 318:163-172.

Kendall, M.G. (1975). Rank Correlation Methods, 4th edition, Charles Griffin, London.

Kienzle, S.W. and Mueller, M. (2013). Mapping Alberta's surface water resources for the period 1971-2000. The Canadian Geographer/Le Géographe canadien. 57(4): 506-518.

Kienzle, S. W., Nemeth, M. W., Byrne, J. M., MacDonald, R. J. (2012). Simulating the hydrological impacts of climate change in the upper north saskatchewan river basin, alberta, canada. Journal of Hydrology, 412-413, 76-89.

Kimball, B.A., R.L. LaMorte, P.J. Pinter Jr., G.W. Wall, D.J. Hunsaker, F.J. Adamsen, S.W. Leavitt, T.L. Thompson, A.D. Matthias, and T.J. Brooks, (1999). Free-air CO2 enrichment and soil nitrogen effects on energy balance and evapotranspiration of wheat. Water Resources Research, 35, 1179 - 1190.

Krishnaswamy, J., Bonell, M., Venkatesh, B., Purandara, B. K., Rakesh, K. N., Lele, S., Badiger, S. (2013). The groundwater recharge response and hydrologic services of tropical humid forest ecosystems to use and reforestation: Support for the "infiltrationevapotranspiration trade-off hypothesis". Journal of Hydrology, 498, 191-209

Kundzewicz, Z. W., Krysanova, V., Benestad, R. E., Hov, Ø., Piniewski, M., Otto, I. M. (2018). Uncertainty in climate change impacts on water resources. Environmental Science \& Policy, 79, 1-8.

Lafleur, P. (1988). Leaf conductance of four species growing in a subarctic marsh. Canadian journal of botany, 66(7), 1367-1375. 
Lavell, A., Oppenheimer, M., Diop, C., Hess, J., Lempert, R., Li, J., Myeong, S. (2012). Climate change: new dimensions in disaster risk, exposure, vulnerability, and resilience.

Law, B. E., Eugster, W., Gianelle, D., Dolman, A. J., Zaehle, S., Bonan, G., Richardson, A. D. (2010). Recent decline in the global land evapotranspiration trend due to limited moisture supply. Nature, 467(7318), 951-954.

Lehner, B., Döll, P., Alcamo, J., Henrichs, T., Kaspar, F. (2006). Estimating the impact of global change on flood and drought risks in Europe: A continental, integrated analysis. Climatic Change, 75(3), 273-299.

Lemmen, D.S., Warren, F.J., Lacroix, J., and Bush, E., editors (2008). From Impacts to Adaptation: Canada in a Changing Climate 2007; Government of Canada, Ottawa, ON, $448 \mathrm{p}$.

Lenderink, G., and Van Meijgaard, E. (2010). Linking increases in hourly precipitation extremes to atmospheric temperature and moisture changes. Environmental Research Letters, 5(2), 025208.

Leung, L., and Ghan, S. (1999a). Pacific Northwest climate sensitivity simulated by a regional climate model driven by a GCM. Part II: $2 \times \mathrm{CO}_{2}$ simulations. Journal of Climate, 12(7), 2031-2053.

Leung, L. R., and Ghan, S. J. (1999b). Pacific northwest climate sensitivity simulated by a regional climate model driven by a GCM. part I: Control simulations. Journal of Climate, 12(7), 2010-2030.

Leung, L. R., and Wigmosta, M. S. (1999). potential climate change impacts on mountain watersheds in the pacific northwest. JAWRA Journal of the American Water Resources Association, 35(6), 1463-1471.

Liao, C., Wang, J., Shang, J., Huang, X., Liu, J., Huffman, T. (2018). Sensitivity study of radarsat-2 polarimetric SAR to crop height and fractional vegetation cover of corn and wheat. International Journal of Remote Sensing, 39(5), 1475.

Lindroth, R. L., King, G. W., Wilson, M. L., Moser, S. C., Union of Concerned Scientists, \& Ecological Society of America. (2003). Confronting climate change in the great lakes region: Impacts on our communities and ecosystems. Cambridge, Mass: Union of Concerned Scientists.

Liu, J., S. Wang and Y. Huang (2007). Effect of climate change on runoff in a basin with mountain permafrost, Northwest China. Permafrost and Periglacial Processes, 18:367377.

Liu, Y., Huo, X., Liu, Y., Hao, Y., Fan, Y., Zhong, Y., Yeh, T. J. (2015). Analyzing streamflow extremes in the upper ürümqi river with the generalized pareto distribution. Environmental Earth Sciences, 74(6), 4885-4895.

Loukas, A., L. Vasiliades and N.R. Dalezios (2002). Potential climate change impacts on flood producing mechanisms in southern British Columbia, Canada using the CGCMA1 simulation results. Journal of Hydrology, 259:163-188. 
Luo, S., Wang, C., Pan, F., Xi, X., Li, G., Nie, S., Xia, S. (2015). Estimation of wetland vegetation height and leaf area index using airborne laser scanning data. Ecological Indicators, 48, 550-559.

Ma, Z., Peng, C., Zhu, Q., Chen, H., Yu, G., Li, W., . . Zhang, W. (2012). Regional drought-induced reduction in the biomass carbon sink of Canada's boreal forests.

Proceedings of the National Academy of Sciences of the United States of America, 109(7), 2423-2427.

Mann, H.B. (1945). Non-parametric tests against trend, Econometrica 13:163-171.

Mann, M. E., Rahmstorf, S., Kornhuber, K., Steinman, B. A., Miller, S. K., Coumou, D. (2017). Influence of anthropogenic climate change on planetary wave resonance and extreme weather events. Scientific Reports, 7.

Marshall, E., and Randhir, T. (2008). Effect of climate change on watershed system: a regional analysis. Climatic Change, 89(3-4), 263-280.

Masih, I., Maskey, S., Mussá, F. E. F., Trambauer, P. (2014). A review of droughts on the African continent: A geospatial and long-term perspective. Hydrology and Earth System Sciences, 18(9), 3635.

Matott, L., (2005). Ostrich: An optimization software tool, documentation and user's guide, Version 1.6. Department of Civil, Structural, and Environmental Engineering, State University of New York at Buffalo, Buffalo, NY Available from www.groundwater.buffalo.edu.

Matti, B., Dahlke, H. E., Lyon, S. W., Stockholms universitet, Institutionen för naturgeografi, and Naturvetenskapliga fakulteten. (2016). On the variability of cold region flooding. Journal of Hydrology, 534, 669-679.

Maurer, E. P., Hidalgo, H. G., Das, T., Dettinger, M. D., Cayan, D. R. (2010). The utility of daily large-scale climate data in the assessment of climate change impacts on daily streamflow in California. Hydrology and Earth System Sciences, 14(6), 1125-1138.

McCarthy, N., Dutilly-Diané, C., Drabo, B. (2004). Cooperation, collective action and natural resources management in Burkina Faso. Agricultural Systems, 82(3), 233-255.

McCaughey, J. H., and Iacobelli, A. (1994). Modelling stomatal conductance in a northern deciduous forest, Chalk River, Ontario. Canadian Journal of Forest Research, 24(5), 904-910.

McFadden, M. A., Patterson, W. P., Mullins, H. T., Anderson, W. T. (2005). Multi-proxy approach to long- and short-term holocene climate-change: Evidence from eastern lake Ontario. Journal of Paleolimnology, 33(3), 371-391.

McKenney, D. W., Hutchinson, M. F., Papadopol, P., Lawrence, K., Pedlar, J., Campbell, K., Owen, T. (2011). Customized spatial climate models for North America. Bulletin of the American Meteorological Society, 92(12), 1611-1622. 
Meals, D. W., Spooner, J., Dressing, S. A., Harcum, J. B. (2011). Statistical analysis for monotonic trends, Tech Notes 6, November 2011. Developed for US Environmental Protection Agency by Tetra Tech, Inc., Fairfax, VA.

Mearns, L.O., S.H. Schneider, S.L. Thompson and L.R. McDaniel (1990). Analysis of climate variability in general circulation models: Comparison with observations and changes in variability in 2XCO2 experiments. J. Geophysical Research, 95(20):469-490.

Mekis, É., Vincent, L.A., (2011). An overview of the second generation adjusted daily precipitation dataset for trend analysis in Canada. Atmosphere-Ocean, 49 (2): 163-177.

Miller, N.L., J. Kim, R.K. Hartman and J. Fararra (1999). Downscaled climate and stream flow study of the southwestern U.S. JAWRA, 35(6):1525-1537.

Milly, P. C. D., Betancourt, J., Falkenmark, M., Hirsch, R. M., Kundzewicz, Z. W., Lettenmaier, D. P., Stouffer, R. J. (2008). Climate change. stationarity is dead: Whither water management? Science (New York, N.Y.), 319(5863), 573.

Minville, M., F. Brissette and R. Leconte (2008). Uncertainty of the impact of climate change on the hydrology of a Nordic watershed. Journal of Hydrology, 358:70-83.

Moriasi, D. N., Arnold, J. G., Van Liew, M. W., Bingner, R. L., Harmel, R. D., Veith, T. L. (2007). Model evaluation guidelines for systematic quantification of accuracy in watershed simulations. Transactions of the ASABE, 50(3), 885-900.

Musa, Z. N., Popescu, I., Mynett, A. (2015). A review of applications of satellite SAR, optical, altimetry and DEM data for surface water modelling, mapping and parameter estimation. Hydrology and Earth System Sciences, 19(9), 3755-3769.

Najibi, N., and Devineni, N. (2017). Recent Trends in Frequency and Duration of Global Floods. Earth Syst. Dynam. Discussion.

NASA. (2017). Long-Term Warming Trend Continued in 2017: NASA, NOAA [Press release]. Retrieved from https://www.nasa.gov/press-release/long-term-warming-trendcontinued-in-2017-nasa-noaa

Nazemi, A., and Wheater, H. S. (2015). On inclusion of water resource management in Earth system models-Part 1: Problem definition and representation of water demand. Hydrology and Earth System Sciences, 19(1), 33-61.

Nearing, M. A. (2001). Potential changes in rainfall erosivity in the U.S. with climate change during the 21st century. Journal of Soil and Water Conservation, 56(3), 229.

Neff, R., H. Chang, C.G. Knight, R.G. Najjar, B. Yarnal and H.A. Walker (2000). Impact of climate variation and change on Mid-Atlantic region hydrology and water resources, Climate Research 14, 207-218.

Nkemdirim, L.C., and Purves, H. (1994). Comparison of recorded temperature and precipitation in the Oldman Basin with scenarios projected in general circulation models. Canadian Water Resources Journal, 19(2), 157-164. 
Novotny, E.V. and H.G. Stefan (2007). Streamflow in Minnesota: indicator of climate change, Journal of Hydrology 334, 319-333.

NRCAN, (2018a). "Extracted from the Environment and Natural Resources Canada Historical Climate Station Data web site:

(www.climate.weather.gc.ca/historical_data/search_historic_data_e.html)on [May 2017]"

NRCAN, (2018b). "Extracted from the Environment and Climate Change Canada Historical Hydrometric Data web site:

(https://wateroffice.ec.gc.ca/mainmenu/historical_data_index_e.html) on [May 2017]"

O'neil, J. M., Davis, T. W., Burford, M. A., Gobler, C. J. (2012). The rise of harmful cyanobacteria blooms: the potential roles of eutrophication and climate change. Harmful algae, 14, 313-334.

OMAFRA (2011). Census of Agriculture and Strategic Policy Branch, Eastern Ontario Region at a Glance http://www.omafra.gov.on.ca/english/stats/county/eastern_ontario

OMNFR (Ontario Ministry of Natural Resources and Forestry Ontario) (2013).

[Technical Release]: Integrated Hydrology Data [DEM].

Oni, S. K., Futter, M. N., Molot, L. A., Dillon, P. J., Crossman, J., Sveriges lantbruksuniversitet. (2014). Uncertainty assessments and hydrological implications of climate change in two adjacent agricultural catchments of a rapidly urbanizing watershed. The Science of the Total Environment, 473-474, 326-337.

ORNL DAAC. (2017). MODIS Collection 6 Land Products Global Subsetting and Visualization Tool. ORNL DAAC, Oak Ridge, Tennessee, USA. https://neo.sci.gsfc.nasa.gov/view.php?datasetId=MOD15A2 M LAI

Orlowsky, B., and Seneviratne, S. I. (2012). Global changes in extreme events: regional and seasonal dimension. Climatic Change, 110(3-4), 669-696.

Ouranos. (2004). "Adapting to Climate Change." Montreal, Canada, print.

Ouranos, Bourdages, L., Huard, D. (2010). Climate change scenario over Ontario based on the Canadian regional climate model (CRCM4. 2). Ouranos, Montreal, Quebec, Canada.

Oyerinde, G. T., and Diekkrüger, B. (2017). Influence of parameter sensitivity and uncertainty on projected runoff in the upper niger basin under a changing climate. 5(3), 67.

Paprotny, D., and Morales-Nápoles, O. (2017). Estimating extreme river discharges in Europe through a Bayesian network. Hydrology and Earth System Sciences, 21(6), 2615.

Pechlivanidis, I. G., McIntyre, N. R., Wheater, H. S. (2010). Calibration of the semidistributed PDM rainfall-runoff model in the upper lee catchment, UK. Journal of Hydrology, 386(1), 198-209.

Pierce, D. W., Das, T., Cayan, D. R., Maurer, E. P., Miller, N. L., Bao, Y., Franco, G. (2013). Probabilistic estimates of future changes in California temperature and 
precipitation using statistical and dynamical downscaling. Climate Dynamics, 40(3-4), 839-856.

Pierce, D.W., T.P. Barnetta, B.D. Santer and P.J. Glecklerb (2009). Selecting global climate models for regional climate change studies. PNAS, 106(21):8441-8446.

Pollard, D. and S.L. Thompson, (1995). Use of a land-surface transfer scheme (LSX) in a global climate model: the response to doubling stomatal conductance. Global and Planetary Change, 10, 129-161.

Qualls, R. J., and Gultekin, H. (1997). Influence of components of the advection-aridity approach on evapotranspiration estimation. Journal of Hydrology, 199(1), 3-12.

Räisänen, J., and Joelsson, R. (2001). Changes in average and extreme precipitation in two regional climate model experiments. Tellus A, 53(5), 547-566.

Raupach, M.R., (1998). Influences of local feedbacks on land-air exchanges of energy and carbon. Global Change Biology, 4, 477-494.

Rawlins, M.A., Steele, M., Holland, M.M., Adam, J.C., Cherry, J.E., Francis, J.A., Groisman, P.Y., Hinzman, L.D., Huntington, T.G., Kane, D.L., Kimball, J.S., Kwok, R., Lammers, R.B., Lee, C.M., Lettenmaier, D.P., McDonald, K.C., Podest, E., Pundsack, J.W., Rudels, B., Serreze, M.C., Shiklomanov, A., Skagseth, O., Troy, T.J., Vorosmarty, C.J., Wensnahan, M., Wood, E.F., Woodgate, R., Yang, D.Q., Zhang, K., Zhang, T.J., (2010). Analysis of the Arctic System for Freshwater Cycle Intensification: Observations and Expectations. J. Clim., 23 (21): 5715-5737.

Robock, A. Konstantin Y. Vinnikov, Govindarajalu Srinivasan, Jared K. Entin, Steven E. Hollinger, Nina A. Speranskaya, Suxia Liu, and A. Namkhai, (2000). The global soil moisture data bank. Bull. Amer. Meteor. Soc., 81, 1281-1299.

Rusli, S. R., Yudianto, D., Liu, J. (2015). Effects of temporal variability on HBV model calibration. Water Science and Engineering, 8(4), 291-300.

RVCA, (Rideau Valley Conservation Authority (2016). JOCK RIVER Subwatershed Report 2016, JOCK RIVER Subwatershed Report, https://watersheds.rvca.ca/files/1064/2016/312/Jock-River-Subwatershed-Report2016.pdf

Sachindra, D. A., Huang, F., Barton, A., Perera, B. J. C. (2014). Statistical downscaling of general circulation model outputs to precipitation - part 1: Calibration and validation. International Journal of Climatology, 34(11), 3264-3281.

Samuel, J., Coulibaly, P., Metcalfe, R. A. (2011). Estimation of continuous streamflow in ontario ungauged basins: Comparison of regionalization methods. Journal of Hydrologic Engineering, 16(5), 447-459.

Schilling, K. E., and Helmers, M. (2008). Effects of subsurface drainage tiles on streamflow in Iowa agricultural watersheds: Exploratory hydrograph analysis. Hydrological Processes, 22(23), 4497-4506. 
Schulz, K., Burgholzer, R., Klotz, D., Wesemann, J., and Herrnegger, M. (2017). Demonstrating the "Unit Hydrograph" and flow routing processes involving active student participation - A university lecture experiment, Hydrol. Earth Syst. Sci. Discuss., in review.

Seck, A., Welty, C., Maxwell, R. M. (2015). Spin-up behavior and effects of initial conditions for an integrated hydrologic model. Water Resources Research, 51(4), 21882210. doi:10.1002/2014WR016371

Seibert, J. (2005). HBV Light, Version 2, User's Manual; Department of Physical Geography and Quaternary Geology, Stockholm University: Stockholm, Sweden.

Sellers, P.J., R.E. Dickinson, D.A. Randall, A.K. Betts, F.G. Hall, J.A. Berry, G.J. Collatz, A.S. Denning, H.A. Mooney, C.A. Nobre, N. Sato, C.B. (1997). Field, and A. Henderson-Sellers,: Modeling the exchanges of energy, water, and carbon between continents and the atmosphere. Science, 275, 502-509.

Seneviratne S.I. Thierry Corti, Edouard L. Davin, Martin Hirschi, Eric B. Jaeger, Irene Lehner, Boris Orlowsky, Adriaan J. Teuling, (2010). Investigating soil moisture-climate interactions in a changing climate: A review Source InformationMay 2010Volume, 99(Issue3-4) Page, p.125-161.

Seneviratne, S. I., Micah Wilhelm,1 Tanja Stanelle, Bart van den Hurk, Stefan Hagemann, Alexis Berg, Frederique Cheruy, Matthew E. Higgins, Arndt Meier, Victor Brovkin, Martin Claussen, Agnès Ducharne, Jean-Louis Dufresne, Kirsten L. Findell, Joséfine Ghattas, David M. Lawrence, Sergey Malyshev, Markku Rummukainen, and Benjamin Smith (2013). Impact of soil moisture-climate feedbacks on CMIP5 projections: First results from the GLACE-CMIP5 experiment, Geophys. Res. Lett., 40, 5212-5217.

Sha, J., Swaney, D. P., Hong, B., Wang, J., Wang, Y., Wang, Z. (2014). Estimation of watershed hydrologic processes in arid conditions with a modified watershed model. Journal of Hydrology, 519, 3550-3556.

Shiogama, H., Stone, D., Emori, S., Takahashi, K., Mori, S., Maeda, A., . . Allen, M. R. (2016). Predicting future uncertainty constraints on global warming projections. Scientific Reports, 6, 18903.

Shook, K., J. W. Pomeroy, C. Spence, and L. Boychuk (2013). Storage dynamics simulations in prairie wetland hydrology models: Evaluationand parameterization,Hydrol. Processes, 27, 1875-1889.

Shuter, B. J., C.K. Minns, and N. P. Lester. (2002). Climate change, freshwater fish, and fisheries: Case studies from Ontario and their use in assessing potential impacts. In: Fisheries in a Changing Climate, N. A. McGinn, Ed., American Fisheries Society Symposium 32. 77-88.

Snyder, M. A., Bell, J. L., Sloan, L. C., Duffy, P. B., Govindasamy, B. (2002). Climate responses to a doubling of atmospheric carbon dioxide for a climatically vulnerable region. Geophysical Research Letters, 29(11). 
Sorooshian, S., Gupta, V. K., Fulton, J. L. (1983). Evaluation of maximum likelihood parameter estimation techniques for conceptual rainfall-runoff models: Influence of calibration data variability and length on model credibility. Water Resources Research, 19(1), 251-259.

Soulis, E. D., Sarhadi, A., Tinel, M., Suthar, M. (2016). Extreme precipitation time trends in Ontario, 1960-2010. Hydrological Processes, 30(22), 4090-4100.

Sterk, A., de Man, H., Schijven, J. F., de Nijs, T., de Roda Husman, A. M. (2016). Climate change impact on infection risks during bathing downstream of sewage emissions from CSOs or WWTPs. Water research, 105, 11-21.

Stewart, I. T., D. R. Cayan, and M. D. Dettinger. (2004). Changes in snowmelt runoff timing in western North America under a 'business as usual' climate change scenario. Climatic Change:217-232.

Stewart, I. T., D. R. Cayan, and M. D. Dettinger. (2005). Changes toward Earlier Streamflow Timing across Western North America. Journal of Climate 18:1136-1155.

Storck, P., Lettenmaier, D. P., Bolton, S. M. (2002). Measurement of snow interception and canopy effects on snow accumulation and melt in a mountainous maritime climate, Oregon, United States. Water Resources Research, 38(11).

Stute, M., A. Clement and G. Lohmann (2001). Global climate models: Past, Present and future. From the Academy, PNAS, 98(19):10529-10530.

Tan, X., and Gan, T. Y. (2015). Contribution of human and climate change impacts to changes in streamflow of Canada. Scientific reports, 5, 17767.

Taylor, K. E., R. J. Stouffer, G. A. Meehl. (2012). An overview of CMIP5 and the experiment design. Bull. American Meteorological Society, vol. 93, n 4, p. 485-498.

Tebaldi, C., Smith, R. L., Nychka, D., Mearns, L. O. (2005). Quantifying uncertainty in projections of regional climate change: A Bayesian approach to the analysis of multimodel ensembles. Journal of Climate, 18(10), 1524-1540.

Tian, Y., Xu, Y., Zhang, X. (2013). Assessment of climate change impacts on river high flows through comparative use of GR4J, HBV and xinanjiang models. Water Resources Management, 27(8), 2871-2888.

Toreti, A., Naveau, P., Zampieri, M., Schindler, A., Scoccimarro, E., Xoplaki, E., Luterbacher, J. (2013). Projections of global changes in precipitation extremes from Coupled Model Intercomparison Project Phase 5 models. Geophysical Research Letters, 40(18), 4887-4892.

USGS, United States Geological Survey, (2004). Climatic fluctuations, drought, and flow in the Colorado River Basin. USGS Fact Sheet 2004-3062, August 2004. Access http://pubs.usgs.gov/fs/2004/3062

Viola, M.R., de Mello, C.R., Chou, S.C., Yanagi, S.N., Gomes, J.L., (2015). Assessing climate change impacts on Upper Grande River Basin hydrology, Southeast Brazil. International Journal of Climatology, 35(6): 1054-1068. 
Walton, D. B., Hall, A., Berg, N., Schwartz, M., Sun, F. (2017). Incorporating snow albedo feedback into downscaled temperature and snow cover projections for California's sierra nevada. Journal of Climate, 30(4), 1417-1438.

Wang, B., J. Liu, H.-J. Kim, P. J. Webster, and S.-Y. Yim (2012). Recent change of the global monsoon precipitation (1979-2008), Climate Dynamics, 39(5), 1123-1135.

Wang, X., Huang, G., Liu, J., Li, Z., Zhao, S. (2015). Ensemble projections of regional climatic changes over Ontario, Canada. Journal of Climate, 28(18), 7327-7346.

Wentz, F. J., Ricciardulli, L., Hilburn, K., Mears, C. (2007). How much more rain will global warming bring? Science, 317(5835), 233-235. doi:10.1126/science.1140746

Wilhite, D. A., and Glantz, M. H. (1985). Understanding: the drought phenomenon: the role of definitions. Water international, 10(3), 111-120.

White, M.D. and K.A. Greer. (2006). The effects of watershed urbanization on the stream hydrology and riparian vegetation of Los Penasquitos Creek, California. Landscape and Urban Planning 74:125-138.

Wu Zhiyong, Lin, Qingxia., Lu, Guihua., He, Hai., Qu, John J., (2015). Analysis of hydrological drought frequency for the Xijiang River Basin in South China using observed streamflow data. Nat Hazards 77:1655-1677.

Xu, C. Y. (2002). Hydrologic models. Textbooks of Uppsala University. Department of Earth Sciences Hydrology.

Yang, L., Wei, W., Chen, L., Mo, B. (2012). Response of deep soil moisture to land use and afforestation in the semi-arid loess plateau, china. Journal of Hydrology, 475, 111 122. 10.1016/j.jhydrol.2012.09.041

Yao, H., Scott, L., Guay, C., Dillon, P. (2009). Hydrological impacts of climate change predicted for an inland lake catchment in ontario by using monthly water balance analyses. Hydrological Processes, 23(16), 2368-2382.

Yilmaz, A. G., and Perera, B. J. C. (2014). Extreme rainfall nonstationarity investigation and Intensity-Frequency-Duration relationship. Journal of Hydrologic Engineering, 19(6), 1160-1172.

Yu, W., Nan, Z., Zhao, Y., Li, S. (2013). Improvement of snowmelt implementation in the SWAT hydrologic model. Acta Ecol Sin 33(21):6992-7001

Zaidman MD, Rees HG (2000). Spatial patterns of streamflow drought in Western Europe 1960-1995.Technical report to the ARIDE project.

Zaidman MD, Rees HG, Young AR (2001). Spatio-temporal development of streamflow droughts in northwest Europe. Hydrol Earth Syst Sci Dis 6(4):733-751.

Zambrano-Bigiarini, Mauricio., (2017). hydroTSM: Time Series Management, Analysis and Interpolation for Hydrological ModellingR package version 0.5-1. URL:

https://github.com/hzambran/hydroTSM. 
Zaytseva, A., Carleton University. Theses and Dissertations. Geography. (2016). Spatiotemporal patterns of extreme weather events and their impacts on corn (zea mays) and soybeans (glycine max) in eastern ontario. Ottawa

Zhang, Y., Peña-Arancibia, J. L., McVicar, T. R., Chiew, F. H., Vaze, J., Liu, C., Miralles, D. G. (2016). Multi-decadal trends in global terrestrial evapotranspiration and its components. Scientific reports, 6, 19124.

Zhang, X., F. W. Zwiers, and G. Hegerl (2009). The influences of data precision on the calculation of temperature percentile indices, Int. J. Climatol., 29, 321-327.

\section{APPENDICES}




\section{APPENDIX A (MODEL CALIBRATION RESULTS)}

This is the results from the calibration process for the different parameter sets that were run for the model.

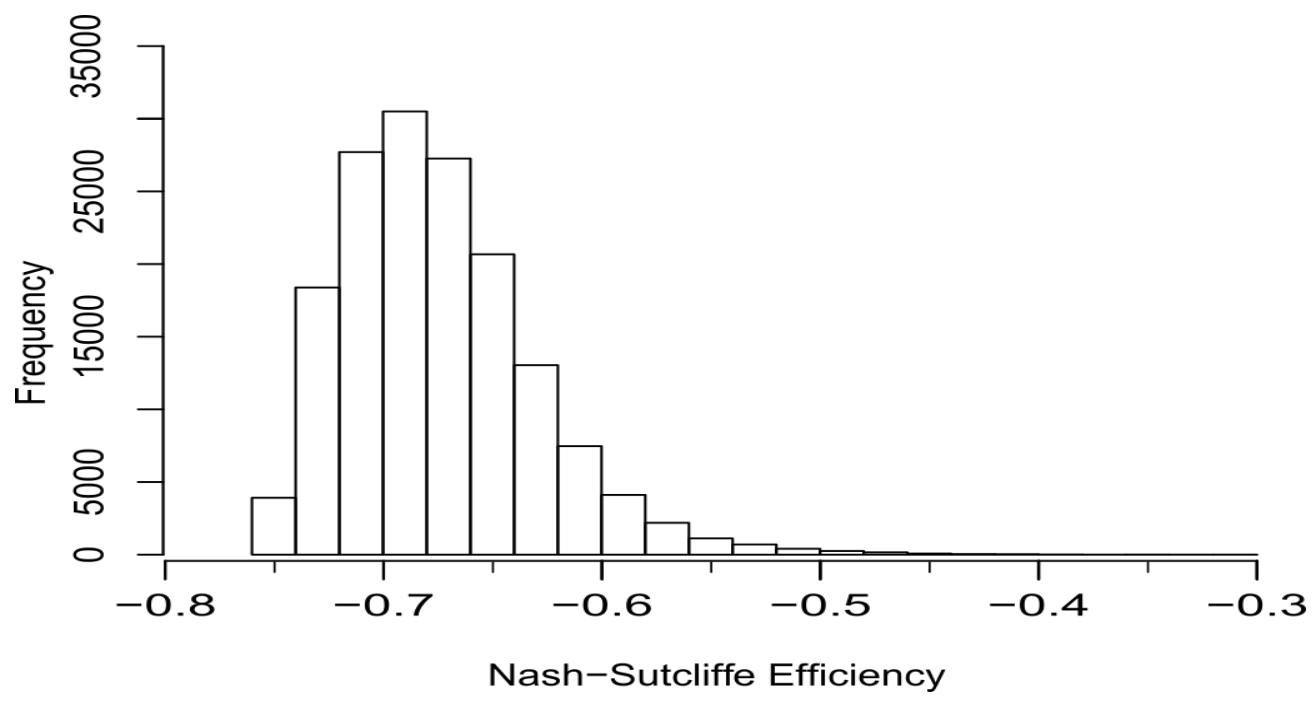

Figure A.1. The number of calibration parameter sets and their respective NSE objective functions for the Jock River Watershed model.

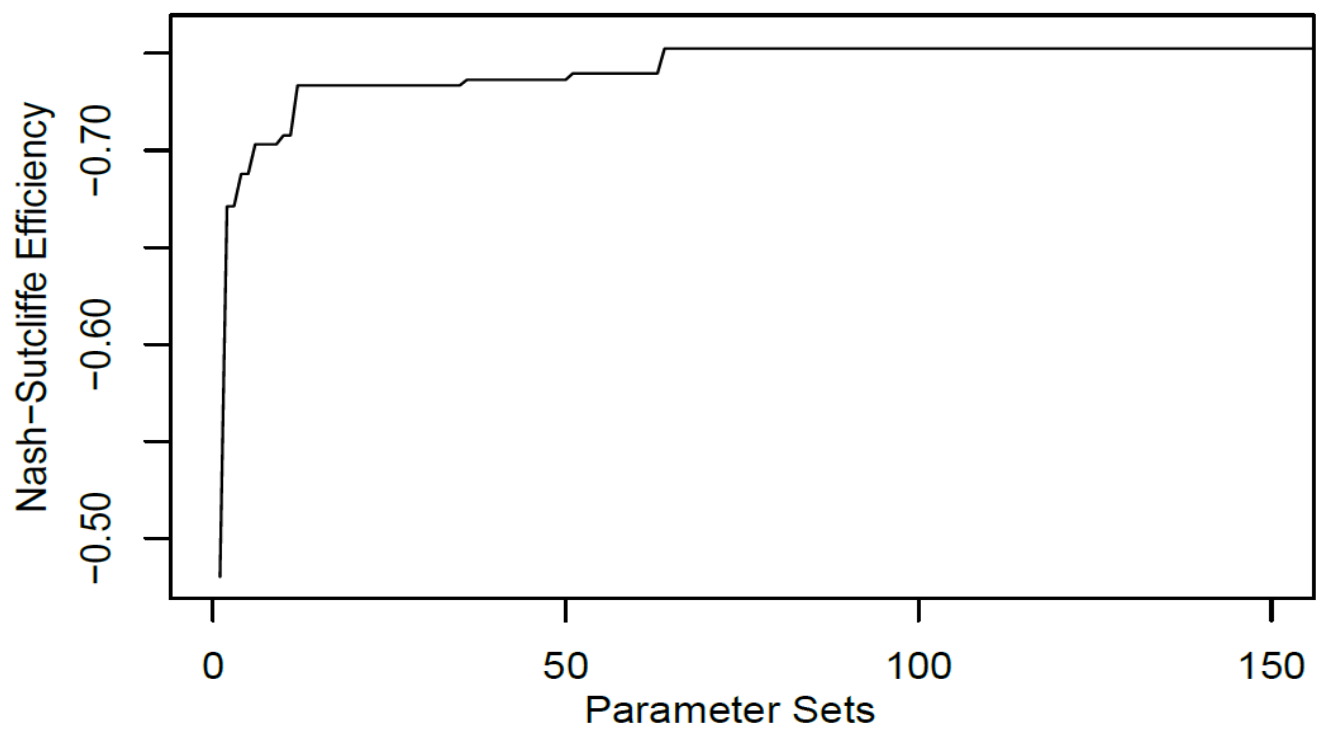

Figure A.2. The number of parameter sets before reaching a high a reasonable NSE 


\section{APPENDIX B (MODEL FIGURES)}

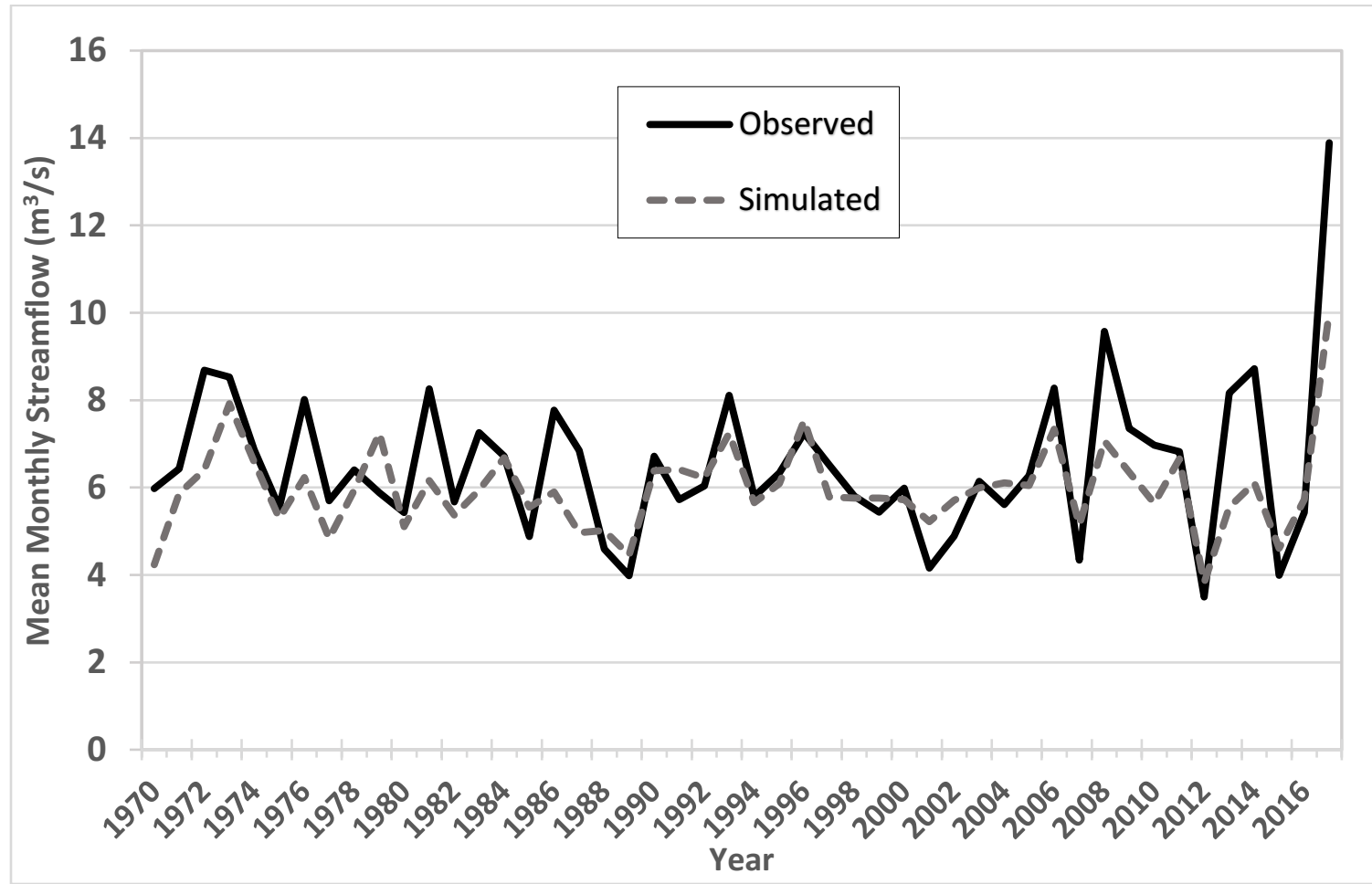

Figure B.1. A continuous plot of mean annual simulated and observed streamflow $\left(\mathrm{m}^{3} / \mathrm{s}\right)$.

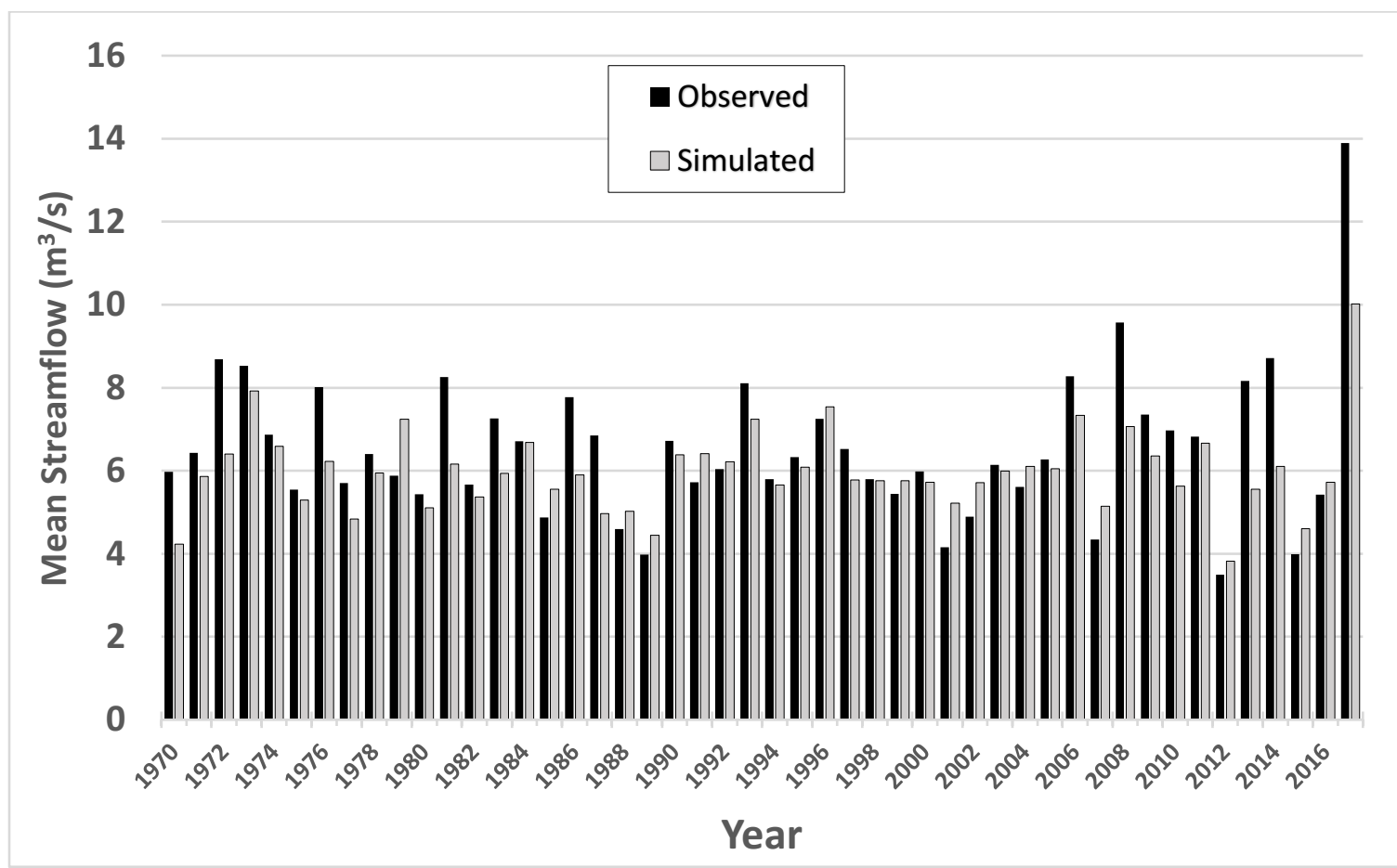

Figure B.2. Mean annual comparison for the Jock River of simulated and observed streamflow $\left(\mathrm{m}^{3} / \mathrm{s}\right)(1970-2017)$. 


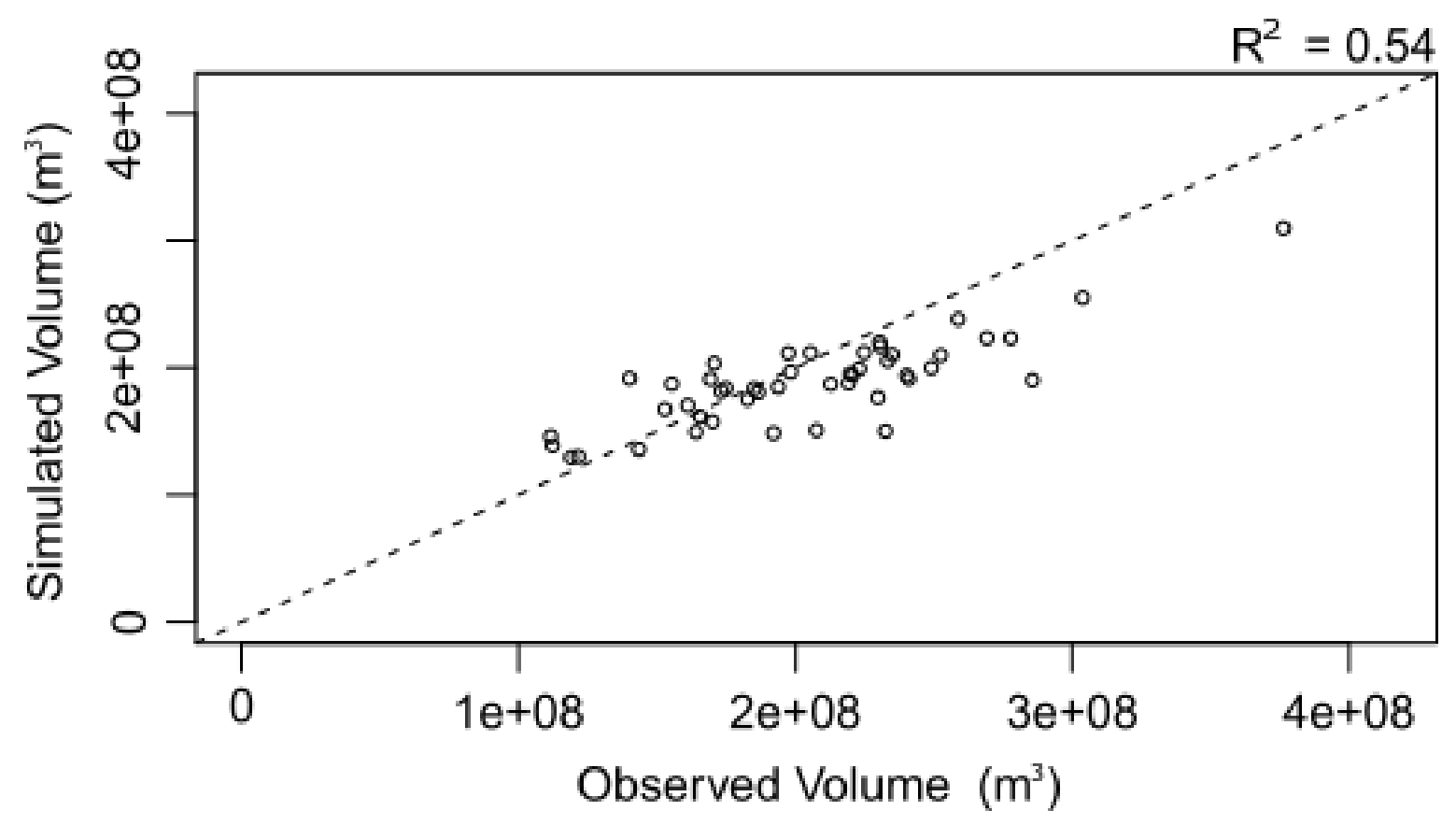

Figure B.3. Total yearly volume for all water years for the Jock River (1970-2017). Linear regression scatterplots of yearly volume simulated and observed streamflow $\left(\mathrm{m}^{3} / \mathrm{s}\right)$.

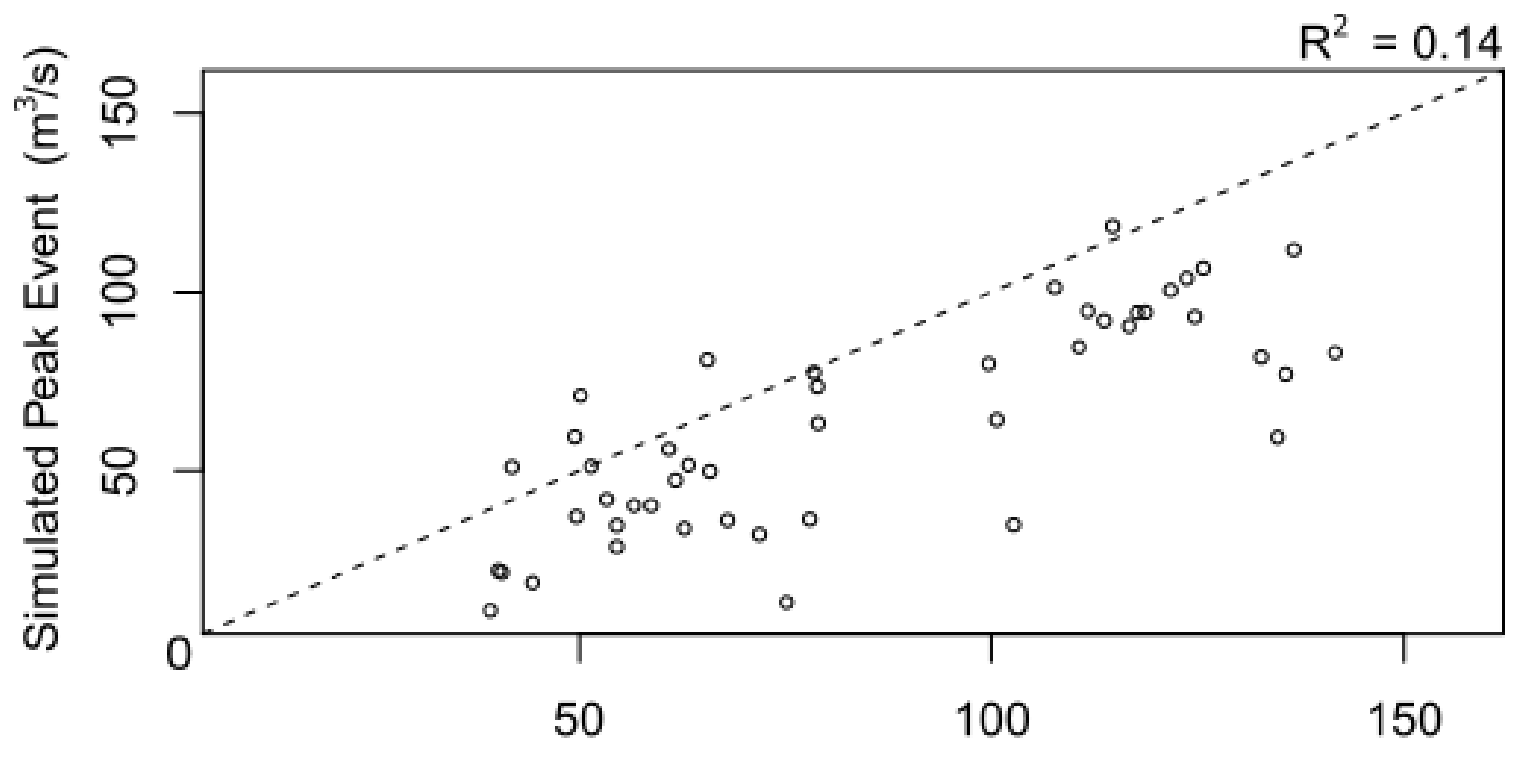

\section{Observed Peak Event $\left(\mathrm{m}^{3} / \mathrm{s}\right)$}

Figure B.4. Scatterplot of the annual observed and simulated peaks, calculated for each available water year of data. The peak event simulated for the same day as the peak event in observed data is used, instead of the largest recorded simulated event. In some sense this captures the timing of the event, i.e. the peak event must be simulated on the same day as the observed peak to be captured well. 


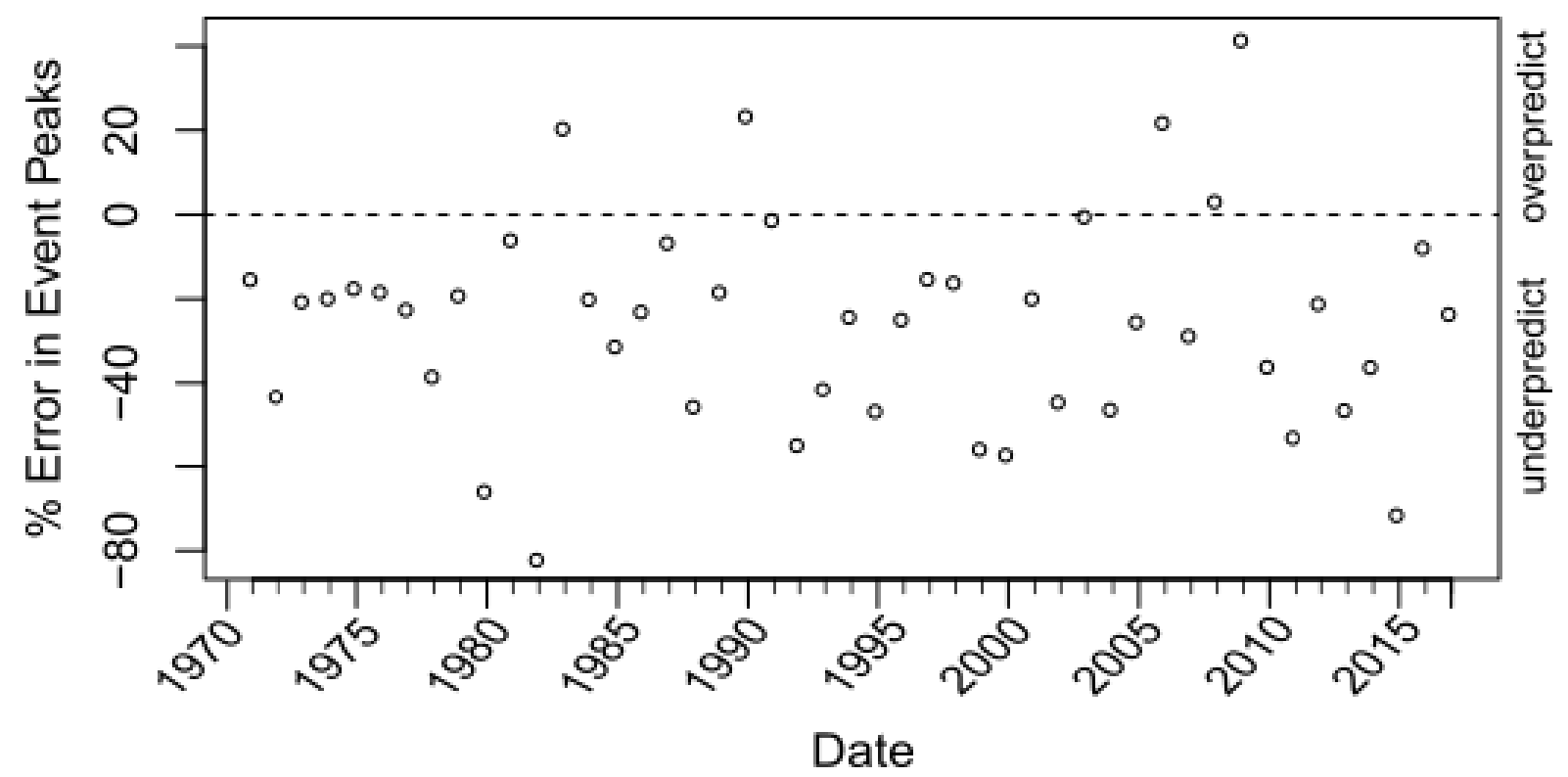

Figure B.5. Plot of the percent errors in simulated peak events for each water year. The peaks are calculated using flows from the same day as the peak event in the observed series, i.e. the timing of the peak is considered here.

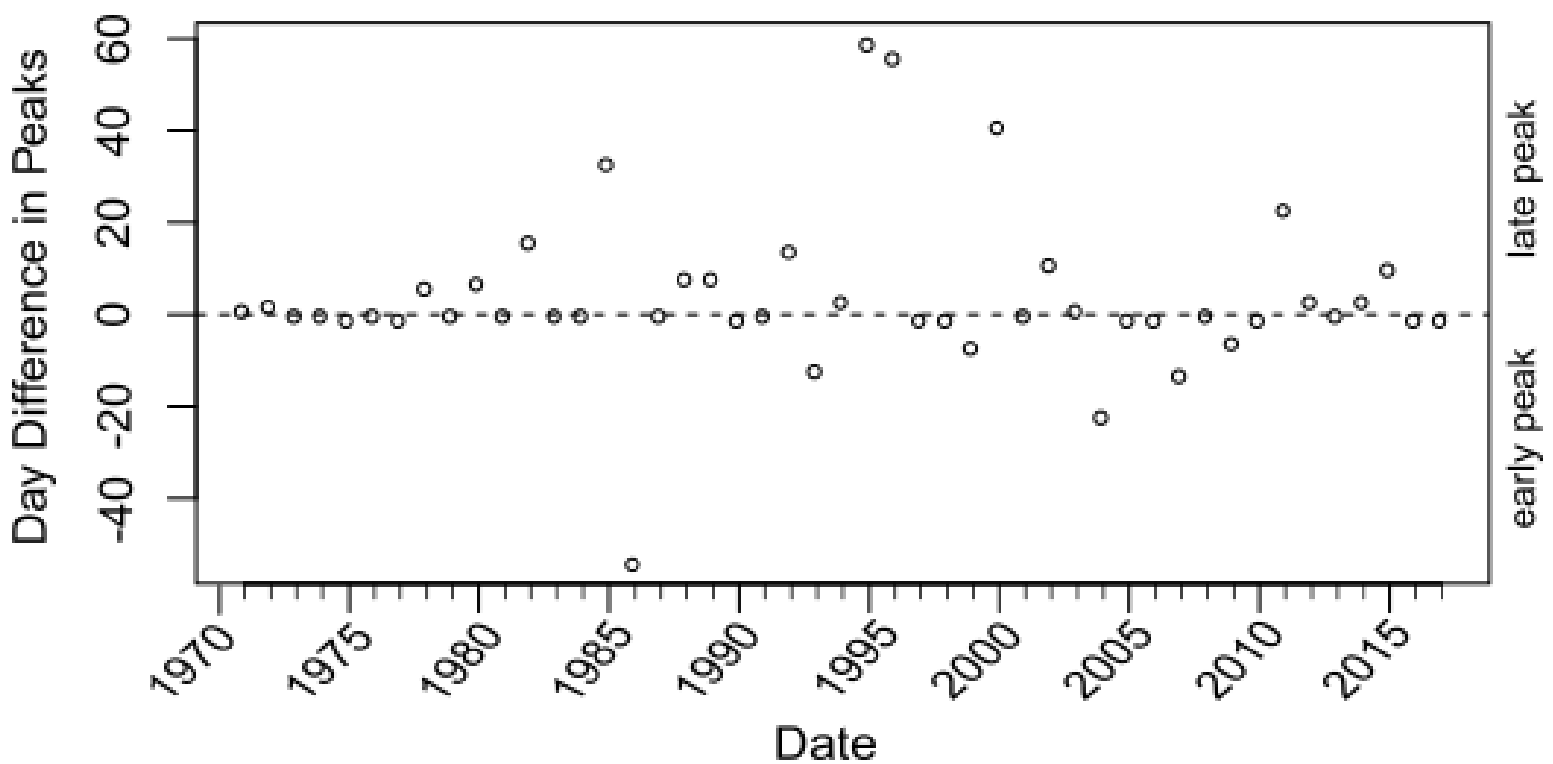

Figure B.6. Plot of the peak timing errors in simulated peaks for each water year. The difference in days between the simulated peak and observed peak are plotted (and/or returned in the data frame) for the water year. This diagnostic is useful in determining how accurate the timing of peak predictions is. 


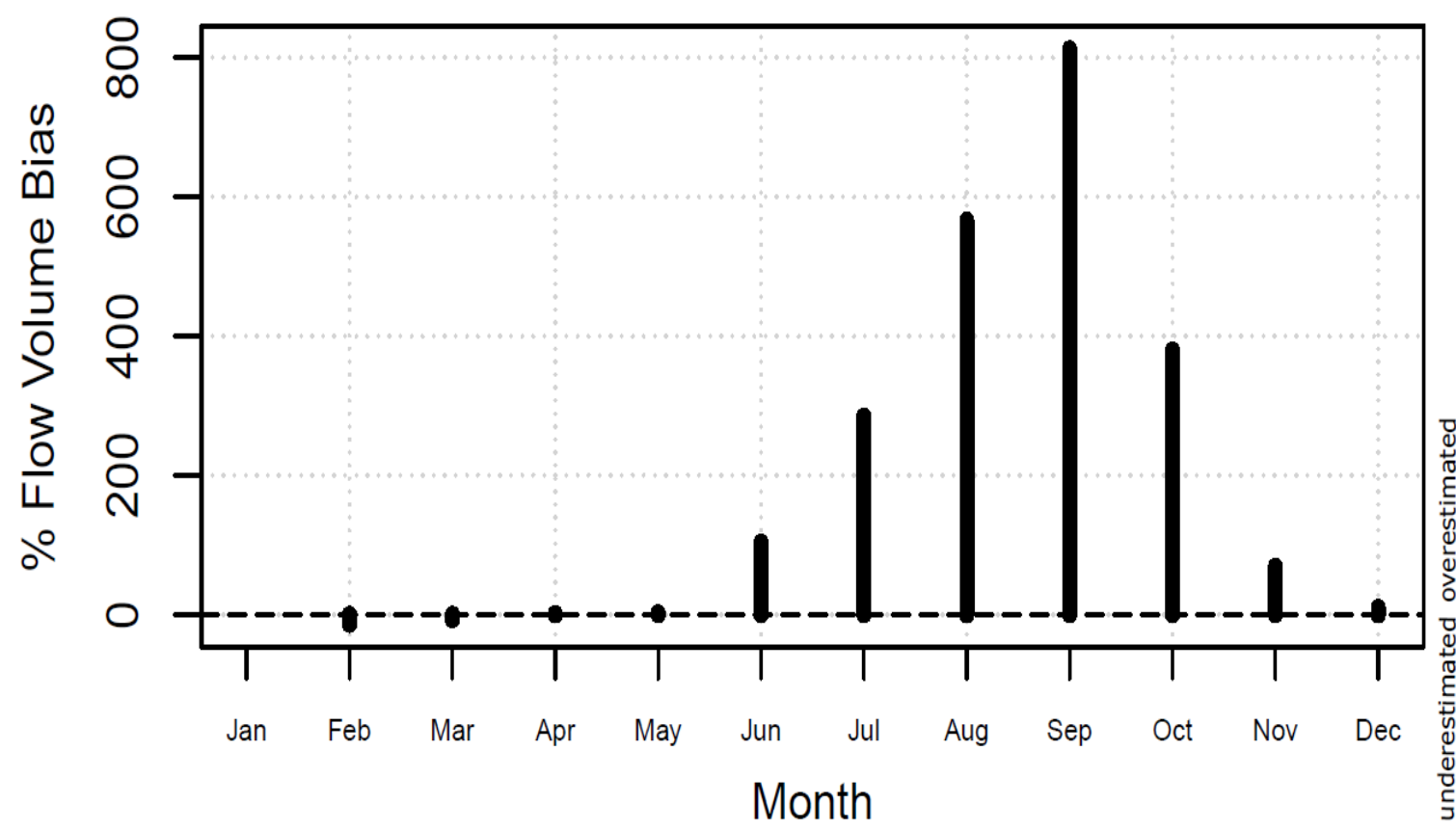

Figure B.7. Normalized monthly volume biases in the simulated flow series, the biases are calculated as a percentage error. The monthly volume biases are averaged across all years of data.

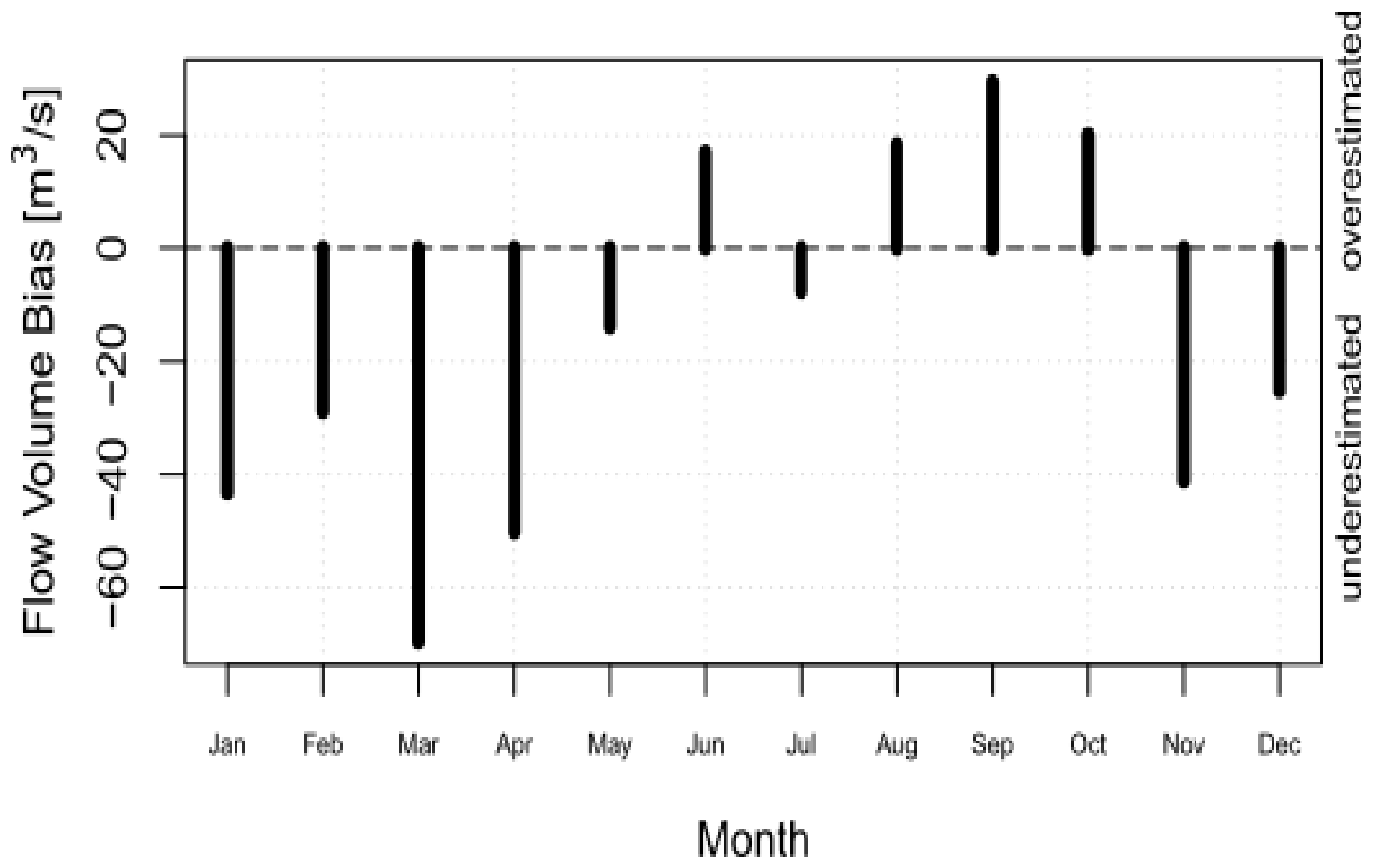

Figure B.8. Non-normalized monthly volume biases in the simulated flow series. The monthly volume biases are averaged across all years of data. 

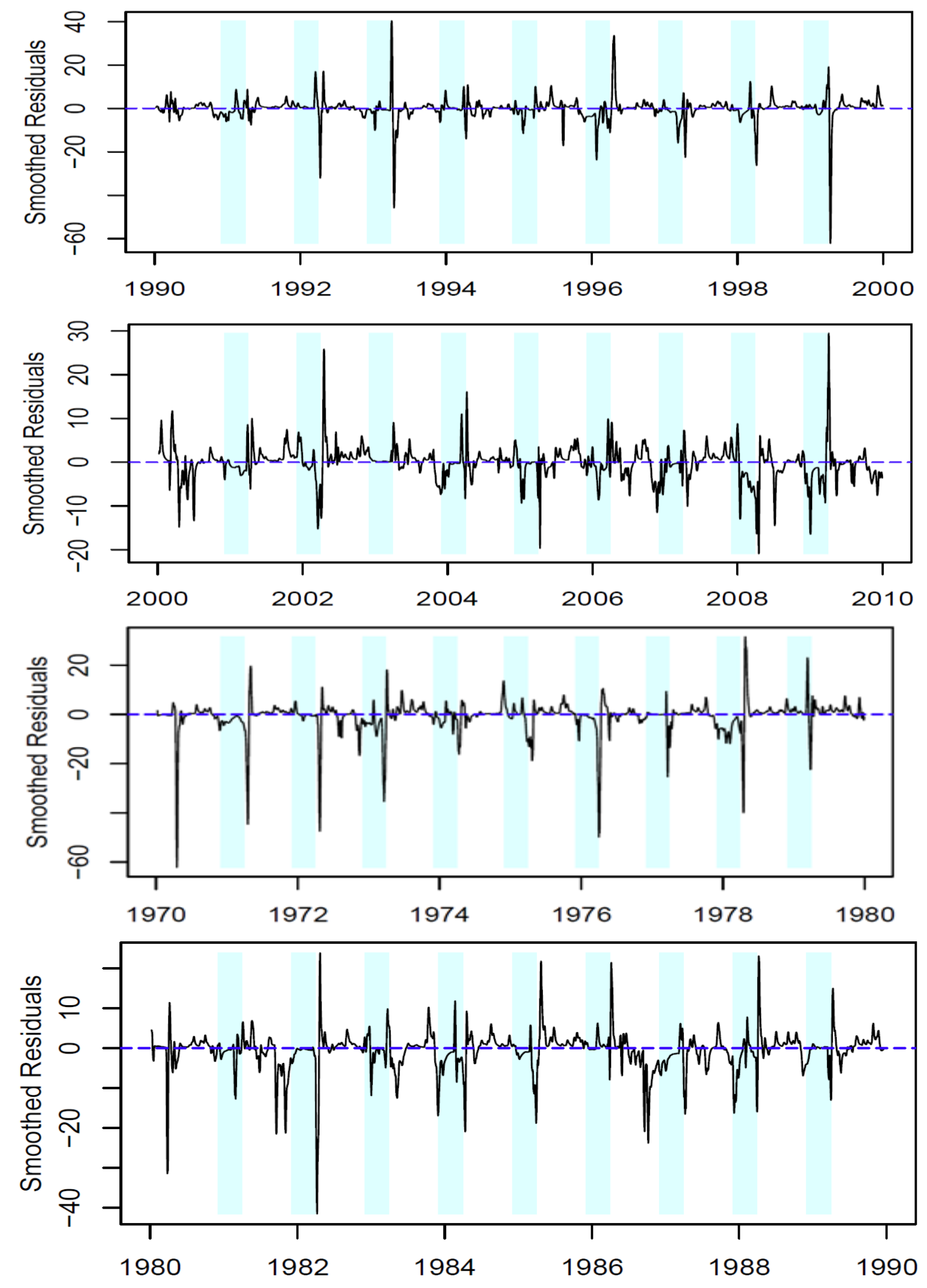

Figure B.9. A residuals time series plot from 1970-2017 for flow values with a 7-day smoothing filter. The residuals are calculated as simulated - observed. 
APPENDIX C (SENSITIVITY)
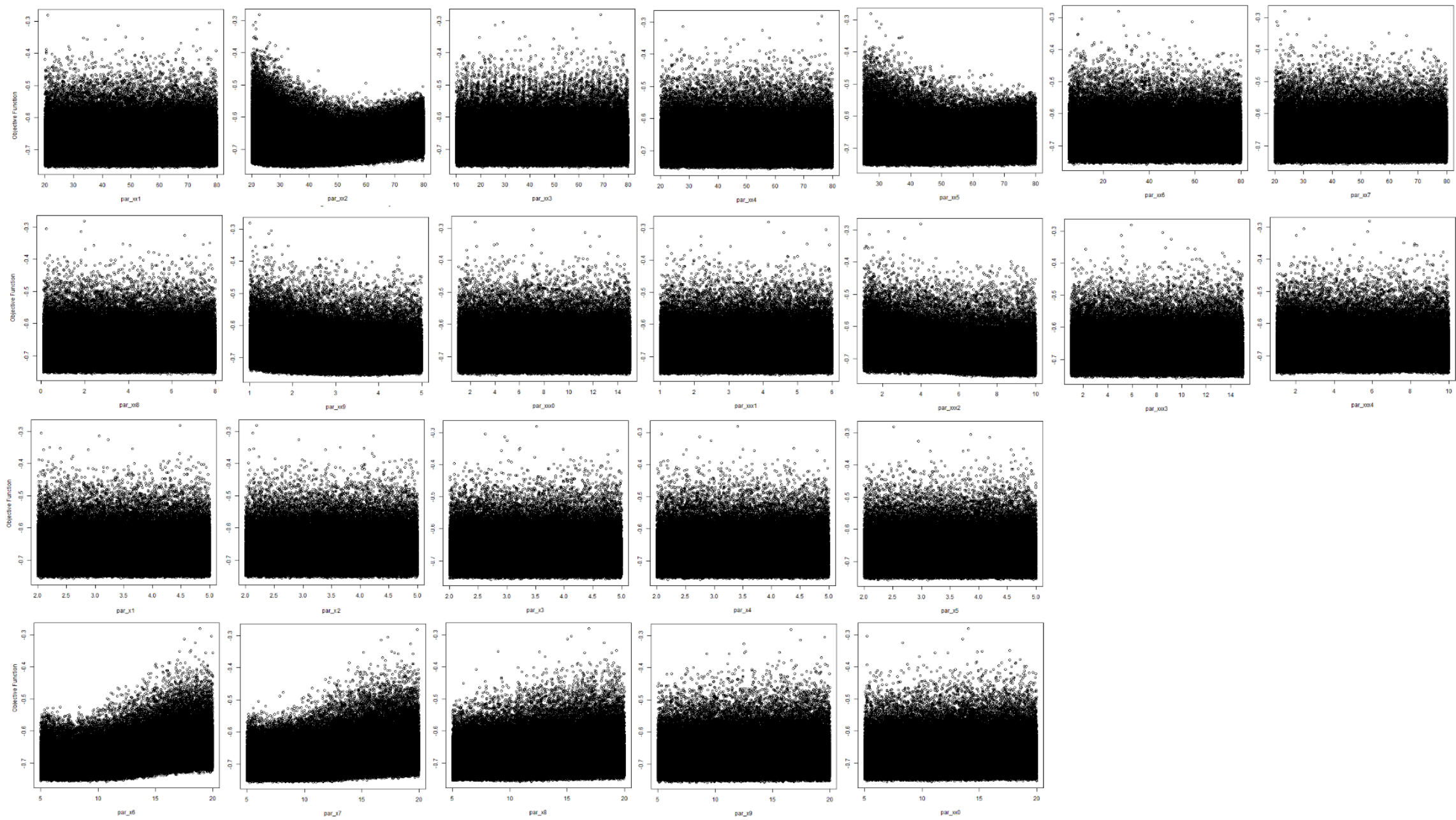

Figure C.1. Sensitivity for all 24 parameters for the 350,000 GLUE parameter sets. 
APPENDIX D (GEV ANALYSIS)

ANNUAL GEV (PROBALITY AND QUANTILE PLOTS)
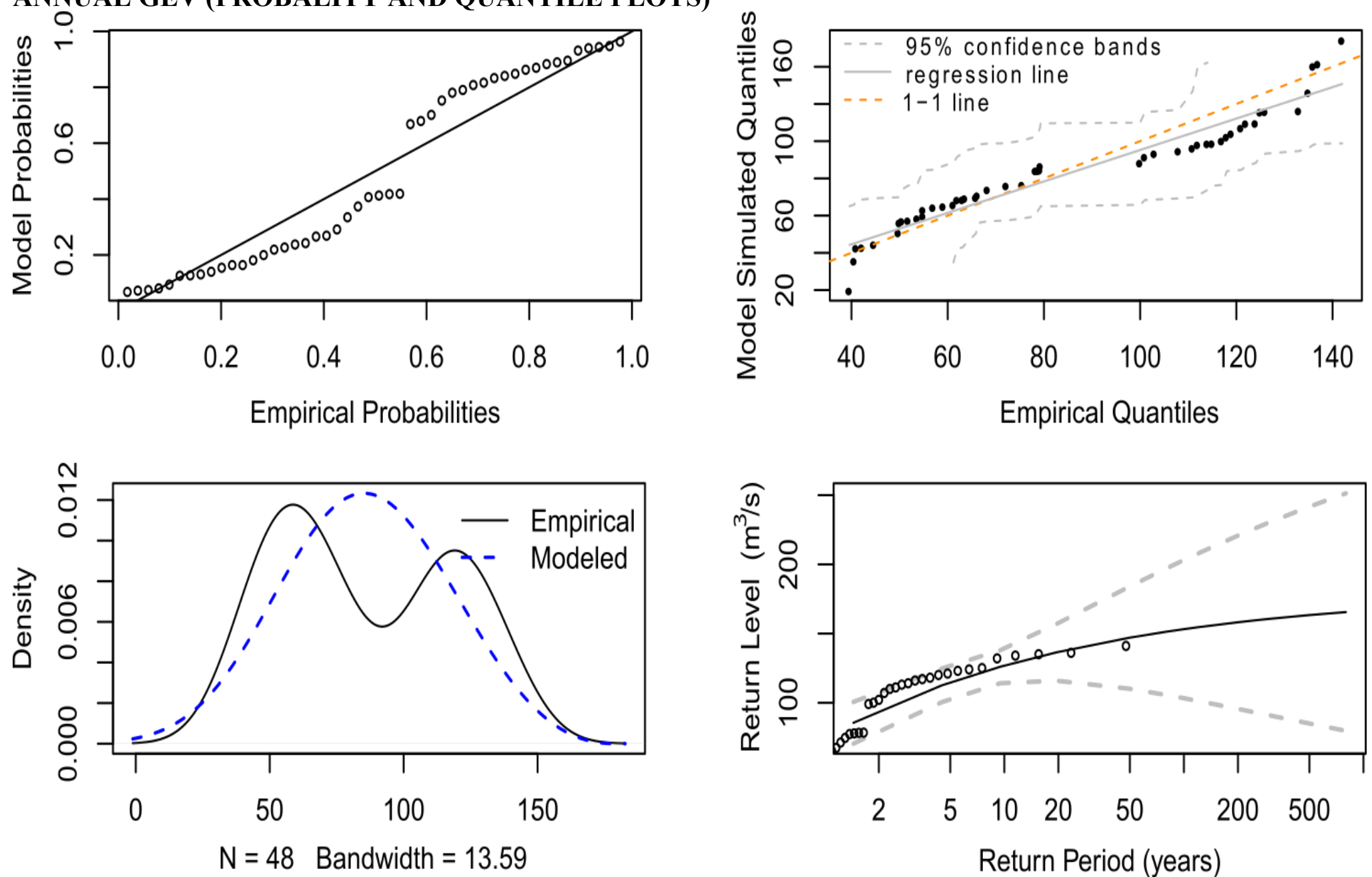

Figure D.1. Gumbel distribution with maximum likelihood for the 1970-2017 observed historical time-period. 
Table D.1. Statistics for return period, with from Mann Kendal and linear model

\begin{tabular}{|c|c|c|c|c|c|c|c|c|}
\hline Annual & 2-year & 5-year & 10-year & 20-year & 50 -year & 100-year & $\begin{array}{l}200 \\
\text { year }\end{array}$ & $\begin{array}{l}500- \\
\text { year }\end{array}$ \\
\hline Streamflow & 83.6 & 113.7 & 130.6 & 144.9 & 160.9 & 171.4 & 180.6 & 191.18 \\
\hline Kendall & tau & $\begin{array}{l}\text { 2-sided } \\
\text { pvalue }\end{array}$ & & & & & & \\
\hline & -0.32 & 0.0013751 & & & & & & \\
\hline Residuals: & Min & $1 \mathrm{Q}$ & Median & $3 \mathrm{Q}$ & Max & & & \\
\hline & -46.985 & -24.87 & -5.498 & 21.994 & 55.6 & & & \\
\hline Coefficients: & Estimate & Std. Error & t value & $\operatorname{Pr}(>|t|)$ & & & & \\
\hline (Intercept) & 110.283774 & 8.429279 & 13.083 & $<2 \mathrm{e} 16$ & & & & \\
\hline date & -0.002843 & 0.000846 & -3.361 & 0.00157 & & & & \\
\hline & $\begin{array}{l}\text { Residual } \\
\text { standard } \\
\text { error }\end{array}$ & $\begin{array}{l}\text { Multiple R- } \\
\text { squared }\end{array}$ & \multicolumn{2}{|c|}{ Adjusted R-squared } & $\begin{array}{l}\text { F- } \\
\text { statistic }\end{array}$ & p-value & & \\
\hline $\begin{array}{l}46 \text { degrees of } \\
\text { freedom }\end{array}$ & 29.66 & 0.1971 & 0.1797 & & 11.29 & 0.00157 & & \\
\hline
\end{tabular}



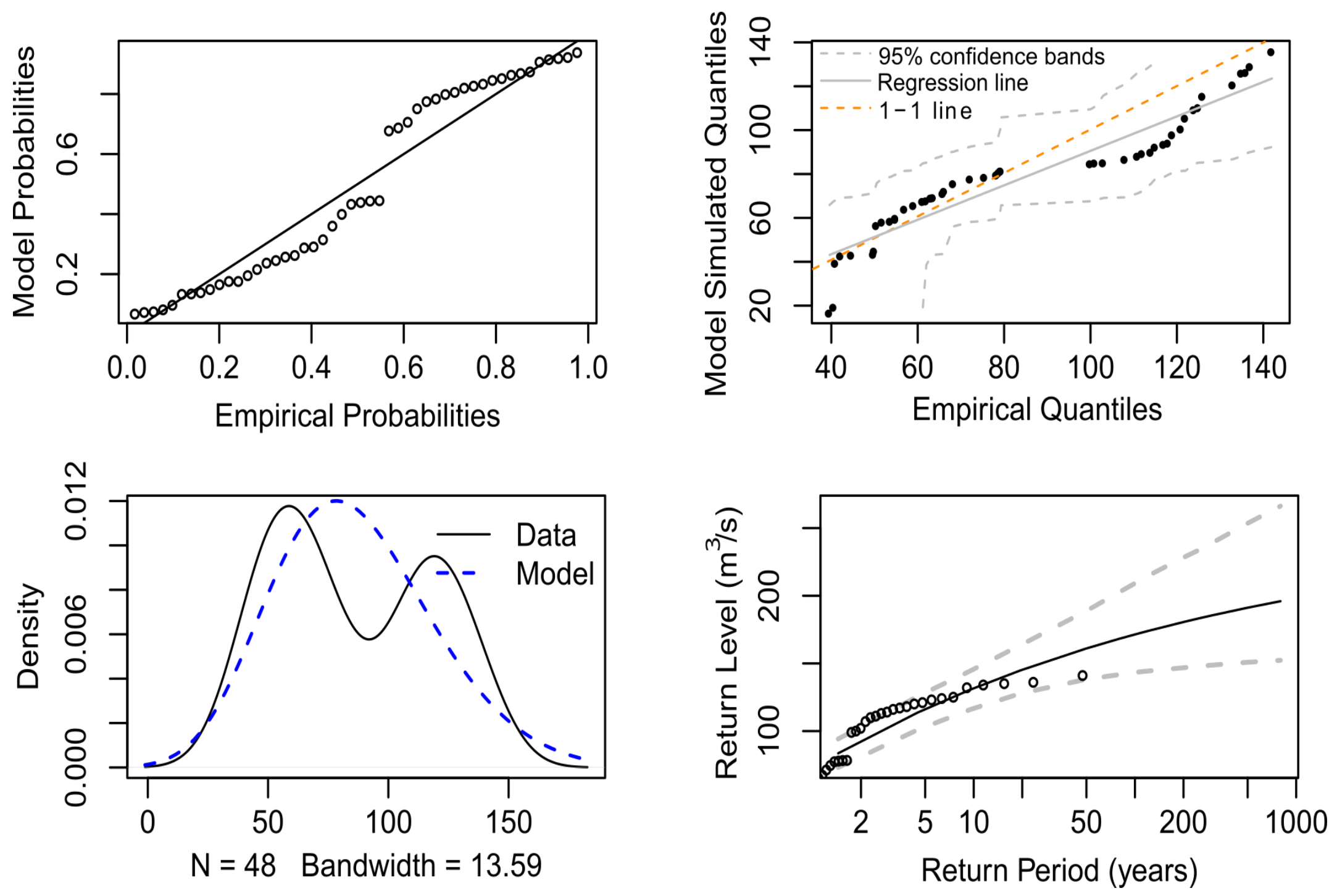

Figure D.2. The GEV distribution for the L-moment and maximum likelihood method of fitting distribution for observed data 


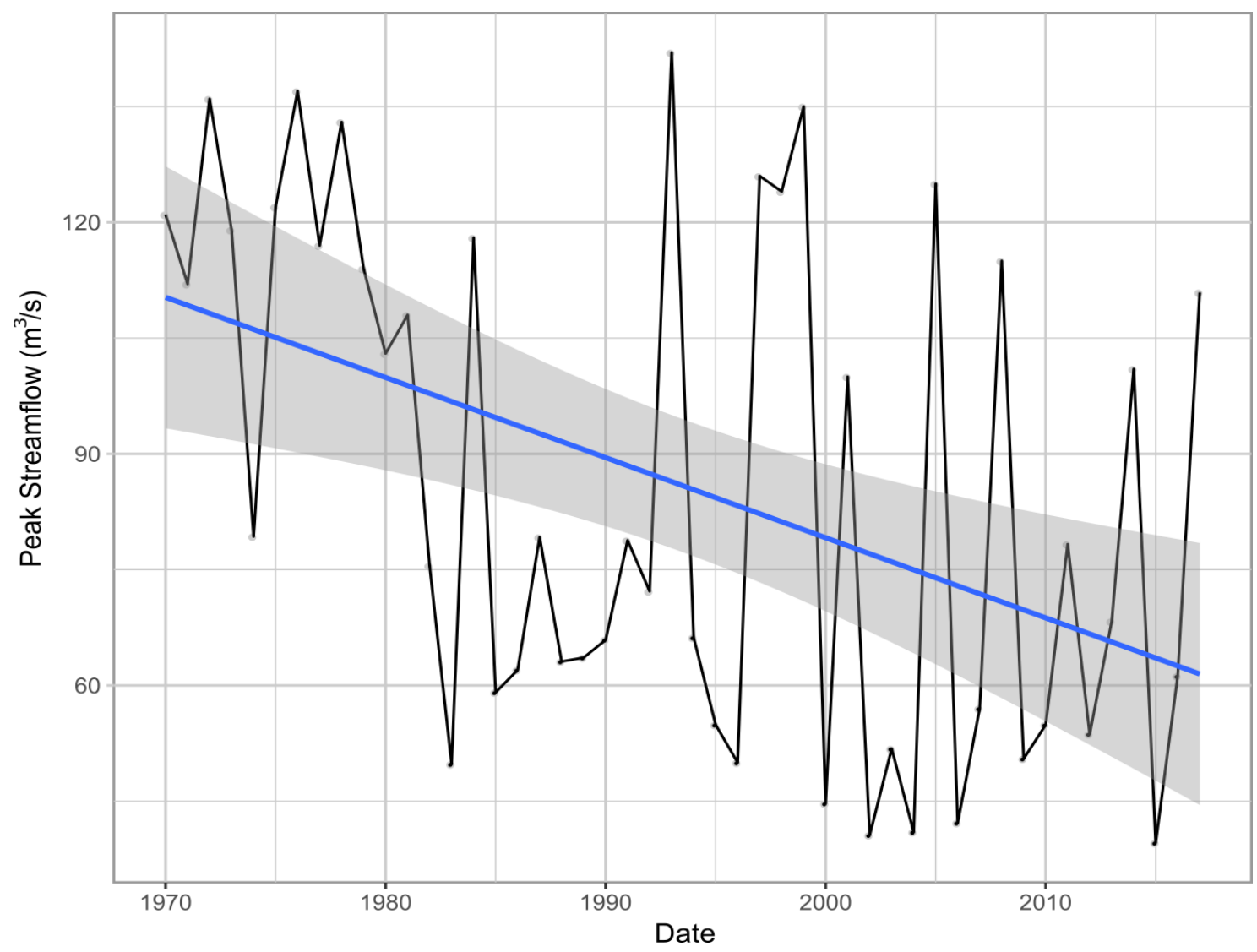

Figure D.3. Trend for the yearly annual dataset from 1970-2017 

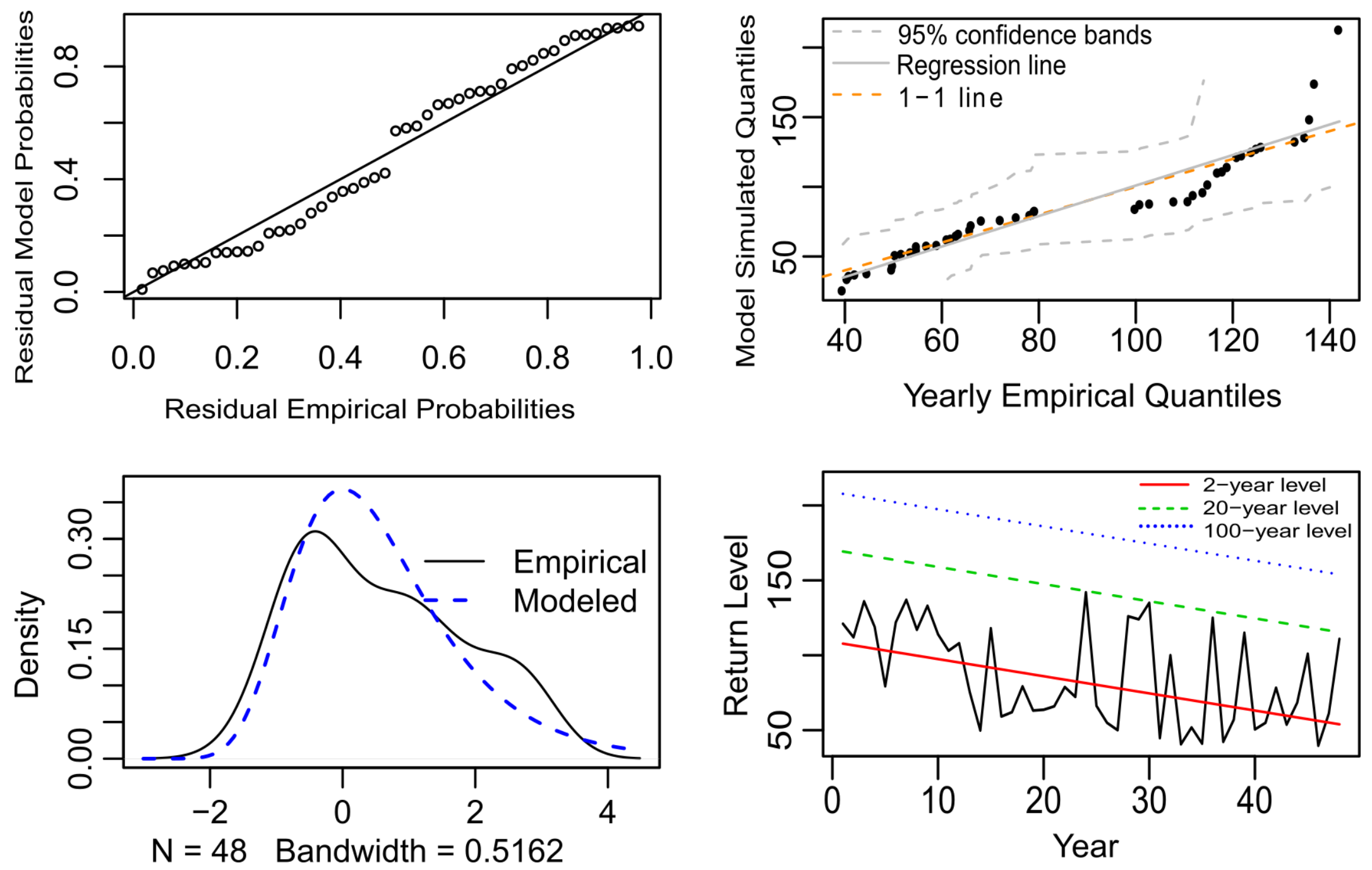

Figure D.4. Detrended plots for the 1970-2017 observed values. 

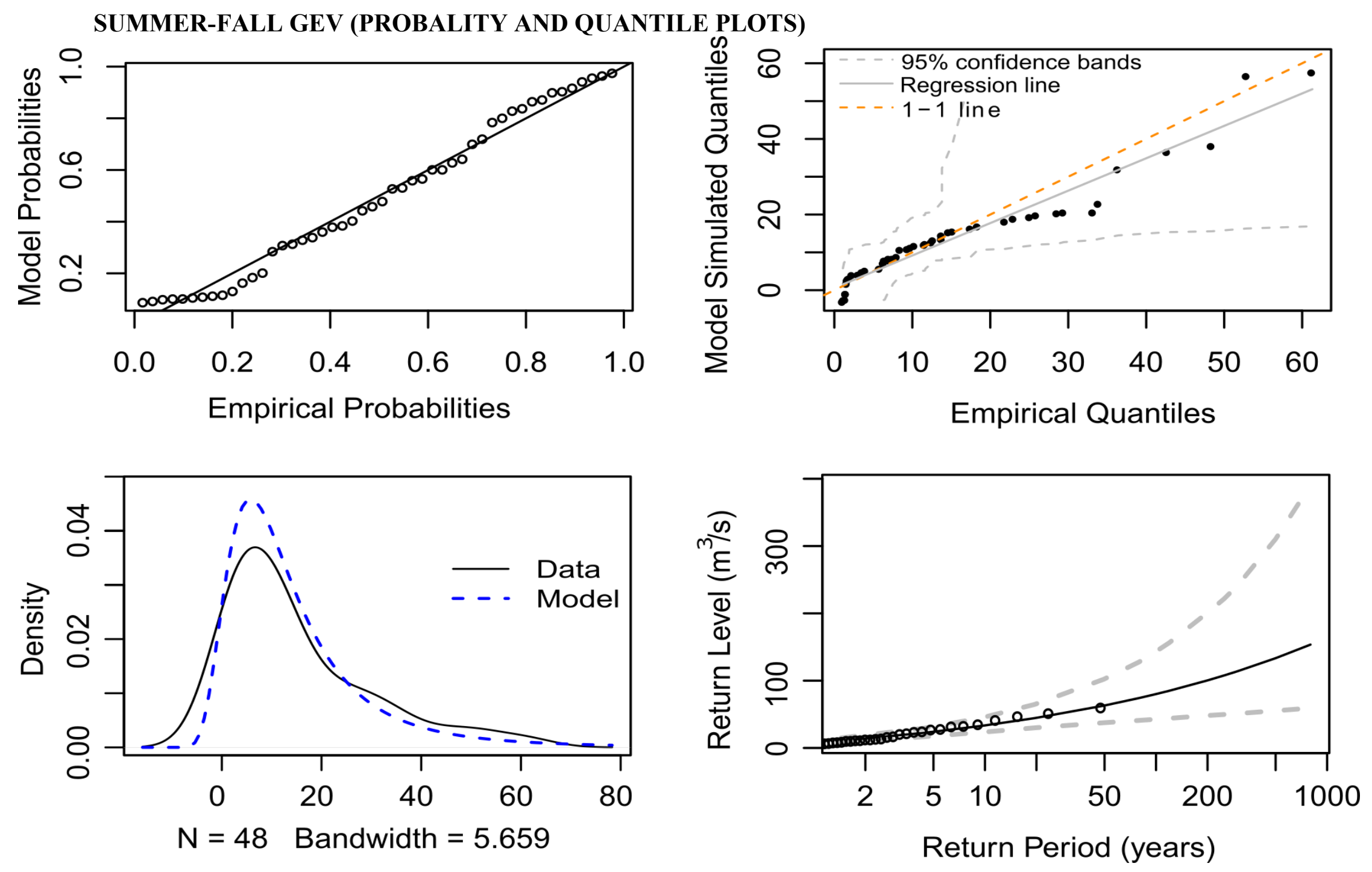

Figure D.5. Summer and Fall Time series plots for return period of GEV using L-moments 


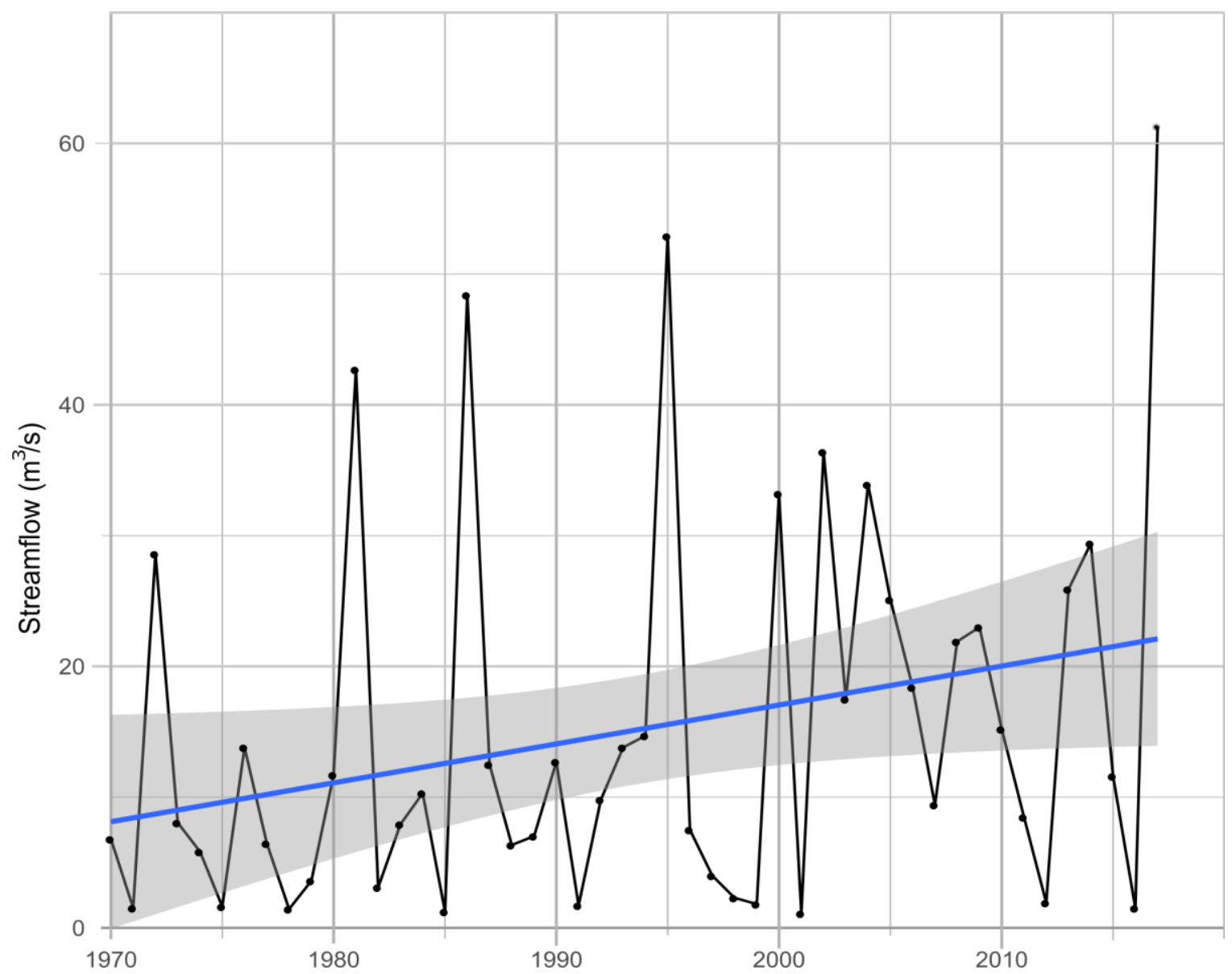

Figure D.6. Trend for Summer and Fall 
Table D.2. Statistics for return period, with from Manm Kendal and linear model

\begin{tabular}{|c|c|c|c|c|c|c|c|}
\hline SummerFall & 2-year & 5-year & 10-year & 20-year & 50-year & 100-year & 500-year \\
\hline Streamflow & 10.75939 & 22.69127 & 32.7185 & 44.3206 & 62.8794 & 79.9846 & 133.381 \\
\hline \multirow[t]{2}{*}{ Kendall } & tau & \multicolumn{2}{|l|}{ 2-sided pvalue } & & & \\
\hline & 0.21 & \multicolumn{2}{|r|}{0.035935} & & & & \\
\hline \multirow[t]{2}{*}{ Residuals: } & Min & $1 Q$ & Median & $3 Q$ & Max & & \\
\hline & -20.297 & -8.707 & -2.732 & 3.43 & 39.194 & & \\
\hline Coefficients: & Estimate & Std. Error & t value & $\operatorname{Pr}(>|t|)$ & & & \\
\hline (Intercept) & 8.1189013 & 4.062367 & 1.999 & 0.0516 & & & \\
\hline \multirow[t]{2}{*}{ date } & 0.0008147 & 0.000408 & 1.998 & 0.0516 & & & \\
\hline & $\begin{array}{l}\text { Residual } \\
\text { standard } \\
\text { error }\end{array}$ & $\begin{array}{l}\text { Multiple R- } \\
\text { squared }\end{array}$ & \multicolumn{2}{|c|}{ Adjusted R-squared } & $\begin{array}{l}\text { F- } \\
\text { statistic }\end{array}$ & p-value & \\
\hline $46 \mathrm{DF}$ & 14.29 & 0.07988 & & 0.05987 & 3.993 & 0.05161 & \\
\hline
\end{tabular}



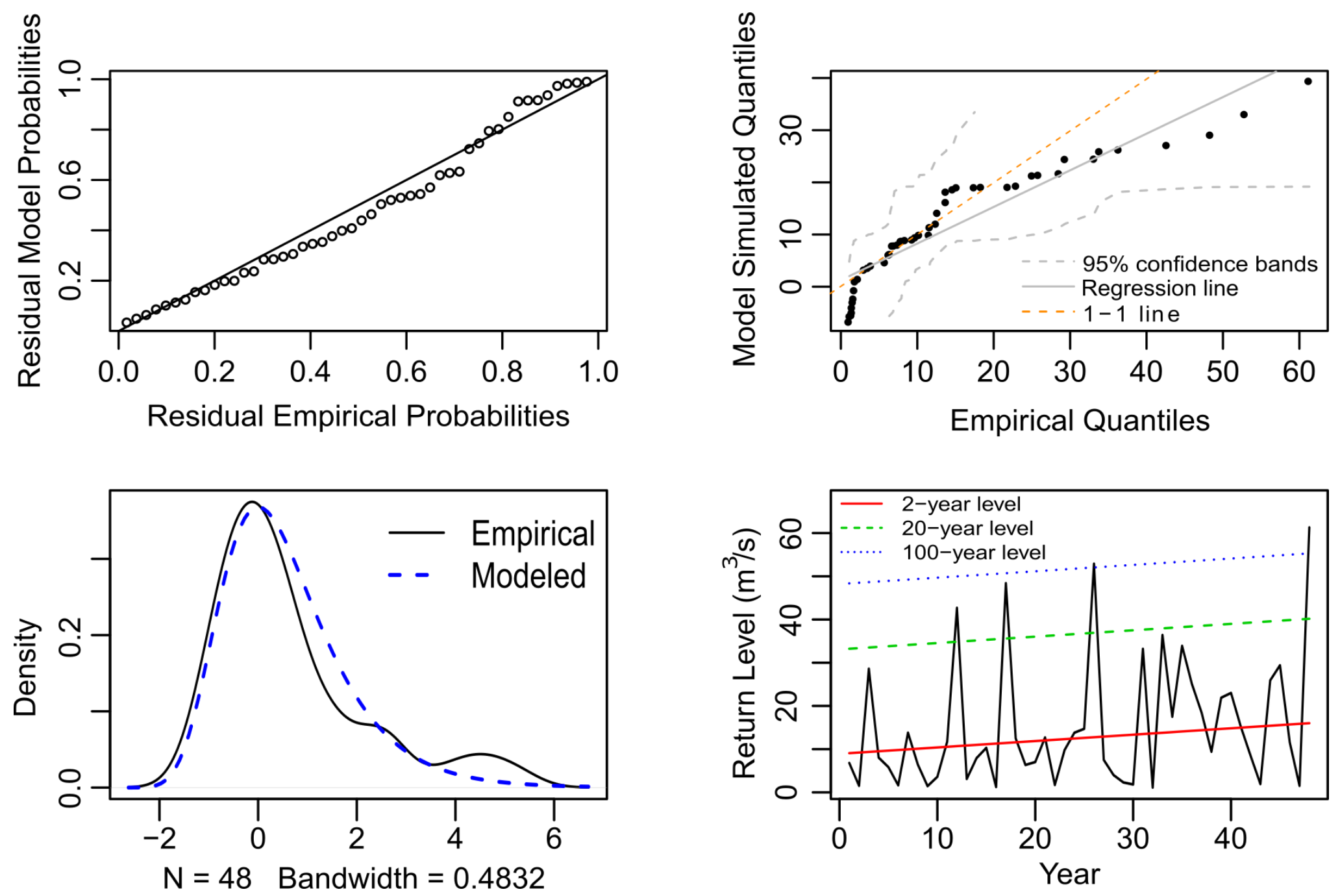

Figure D.7. Compared to the return level plots of the previous posts (without trend), this return level plot looks different. It displays the change of the return levels over time. 


\section{APPENDIX E (FUTURE SCENARIO RESULTS)}

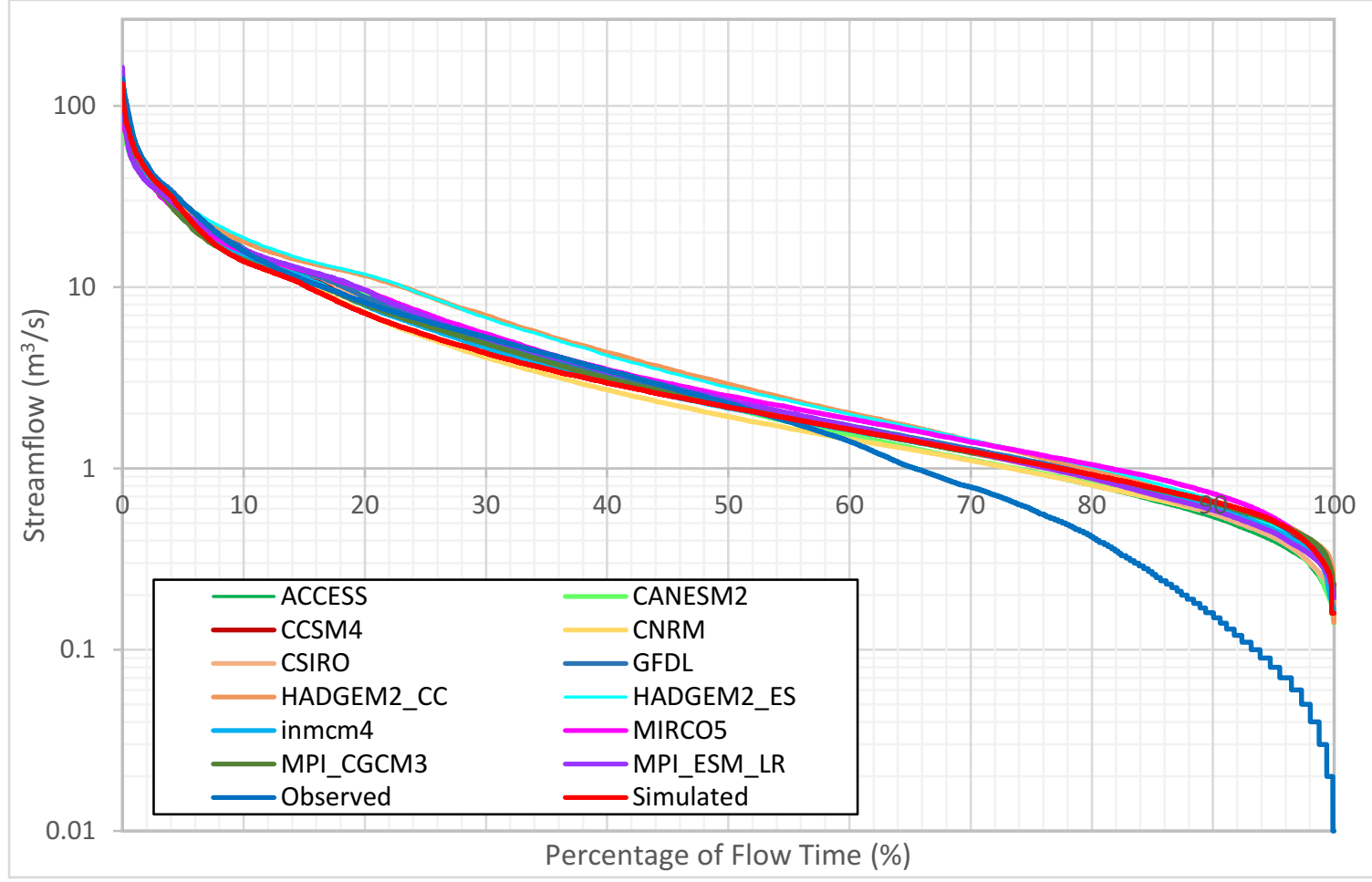

Figure E.1 Flow duration curve for the 2011-2040 time period.

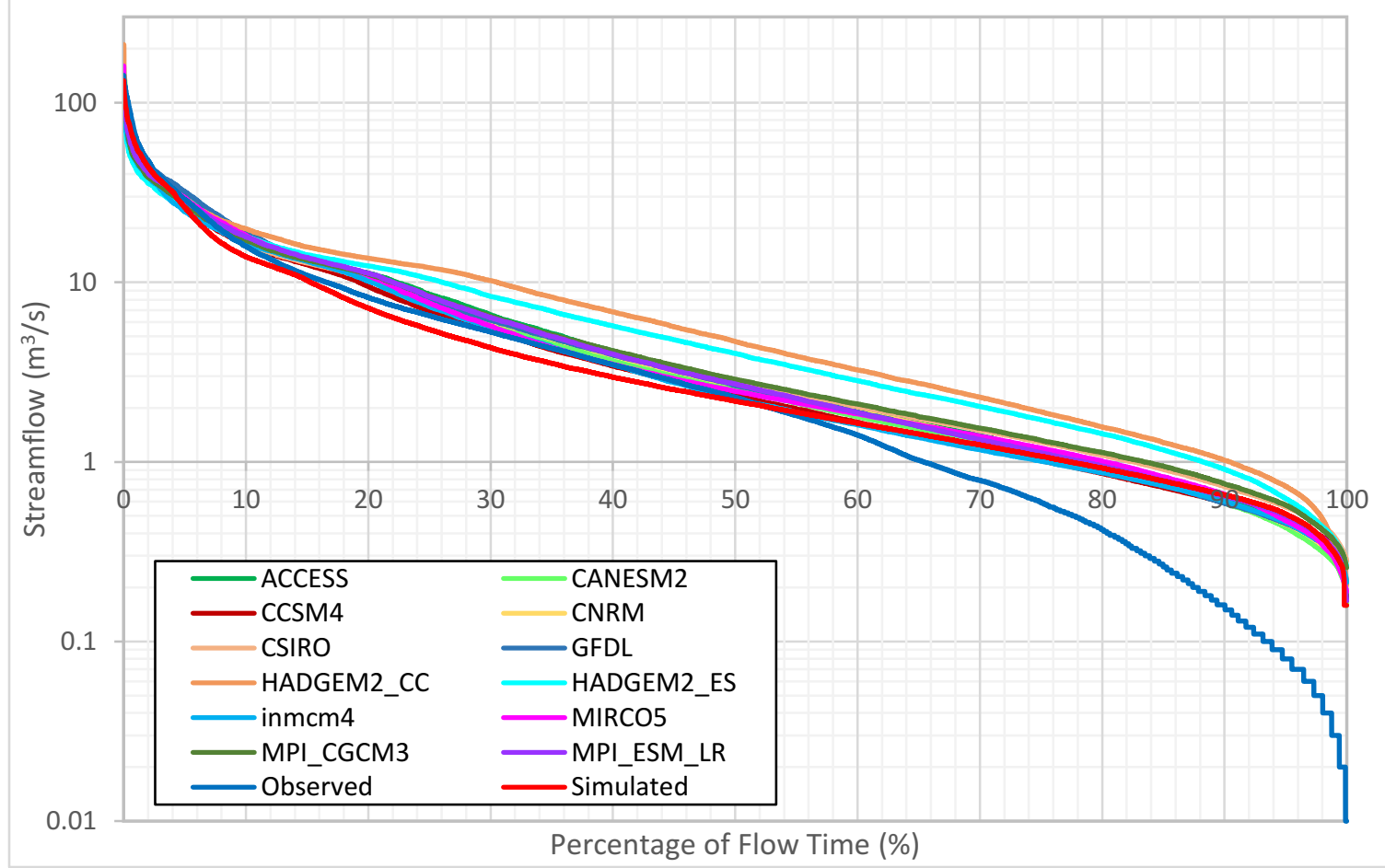

Figure E.2 Flow duration curve for the 2041-2070 time period. 


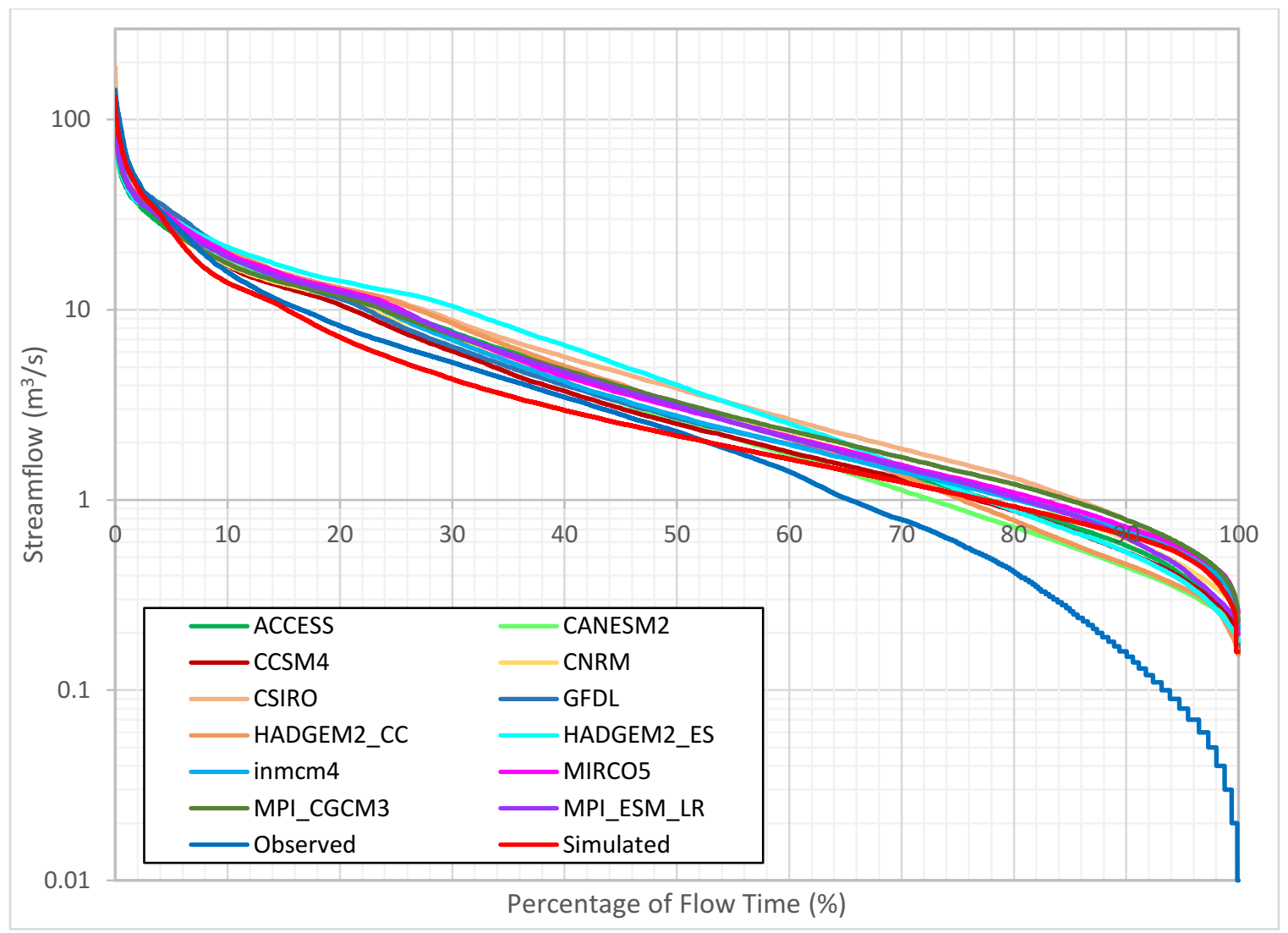

Figure E.3 Flow duration curve for the 2071-2099 time period. 
Table E.1. Individual model results for GEV climate change scenario distribution summer-fall for Gumbel distribution.

\begin{tabular}{|c|c|c|c|c|c|c|c|c|c|}
\hline \multirow{2}{*}{$\begin{array}{l}\text { Time- } \\
\text { period }\end{array}$} & \multirow[t]{2}{*}{ Model } & \multicolumn{8}{|c|}{ Return Periods (Years) } \\
\hline & & 2 & 5 & 10 & 20 & 50 & 100 & 200 & 500 \\
\hline \multirow[t]{2}{*}{ 1970-2017 } & Observed - Gumbel & 80.1 & 110.9 & 131.3 & 150.8 & 176.1 & 195.1 & 214.0 & 238.9 \\
\hline & Simulated - Gumbel & 74.2 & 100.0 & 117.0 & 133.4 & 154.5 & 170.4 & 186.2 & 207.1 \\
\hline \multirow[t]{13}{*}{ 2011-2040 } & ACCESS & 63.0 & 84.3 & 98.4 & 111.9 & 129.4 & 142.6 & 155.6 & 172.9 \\
\hline & CANESM2 & 59.3 & 77.6 & 89.8 & 101.4 & 116.5 & 127.8 & 139.0 & 153.9 \\
\hline & CCSM4 & 73.0 & 98.8 & 115.8 & 132.2 & 153.3 & 169.2 & 185.0 & 205.9 \\
\hline & CNRM & 61.6 & 85.8 & 101.8 & 117.2 & 137.1 & 152.0 & 166.9 & 186.5 \\
\hline & CSIRO & 80.3 & 107.7 & 125.9 & 143.3 & 165.8 & 182.7 & 199.6 & 221.8 \\
\hline & GFDL & 77.3 & 106.1 & 125.2 & 143.5 & 167.2 & 185.0 & 202.7 & 226.1 \\
\hline & HADGEM2_CC & 60.4 & 78.9 & 91.1 & 102.9 & 118.1 & 129.5 & 140.8 & 155.8 \\
\hline & HADGEM2_ES & 66.9 & 89.9 & 105.1 & 119.7 & 138.7 & 152.9 & 167.0 & 185.6 \\
\hline & inmcm4 & 65.2 & 92.9 & 111.2 & 128.8 & 151.5 & 168.6 & 185.5 & 207.9 \\
\hline & MIRCO5 & 59.0 & 80.1 & 94.1 & 107.5 & 124.9 & 137.9 & 150.8 & 167.9 \\
\hline & MPI_CGCM3 & 63.6 & 85.6 & 100.1 & 114.1 & 132.1 & 145.6 & 159.1 & 176.9 \\
\hline & MPI_ESM_LR & 64.3 & 88.3 & 104.2 & 119.5 & 139.3 & 154.1 & 168.8 & 188.3 \\
\hline & Mean & 66.2 & 89.7 & 105.2 & 120.2 & 139.5 & 154.0 & 168.4 & 187.5 \\
\hline \multirow[t]{13}{*}{ 2041-2070 } & ACCESS & 65.6 & 88.4 & 103.4 & 117.8 & 136.5 & 150.5 & 164.5 & 182.9 \\
\hline & CANESM2 & 74.6 & 108.5 & 130.9 & 152.3 & 180.1 & 201.0 & 221.7 & 249.1 \\
\hline & CCSM4 & 65.7 & 93.1 & 111.2 & 128.6 & 151.1 & 167.9 & 184.7 & 206.9 \\
\hline & CNRM & 60.8 & 82.2 & 96.3 & 109.9 & 127.5 & 140.6 & 153.7 & 171.0 \\
\hline & CSIRO & 75.3 & 103.4 & 122.0 & 139.8 & 162.9 & 180.2 & 197.5 & 220.2 \\
\hline & GFDL & 80.2 & 107.8 & 126.0 & 143.6 & 166.3 & 183.3 & 200.2 & 222.6 \\
\hline & HADGEM2_CC & 63.9 & 91.4 & 109.6 & 127.0 & 149.6 & 166.6 & 183.4 & 205.7 \\
\hline & HADGEM2_ES & 55.8 & 74.5 & 86.8 & 98.6 & 114.0 & 125.5 & 136.9 & 152.0 \\
\hline & inmcm4 & 53.6 & 75.8 & 90.5 & 104.6 & 122.9 & 136.6 & 150.2 & 168.2 \\
\hline & MIRCO5 & 70.3 & 93.2 & 108.4 & 122.9 & 141.7 & 155.8 & 169.9 & 188.4 \\
\hline & MPI_CGCM3 & 64.5 & 86.0 & 100.2 & 113.9 & 131.6 & 144.8 & 158.0 & 175.4 \\
\hline & MPI_ESM_LR & 67.3 & 91.6 & 107.7 & 123.2 & 143.2 & 158.2 & 173.1 & 192.8 \\
\hline & Mean & 66.5 & 91.3 & 107.7 & 123.5 & 143.9 & 159.2 & 174.5 & 194.6 \\
\hline \multirow[t]{13}{*}{ 2071-2097 } & ACCESS & 54.5 & 73.2 & 85.7 & 97.6 & 113.1 & 124.6 & 136.2 & 151.4 \\
\hline & CANESM2 & 62.4 & 86.6 & 102.7 & 118.0 & 137.9 & 152.8 & 167.7 & 187.3 \\
\hline & CCSM4 & 69.7 & 99.5 & 119.3 & 138.2 & 162.7 & 181.1 & 199.4 & 223.5 \\
\hline & CNRM & 61.1 & 82.8 & 97.1 & 110.8 & 128.6 & 142.0 & 155.2 & 172.8 \\
\hline & CSIRO & 77.9 & 109.9 & 131.0 & 151.3 & 177.6 & 197.3 & 216.9 & 242.8 \\
\hline & GFDL & 73.6 & 99.4 & 116.5 & 132.8 & 154.0 & 169.9 & 185.7 & 206.6 \\
\hline & HADGEM2_CC & 60.6 & 82.4 & 96.9 & 110.8 & 128.7 & 142.2 & 155.6 & 173.3 \\
\hline & HADGEM2_ES & 56.8 & 75.5 & 87.9 & 99.8 & 115.2 & 126.8 & 138.3 & 153.4 \\
\hline & inmem4 & 57.6 & 75.2 & 86.8 & 97.9 & 112.3 & 123.1 & 133.9 & 148.1 \\
\hline & MIRCO5 & 64.1 & 84.8 & 98.5 & 111.6 & 128.6 & 141.4 & 154.1 & 170.8 \\
\hline & MPI_CGCM3 & 64.1 & 83.8 & 96.9 & 109.4 & 125.7 & 137.9 & 150.0 & 166.0 \\
\hline & MPI_ESM_LR & 59.5 & 81.1 & 95.3 & 109.0 & 126.7 & 139.9 & 153.2 & 170.6 \\
\hline & Mean & 63.5 & 86.2 & 101.2 & 115.6 & 134.3 & 148.2 & 162.2 & 180.5 \\
\hline
\end{tabular}


Table E.2. Individual model results for GEV climate change scenario distribution

\begin{tabular}{|c|c|c|c|c|c|c|c|c|c|}
\hline \multirow[t]{2}{*}{ Time period } & \multirow[t]{2}{*}{ Model } & \multicolumn{8}{|c|}{ Return Periods } \\
\hline & & 2 & 5 & 10 & 20 & 50 & 100 & 200 & 500 \\
\hline \multirow[t]{2}{*}{ 1970-2017 } & Observed - L-moment & 10.9 & 22.9 & 32.9 & 44.4 & 61.1 & 79.3 & 99.0 & 130.8 \\
\hline & Simulated - L-moment & 10.1 & 15.0 & 18.9 & 23.3 & 29.9 & 35.7 & 42.4 & 52.7 \\
\hline \multirow[t]{13}{*}{ 2011-2040 } & ACCESS & 8.9 & 15.2 & 20.2 & 25.6 & 33.7 & 40.8 & 48.7 & 60.9 \\
\hline & CANESM2 & 9.3 & 14.4 & 18.7 & 23.7 & 31.5 & 38.6 & 47.0 & 60.5 \\
\hline & CCSM4 & 11.1 & 19.5 & 27.7 & 38.3 & 57.9 & 78.5 & 105.9 & 156.7 \\
\hline & CNRM & 7.9 & 11.1 & 13.2 & 15.0 & 17.3 & 18.9 & 20.5 & 22.4 \\
\hline & CSIRO & 11.5 & 18.7 & 24.3 & 30.4 & 39.6 & 47.5 & 56.3 & 69.8 \\
\hline & GFDL & 8.3 & 14.0 & 19.2 & 25.6 & 36.7 & 47.6 & 61.5 & 85.7 \\
\hline & HADGEM2_CC & 13.0 & 21.0 & 27.7 & 35.2 & 47.0 & 57.7 & 70.1 & 89.8 \\
\hline & HADGEM2_ES & 12.5 & 20.8 & 27.8 & 35.7 & 48.3 & 59.8 & 73.4 & 95.2 \\
\hline & inmem4 & 10.9 & 15.4 & 18.4 & 21.3 & 25.1 & 28.0 & 30.9 & 34.8 \\
\hline & MIRCO5 & 11.1 & 17.4 & 22.3 & 27.7 & 35.9 & 43.0 & 51.0 & 63.3 \\
\hline & MPI_CGCM3 & 10.7 & 18.0 & 24.0 & 30.9 & 41.6 & 51.2 & 62.6 & 80.5 \\
\hline & MPI_ESM_LR & 11.1 & 17.0 & 21.1 & 25.2 & 30.7 & 35.0 & 39.4 & 45.4 \\
\hline & Mean & 10.5 & 16.9 & 22.1 & 27.9 & 37.1 & 45.5 & 55.6 & 72.1 \\
\hline \multirow[t]{13}{*}{ 2041-2070 } & ACCESS & 10.0 & 15.2 & 18.6 & 22.0 & 26.2 & 29.5 & 32.7 & 36.9 \\
\hline & CANESM2 & 8.7 & 14.7 & 20.9 & 29.3 & 45.3 & 62.8 & 87.1 & 134.1 \\
\hline & CCSM4 & 9.7 & 17.3 & 25.3 & 36.3 & 57.9 & 82.0 & 115.9 & 183.0 \\
\hline & CNRM & 9.8 & 15.9 & 21.2 & 27.6 & 38.3 & 48.6 & 61.3 & 82.9 \\
\hline & CSIRO & 12.4 & 17.2 & 20.7 & 24.5 & 29.9 & 34.4 & 39.4 & 46.6 \\
\hline & GFDL & 11.0 & 16.4 & 20.4 & 24.6 & 30.6 & 35.6 & 40.9 & 48.7 \\
\hline & HADGEM2_CC & 24.8 & 39.7 & 50.6 & 61.8 & 77.6 & 90.4 & 104.1 & 123.8 \\
\hline & HADGEM2_ES & 31.0 & 51.7 & 67.4 & 84.0 & 108.1 & 128.4 & 150.6 & 183.5 \\
\hline & inmem4 & 9.5 & 14.5 & 18.3 & 22.4 & 28.5 & 33.7 & 39.6 & 48.4 \\
\hline & MIRCO5 & 11.0 & 20.8 & 30.7 & 44.0 & 69.1 & 96.4 & 133.7 & 205.2 \\
\hline & MPI_CGCM3 & 10.1 & 17.9 & 25.1 & 34.1 & 49.9 & 65.6 & 85.8 & 121.4 \\
\hline & MPI_ESM_LR & 11.1 & 20.1 & 28.9 & 40.3 & 61.0 & 82.7 & 111.4 & 164.2 \\
\hline & Mean & 13.3 & 21.8 & 29.0 & 37.6 & 51.9 & 65.8 & 83.5 & 114.9 \\
\hline \multirow[t]{13}{*}{ 2071-2097 } & ACCESS & 9.6 & 13.6 & 16.3 & 18.7 & 21.9 & 24.2 & 26.5 & 29.5 \\
\hline & CANESM2 & 8.1 & 13.9 & 18.3 & 23.2 & 30.4 & 36.6 & 43.5 & 53.9 \\
\hline & CCSM4 & 9.6 & 13.5 & 16.3 & 19.2 & 23.1 & 26.2 & 29.5 & 34.2 \\
\hline & CNRM & 11.1 & 17.4 & 21.5 & 25.4 & 30.4 & 34.1 & 37.8 & 42.6 \\
\hline & CSIRO & 13.7 & 22.4 & 31.0 & 42.4 & 63.4 & 85.7 & 115.9 & 172.3 \\
\hline & GFDL & 9.9 & 14.2 & 18.7 & 24.9 & 36.9 & 50.3 & 69.2 & 106.2 \\
\hline & HADGEM2_CC & 12.6 & 19.4 & 24.9 & 31.2 & 41.0 & 49.7 & 59.9 & 76.0 \\
\hline & HADGEM2_ES & 11.3 & 19.0 & 25.7 & 33.4 & 46.1 & 58.0 & 72.3 & 96.0 \\
\hline & inmem4 & 8.4 & 12.1 & 14.5 & 16.7 & 19.4 & 21.3 & 23.2 & 25.6 \\
\hline & MIRCO5 & 13.4 & 22.0 & 28.2 & 34.5 & 43.3 & 50.4 & 57.8 & 68.4 \\
\hline & MPI_CGCM3 & 10.2 & 19.3 & 28.3 & 40.2 & 62.4 & 85.9 & 117.6 & 177.1 \\
\hline & MPI_ESM_LR & 14.7 & 23.8 & 30.2 & 36.7 & 45.6 & 52.7 & 60.1 & 70.5 \\
\hline & Mean & 11.1 & 17.6 & 22.8 & 28.9 & 38.7 & 47.9 & 59.5 & 79.4 \\
\hline
\end{tabular}




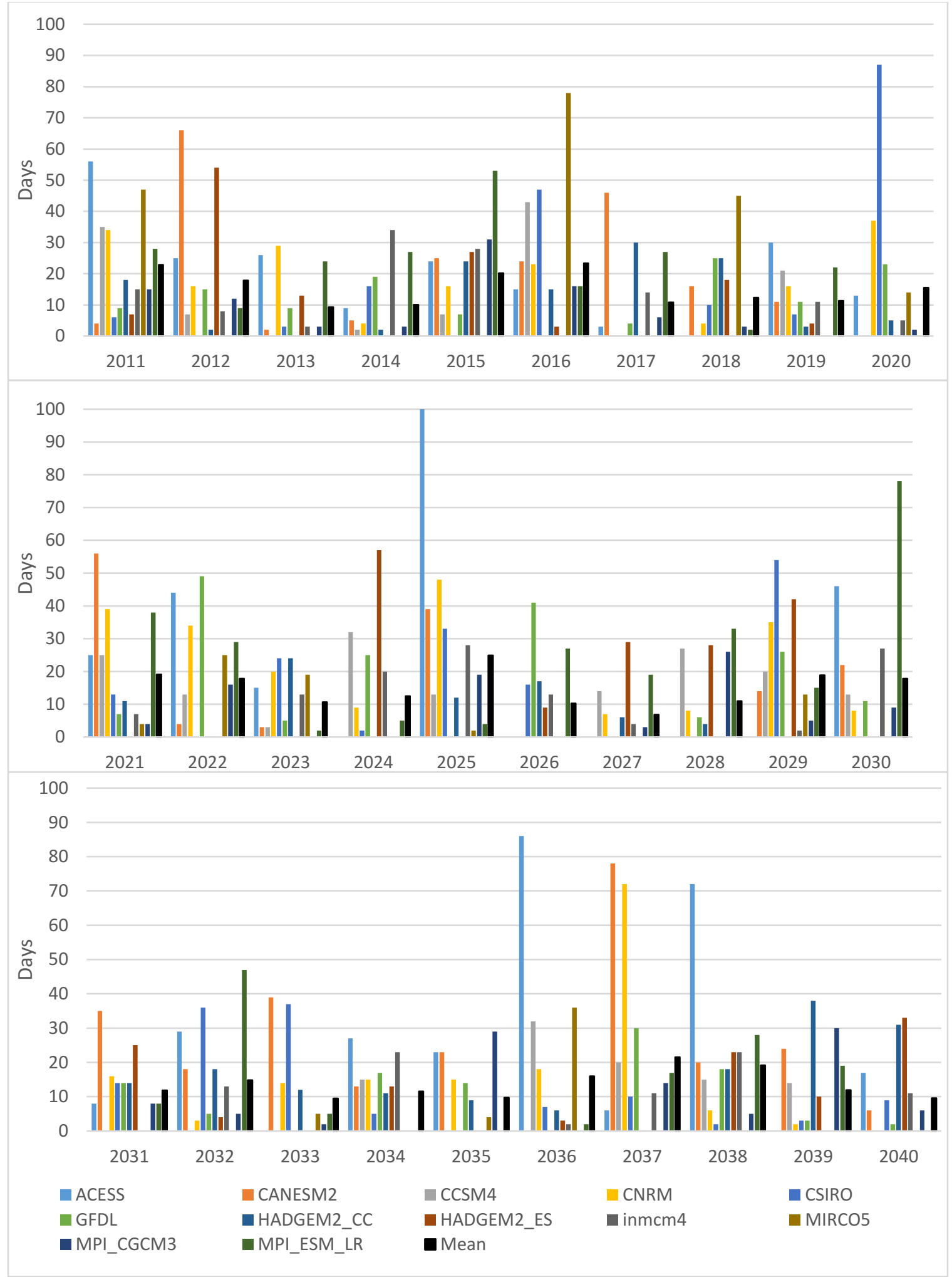

Figure E.4. STL analysis representing the CDDs for the 2011-2040 time-period. 


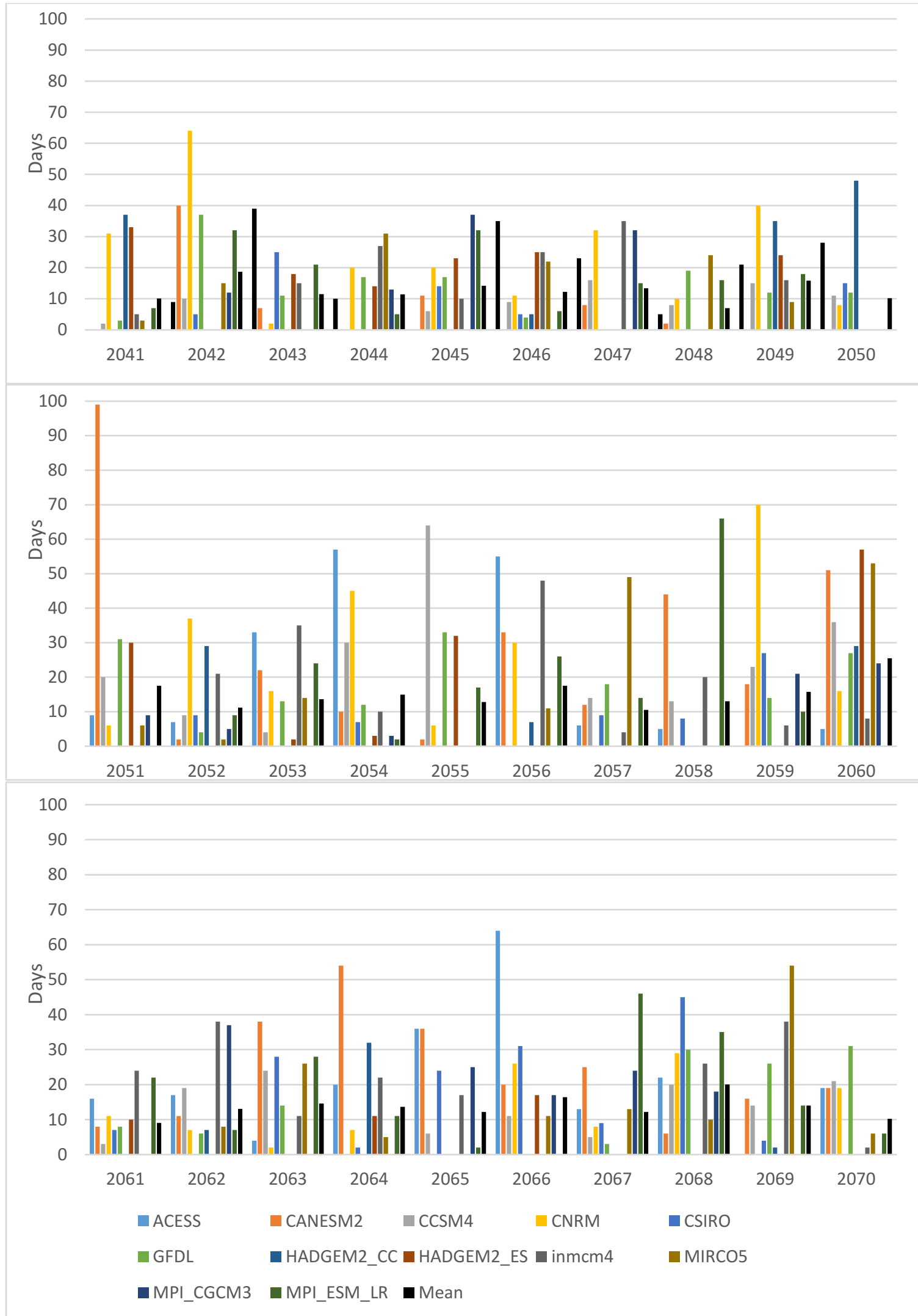

Figure E.5. STL analysis representing the CDDs for the 2041-2070 time-period. 


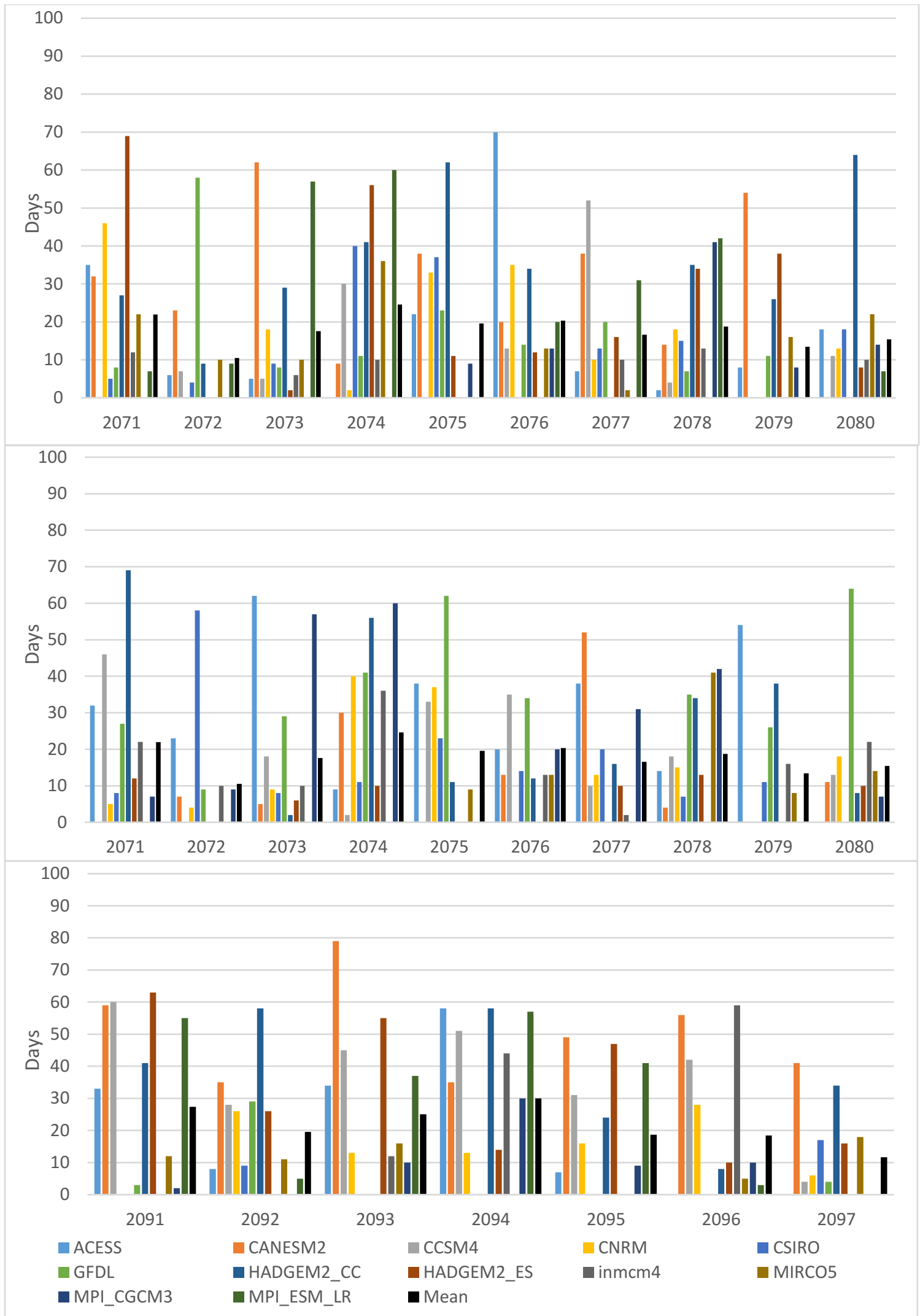

Figure E.6. STL analysis representing the CDDs for the 2071-2097 time-period. 


\section{APPENDIX F (RAVEN MODEL SCRIPT)}

There are 8 Raven specific files they are written in C programing language, the follow are the basic setup and code for the Jock River Watershed model. Source code found at Raven

\section{F.1 JockClimate.rvt}

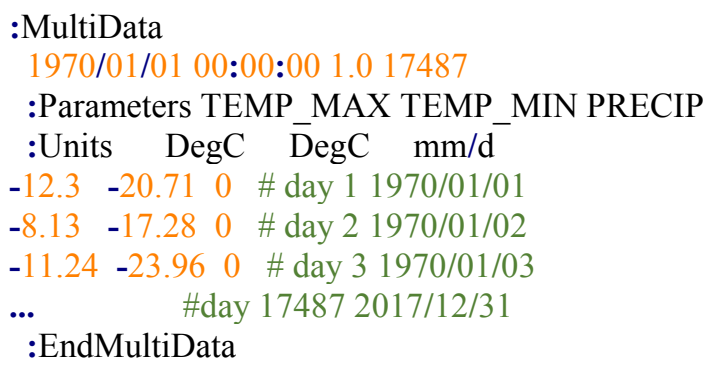

\section{F.2 JockFlow.rvt}

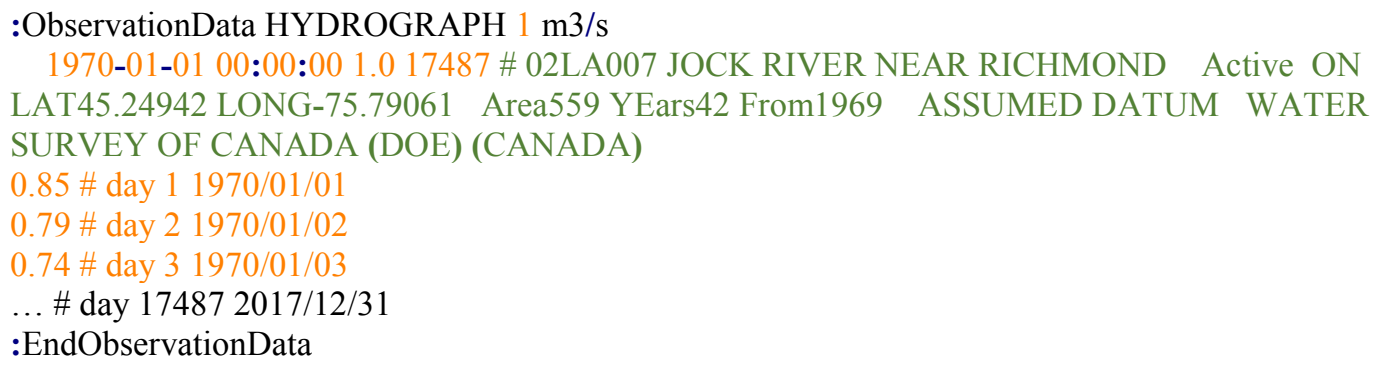

\section{F.3 JockGR4J.rvc}

:FileType rvc ASCII Raven 2.7

:WrittenBy Cameron Samson

:CreationDate July 2017

:UniformInitialConditions SOIL[0] 0

:UniformInitialConditions SOIL[1] 0

:UniformInitialConditions SOIL[2] 0

:UniformInitialConditions SOIL[3] 0 


\section{F.4 JockGR4J.rvh}

\begin{tabular}{lcccc} 
:SubBasins & & & \\
:Attributes & NAME & DOWNSTREAM_ID & \multicolumn{2}{c}{ PROFILE } \\
:Units & none & none none & km & none \\
1 & Sub2 & -1 default_trap & AUTO & 1 \\
2 & Sub1 & 1 default_trap & AUTO & 0 \\
3 & Sub3 & 1 default_trap & -AUTO & 0 \\
4 & Sub4 & 3 default_trap & -AUTO & 0 \\
5 & Sub5 & 6 default_trap & -AUTO & 0 \\
6 & Sub6 & 3 default_trap & -AUTO & 0 \\
7 & Sub7 & 8 default_trap & -AUTO & 0 \\
8 & Sub8 & 6 default_trap & AUTO & 0 \\
9 & Sub9 & 6 default_trap & AUTO AUTO & 0 \\
10 & Sub10 & 8 default_trap & -AUTO & 0 \\
11 & Sub11 & 6 default_trap & _AUTO & 0
\end{tabular}

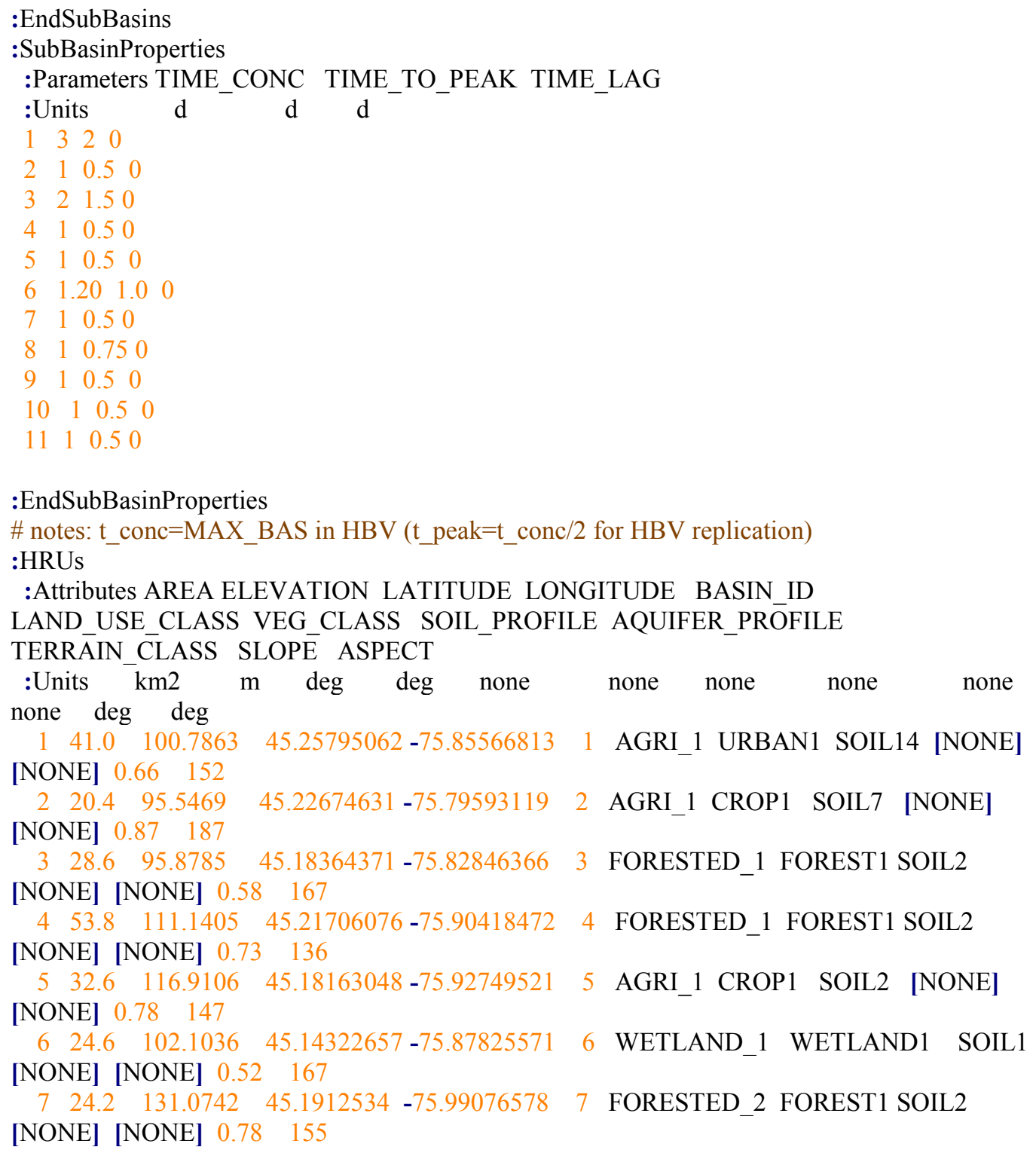




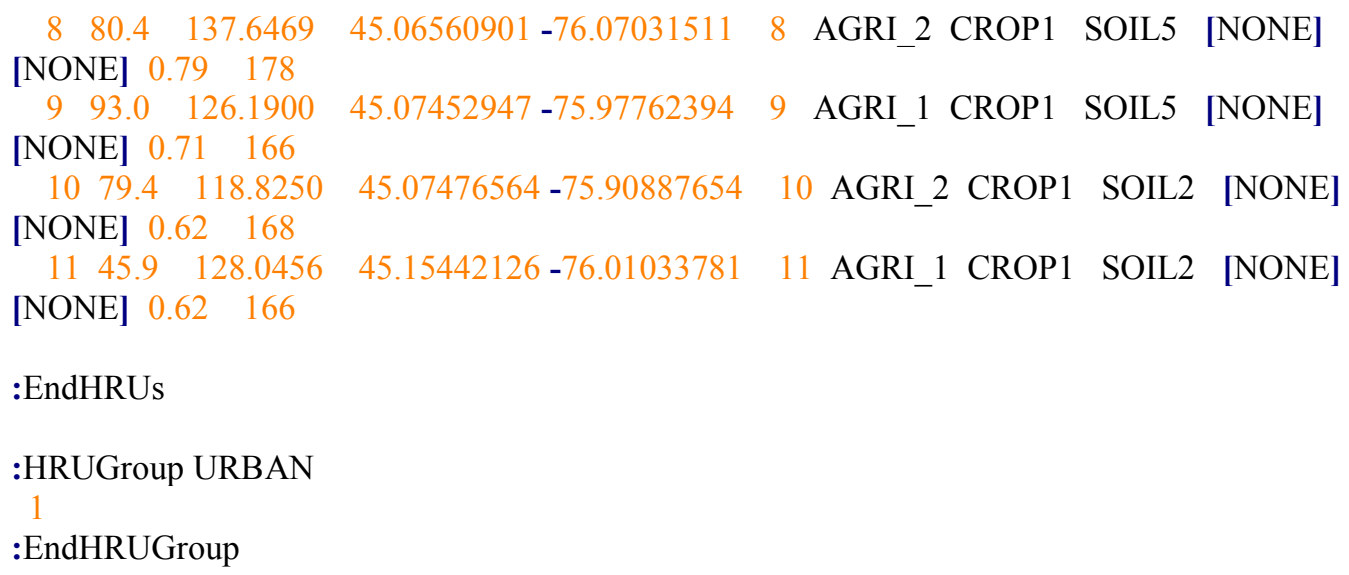

\section{F.5 JockGR4J.rvi}

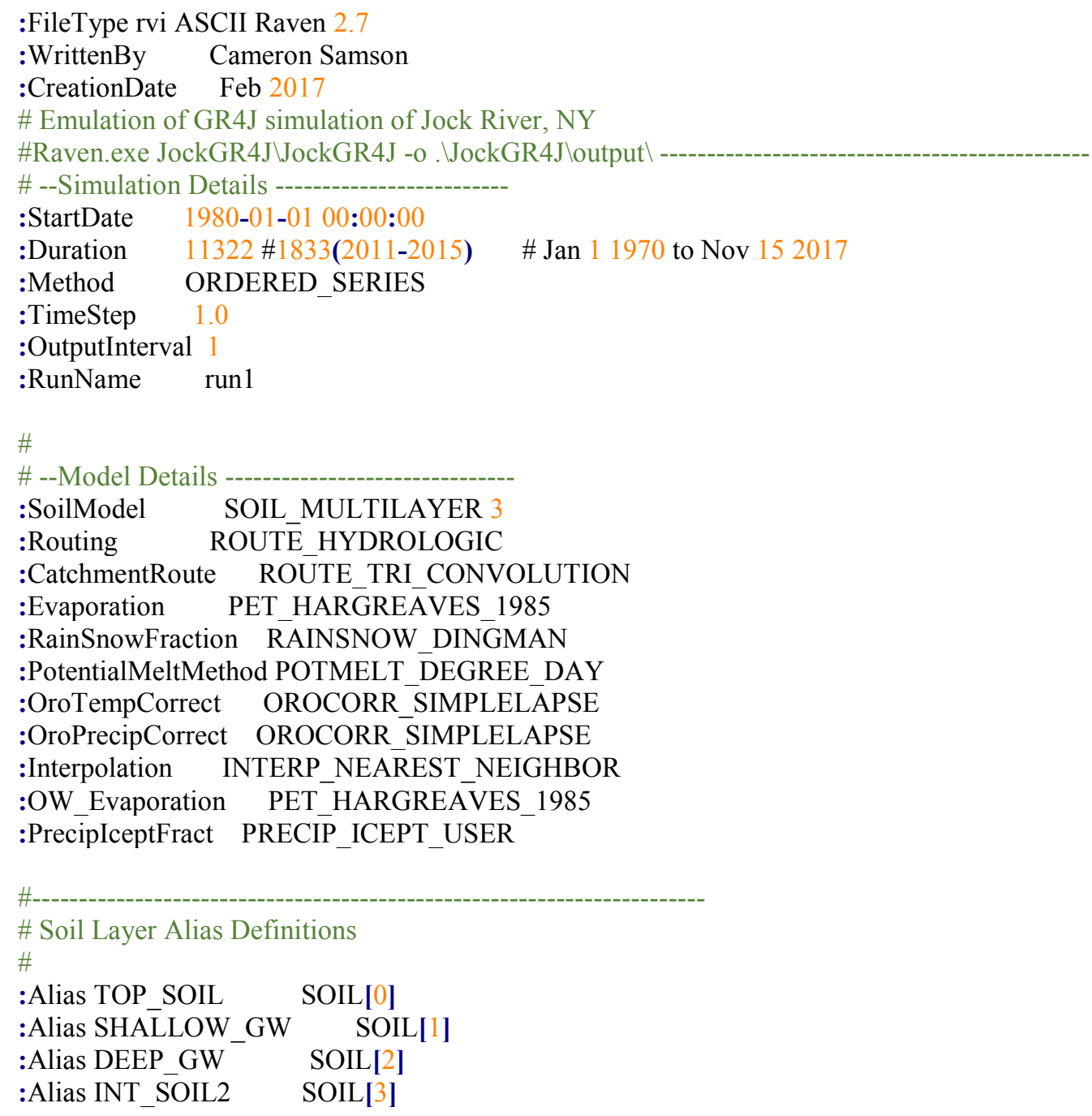




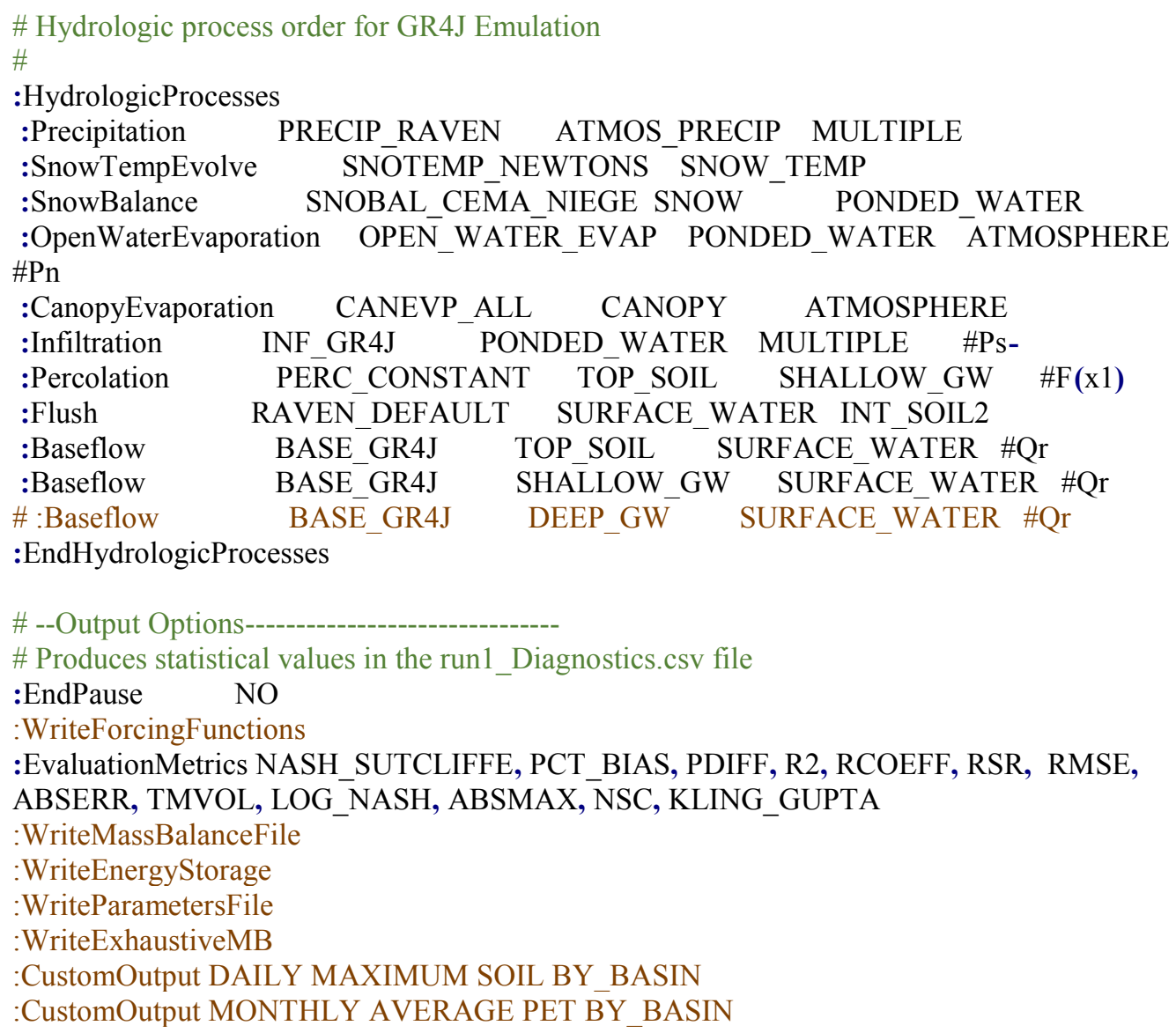




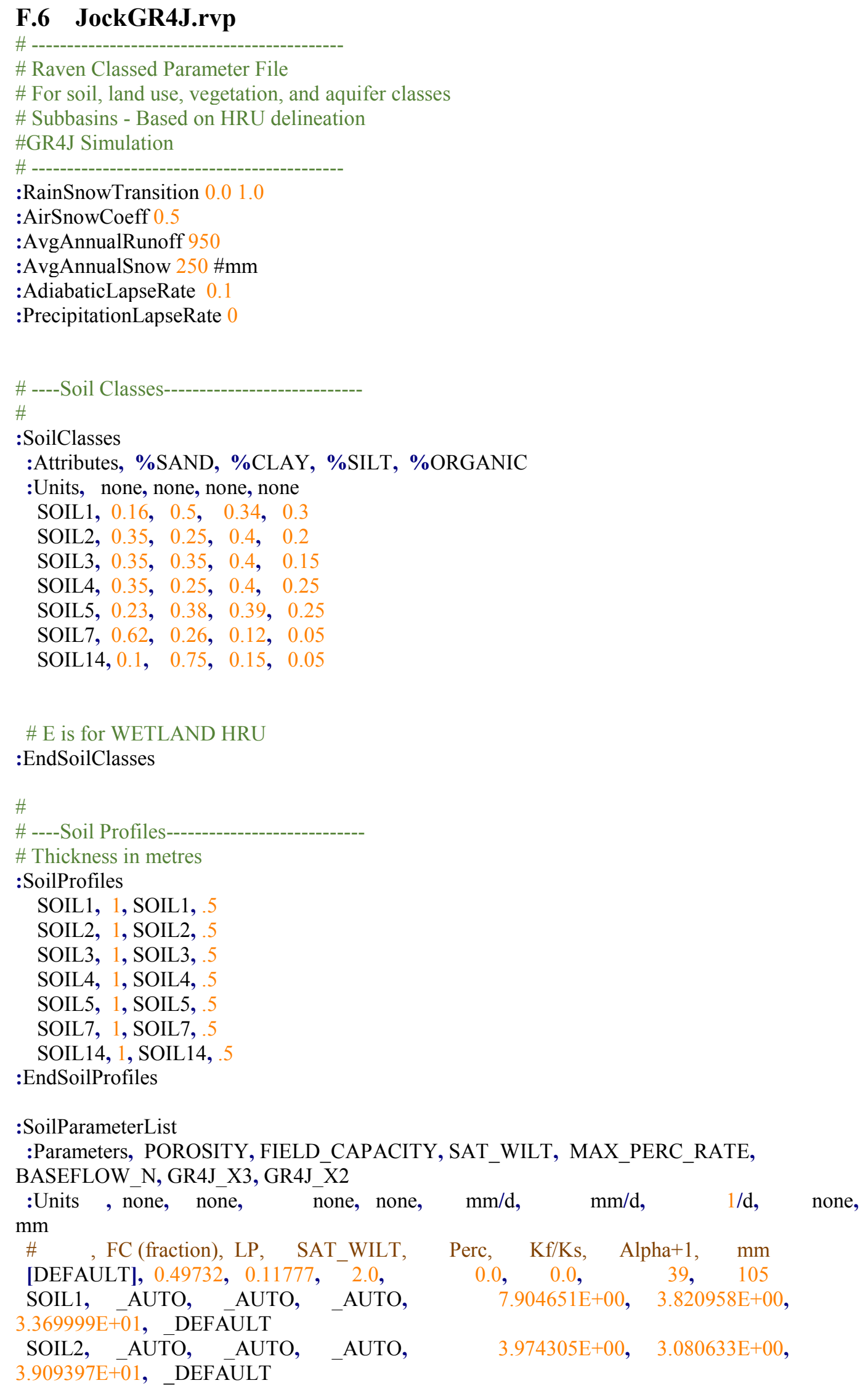




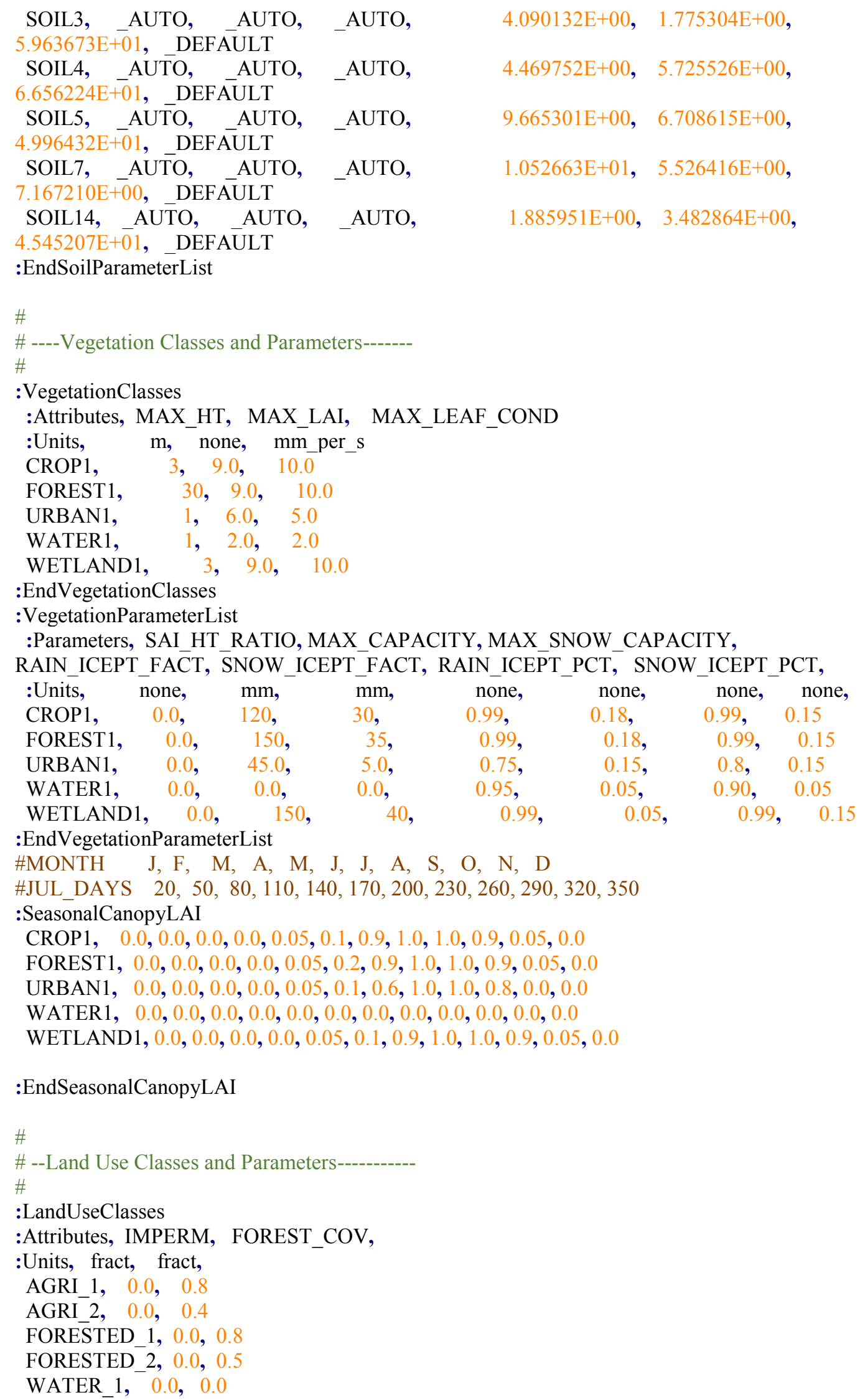




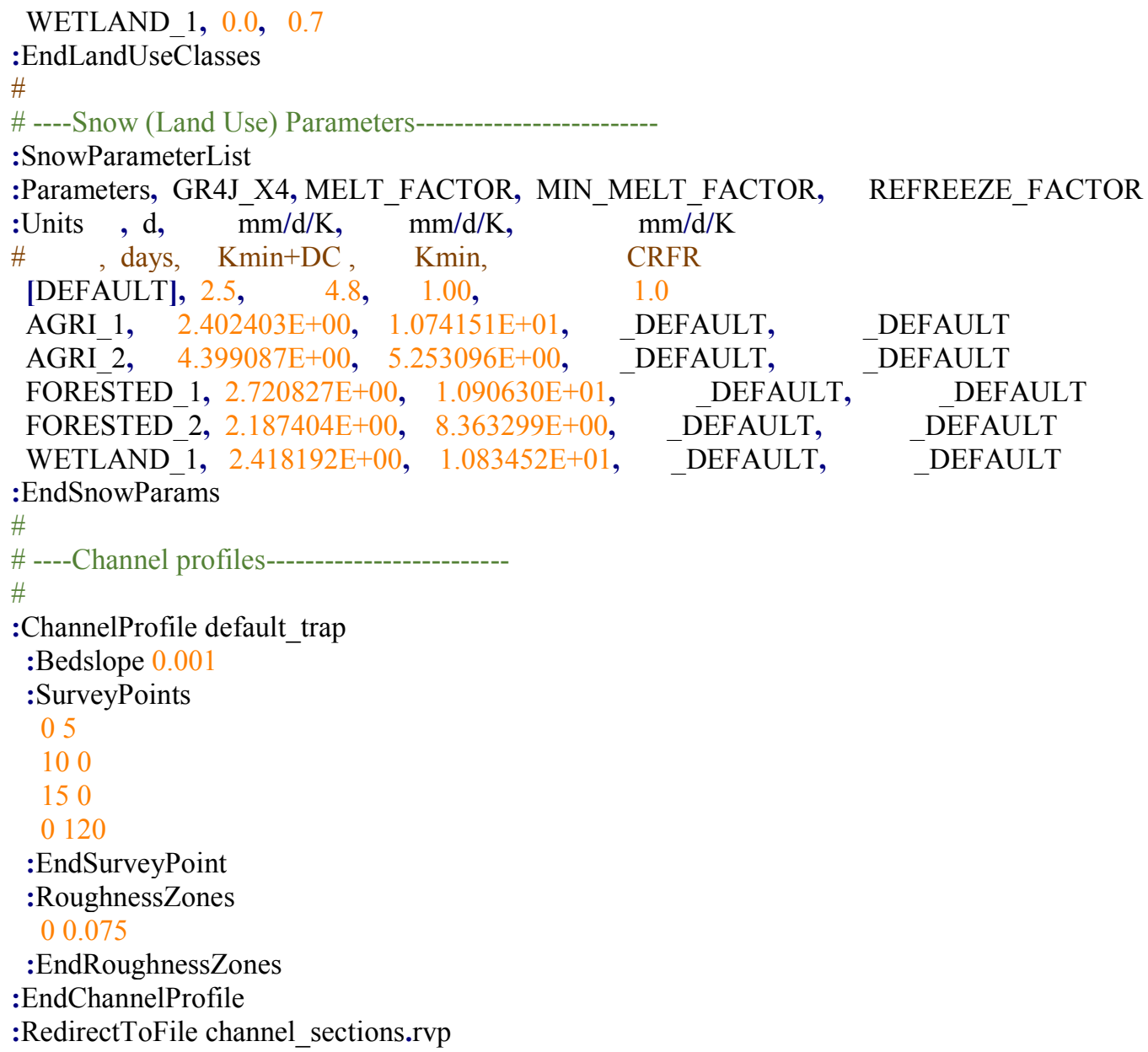

\section{F.7 JockGR4J.rvt}

\# Raven Time Series Input file and Meteorological Gauges

:Gauge JockGauge \#ID58082

:Latitude 45.24942

:Longitude -75.7906

:Elevation 115 \# COELPT

:RainCorrection 1.0 \# 1+P0RREP

:SnowCorrection 1.0 \# 1+P0SREP

:CloudTempRanges 814 \# A0FOGY A0SUNY

:MonthlyAveTemperature, -10.3, -8.1, -2.3, 6.3, 13.3, 18.5, 21, 19.8, 15, 8, 1.5, -6.2,

:MonthlyAveEvaporation, $0.14,0.15,0.29,0.49,0.74,0.86,0.86,0.82,0.52,0.36,0.16,0.14$,

\# Data:

:RedirectToFile JockClimate.rvt

:EndGauge

:RedirectToFile JockFlow.rvt 